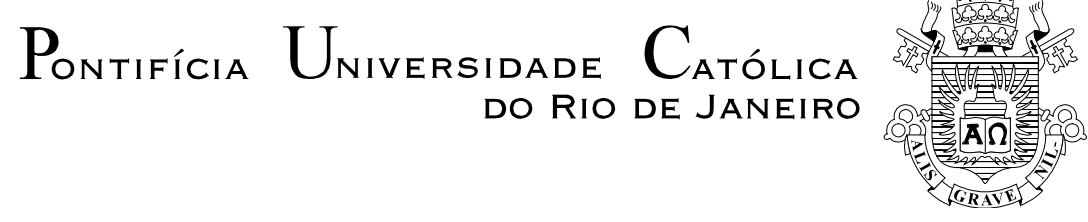

Roberta Rodrigues Mendes

Estudo experimental de corpos de prova de concreto com fibras de aço sujeitos à tração por compressão diametral e à tração direta

Dissertação de Mestrado

Dissertação apresentada como requisito parcial para obtenção do grau de Mestre pelo Programa de Pós-Graduação em Engenharia Civil do Departamento de Engenharia Civil do Centro Técnico Científico da PUC-Rio.

Orientadora: Prof ${ }^{a}$. Deane de Mesquita Roehl Co-orientador: Prof. Emil de Souza Sánchez Filho 


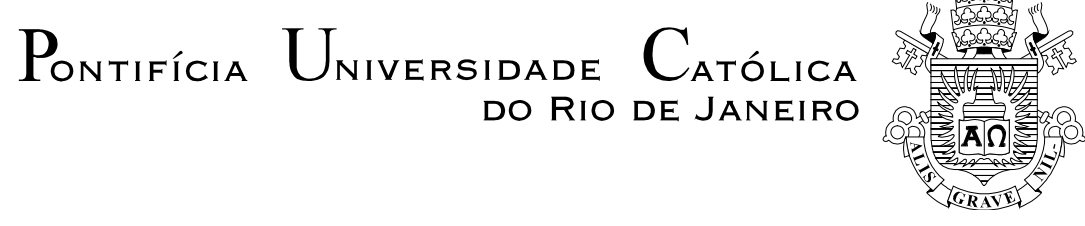

Roberta Rodrigues Mendes

Estudo experimental de corpos de prova de concreto com fibras de aço sujeitos à tração por compressão diametral e à tração direta

Dissertação apresentada como requisito parcial para obtenção do grau de Mestre pelo Programa de Pós-Graduação em Engenharia Civil do Departamento de Engenharia Civil do Centro Técnico Científico da PUC-Rio Aprovada pela Comissão Examinadora abaixo assinada.

Prof ${ }^{a}$. Deane de Mesquita Roehl

Orientadora

Departamento de Engenharia Civil - PUC-Rio

Prof. Emil de Souza Sánchez Filho

Co-orientador

Universidade Federal Fluminense

Prof. Júlio Jerônimo Holtz Silva Filho

Departamento de Engenharia Civil - PUC-Rio

Profạ. Cláudia Valéria Gávio Coura

Instituto Federal de Educação Ciência e tecnologia do Sudeste/MG

Prof. Márcio da Silveira Carvalho

Coordenador Setorial do

Centro Técnico Científico - PUC-Rio

Rio de Janeiro, 29 de Abril de 2016 
Todos os direitos reservados. É proibida a reprodução total ou parcial do trabalho sem autorização da universidade, da autora e do orientador.

\section{Roberta Rodrigues Mendes}

Graduou-se em Engenharia Civil na PUC-Rio (Pontifícia Universidade Católica do Rio de Janeiro) em 2013. Em 2010 trabalhou na empresa SOTER. Em 2012 estagiou na CSP Projetos e Consultoria, desenvolvendo consultoria estrutural. Ingressou no mestrado da PUC-Rio em março de 2014, desenvolvendo dissertação na linha de pesquisa de estruturas de concreto com fibras de aço.

Ficha Catalográfica

Mendes, Roberta Rodrigues

Estudo experimental de corpos de prova de concreto com fibras de aço sujeitos à tração por compressão diametral e à tração direta / Roberta Rodrigues Mendes ; orientadora: Deane de Mesquita Roehl ; co-orientador: Emil de Souza Sánchez Filho. -2016 .

161 f. : il. color. ; $30 \mathrm{~cm}$

Dissertação (mestrado)-Pontifícia Universidade Católica do Rio de Janeiro, Departamento de Engenharia Civil, 2016.

Inclui bibliografia

1. Engenharia civil - Teses. 2. Concreto. 3. Fibras de aço. 4. Tração por compressão diametral. 5. Tração direta. 6. Efeito escala I. Roehl, Deane de Mesquita. II. Sánchez Filho, Emil de Souza. III. Pontifícia Universidade Católica do Rio de Janeiro. Departamento de Enaenharia Civil. IV. Título. 


\section{Agradecimentos}

A Deus pela força de poder concluir este trabalho.

Ao meu noivo Bruno pelo amor, compreensão e constante paciência nos momentos de ausência, quesitos indispensáveis para a execução deste trabalho.

Aos meus queridos pais Wilson e Rosali, pelo incentivo, carinho e dedicação durante toda minha vida, principalmente durante minha formação. Por todos esses anos acreditando e me apoiando sempre nas minhas decisões.

À minha irmã Erica, pelo carinho e amizade.

Aos meus afilhados Rafael, Julia e João e ao meu sobrinho Marcelo, pelos sorrisos e abraços de crianças que sempre me divertiam.

Aos meus familiares e amigos que, indiretamente ajudaram na conclusão deste trabalho.

À professora Deane, orientadora deste trabalho, pelo apoio durante toda minha formação e pelos ensinamentos prestados.

Ao professor Emil, co-orientador dessa pesquisa, pela paciência e dedicação, pelos sinceros conselhos e ensinamentos essenciais para o desenvolvimento deste trabalho.

A todos os amigos conquistados durante este tempo na PUC, em especial a Helena, pela amizade, auxílio e inesquecíveis risadas.

Aos funcionários da PUC-Rio: Euclides, José Nilson, Rogério, Rita, Rafael, Lenilson, dentre outros, por me ajudarem na execução do meu trabalho experimental.

À CAPES pelo apoio financeiro. 


\section{Resumo}

Mendes, Roberta Rodrigues; Mesquita Roehl, Deane; Sánchez Filho, Emil de Souza. Estudo experimental de corpos de prova de concreto com fibras de aço sujeitos à tração por compressão diametral e à tração direta. Rio de Janeiro, 2016. 161 p. Dissertação de Mestrado - Departamento de Engenharia Civil, Pontifícia Universidade Católica do Rio de Janeiro.

Esta pesquisa apresenta um estudo experimental do comportamento de corpos de prova de concreto armado com fibras metálicas comprimidos diametralmente $\mathrm{e}$ os submetidos à tração direta. Foram analisados 72 corpos de prova no LEM-DEC da PUC-Rio, sendo 54 cilíndricos variando-se o diâmetro e o consumo de fibras para o ensaio de compressão diametral e 18 variando-se o consumo de fibras para o ensaio de tração direta. Os 54 corpos de prova foram divididos em três grupos de acordo com a resistência à compressão (20, 30 e $50 \mathrm{MPa})$, cada grupo com 18 corpos de prova com consumo de fibras $\left(20 \mathrm{~kg} / \mathrm{m}^{3}, 40 \mathrm{~kg} / \mathrm{m}^{3}\right.$ e $\left.60 \mathrm{~kg} / \mathrm{m}^{3}\right)$ e diâmetros distintos $(5 \mathrm{~cm}, 10 \mathrm{~cm}$ e $15 \mathrm{~cm})$. Foram avaliados a resistência de tração, energia de deformação e efeito escala. Os resultados obtidos permitem analisar a influência do consumo de fibras e do diâmetro do corpo de prova. A resistência à tração varia linearmente com o consumo e o diâmetro do corpo de prova, verificando-se que a resistência do corpo de prova com diâmetro de $15 \mathrm{~cm}$ é $42 \%$ menor que o de $5 \mathrm{~cm}$. A energia de deformação não apresentou acréscimo significativo com o aumento do consumo de fibras de $40 \mathrm{~kg} / \mathrm{m}^{3}$ para $60 \mathrm{~kg} / \mathrm{m}^{3}$. A análise do efeito escala mostra um decréscimo da resistência à tração com incremento da dimensão do corpo de prova, e os resultados se assemelham aos estudos realizados por Carpinteri (1995), mesmo com consumos de fibras distintos. Os 18 corpos de prova submetidos à tração direta têm a mesma dimensão, diferindo em resistência (20, 30 e $50 \mathrm{MPa})$ e consumo $\left(20 \mathrm{~kg} / \mathrm{m}^{3}, 40 \mathrm{~kg} / \mathrm{m}^{3}\right.$ e $\left.60 \mathrm{~kg} / \mathrm{m}^{3}\right)$. Nesses foi avaliada a energia de deformação plástica e elástica. A região plástica não fica delineada para o consumo de $20 \mathrm{~kg} / \mathrm{m}^{3}$ apresentando um comportamento similar ao concreto convencional.

\section{Palavras-chave}

Concreto; Fibras de Aço; Tração por compressão diametral; Tração direta; Efeito escala. 


\section{Abstract}

Mendes, Roberta Rodrigues; Mesquita Roehl, Deane (Advisor); Sánchez Filho, Emil de Souza (Co-Advisor). Experimental Study of Concrete Specimens reinforced with Steel Fibers Subject to tension under Diametral Compression and Direct Tension. Rio de Janeiro, 2016. 161 p. MSc. Dissertation - Departamento de Engenharia Civil, Pontifícia Universidade Católica do Rio de Janeiro.

This research presents an experimental study on the behavior of reinforced concrete specimens with steel fibers submitted to the splitting test and to direct tension. A total of 72 specimens were tested in the LEM-DEC PUC-Rio; 54 specimens with three different diameters and fiber consume for the diametral compression test and 18 with variations of fiber volume fraction for the direct tension test. The 54 specimens were divided into three groups according to their compressive strength (20,30 and $50 \mathrm{MPa})$, each group having 18 specimens with variations of fiber volume fraction $\left(20 \mathrm{~kg} / \mathrm{m}^{3}, 40 \mathrm{~kg} / \mathrm{m}^{3}\right.$ and $\left.60 \mathrm{~kg} / \mathrm{m}^{3}\right)$ and diameter $(5 \mathrm{~cm}, 10 \mathrm{~cm}$ and $15 \mathrm{~cm})$. The purpose was to investigate the tensile stress, the fracture energy and the size effect. The results allowed the analysis of the influence of the fibers and specimen diameter on each variable before mentioned. The tensile stress varies linearly with fiber volume fraction and diameter, and the resistance of the specimens with $15 \mathrm{~cm}$ in diameter is $42 \%$ less than the resistance of the $5 \mathrm{~cm}$ specimen. The fracture energy was not increased significantly with the increase of fiber content from $40 \mathrm{~kg}$ fibers $/ \mathrm{m}^{3}$ to $60 \mathrm{~kg} / \mathrm{m}^{3}$. The size effect analysis shows that tensile strength decreases as the diameter increases. These results are similar to those of studies conducted by Carpinteri (1995), even with different values of fiber consume. The 18 specimens submitted to direct tension had the same diameter, varying in resistance (20, 30 and $50 \mathrm{MPa})$ and fiber volume fraction (20 $\mathrm{kg} / \mathrm{m}^{3}, 40 \mathrm{~kg} / \mathrm{m}^{3}$ and $\left.60 \mathrm{~kg} / \mathrm{m}^{3}\right)$. Here the plastic and elastic deformations were evaluated. The plastic region is not clearly defined for the fiber fraction of $20 \mathrm{~kg} /$ $\mathrm{m}^{3}$ presenting a behavior similar to the conventional concrete.

\section{Keywords}

Concrete; Steel fibers; Tension by Diametral compression; Direct tension; Size effect. 


\section{Sumário}

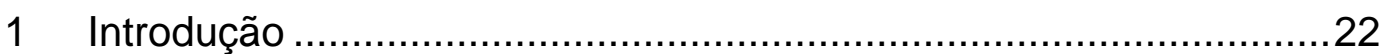

1.1 Relevância e justificativa da pesquisa 22

1.2 Objetivos 23

1.3 Metodologia 23

1.4 Estrutura do trabalho 24

2 Comportamento mecânico do concreto com fibras ..........................25

2.1 Concreto armado com fibras 25

2.2 As fibras de aço 26

2.2.1 Mecanismo de atuação das fibras .................................29

2.2.2 A Interação fibra-matriz...........................................29

2.2.3 Teor de fibras ........................................................... 30

2.2.4 Volume crítico ........................................................ 31

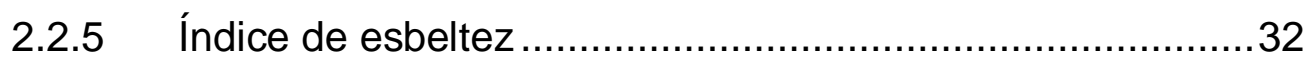

2.2.6 Comprimento crítico ...................................................33

2.2.7 Distribuição das fibras..............................................34

2.3 Propriedades do concreto armado com fibras de aço 36

2.3.1 Resistência à compressão ..........................................36

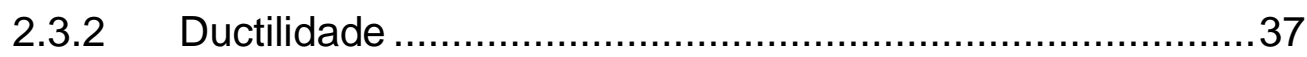

2.3.3 Resistência à tração ................................................38

2.3.4 Trabalhabilidade .....................................................40

2.3.5 Durabilidade .......................................................... 41

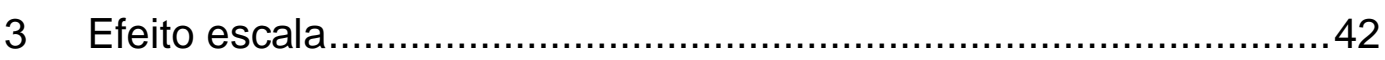

$\begin{array}{lll}3.1 & \text { Introdução } & 42\end{array}$ 
3.2 Lei de Bazant 42

3.3 Multifractal Scaling Law - MFSL (CARPINTERI-1992) 44

$\begin{array}{lll}3.4 & \text { Outras pesquisas } & 45\end{array}$

4 Programa experimental ..................................................... 46

4.1 Considerações iniciais $\quad 46$

$\begin{array}{lll}4.2 & \text { Materiais } & 47\end{array}$

4.2.1 As fibras de aço .........................................................4 47

4.2.2 Concreto ................................................................... 48

4.2.2.1 Resistência à tração direta ......................................53

4.2.2.2 Resistência à compressão ........................................54

4.2.2.3 Resistência à tração por compressão diametral.............56

4.2.2.4 Módulo de elasticidade ...............................................59

4.3 Confecção dos corpos de prova 62

4.3.1 Formas....................................................................... 62

4.3.2 Corpos de prova de concreto .......................................63

4.3.3 Concretagem ..........................................................64

4.4 Esquema dos ensaios 65

5 Apresentação e análise dos resultados...................................67

$\begin{array}{lll}5.1 & \text { Introdução } & 67\end{array}$

$\begin{array}{lll}5.2 & \text { Apresentação dos grupos } & 67\end{array}$

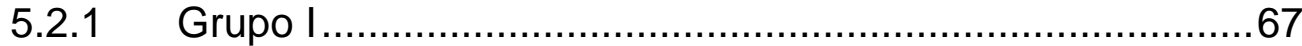

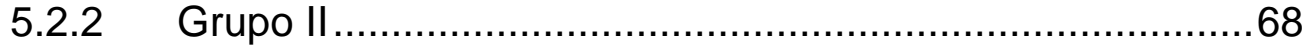

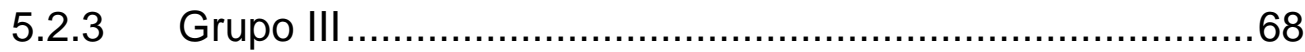

5.3 Apresentação dos resultados $\quad 69$

5.3.1 Compressão........................................................69

5.3.2 Tensão de tração por compressão diametral ....................69

5.3.3 Gráficos ft x consumo de fibras .....................................71

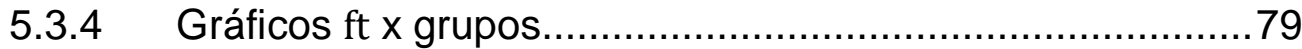

5.3.5 Gráficos ft $x$ diâmetro.................................................86

5.3.6 Gráficos $\Psi$ x consumo ...............................................92

5.3.7 Gráficos $\Psi$ x diâmetro .............................................97 
5.3.8 Força de tração direta $x$ deslocamento ............................103

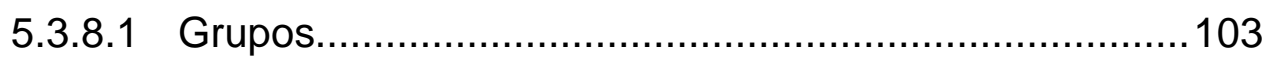

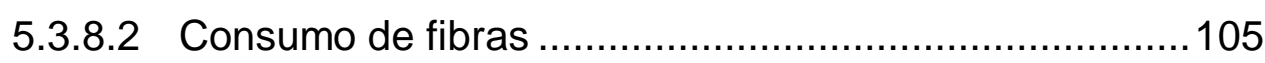

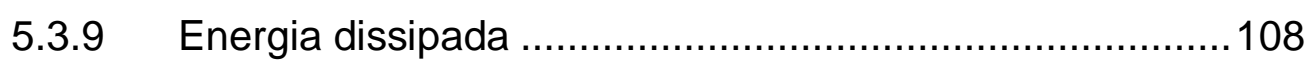

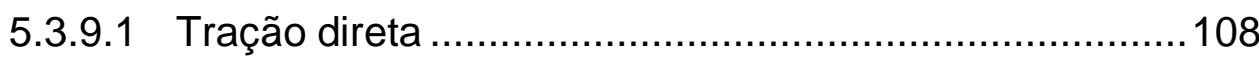

5.3.9.2 Compressão diametral ...............................................111

5.3.10 Curva tensão vs. deformação específica ..........................113

5.3.11 Relação da força de tração nos corpos de prova...............115

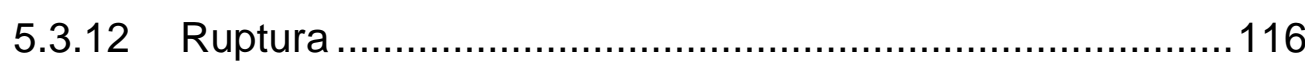

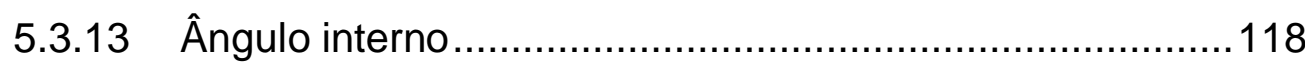

5.3.14 Métodos comparativos ..................................................119

5.3.15 Efeito escala ............................................................ 120

6 Conclusões e sugestões para trabalhos futuros ............................123

6.1 Conclusões 123

6.1.1 Ensaio de tração por compressão diametral ....................123

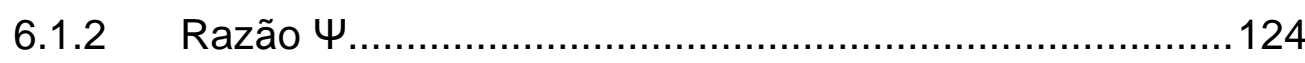

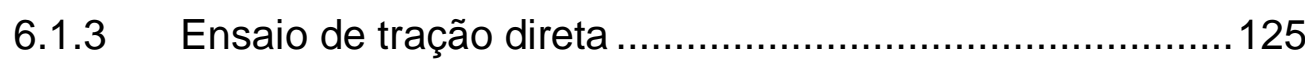

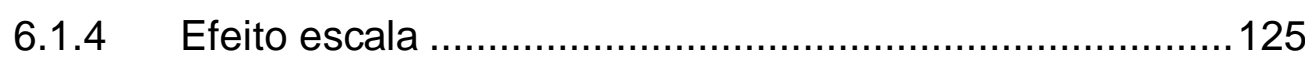

6.2 Sugestões para trabalhos futuros $\quad 126$

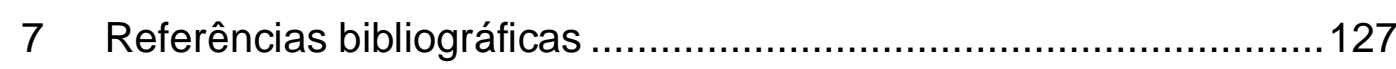

A. Anexo A - Ensaios de compressão diametral..................................132

B. Anexo B - Ensaios de compressão simples ...................................137

C. Anexo C - Ensaios de tração direta .............................................146

D. Anexo D - Tensão x deformação específica.................................154 


\section{Lista de Figuras}

Figura 2.1 - Esquema de concentração de tensões

(FIGUEIREDO, 2005).

Figura 2.2 - Exemplos de diferentes formas de fibras metálicas (SARZALEJO, 2009).

Figura 2.3 - Classificação e geometria das fibras de aço para reforço de concreto (FIGUEIREDO, 2008).

Figura 2.4 - Curvas médias de carga por deslocamento com diferentes consumos de fibra de aço (FIGUEIREDO,2000).

Figura 2.5 - Diagramas carga $x$ deslocamento de concreto com fibras em teor inferior (A), superior (B) e igual (C) ao volume crítico de fibras (FIGUEIREDO, 2000).

Figura 2.6 - Concreto armado com fibras onde há compatibilidade dimensional entre as fibras e o agregado graúdo (FIGUEIREDO, 2000). 33

Figura 2.7 - Concreto armado com fibras onde não há compatibilidade dimensional entre as fibras e o agregado graúdo (FIGUEIREDO, 2000). 34

Figura 2.8 - Orientação das fibras (BENTUR e MINDESS, 1990).

Figura 2.9 - Tensão de compressão x deformação específica de concretos sem e com fibras de aço.

Figura 2.10 - Curvas carga x flecha para concretos com diferentes volumes de fibras.

Figura 2.11 - Curvas tensão $x$ deformação específica de argamassas com fibras (ACl 544.4R88).

Figura 2.12 - Esquema de corpo de prova para ensaio de tração por compressão diametral.

Figura 2.13 - Resultados de ensaio de compressão diametral para concreto com e sem adição de fibras (CUCHIARA, 2004).

Figura 3.1 - Lei de Bazant; adaptado de BAZANT (1984).

Figura 3.2 - Multifractal Scaling Law; adaptado de

CARPINTERI (1995).

Figura 4.1 - Fibras RL 45/30 BN.

Figura 4.2 - Abatimento do tronco de cone para série 5.

Figura 4.3 - Abatimento de tronco de cone para série 8. 50

Figura 4.4 - Abatimento de tronco de cone para série 9.

Figura 4.5 - Ensaio de tração direta. 53 
Figura 4.6 - Corpo de prova de tração direta 53

Figura 4.7 - Ensaio de compressão simples. 56

Figura 4.8 - Vista frontal do ensaio de compressão diametral. $\quad 57$

Figura 4.9 - Vista lateral do ensaio de compressão diametral. $\quad 57$

Figura 4.10 - Extensômetro. $\quad 61$

Figura 4.11 - Ensaio de módulo de elasticidade. 62

Figura 4.12 - Formas metálicas. 63

Figura 4.13 - Forma de silicone. 63

Figura 4.14 - Corpos de prova: a) CP $5 \mathrm{~cm} \times 10 \mathrm{~cm}$; b) CP $10 \mathrm{~cm} \times 20 \mathrm{~cm}$; c) CP $15 \mathrm{~cm} \times 30 \mathrm{~cm}$. 64

Figura 4.15 - Corpo de prova para o ensaio de tração direta. 64

Figura 4.16 - Máquina da MTS com capacidade máxima de 1000 kN. 65

Figura 4.17 - Máquina da MTS com capacidade máxima de 500 kN. $\quad 66$

Figura 5.1 - Resistência à tração por compressão

diametral x consumo, D5-I.

Figura 5.2 - Resistência à tração por compressão

diametral $x$ consumo, D5-II.

72

Figura 5.3 - Resistência à tração por compressão

diametral $x$ consumo, D5-III.

Figura 5.4 - Resistência à tração por compressão diametral x consumo, D5-II - sem média.

Figura 5.5 - Resistência à tração por compressão diametral $x$ consumo, comparativo D5 grupos I e III.

Figura 5.6 - Resistência à tração por compressão diametral $x$ consumo, D10-I.

Figura 5.7 - Resistência à tração por compressão diametral $x$ consumo, D10-II.

Figura 5.8 - Resistência à tração por compressão diametral $x$ consumo, D10-III.

Figura 5.9 - Resistência à tração por compressão diametral x consumo, comparativo D10 grupos I, II e III. 76

Figura 5.10 - Resistência à tração por compressão diametral $x$ consumo, D15-I.

Figura 5.11 - Resistência à tração por compressão diametral $x$ consumo, D15-II.

Figura 5.12 - Resistência à tração por compressão diametral $x$ consumo, D15-II - sem média.

Figura 5.13 - Resistência à tração por compressão diametral $x$ consumo, D15-III. 
Figura 5.14 - Resistência à tração por compressão diametral x consumo, comparativo D15 grupos I e III.

Figura 5.15 - Resistência à tração por compressão diametral $x$ grupos, D5-F20.

Figura 5.16 - Resistência à tração por compressão diametral $x$ grupos, D5-F40.

Figura 5.17 - Resistência à tração por compressão diametral $x$ grupos, D5-F60.

Figura 5.18 - Resistência à tração por compressão diametral x grupos, comparativo D5 consumo F20, 40 e 60 .

Figura 5.19 - Resistência à tração por compressão diametral $x$ grupos, D10-F20.

Figura 5.20 - Resistência à tração por compressão diametral $x$ grupos, D10-F40.

Figura 5.21 - Resistência à tração por compressão diametral x grupos, D10-F60.

Figura 5.22 - Resistência à tração por compressão diametral x grupos, comparativo D10 consumo 20, 40 e 60 .

Figura 5.23 - Resistência à tração por compressão diametral x grupos, D15-F20.

Figura 5.24 - Resistência à tração por compressão diametral x grupos, D15-F40.

Figura 5.25 - Resistência à tração por compressão diametral $x$ grupos, D15-F60.

Figura 5.26 - Resistência à tração por compressão diametral x grupos, comparativo D15 consumo F20, 40 e 60 .

Figura 5.27 - Resistência à tração por compressão diametral x diâmetro, F20-I.

Figura 5.28 - Resistência à tração por compressão diametral $x$ diâmetro, F20-II.

Figura 5.29 - Resistência à tração por compressão diametral $x$ diâmetro, F20-III.

Figura 5.30 - Resistência à tração por compressão diametral x diâmetro, comparação F20 com os grupos I, II, III.

Figura 5.31 - Resistência à tração por compressão diametral $x$ diâmetro, F40-I.

Figura 5.32 - Resistência à tração por compressão diametral $x$ diâmetro, F40-II.

Figura 5.33 - Resistência à tração por compressão diametral x diâmetro, F40-III.

Figura 5.34 - Resistência à tração por compressão diametral x diâmetro, comparação F40 com os grupos I, II e III. 
Figura 5.35 - Resistência à tração por compressão

diametral x diâmetro, F60-I.

Figura 5.36 - Resistência à tração por compressão

diametral $x$ diâmetro, F60-II.

Figura 5.37 - Resistência à tração por compressão

diametral $x$ diâmetro, F60-III.

Figura 5.38 - Resistência à tração por compressão

diametral x diâmetro, comparação F40 com os grupos I, II e III. 91

Figura $5.39-\Psi$ x consumo, I-D5. 92

Figura $5.40-\Psi \times$ consumo, I-D10. 93

Figura $5.41-\Psi \times$ consumo, I-D15. 93

Figura 5.42 - Gráficos comparativos de $\Psi$ x consumo, grupo I. 93

Figura $5.43-\Psi$ x consumo, II-D5. 94

Figura $5.44-\Psi$ x consumo, II-D10. 95

Figura $5.45-\Psi$ x consumo, II-D15. 95

Figura 5.46 - Gráficos comparativos de $\Psi$ x consumo, grupo II. 95

Figura $5.47-\Psi$ x consumo, III-D5. 96

Figura $5.48-\Psi$ x consumo, III-D10. 96

Figura $5.49-\Psi \times$ consumo, III-D15. 97

Figura 5.50 - Gráficos comparativos de $\Psi$ x consumo, grupo III. 97

Figura $5.51-\Psi$ x diâmetro, I-F20. 98

Figura $5.52-\Psi$ x diâmetro, I-F40. 98

Figura $5.53-\Psi$ x diâmetro, I-F60. 98

Figura 5.54 - Gráficos comparativos de $\Psi$ x diâmetro, grupo I. 99

Figura $5.55-\Psi$ x diâmetro, II-F20. 99

Figura $5.56-\Psi$ x diâmetro, II-F40. 100

Figura $5.57-\Psi$ x diâmetro, II-F60. 100

Figura 5.58 - Gráficos comparativos de $\Psi$ x diâmetro, grupo II. 100

Figura $5.59-\Psi$ x diâmetro, III-F20. 101

Figura $5.60-\Psi$ x diâmetro, III-F40. 101

Figura $5.61-\Psi \times$ diâmetro, III-F60. 102

Figura 5.62 - Gráficos comparativos de $\Psi$ x diâmetro, grupo III. 102

Figura 5.63 - Força x deslocamento, Grupo I. 103

Figura 5.64 - Força x deslocamento, Grupo II. 104

Figura 5.65 - Força x deslocamento, Grupo III. 104

Figura 5.66 - Força x deslocamento, TD-F20. 106 
Figura 5.67 - Força x deslocamento, TD-F40. 106

Figura 5.68 - Força $x$ deslocamento, TD-F60. 107

Figura 5.69 - Energia elástica x consumo de fibras. 109

Figura 5.70 - Energia plástica $\times$ consumo de fibras. 109

Figura 5.71 - Energia elástica x grupos. 110

Figura 5.72 - Energia plástica x grupos. 111

Figura 5.73 - Curva tensão-deformação específica, I-TD-F20-2. 114

Figura 5.74 - Curva tensão-deformação específica, I-TD-F40-1. 114

Figura 5.75 - Curva tensão-deformação específica, I-TD-F60-2. 114

Figura 5.76 - Corpos de prova com consumo de fibra de $20 \mathrm{~kg} / \mathrm{m}^{3}$. 116

Figura 5.77 - Corpos de prova com consumo de fibra de $60 \mathrm{~kg} / \mathrm{m}^{3}$. $\quad 117$

Figura 5.78 - Corpos de prova D10 com consumo de fibra de $20 \mathrm{~kg} / \mathrm{m}^{3}$ e $60 \mathrm{~kg} / \mathrm{m}^{3}$. 117

Figura 5.79 - Corpos de prova D5 com consumo de fibra de $20 \mathrm{~kg} / \mathrm{m}^{3}$ e $60 \mathrm{~kg} / \mathrm{m}^{3}$.

Figura 5.80 - Variação do ângulo de atrito interno em função de $f c f t .118$

Figura 5.81 - Razão da força de tração pela fórmula proposta por HILSDORF pela obtida experimentalmente.

Figura 5.82 - Lei de Carpinteri $x$ valores experimentais,

Séries 1,2 e 3.

Figura 5.83 - Lei de Carpinteri $x$ valores experimentais, Séries 4,5 e 6.

Figura 5.84 - Lei de Carpinteri $x$ valores experimentais, Séries 7,8 e 9.

Figura A.1 - Força x deslocamento, Série 1.

Figura A.2 - Força $x$ deslocamento, Série 2.

Figura A.3 - Força x deslocamento, Série 3.

Figura A.4 - Força x deslocamento, Série $4 . \quad 134$

Figura A.5 - Força $x$ deslocamento, Série 5.

Figura A.6 - Força x deslocamento, Série 6.

Figura A.7 - Força x deslocamento, Série 7.

Figura A.8 - Força x deslocamento, Série 8.

Figura A.9 - Força $x$ deslocamento, Série 9

Figura B.1 - Força x deslocamento, CON-1-1. 137

Figura B.2 - Força x deslocamento, CON-1-2. 137

Figura B.3 - Força x deslocamento, CON-2-1. 138

Figura B.4 - Força $\times$ deslocamento, CON-2-2. 138 
Figura B.5 - Força $x$ deslocamento, CON-3-1.

Figura B.6 - Força $x$ deslocamento, CON-3-2.

Figura B.7 - Força $x$ deslocamento, CON-4-1.

Figura B.8 - Força $x$ deslocamento, CON-4-2.

Figura B.9 - Força $x$ deslocamento, CON-5-1.

Figura B.10 - Força $x$ deslocamento, CON-5-2.

Figura B.11 - Força $x$ deslocamento, CON-6-1.

Figura B.12 - Força $x$ deslocamento, CON-6-2.

Figura B.13 - Força $x$ deslocamento, CON-7-1.

Figura B.14 - Força $x$ deslocamento, CON-7-2.

Figura B.15 - Força $x$ deslocamento, CON-8-1.

Figura B.16 - Força x deslocamento, CON-8-2.

Figura B.17 - Força $x$ deslocamento, CON-9-1.

Figura B.18- Força $x$ deslocamento, CON-9-2

Figura.C.1 - Força $x$ deslocamento, I-TD-F20-2.

Figura C.2 - Força $x$ deslocamento, I-TD-F40-2.

Figura C.3 - Força $x$ deslocamento, I-TD-F40-1.

Figura C.4 - Força $x$ deslocamento, I-TD-F60-2.

Figura C.5 - Força $x$ deslocamento, II-TD-F20-1.

Figura C.6 - Força $x$ deslocamento, II-TD-F20-2.

Figura C.7 - Força $x$ deslocamento, II-TD-F40-2.

Figura C.8 - Força $x$ deslocamento, II-TD-F40-1.

Figura C.9 - Força $x$ deslocamento, II-TD-F60-1.

Figura C.10 - Força $x$ deslocamento, II-TD-F60-2.

Figura C.11 - Força $x$ deslocamento, III-TD-F20-1.

Figura C.12 - Força $x$ deslocamento, III-TD-F40-1.

Figura C.13 - Força $x$ deslocamento, III-TD-F40-2. 152

Figura C.14- Força $x$ deslocamento, III-TD-F60-1. 152

Figura C.15 - Força $x$ deslocamento, III-TD-F60-2 153

Figura D.1 - Tensão x deformação específica, I-TD-F20-2. 154

Figura D.2 - Tensão x deformação específica, I-TD-F40-1. 154

Figura D.3 - Tensão x deformação específica, I-TD-F40-2. 155

Figura D.4 - Tensão x deformação específica, I-TD-F60-2. 155

Figura D.5 - Tensão x deformação específica, II-TD-F20-1. 156

Figura D.6 - Tensão x deformação específica, II-TD-F20-2. 156 
Figura D.7 - Tensão x deformação específica, II-TD-F40-1.

Figura D.8 - Tensão $x$ deformação específica, II-TD-F40-2.

Figura D.9 - Tensão $x$ deformação específica, II-TD-F60-1.

Figura D.10 - Tensão x deformação específica, II-TD-F60-2.

Figura D.11 - Tensão $x$ deformação específica, III-TD-F20-1.

Figura D.12 - Tensão $x$ deformação específica, III-TD-F40-1.

159

Figura D.13 - Tensão $x$ deformação específica, III-TD-F40-2.

160

Figura D.14 - Tensão $x$ deformação específica, III-TD-F60-1.

160

Figura D.15 - Tensão x deformação específica, III-TD-F60-2. 


\section{Lista de Tabelas}

Tabela 4.1 - Consumo de material por $\mathrm{m}^{3}$ de concreto. 49

Tabela 4.2 - Valores do abatimento do tronco de cone. 49

Tabela 4.3 - Programa de concretagem. 52

Tabela 4.4 - Valores da resistência à tração direta do concreto 54

Tabela 4.5 - Resultados dos ensaios de resistência à compressão do concreto. $\quad 55$

Tabela 4.6 - Resultados dos ensaios de resistência a compressão. $\quad 55$

Tabela 4.7- Resultados dos ensaios de resistência à tração por compressão diametral. $\quad 58$

Tabela 4.8 - Resistência à tração média.

Tabela 4.9 - Valores de resistência à compressão obtidos nos ensaios para obtenção do módulo de elasticidade.

Tabela 4.10 - Módulo de elasticidade. 61

Tabela 5.1 - Data dos ensaios séries 1, 2 e $3 . \quad 67$

Tabela 5.2 - Data dos ensaios séries 4, 5 e 6.

Tabela 5.3 - Data dos ensaios séries 7, 8 e 9.

Tabela 5.4 - Razão da tensão de tração por compressão diametral. $\quad 69$

Tabela 5.5 - Razão entre as tensões de compressão diametral e axial. 71

Tabela 5.6 - Decréscimo da resistência a tração por compressão diametral. $\quad 92$

Tabela 5.7 - Energias plásticas e elásticas de deformação. 105

Tabela 5.8 - Energia total dissipada. 112

Tabela 5.9 - Razões entre as energias dissipadas. 112

Tabela 5.10 - Percentual de deformação específica. 115

Tabela 5.11 - Razão da força de tração. 116

Tabela 5.12 - Ângulo de atrito interno. 118

Tabela 5.13 - Razão entre valores teóricos e experimentais. 119

Tabela 5.14 - Resultados da expressão 3.5 e dados experimentais. 120 


\section{Lista de Abreviaturas}

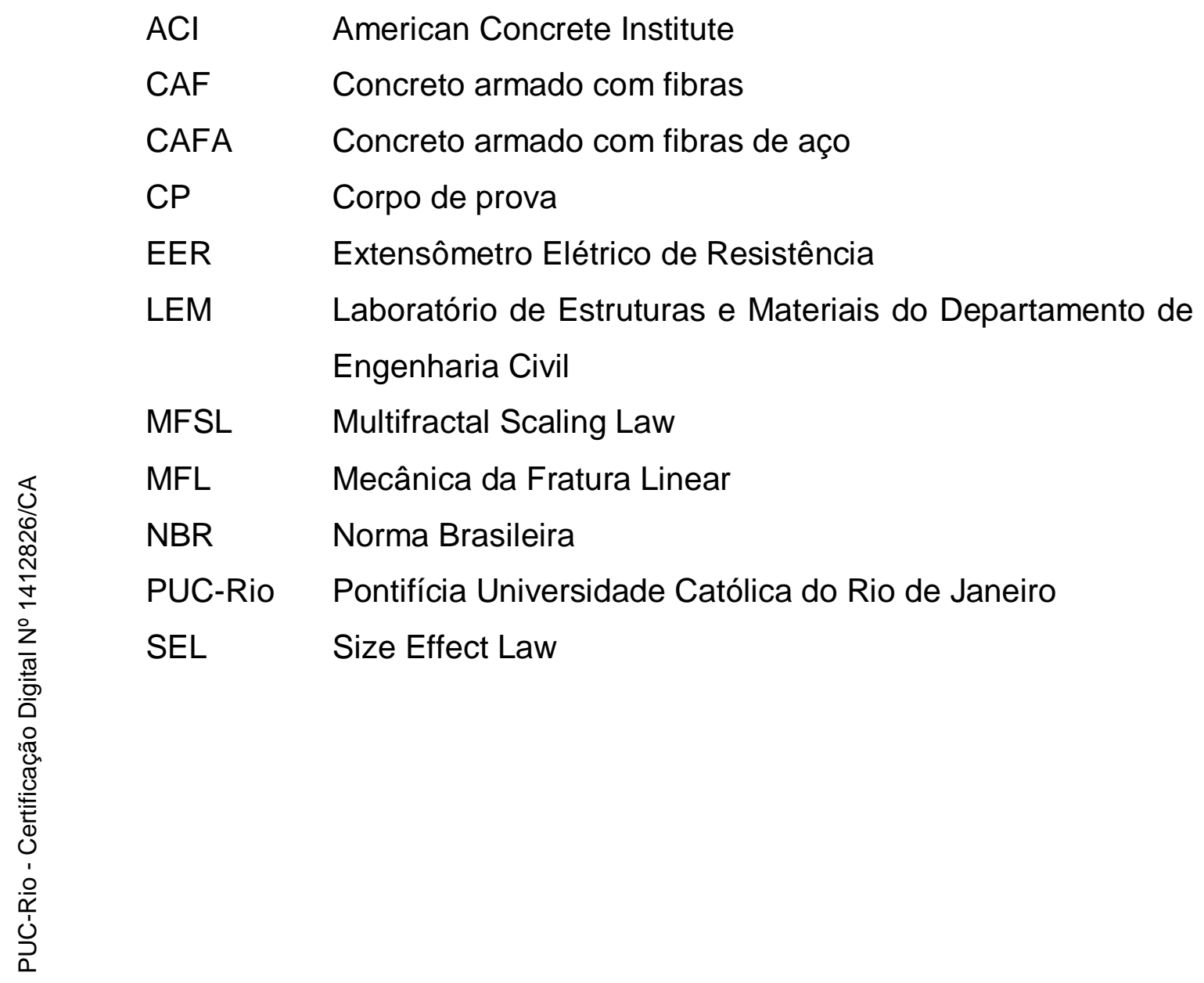




\section{Lista de Símbolos}

$\begin{array}{ll}\alpha_{0} & \text { Valor adimensional } \\ A & \text { Constante física } \\ A, B & \text { Constantes físicas } \\ d & \text { Diâmetro do corpo de prova } \\ D_{\text {máx }} & \text { Diâmetro máximo do agregado } \\ E_{c i} & \text { Módulo de deformação (GPa) } \\ \varepsilon & \text { Deformação especifica } \\ \varepsilon_{\mathrm{b}} & \text { Deformação específica média dos corpos de prova sob } \\ & \text { tensão maior (m/m) } \\ \varepsilon_{0,5} & \text { Deformação específica média dos corpos de prova sob a } \\ & \text { tensão básica de } 0,5 \text { MPa (m/m). } \\ F & \text { Força máxima aplicada, equivalente à carga de ruptura } \\ f_{\mathrm{c}, 28} & \text { Resistência à compressão axial aos } 28 \text { dias de idade } \\ \mathrm{f}_{\mathrm{tD}, \mathrm{i}} & \text { Resistência à tração do corpo de prova de concreto quando } \\ & \text { comprimido diametralmente } \\ f_{t} & \text { Resistência à tração do concreto } \\ f_{t, 5} & \text { Força de tração do corpo de prova de } 5 \mathrm{~cm} \text { de diâmetro } \\ f_{t, 10} & \text { Força de tração do corpo de prova de } 10 \mathrm{~cm} \text { de diâmetro } \\ f_{t, 15} & \text { Força de tração do corpo de prova de } 15 \mathrm{~cm} \text { de diâmetro } \\ f_{\text {dir }} & \text { Tensão de tração direta } \\ f_{\text {dir,médio }} & \text { Tensão média de tração direta } \\ f_{c} & \text { Resistência à compressão do concreto } \\ f_{c, e f} & \text { Resistência efetiva } \\ f_{c t m} & \text { Resistência média à tração axial (MPa) } \\ f_{c m} & \text { Tensão normal } \\ L & \end{array}$




$\begin{array}{ll}\sigma_{\mathrm{b}} & \text { Tensão correspondente à } 30 \% \text { da força de ruptura } \\ \sigma_{0,5} & \text { Tensão mais próxima de } 0,5 \mathrm{MPa} \text { no corpo de prova de } \\ & \text { concreto } \\ \sigma_{\text {rup }} & \text { Tensão de ruptura do corpo de prova de concreto } \\ \sigma_{n} & \text { Resistência nominal } \\ \sigma_{\text {inf }} & \text { Tensão mais próxima de } 0,5 \mathrm{MPa} \text { aplicada ao corpo de } \\ & \text { prova } \\ & \text { Razão entre a resistência à tração por compressão } \\ & \text { diametral pela tração direta }\end{array}$


"Que a arte me aponte uma resposta Mesmo que ela mesma não saiba E que ninguém a tente complicar Pois é preciso simplicidade para fazê-la florescer Pois metade de mim é plateia A outra metade é canção Que a minha loucura seja perdoada Pois metade de mim é amor E a outra metade também“ 


\section{1 \\ Introdução}

\section{1 \\ Relevância e justificativa da pesquisa}

O concreto de cimento Portland é o material mais utilizado em construções, e isso decorre de suas inúmeras vantagens, como sua aplicação em estruturas com infinitas variações de forma. É capaz de apresentar grande variação de suas propriedades em função do tipo e das proporções de seus componentes. No entanto as estruturas de concreto armado têm apresentado patologias diversas ao longo do tempo, não só devido às falhas humanas cometidas durante o ciclo de vida da estrutura (etapas de concepção e elaboração do projeto, execução, uso e manutenção), mas também devido a outros fatores muitas vezes não levados em consideração pelos projetistas e construtores, tais como a agressividade do ambiente no qual a estrutura será executada. Além dessas patologias o que vem preocupando é a rápida deterioração do concreto, que está associada com a sua baixa ductilidade.

No mercado brasileiro vêm surgindo diversos materiais que visam suprir ou melhorar o desempenho das práticas construtivas existentes. Os novos produtos originários de pesquisas vêm substituindo ou adicionando novos materiais para aplicação em construções, porém, esse uso exige a compreensão e o estudo do comportamento desses materiais.

Mesmo tendo um bom comportamento quando submetido a compressão, segundo METHA e MONTEIRO (1994) o concreto apresenta limitações. Sua capacidade de deformação é bem inferior quando comparada com a de outros materiais. Além disso, sua resistência à tração é cerca de $7 \%$ a $10 \%$ da de compressão. A ruptura na compressão se dá pela união de numerosas fissuras e não somente por algumas como no caso do concreto tracionado.

Buscando-se uma melhoria de suas características tem-se os concretos de alta resistência, de alto desempenho e o concreto com adição de fibras.

Dentre os diversos tipos de fibras incluem-se as fibras de aço, náilon, vidro, de carbono, fibras de polipropileno, as fibras vegetais (sisal, juta, celulose) e as 
minerais (volastonita e mica). Essas fibras variam em propriedades, eficiência e custo. CALLISTER (2012) afirma que dentro das diversas fibras disponíveis as mais usadas são as de vidro, as sintéticas, as naturais e as metálicas.

O concreto armado com fibras de aço (CAFA) tem a finalidade de aumentar a vida útil do concreto conferindo-lhe uma maior resistência à tração, diminuindo a abertura de fissuras e reduzindo as diversas patologias encontradas nas estruturas de concreto.

A fissuração no concreto sem fibras representa uma barreira à propagação de tensões, representada pelas linhas de tensão. Essa barreira implica na concentração de tensões na extremidade da fissura e, no caso dessa tensão superar a resistência da matriz, tem-se a ruptura abrupta do material. A adição das fibras de aço ao concreto inibe a ampliação das fissuras devido à função das fibras de atuar como ponte de transferência de tensões em suas extremidades.

O CAFA vem sendo cada vez mais utilizado, pois além de ser um produto de baixo custo, as fibras pouco interferem na consistência do concreto desde que utilizadas em dosagens corretas.

\section{2 \\ Objetivos}

O objetivo principal deste estudo experimental realizado no Laboratório de Estruturas e Materiais do Departamento de Engenharia Civil da PUC-Rio, é analisar a influência da adição das fibras de aço ao concreto no comportamento de corpos de prova submetidos aos ensaios de compressão diametral e tração direta. $\mathrm{O}$ efeito escala será analisado a partir das diferentes dimensões dos corpos de prova nos ensaios de tração por compressão diametral.

\section{3 \\ Metodologia}

Foram ensaiados 72 corpos de prova divididos em três grupos em função de suas resistências. Em cada grupo os corpos de prova tinham características distintas, como as suas dimensões e consumo de fibras.

A partir da análise dos resultados obtidos neste programa experimental pretendeu-se por meio do ensaio de compressão diametral avaliar: 
- a força de tração versus a resistência do concreto;

- a força de tração versus as dimensões de cada corpo de prova estudando-se o efeito escala, por meio da análise do comportamento de corpos de prova de diferentes tamanhos;

- a força de tração versus volume de fibras presentes no concreto, para se verificar sua influência no concreto;

- o efeito escala em corpos de prova armado com fibras de aço submetidos à tração por compressão diametral e a lei existente de Carpinteri (1995);

- a razão da força de tração obtida no ensaio de compressão diametral pela obtida no ensaio de tração direta;

- o ângulo de atrito interno do CAFA;

- as curvas de tensão x deformação específica dos ensaios.

\section{4}

\section{Estrutura do trabalho}

Este estudo está dividido em seis capítulos, referências bibliográficas e anexos.

O primeiro capítulo apresenta a motivação e os objetivos do trabalho.

No segundo capítulo são relatados o comportamento mecânico do CAFA e as principais características desse tipo de fibra.

O terceiro capítulo relata as teorias do efeito escala.

No capítulo quatro é mostrada a metodologia dos ensaios, os materiais utilizados, bem como a caracterização das propriedades mecânicas desses materiais. É estabelecida a nomenclatura de identificação dos corpos de prova e finalmente a instrumentação que foi utilizada no ensaio.

O quinto capítulo apresenta e analisa os resultados obtidos nos ensaios dos corpos de prova.

As conclusões do trabalho juntamente com as sugestões de trabalhos futuros estão no capítulo seis.

Os dados obtidos nos ensaios se encontram nos anexos de A a D. 


\section{2 \\ Comportamento mecânico do concreto com fibras}

\section{1 \\ Concreto armado com fibras}

Desde a antiguidade, as fibras vêm sendo utilizadas em materiais frágeis. Segundo relatos, palhas e pelos de cavalos foram utilizados para reforçar tijolos de adobe e alvenarias de argamassa e gesso.

Os primeiros estudos de concretos armados com fibras (CAF) se deu nos anos 1950 e 1960. Desde então o mercado oferece uma grande variedade de fibras com diferentes propriedades mecânicas, físicas e químicas. A sua escolha depende das características que se deseja fornecer ao compósito (FIGUEIREDO, 2000).

A adição das fibras no concreto controla a propagação de fissuras (MAIDL,1995). Isso ocorre, pois, as fibras servem como ponte de transferência de tensões pelas fissuras, minimizando a concentração de tensões em suas extremidades (Figura 2.1). Com isto tem-se uma redução da velocidade de propagação das fissuras no concreto e o material passa a ter um comportamento pseudoductil, ou seja, continua apresentando uma resistência residual às solicitações atuantes após sua fissuração (FIGUEIREDO, 2000). Uma menor fissuração do concreto será proporcionada com a presença das fibras.

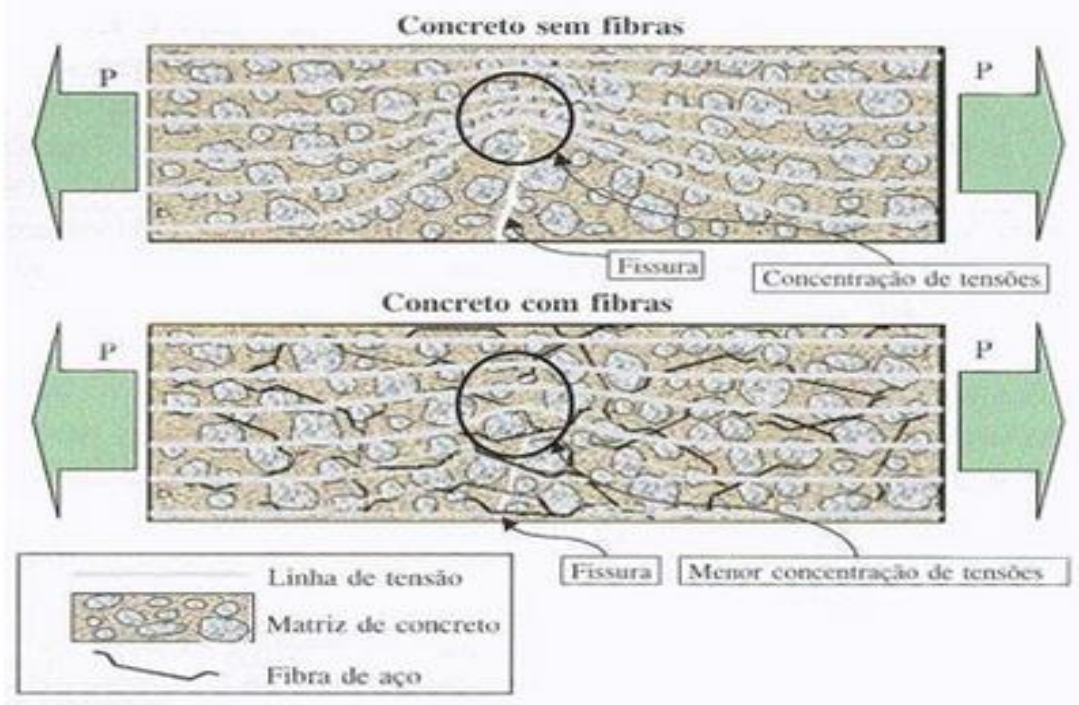

Figura 2.1 - Esquema de concentração de tensões (FIGUEIREDO, 2005). 
Ensaios realizados por MARANGON (2011) mostram que as substituições parciais em $37 \%$ da taxa de armadura por fibras acarretam um aumento de $40 \%$ na carga de serviço e reduzem em $34 \%$ a abertura de fissuras.

As melhorias no comportamento do CAF são funções das propriedades dos elementos constituintes da matriz, das propriedades mecânicas e características geométricas das fibras, da composição e processo de fabricação do material compósito, bem como a interação entre as fibras e a matriz (BARROS,1996). Dessa forma a dosagem da fibra deve atender aos requisitos de projeto, tanto específicos como gerais, e o material compósito passa a ter exigências especificas, tanto para o seu controle de qualidade quanto para sua aplicação.

Segundo FIGUEIREDO (2000), o CAF apresenta vantagens tecnológicas e econômicas em relação ao convencional em diversas aplicações, como é o caso do concreto projetado, dos pré-moldados, estruturas para túneis entre outros.

\section{2 \\ As fibras de aço}

As fibras metálicas são as mais utilizadas no CAF, principalmente as de aço. O intuito da utilização deste tipo de fibra é aumentar a tenacidade, resistência à flexão, resistência ao impacto, resistência à fadiga e o controle da fissuração do concreto.

As fibras de aço podem ser classificadas como fibras de alto módulo, ou seja, possuem módulo de elasticidade superior ao do concreto convencional (FIGUEIREDO, 2000). Portanto elas podem ser usadas não somente como controle de fissuração, mas também como reforço primário do concreto. As fibras permitem também uma redistribuição de esforços no material mesmo utilizadas em quantidades reduzidas.

Segundo MAIDL (1995), mesmo com alto módulo de elasticidade as fibras têm como objetivo somente controlar as fissuras que são naturalmente formadas e não prevenir que elas se formem.

As vantagens do uso do CAFA são bem conhecidas. MINDESS (1995) aponta que sua utilização, mesmo em estruturas de concreto armado convencional aumenta a competitividade do material, quando comparado com outros materiais, como as estruturas de aço por exemplo. 
As fibras de aço são produzidas a partir de fios de aço trefilados ou laminados (formados por multifilamentos de aço, compostos de segmentos pequenos) com comprimentos e diâmetros variados. Elas podem ser fabricadas com extremidades dobradas ou alargadas aumentando sua aderência à matriz. As fibras são geralmente frisadas ou deformadas com um gancho em cada ponta ou com uma cabeça pequena, a fim de melhorar a ligação entre fibra e matriz de concreto (MAIDL, 1995). Axialmente, a forma pode ser retilínea ou corrugada e, transversalmente, a fibra pode apresentar seção circular, retangular ou variada. Na Figura 2.2 são apresentadas fibras de diferentes formas.

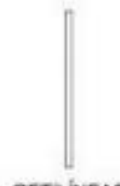

RETLINEAS
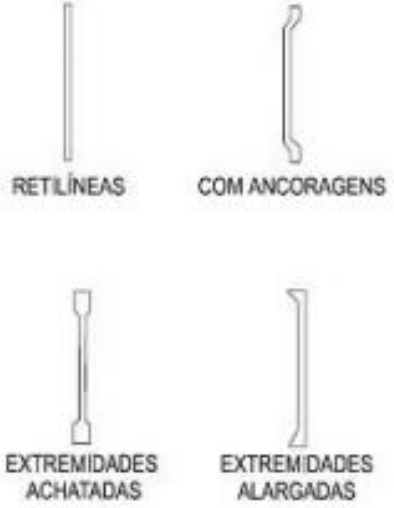

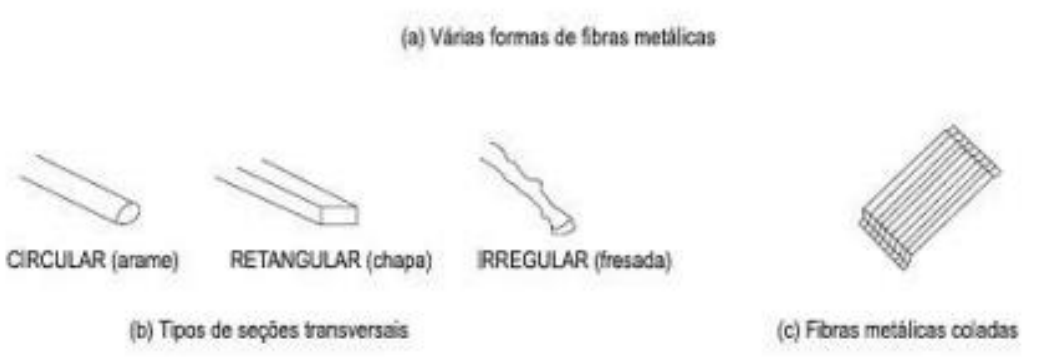

Figura 2.2 - Exemplos de diferentes formas de fibras metálicas (SARZALEJO, 2009).

A NBR 15530 (2007) - Fibras de aço para concreto - Especificação, estabelece parâmetros para a classificação das fibras, além de requisitos mínimos de geometria e tolerâncias dimensionais, defeitos de fabricação, resistência à tração e dobramento (FIGUEIREDO et al, 2008).

São previstos na norma três tipos básicos de fibras em função de sua geometria:

- Tipo A - fibra de aço com ancoragens nas extremidades.

- Tipo C - fibra de aço corrugada.

- Tipo R - fibra de aço reta. 
Além disso, segundo a norma existem três classes previstas para as fibras definidas de acordo com o aço que as deu origem:

- Classe I - fibra de arame trefilado a frio.

- Classe II - fibra oriunda de chapa laminada cortada a frio.

- Classe III - fibra oriunda de arame trefilado e escarificado.

Na Figura 2.3 têm-se as correspondências entre as classes e as geometrias definidas em norma.

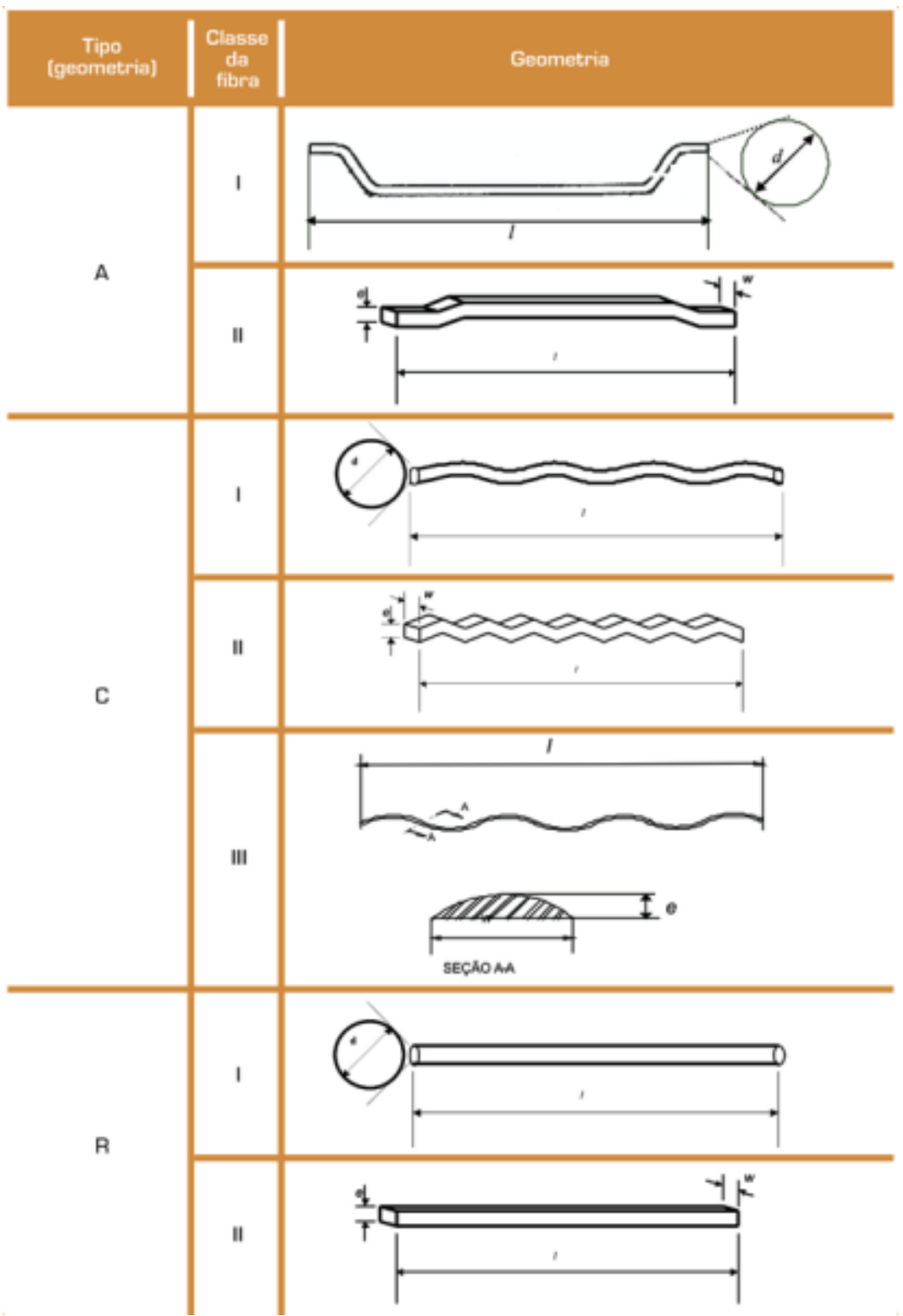

Figura 2.3 - Classificação e geometria das fibras de aço para reforço de concreto (FIGUEIREDO, 2008). 
Essa classificação possibilitou o estabelecimento de requisitos mínimos que podem ser correlacionados com o desempenho final do CAFA (FIGUEIREDO, 2008).

Diversos são os parâmetros adotados para esse controle como a dosagem, fator de forma da fibra, geometria, interação fibra matriz, fração volumétrica de fibra adicionada e pelo traço do concreto.

\subsection{1 \\ Mecanismo de atuação das fibras}

As fibras agem como pontes de ligações, transferindo as solicitações de um lado para o outro da matriz e minimizando as tensões nas extremidades das fissuras, que por sua vez ficam mais finas, menos espaçadas e melhor distribuídas ao longo da estrutura (NUNES e AGOPYAN, 1998). A velocidade de propagação dessas fissuras também é reduzida, necessitando assim uma maior quantidade de energia para sua abertura e propagação. Sendo assim a ruptura do concreto se torna menos frágil, propiciando um eventual ganho de ductilidade da estrutura.

É possível ver que o comportamento do CAF tem sua importância ligada diretamente com sua capacidade de ligar as fissuras. Essa capacidade está associada pela eficiência da interação fibra-matriz que por sua vez é influenciada pela geometria e propriedades mecânicas das fibras e pela composição da matriz.

\subsection{2}

\section{A Interação fibra-matriz}

A aderência entre as fibras e a matriz é essencial. A interface entre os elementos apresenta influência dominante sobre as características dos materiais empregados. A principal função dessa interface é possibilitar uma adequada transferência dos esforços entre as fibras e a matriz (MAIDL, 1995).

As fibras são arrancadas em sua maioria, mostrando assim que o importante não é a resistência da fibra e sim a eficiência da aderência desta à matriz.

A aderência fibra-matriz está relacionada a diversos fatores como a ancoragem da fibra na matriz, adesão físico-química entre os materiais, o atrito fibra-matriz e a dimensão do agregado. Esses fatores são influenciados pelas características das fibras (volume, módulo de elasticidade, resistência, geometria e 
orientação) e características da própria matriz (composição, resistência e propriedades físicas e mecânicas).

\subsection{3}

\section{Teor de fibras}

O teor de fibras presente na matriz atua diretamente na capacidade de reforço que as fibras apresentam. Quanto maior for o teor, maior a quantidade de fibras que vão atuar como ponte de transferência de tensões ao longo da fissura, aumentando assim o reforço pós-fissuração do concreto.

Um exemplo da influência do teor de fibras no concreto pode ser visto na Figura 2.4. Nela podem ser vistas as curvas médias de carga por deslocamento em um ensaio de tração na flexão com deslocamento controlado. No gráfico podemos ver que o trecho elástico inicial, em que a matriz trabalha antes de fissurar fica praticamente estável, ou seja, a influência do teor de fibras não é significativa.

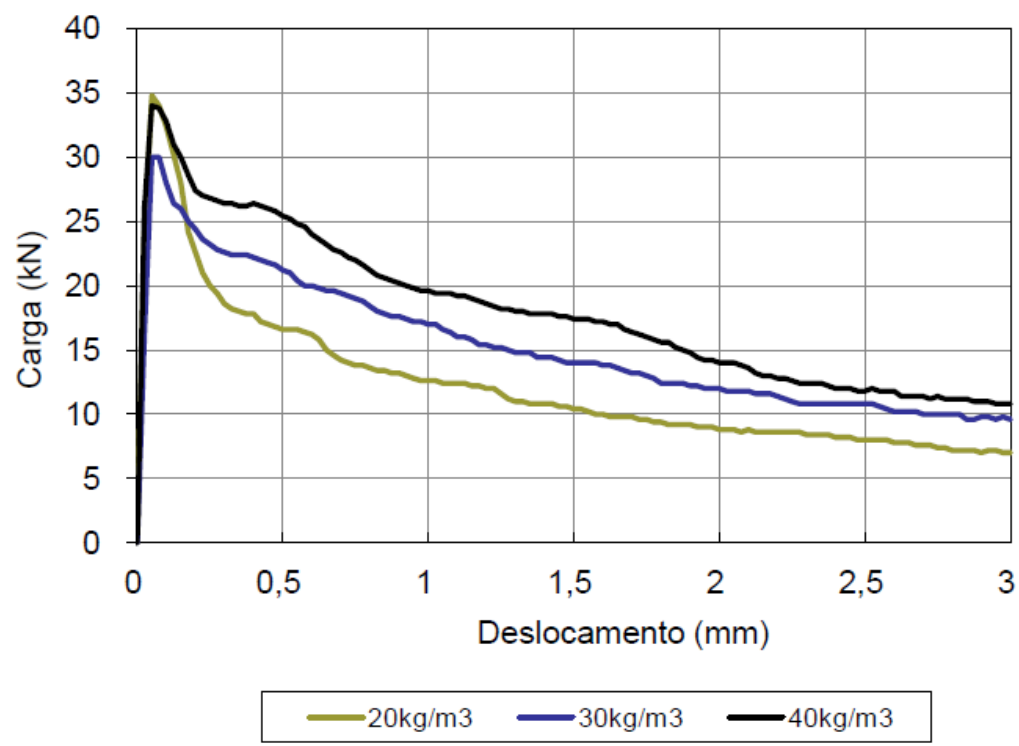

Figura 2.4 - Curvas médias de carga por deslocamento com diferentes consumos de fibra de aço (FIGUEIREDO,2000).

Porém, após a fissuração a carga resistida aumenta com o acréscimo do teor de fibras, isto é, o maior consumo de fibra proporciona uma resistência residual pós-fissuração. 


\subsection{4 \\ Volume crítico}

Segundo FIGUEIREDO (2000), a definição de volume crítico é a de que ele corresponde ao teor de fibras que mantém a mesma capacidade resistente para o compósito a partir do momento em que ocorre a ruptura da matriz. Abaixo do volume crítico, no momento em que ocorre a ruptura da matriz ocorre o comportamento strain-softening que significa uma perda da capacidade resistente. Acima do volume crítico o compósito apresenta comportamento strain-hardening, ou seja, ele continua aceitando níveis de carregamentos crescentes mesmo após a ruptura do concreto. Podemos observar isto na Figura 2.5. O trecho elástico linear inicial corresponde ao estágio pré-fissurado da matriz e o trecho similar a um patamar de escoamento é onde podemos ver a diferença do comportamento do CAFA com teores superiores, inferiores e iguais ao volume crítico de fibras.

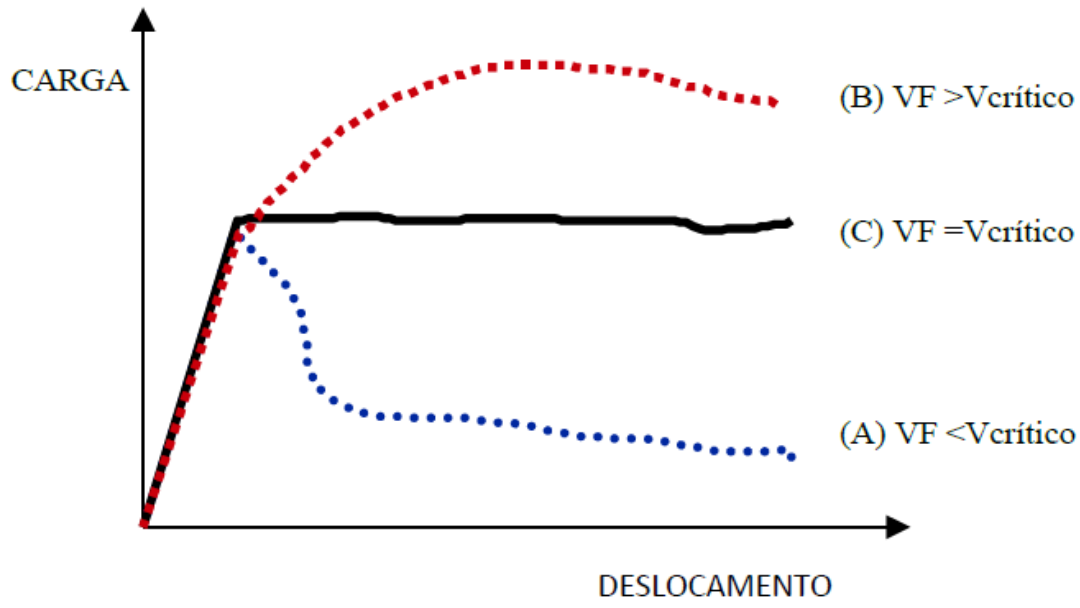

Figura 2.5 - Diagramas carga $x$ deslocamento de concreto com fibras em teor inferior (A), superior (B) e igual (C) ao volume crítico de fibras (FIGUEIREDO, 2000).

O Volume crítico pode ser calculado a partir de modelos que estimam a contribuição das fibras na rigidez da matriz após a fissuração. AVESTON et al (1971) propôs uma modelagem, que FIGUEIREDO (2000) comenta, onde ele focaliza um compósito ideal, com fibras contínuas e alinhadas à direção principal. Porém este modelo não representa a realidade do CAFA, onde as fibras são distribuídas aleatoriamente e descontínuas. Para a correção desses erros são utilizados os chamados fatores de eficiência, que permitem uma maior aproximação 
do volume crítico teórico do obtido experimentalmente. Após a introdução desses coeficientes o autor estima em $0,91 \%$ o volume crítico para o caso de fibras de aço.

Segundo NUNES et al (2006), esse volume crítico é da ordem de $1 \%$ em volume, ou seja, cerca de $80 \mathrm{~kg} / \mathrm{m}^{3}$ de concreto, valor este que está na mesma ordem de grandeza do valor calculado analiticamente por AVESTON et al (1971).

METHA e MONTEIRO (1994), ressalta que a adição de fibras a matrizes cimentícias reduz a trabalhabilidade, independentemente do tipo de fibra. Essa redução é proporcional à concentração do volume de fibras no concreto. Volumes altos devem ser utilizados com cuidado, pois podem causar problemas na homogeneidade.

\subsection{5 Índice de esbeltez}

A geometria da fibra é um dos principais aspectos que definem o desempenho do material no CAFA (FIGUEIREDO et al, 1997), sendo o índice de esbeltez da fibra um dos principais fatores que influenciam esse desempenho.

Índice de esbeltez, ou relação de aspecto é a relação entre o comprimento da fibra e o seu diâmetro equivalente (diâmetro do círculo cuja seção equivale à superfície da fibra). Este índice é capaz de indicar o grau de eficiência da fibra em função de sua geometria (NUNES e AGOPYAN, 1998). Este parâmetro varia entre 30 e 100 para as fibras de aço normalmente empregadas em concreto.

Fibras de maior seção transversal apresentam um desempenho maior pois essa seção transversal proporciona uma grande área de contato com a matriz aumentando assim a resistência ao arrancamento da fibra. Segundo MEHTA e MONTEIRO (1994), um maior índice de esbeltez pode tanto significar uma melhora na resistência ao arrancamento da fibra, pelo aumento do comprimento de ancoragem, como um aumento ao número de fibras que podem interceptar uma fissura, decorrente da utilização de um número maior de fibras. No entanto, quanto maior for o índice de esbeltez, maior será também a influência da fibra na perda de fluidez do material.

Devido a importância do índice de esbeltez no desempenho do concreto reforçado com fibras de aço, a NBR 15530 (2007) procurou regular dois fatores importantes: a geometria da fibra e a resistência do aço utilizado na fabricação da 
mesma. A norma estabelece diferentes níveis de resistência em função do tipo e, principalmente, da classe de fibra avaliada.

Quanto maior for o índice de esbeltez da fibra, maior será a capacidade resistência pós-fissuração do concreto, desde que não se ultrapasse o comprimento crítico da fibra. Assim, o comprimento da fibra sempre merece atenção.

\subsection{6}

\section{Comprimento crítico}

FIGUEIREDO (2000) afirma que o comprimento crítico $l_{c}$ pode ser definido como um mecanismo de transferência de tensão entre a matriz e a fibra. Esta tensão é máxima quando a tensão a que está submetida a fibra se iguala à tensão de cisalhamento entre a fibra e a matriz. À medida que as tensões de aderência superam a resistência de aderência, a fibra perde seu papel de transferência e é arrancada da matriz.

Segundo MAIDL (1995) deve haver compatibilidade dimensional entre agregados e fibras, possibilitando que as mesmas interceptem a fissura. A compatibilidade dimensional faz com que a fibra atue não somente como reforço da argamassa, mas sim como reforço do concreto. Isto é importante pois a fratura se propaga na região de interface entre o agregado graúdo e a pasta para concretos de baixa e moderada resistência. Quando não há essa compatibilidade poucas fibras trabalham como ponte de transferência de tensões na fissura (Figura 2.6 e Figura 2.7). Duas alternativas são empregadas de maneira a compatibilizar a mistura de concreto com fibras: reduzir a dimensão máxima característica do agregado, ou aumentar o comprimento da fibra.

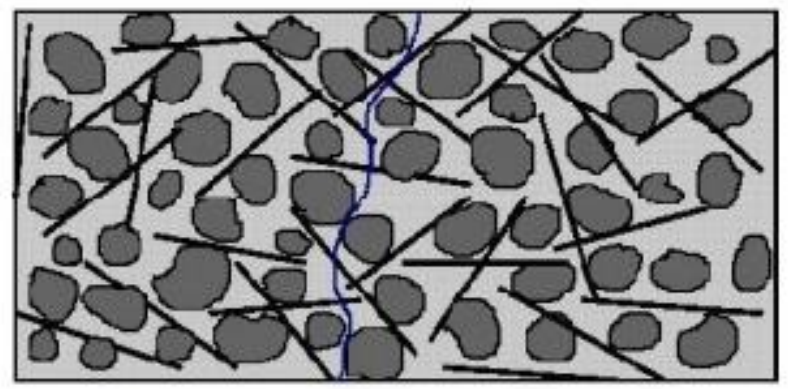

Figura 2.6 - Concreto armado com fibras onde há compatibilidade dimensional entre as fibras e o agregado graúdo (FIGUEIREDO, 2000). 


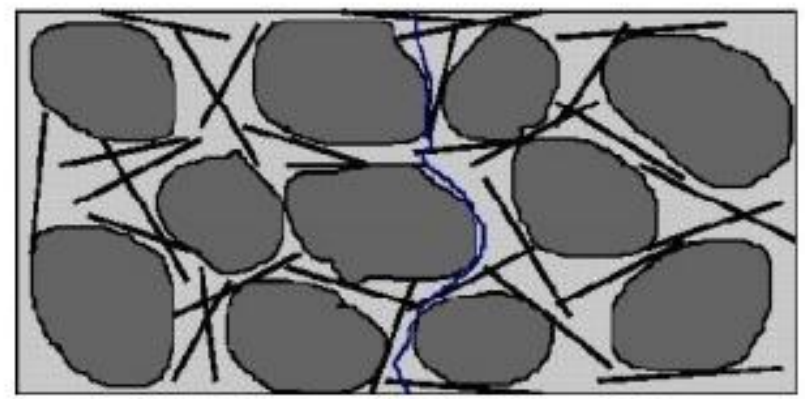

Figura 2.7 - Concreto armado com fibras onde não há compatibilidade dimensional entre as fibras e o agregado graúdo (FIGUEIREDO, 2000).

\subsection{7 \\ Distribuição das fibras}

Na maioria dos casos as fibras metálicas se encontram soltas, embora aquelas com extremidades dobradas sejam fornecidas em pentes e unidas nas extremidades por uma cola solúvel em água, durante essa mistura essas fibras se soltam e se dispersam individualmente. Esse processo facilita a mistura da fibra com o concreto e evita que elas fiquem agrupadas e má distribuídas.

Segundo BENTUR e MINDESS (1990), o arranjo das fibras nos compósitos pode assumir várias geometrias em função da forma das fibras individuais e da sua dispersão na matriz. Podendo-se apresentar em três formas: arranjo unidimensional, bidimensional e tridimensional. Conforme se observa na Figura 2.8 o arranjo das fibras pode ser contínuo, com fibras longas $(a, c)$ ou discreto, com fibras curtas ( $\leq 50 \mathrm{~mm}$ de comprimento) (b, d). No concreto as fibras normalmente utilizadas são discretas e curtas e tendem a se orientar de forma dispersa e não-uniforme. 


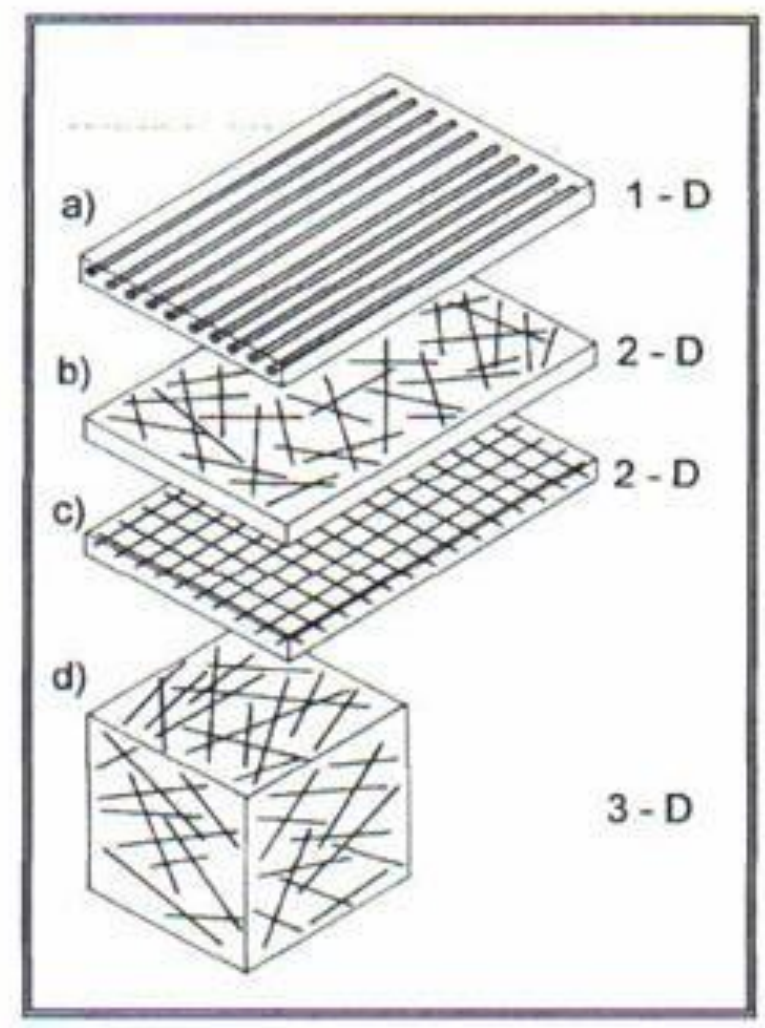

Figura 2.8 - Orientação das fibras (BENTUR e MINDESS, 1990).

Os compósitos formados por fibras longas se apresentam com um grande grau de orientação, pois as fibras tendem a se alinhar na direção maior. Já os de fibras curtas apresentam fibras orientadas em diversas direções. Na prática a distribuição das fibras de maneira uniforme é raramente obtida, essa uniformidade depende muito do processo de mistura, lançamento e adensamento.

SILVA et al (2008) desenvolveram compósitos reforçados com fibras de sisal alinhadas em somente uma direção e esses apresentaram múltipla fissuração nos ensaios de tração direta e flexão.

Em geral, para que as fibras produzam uma maior uniformidade nas propriedades de resistência do compósito, elas devem apresentar boa resistência à tração e possibilitar uma dispersão uniforme e uma orientação aleatória por todo o concreto. 


\section{3 \\ Propriedades do concreto armado com fibras de aço}

FIGUEIREDO (2000) afirma que quando adicionadas ao concreto, as fibras dificultam a fissuração devido ao seu alto módulo de elasticidade. Elas permitem uma redistribuição dos esforços mesmo aplicada com baixos teores.

Segundo BARROS et al (1999), as fibras fornecem capacidade de absorção adicional de energia, melhoram a resistência à flexão do concreto, bem como sua resistência ao impacto, à tração e ductilidade.

A fragilidade do concreto é reduzida com a inserção das fibras, o mesmo passa a ter um comportamento pseudo-dúctil, permitindo uma redistribuição dos esforços aumentando sua capacidade de suporte à fadiga e ao impacto e em contrapartida sua durabilidade (NUNES et al 2006).

Diversos fatores supracitados podem influenciar as propriedades mecânicas do concreto com fibras de aço, dentre eles: interação fibra/matriz, comprimento das fibras, orientação e volume das fibras no concreto.

\subsection{1 \\ Resistência à compressão}

A resistência à compressão é considerada a propriedade essencial do concreto convencional, entretanto, BENTUR e MINDESS (1990), afirmam que a adição de fibras de aço no concreto produz um pequeno ou nenhum aumento na resistência à compressão do concreto. Em alguns casos pode ocorrer o decréscimo desse valor devido à adição de mais água, que é necessária com a adição das fibras, para aumentar a trabalhabilidade do concreto (FIGUEIREDO, 2000). MAIDL (1995) diz que o aumento da resistência à compressão pode ficar na faixa de 0 a 30\%. De acordo com ACI 544.1R-96, na compressão, a carga última é sensivelmente afetada pelo acréscimo de fibras de aço ao concreto, onde são observados aumentos entre 0 e $15 \%$ para frações volumétricas de fibras acima de $1,5 \%$.

Uma mudança significativa pode ser observada no comportamento pós-pico do material com a adição da fibra, tornando sua resposta mais suave em termos de declividade do ramo descendente do diagrama tensão-deformação específica, e levando-o a atingir níveis de deformação específica maiores, até a ruptura. $\mathrm{Na}$ Figura 2.9 pode-se observar a influência do teor de fibras nas curvas 
tensão-deformação do CAFA. Nota-se um aumento significativo na deformação específica no pico da tensão de compressão, e um menor declive na parte descendente da curva comparado com concreto sem adição de fibras

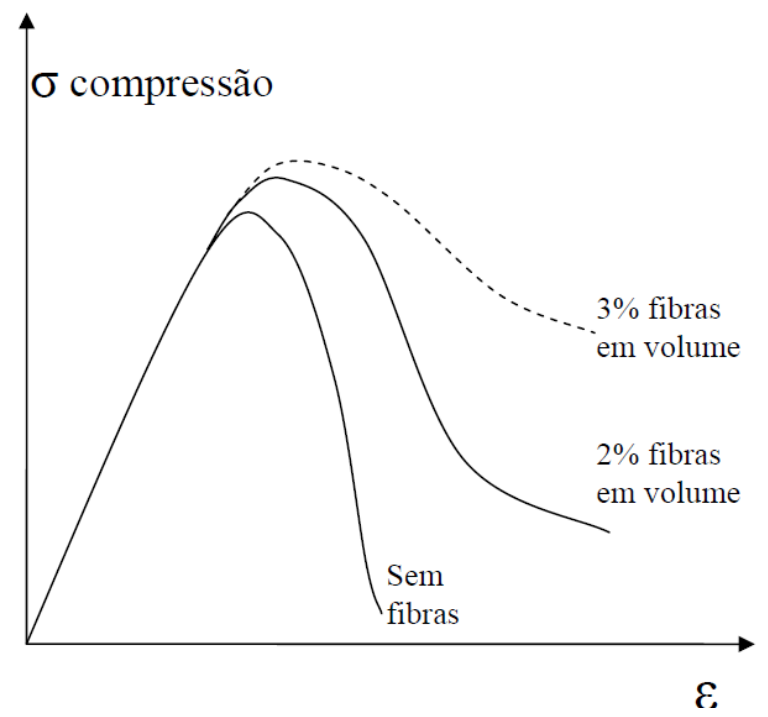

Figura 2.9 - Tensão de compressão x deformação específica de concretos sem e com fibras de aço.

Entretanto, segundo o ACI 544.4R-88, as fibras de aço com teores de fibras menores que $2 \%$ não acrescentam melhoria na resistência à compressão do concreto, podendo levar a uma pequena redução desta propriedade.

Independente da incerteza quanto ao aumento da resistência à compressão do CAFA, o objetivo da adição das fibras não é promover alterações nesta propriedade e sim melhorar o comportamento pós-fissuração, permitindo assim que o concreto deforme bem mais quando tracionado.

\subsection{2}

\section{Ductilidade}

CARMONA et al (1995) afirma que as fibras de aço quando inseridas ao concreto aumentam a sua ductilidade. Ductilidade é definida como sendo a área sob a curva carga x flecha, para qualquer tipo de carregamento. Elas não aumentam significativamente a deformação específica referente à carga de pico, porém, aumentam muito a absorção de energia na parte pós-pico da curva em função da quantidade de fibras que é incorporada a mistura (Figura 2.10). 


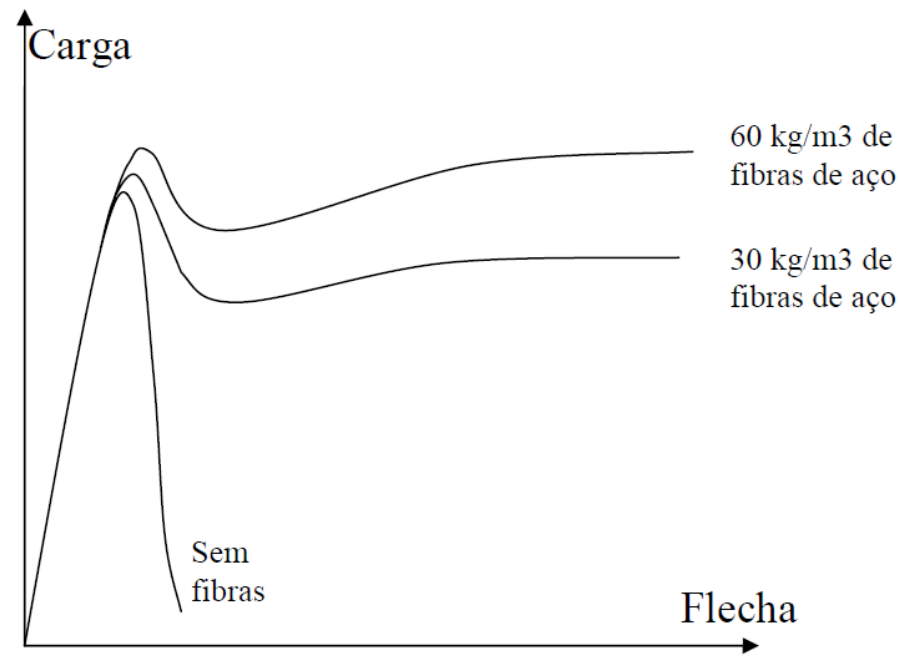

Figura 2.10 - Curvas carga $x$ flecha para concretos com diferentes volumes de fibras.

No estudo realizo por MARANGON (2006) contata-se um aumento na ductilidade em concretos fibrosos quando comparados à matriz de referência.

\subsection{3}

\section{Resistência à tração}

A adição de fibras de aço, em frações volumétricas adequadas, é uma aliada ao concreto armado no que diz respeito ao combate às tensões de tração induzidas. O uso das fibras auxilia na redução do aparecimento de fissuras, inclusive aquelas decorrentes da retração do concreto.

Segundo o ACI 544.1R (1996), para adições de fibra de aço ao concreto a uma fração volumétrica de 1,5 \% são observados incrementos entre 30 e $40 \%$ na resistência à tração direta de matrizes de concreto. Para BENTUR e MINDESS (1990) é preciso adicionar teores elevados de fibras com alta resistência à tração para que seja notado o aumento da resistência à tração do compósito. Isso ocorre devido a capacidade das fibras de manter uma parcela resistente mesmo após o aparecimento da primeira fissura no concreto.

Um aumento da resistência pode ser observado quando se criam situações favoráveis como por exemplo: utilização de volume de fibras elevados, alinhamento das fibras na direção da tração, dosagem, o tipo da fibra e a boa aderência das fibras a matriz do concreto.

A Figura 2.11 mostra curvas de tensão x deformação específica de argamassas com e sem fibras. Nota-se que na parte crescente da curva, antes da fissuração, não 
há muita diferença, porém na parte decrescente a curva depende do teor e da geometria da fibra utilizada.

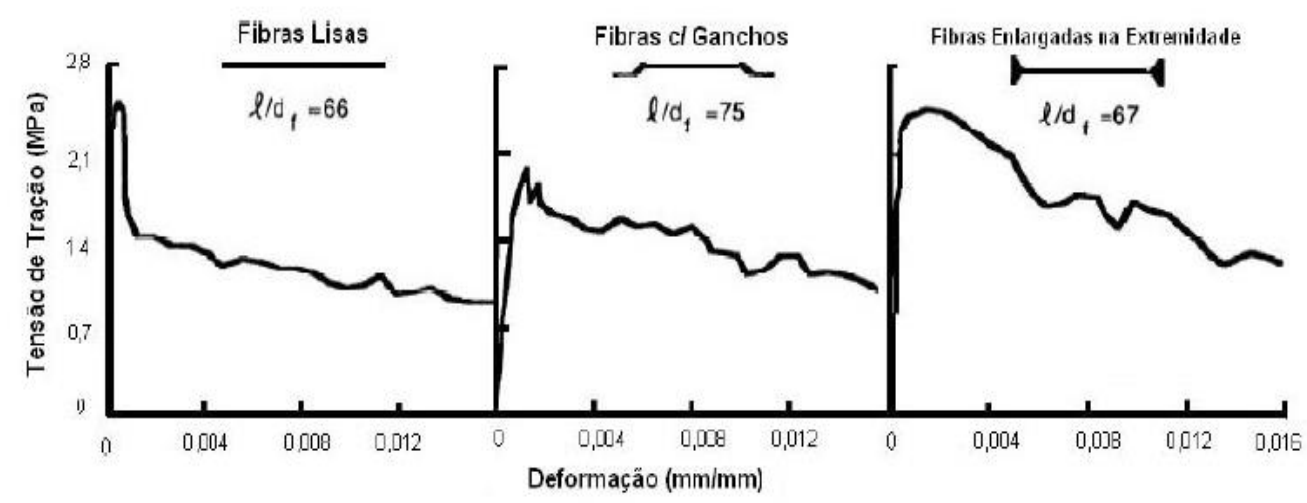

Figura 2.11 - Curvas tensão x deformação específica de argamassas com fibras (ACl 544.4R88).

A inserção das fibras proporciona uma melhoria na resistência à tração do concreto dependendo do volume de fibras que é utilizado. Um volume de $5 \%$ de fibras de aço lisas e retas orientadas na direção da tração pode ocasionar um aumento de até $133 \%$ da resistência a tração. Já quando são colocadas aleatoriamente este acréscimo só chega ao máximo de 60\% (BENTUR e MINDESS, 1990).

O ensaio de tração direta não apresenta fácil execução, pois é recomendado entalhar o corpo de prova de maneira a induzir a fissura. Esta dificuldade levou ao desenvolvimento de métodos alternativos para obter a resistência à tração do concreto com fibras. O ensaio de tração por compressão diametral conhecido também como Ensaio Brasileiro é um desses métodos. Este ensaio vem sendo adotado desde 1953 devido a sua fácil execução e pelo seu desenvolvimento teórico, que permite transformar a carga de compressão aplicada ao longo de duas linhas axiais que são opostas no sentido diametral, em resistência à tração do material ensaiado. Nesse ensaio um corpo de prova cilíndrico de concreto é submetido a uma força de compressão aplicada em uma região reduzida ao longo de seu comprimento. Essa força é uniforme e produz uma tensão de tração ao longo da sua geratriz. A ruptura ocorre quando a resistência à tração atinge seu máximo valor. Portanto, é possível estimar a resistência à tração direta a partir da indireta. Uma desvantagem do ensaio de compressão diametral comparado ao de tração direta é que ele não fornece dados apropriados do comportamento do material pós fratura (DENNEMAN et al, 2011). 


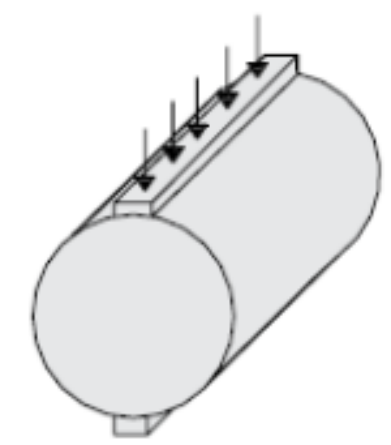

Figura 2.12 - Esquema de corpo de prova para ensaio de tração por compressão diametral.

CUCCHIARA et al (2004) monstra um aumento significativo da resistência à tração em ensaios de tração por compressão diametral com volumes variados de fibras. A tração não aumenta significativamente quando são utilizados volumes inferiores a $2 \%$.

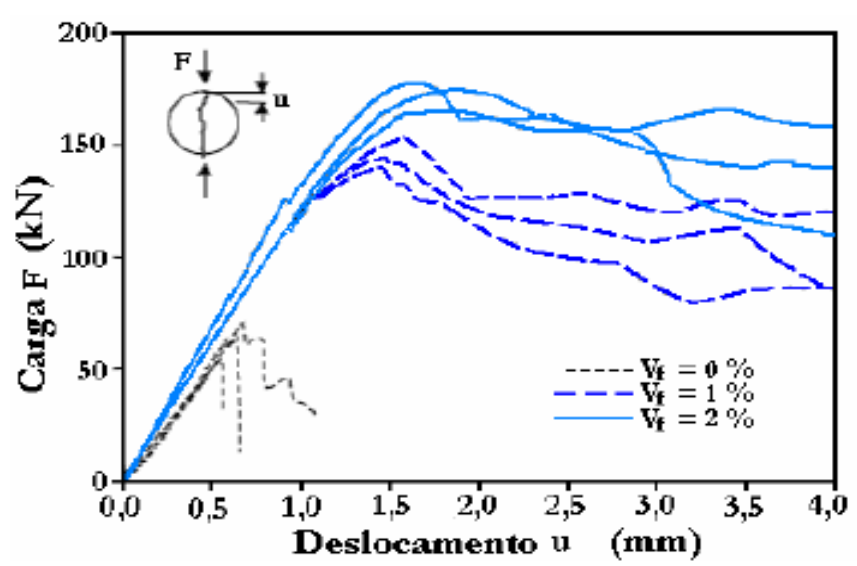

Figura 2.13 - Resultados de ensaio de compressão diametral para concreto com e sem adição de fibras (CUCHIARA, 2004).

\subsection{4}

\section{Trabalhabilidade}

Sabe-se que a trabalhabilidade é uma das propriedades mais afetadas pelo uso de fibras, sendo sua redução diretamente proporcional ao teor volumétrico de fibras utilizado. (METHA e MONTEIRO, 1994).

Um dos efeitos mais importantes da adição de fibras de aço ao concreto no estado fresco, é a redução da trabalhabilidade, uma vez que as fibras enrijecem a mistura provocando a redução da fluidez e mobilidade do mesmo (CASTRO, 2010). 
Essa redução é proporcional à quantidade de fibras no concreto, pois ao adicionálas, a área superficial é aumentada demandando água de molhagem. Assim é muito importante um cuidado com a dosagem para que se assegure uma maior dispersão das fibras na matriz.

Segundo TOLEDO FILHO (1997) para que se avalie a mistura fresca reforçada com fibras é recomendado que se faça testes de trabalhabilidade nos quais efeitos dinâmicos estejam envolvidos.

\subsection{5 \\ Durabilidade}

A durabilidade dos CAFA depende não somente da durabilidade das fibras, mas também da durabilidade do compósito e dos agentes agressivos externos (FIGUEIREDO, 2000).

Os CAFA apresentam boa durabilidade, desde que sejam bem compactados e curados. As fibras devem estar sempre protegidas pela pasta. Em geral é inevitável que ocorra corrosão em fibras mais superficiais, porém as fibras mais internas ficam protegidas e permanecem sem corrosão. A corrosão na superfície pode ser evitada utilizando fibras de aço inoxidável ou resistentes à corrosão. 


\section{3 \\ Efeito escala}

\section{1 Introdução}

Em engenharia muitos experimentos são realizados em dimensões menores do que as utilizadas em diversos elementos estruturais. Sendo assim, surge a necessidade de avaliar a influência do tamanho do espécime nos resultados obtidos para que esses possam ser aplicados em casos reais. Desse modo tem-se o efeito escala, que segundo RIOS et al (2002) deve ser levado em conta em qualquer teoria física. Ele pode ser explicado por uma combinação da teoria da plasticidade e mecânica da fratura. COURA et al (2007) relatam que esse fenômeno é a influência das dimensões da estrutura sobre as propriedades dos materiais. ELFAHAL et al (2004 e 2005) verificaram que as dimensões dos componentes do concreto influenciam seu comportamento quando submetido a uma carga estática. Existem diversos estudos teóricos e experimentais sobre este assunto. Os primeiros estudos foram realizados por Weilbull, porém, não se aplicam a materiais frágeis não homogêneos. Atualmente existem duas formulações teóricas que são a de BAZANT (1984) e a de CARPINTERI (1992).

\section{2}

\section{Lei de Bazant}

Este autor relaciona a resistência do concreto em função das dimensões do corpo de prova e do agregado. A Lei de Bazant, ou “Size Effect Law” (SEL), pode ser descrita por (BAZANT et al, 1991):

$$
\sigma_{n}=\mathrm{B} f_{t}\left(1+\frac{d}{d_{0}}\right)^{-1 / 2}
$$


onde

$d$ - dimensão do corpo de prova;

$\sigma_{n}-$ resistência nominal;

$f_{t}-$ resistência à tração do concreto;

$\mathrm{B}, d_{0}-$ constantes a serem determinadas nos ensaios.

De acordo com a expressão 3.1 o efeito escala é uma transição da Teoria da Plasticidade (efeito escala mínimo) e da Mecânica da Fratura Linear (efeito escala máximo). As estruturas que têm $d \geq d_{0}$ são mais frágeis prevalecendo a Mecânica da Fratura Linear (MFL), e a resposta de elementos com $d \leq d_{0}$ ficam mais próximas da Teoria da Plasticidade e são mais dúcteis (Figura 3.1).

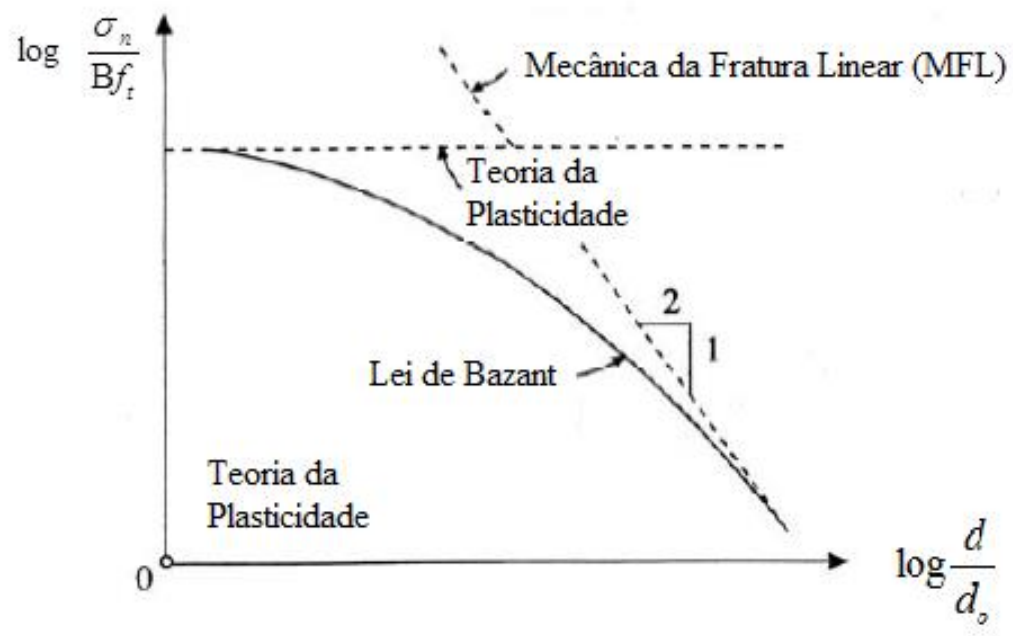

Figura 3.1 - Lei de Bazant; adaptado de BAZANT (1984).

Segundo COURA et al (2007), quando se aplica a SEL em corpos de prova não fissurados a hipótese torna-se falha. Um termo $\sigma_{0}$, designado como sendo a resistência de um corpo de prova infinitamente grande foi introduzido por Bazant na equação 3.1 .

BAZANT (1991) por meio de resultados experimentais afirma que existe efeito escala no ensaio brasileiro proposto por Lobo Carneiro, porém, só é válido até um certo diâmetro. Acima deste diâmetro essa lei não pode ser aplicada pois a curva da tensão nominal versus diâmetro tende para uma assíntota horizontal, significando o desaparecimento do efeito escala. 


\section{3 Multifractal Scaling Law - MFSL (CARPINTERI-1992)}

A lei de Carpinteri é aplicável em concretos e considera que em elementos com pequenas dimensões, a dimensão do agregado é de grande magnitude acentuando o efeito escala. Em elementos com grandes dimensões em relação ao tamanho do agregado o efeito escala tende a desaparecer. A expressão que representa essa lei é (CARPINTERI,1992):

$$
\sigma_{n}=\left(\mathrm{A}+\frac{B}{d}\right)^{1 / 2}
$$

onde

$\sigma_{n}-$ resistência nominal;

$d$ - dimensão do corpo de prova;

A , $B$ - são constantes a serem determinadas nos ensaios.

Se $d$ tende para o infinito a resistência nominal tende para um valor constante diferente de zero (resistência limite). Quando $d$ tende para zero o valor da resistência tende para o infinito, significando que o efeito escala para alguns elementos de concreto é grande somente para alguns valores de dimensões, que podem ser grandes ou pequenos, dependendo da geometria da estrutura. $\mathrm{Na}$ expressão 3.2 a constante B depende das dimensões do elemento. Para estruturas com $d \geq B$ o efeito escala tende a ser nulo, a peça falha no início da fissuração (ruptura não dúctil). Porém, para $d \leq B$ o efeito escala é grande e a ruptura é dúctil.

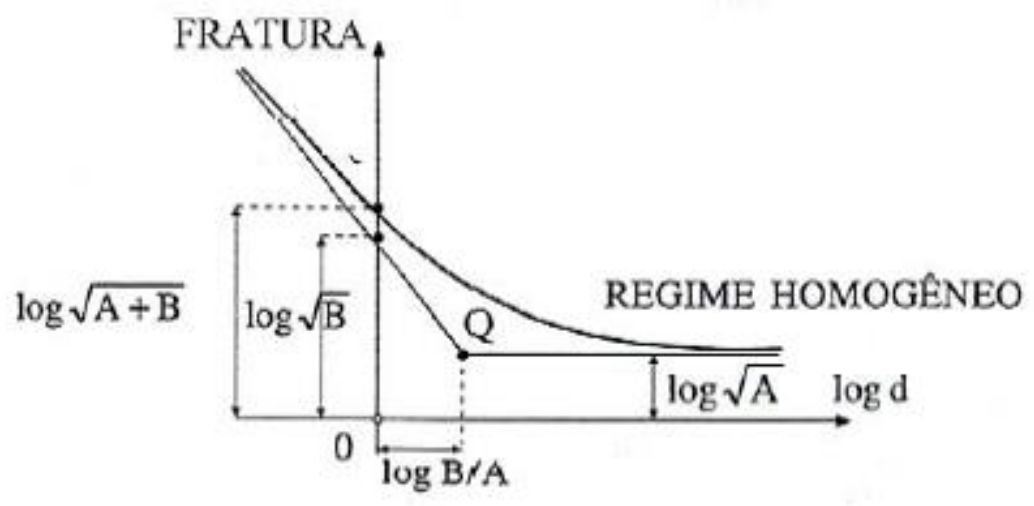

Figura 3.2 - Multifractal Scaling Law; adaptado de CARPINTERI (1995). 
Segundo CARPINTERI et al (1995) a expressão 3.2 pode ser reorganizada da seguinte forma:

$$
\sigma_{n}=f_{t}\left(1+\alpha_{0} \frac{d_{m a ́ x}}{d}\right)^{1 / 2}
$$

Os parâmetros $f_{t}$ e $\alpha_{0}$ representam constantes a serem determinadas a partir do melhor ajuste dos dados experimentais e $d_{\text {máx }}$ é o diâmetro máximo do agregado.

\section{4}

\section{Outras pesquisas}

COURA et al (2007) por meio de resultados obtidos experimentalmente constatou que as curvas obtidas para a resistência média à compressão (MPa) x dimensão do corpo de prova $(\mathrm{mm})$ apresentam uma tendência a se comportar de acordo com a formulação de CARPINTERI (1995). Buscando representar os resultados para resistência à compressão em função do corpo de prova e da dimensão do agregado, COURA (2006) obteve a seguinte expressão limitada a corpos de prova de dimensão $100 \mathrm{~mm}$ x $200 \mathrm{~mm}$ a $200 \mathrm{~mm}$ x $400 \mathrm{~mm}$ :

$$
f_{c}=33,448-0,037 d-0,106 d_{\text {máx }}
$$

onde

$f_{c}$ - resistência à compressão do concreto $(\mathrm{MPa})$;

$d$ - diâmetro do corpo de prova;

$d_{\text {máx }}$ - diâmetro máximo do agregado.

HILSDORF (1999) apud COURA (2007) estima para a resistência à tração indireta a seguinte expressão:

$$
f_{c t m}=f_{c t m o} \ln \left(1+\frac{f_{c m}}{f_{c m o}}\right)
$$

onde

$f_{c t m}$ - resistência média à tração axial $(\mathrm{MPa})$;

$f_{\text {ctmo }}-2,12 \mathrm{MPa}$;

$f_{c m}$ - resistência média à compressão (MPa);

$f_{c m o}-10 \mathrm{MPa}$. 


\section{4 \\ Programa experimental}

\section{1}

\section{Considerações iniciais}

Os procedimentos de ensaio são descritos neste capítulo, bem como a caracterização dos materiais utilizados.

O objetivo dos ensaios é verificar o comportamento de corpos de prova de CAFA submetidos à tração por compressão diametral e à tração direta, mediante a variação dos seguintes parâmetros:

1. resistências médias do concreto à compressão - 20 MPa, $30 \mathrm{MPa}$ e $50 \mathrm{MPa}$;

2. dimensões dos corpos de prova $-5 \mathrm{~cm}$ x $10 \mathrm{~cm}, 10 \mathrm{~cm}$ x $20 \mathrm{~cm}, 15 \mathrm{~cm}$ x 30 cm para os ensaios de compressão diametral (Figura 4.14) e corpos de prova (Figura 4.5) para ensaio de tração direta.

3. consumo de fibras $-20 \mathrm{~kg} / \mathrm{m}^{3}, 40 \mathrm{~kg} / \mathrm{m}^{3}, 60 \mathrm{~kg} / \mathrm{m}^{3}$.

Foram ensaiados 54 corpos de prova por compressão diametral, sendo diferenciados pelos parâmetros adotados e identificados em função dos mesmos, recebendo a seguinte nomenclatura: G-DX-FY-Z, onde G é o grupo ao qual o corpo de prova pertence. Os algarismos romanos I, II e III, referem-se à resistência do concreto, $f_{c}=20 \mathrm{MPa}, f_{c}=30 \mathrm{MPa}$ e $f_{c}=50 \mathrm{MPa}$, respectivamente. A letra X varia de acordo com os diâmetros dos corpos de prova, $5 \mathrm{~cm}, 10 \mathrm{~cm}, 15 \mathrm{~cm}$. A letra Y indica o consumo de fibras em $\mathrm{kg} / \mathrm{m}^{3}$, ou seja, 20, 40 ou 60 . A letra $\mathrm{Z}$ indica o número do corpo de prova, 1 ou 2.

Por exemplo, I-D15-F60-2 corresponde ao corpo de prova com resistência de $20 \mathrm{MPa}$, dimensões $15 \mathrm{~cm}$ x $30 \mathrm{~cm}$, consumo de fibras igual a $60 \mathrm{~kg} / \mathrm{m}^{3}$ e indica o corpo de prova número dois.

Foram ensaiados 18 corpos de prova por tração direta seguindo-se os parâmetros adotados e identificados em função dos mesmos, recebendo a nomenclatura: G-TD-FY-Z, onde as letras variam de acordo com as explicações apresentadas anteriormente, variando somente a sigla TD que significa que o corpo de prova é do ensaio de tração direta. 
Por exemplo, II-TD-F20-1 corresponde ao corpo de prova com resistência de $30 \mathrm{MPa}$, para o ensaio de tração direta, com o consumo de fibras igual a $20 \mathrm{~kg} / \mathrm{m}^{3}$, e indica o corpo de prova número um.

\section{2}

\section{Materiais}

\subsection{1}

\section{As fibras de aço}

As fibras de aço Dramix utilizadas foram fabricadas pela empresa Belga Bekaert.

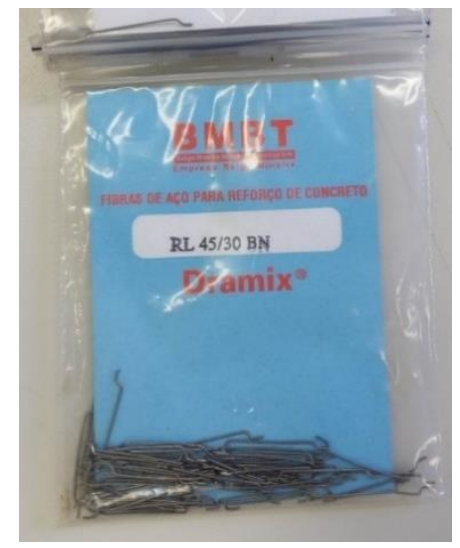

Figura 4.1 - Fibras RL 45/30 BN.

A fibra utilizada na pesquisa foi a RL 45/30 BN (Figura 4.11) e segundo a empresa Belga Bekaert essa fibra é utilizada nas seguintes aplicações:

- $\quad$ capas de compressão;

- $\quad$ estabilização de taludes;

- concreto projetado.

As letras que compõem a denominação da fibra RL 45/30 BN significam:

- $\quad$ letra $\mathrm{R}$ - dupla ancoragem nas extremidades da fibra;

- $\quad$ letra L - indica que as fibras são produzidas soltas entre si;

- número 45 indica o índice de esbeltez $\mathrm{l} / \mathrm{d}$;

- número 30 indica o comprimento da fibra em mm;

- letra B indica que o aço é sem cobrimento;

- letra $\mathrm{N}$ indica baixo teor de carbono no material. 
Essa empresa recomenda que para a dosagem do concreto seja utilizado um teor de argamassa maior que 50\%, um fator água cimento menor que 0,55 e um abatimento do tronco de cone de $100 \pm 20 \mathrm{~mm}$.

A Belga Bekaert recomenda para dosar o Dramix no concreto as seguintes prescrições:

- ajustar o slump do concreto para, no mínimo $12 \mathrm{~cm}$;

- adicionar o Dramix com velocidade máxima de $40 \mathrm{~kg} / \mathrm{mim}$ (dois sacos);

- depois de adicionar o Dramix continuar misturando em alta velocidade durante $5 \mathrm{mim}$;

- nunca adicionar as fibras como o primeiro componente da mistura.

\subsection{2}

\section{Concreto}

A concretagem dos corpos de prova e os seus ensaios foram realizados no Laboratório de Estruturas e Materiais (LEM) do Departamento de Engenharia Civil da PUC-Rio, entre os meses de agosto e outubro.

Foram realizadas nove séries de concretagem de acordo com a resistência à compressão do concreto e quantidade de fibras. Para cada série foram obtidas as seguintes dosagens em massa conforme a nomenclatura (cimento:areia:agregado graúdo:fator água/cimento) :

- série $1\left(20 \mathrm{MPa} / 20 \mathrm{~kg} / \mathrm{m}^{3}\right)$ - 1:2,00:2,02:0,55;

- $\quad$ série $2\left(20 \mathrm{MPa} / 40 \mathrm{~kg} / \mathrm{m}^{3}\right)$ - 1:2,00:2,02:0,55;

- $\quad$ série $3\left(20 \mathrm{MPa} / 60 \mathrm{~kg} / \mathrm{m}^{3}\right)$ - 1:2,00:2,02:0,55;

- $\quad$ série $4\left(30 \mathrm{MPa} / 20 \mathrm{~kg} / \mathrm{m}^{3}\right)$ - 1:1,48:1,65:0,45;

- $\quad$ série $5\left(30 \mathrm{MPa} / 40 \mathrm{~kg} / \mathrm{m}^{3}\right)$ - 1:1,48:1,65:0,45;

- $\quad$ série $6\left(30 \mathrm{MPa} / 60 \mathrm{~kg} / \mathrm{m}^{3}\right)$ - 1:1,48:1,65:0,45;

- $\quad$ série $7\left(50 \mathrm{MPa} / 20 \mathrm{~kg} / \mathrm{m}^{3}\right)$ - 1:1,16:1,43:0,39;

- $\quad$ série $8\left(50 \mathrm{MPa} / 40 \mathrm{~kg} / \mathrm{m}^{3}\right)$ - 1:1,16:1,43:0,39;

- série $9\left(50 \mathrm{MPa} / 60 \mathrm{~kg} / \mathrm{m}^{3}\right)-1: 1,16: 1,43: 0,39$. 
Para cada composição do concreto foi realizada uma única betonada por série com o objetivo de se obter uma homogeneidade nos corpos de prova, sendo que todos foram moldados seguindo as recomendações da NBR 5738-2003.

O cimento utilizado foi o CP II-32.

A areia tinha dimensão máxima característica $D_{\text {máx }}$ inferior à $4,75 \mathrm{~mm}$ e Módulo de Finura igual a 2,6 mm.

O agregado graúdo era a brita com dimensão máxima característica de 9,5 mm, valor obtido em laboratório de acordo com a NBR 7217-1987 e NBR 7211-2005.

Foi utilizado o aditivo superplastificante ADVA FLOW 20 A para uma melhor trabalhabilidade do concreto.

O consumo dos materiais empregados e os valores do abatimento do tronco de cone para cada série são mostrados nas Tabela 4.1 e Tabela 4.2, respectivamente.

O consumo dos materiais das séries 1, 2, 3 são iguais; o que diferencia uma série da outra é a quantidade de fibras. O mesmo é válido para as outras séries.

Tabela 4.1 - Consumo de material por $\mathrm{m}^{3}$ de concreto.

\begin{tabular}{c|c|c|c}
\hline \multirow{2}{*}{ Material } & \multicolumn{3}{|c}{ Consumo em $\mathbf{~ k g} / \mathbf{m}^{\mathbf{3}}$} \\
\cline { 2 - 4 } & Série $\mathbf{1 , 2 , 3}$ & Série 4,5,6 & Série $\mathbf{7 , 8 , 9}$ \\
\hline Cimento (kg) & 418 & 511 & 589,74 \\
\hline Areia (Kg) & 837,4 & 757,9 & 689 \\
\hline Brita 0 (kg) & 847,5 & 847,5 & 847,5 \\
\hline Água (I) & 230 & 230 & 230 \\
\hline
\end{tabular}

Tabela 4.2 - Valores do abatimento do tronco de cone.

\begin{tabular}{c|c|c|c|c|c|c|c|c}
\hline \multicolumn{1}{c}{ Abatimento de cone $(\mathbf{m m})$} \\
\hline Série 1 & Série 2 & Série 3 & Série 4 & Série 5 & Série 6 & Série 7 & Série 8 & Série 9 \\
\hline 65 & 75 & 120 & 45 & 74 & 60 & 110 & 95 & 30 \\
\hline
\end{tabular}

O ensaio de abatimento do tronco de cone foi realizado para cada série, de acordo com a NBR NM 67 - 1998 (Figura 4.2, 4.2 e 4.3). 


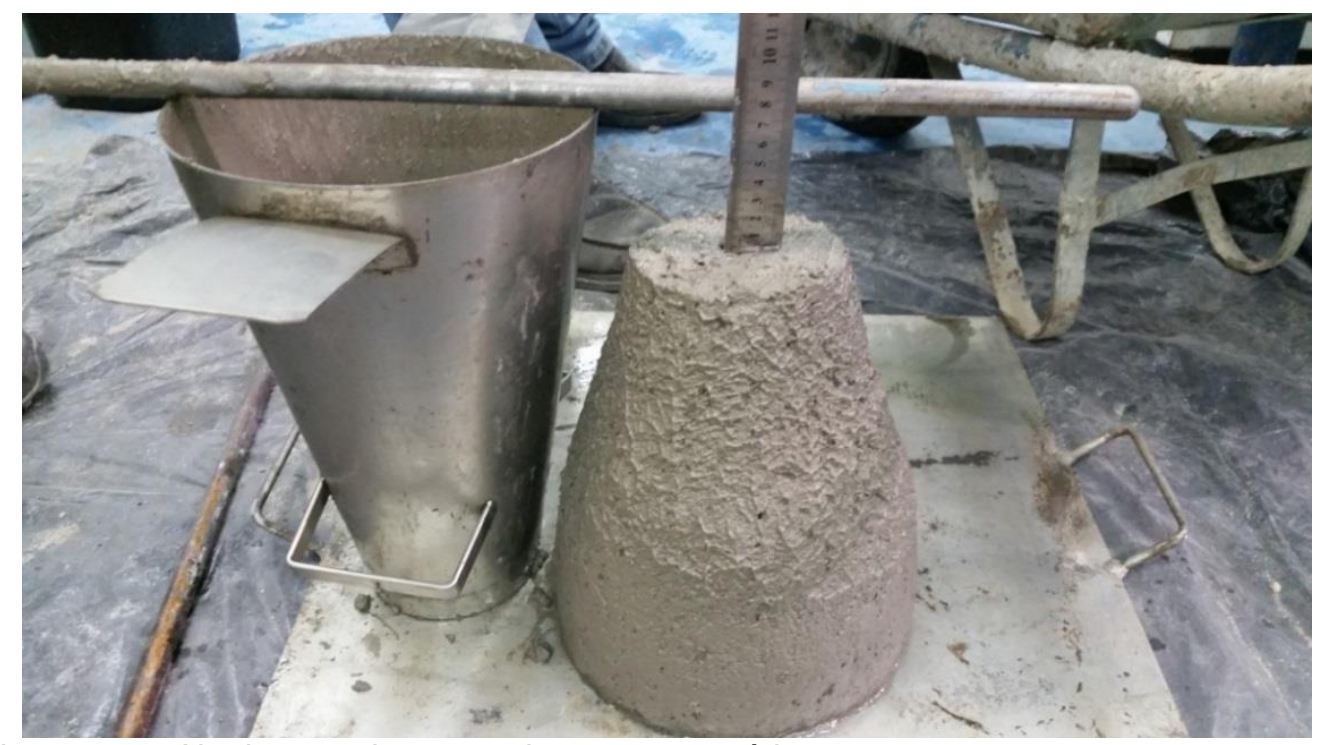

Figura 4.2 - Abatimento do tronco de cone para série 5.

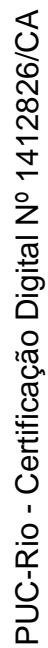

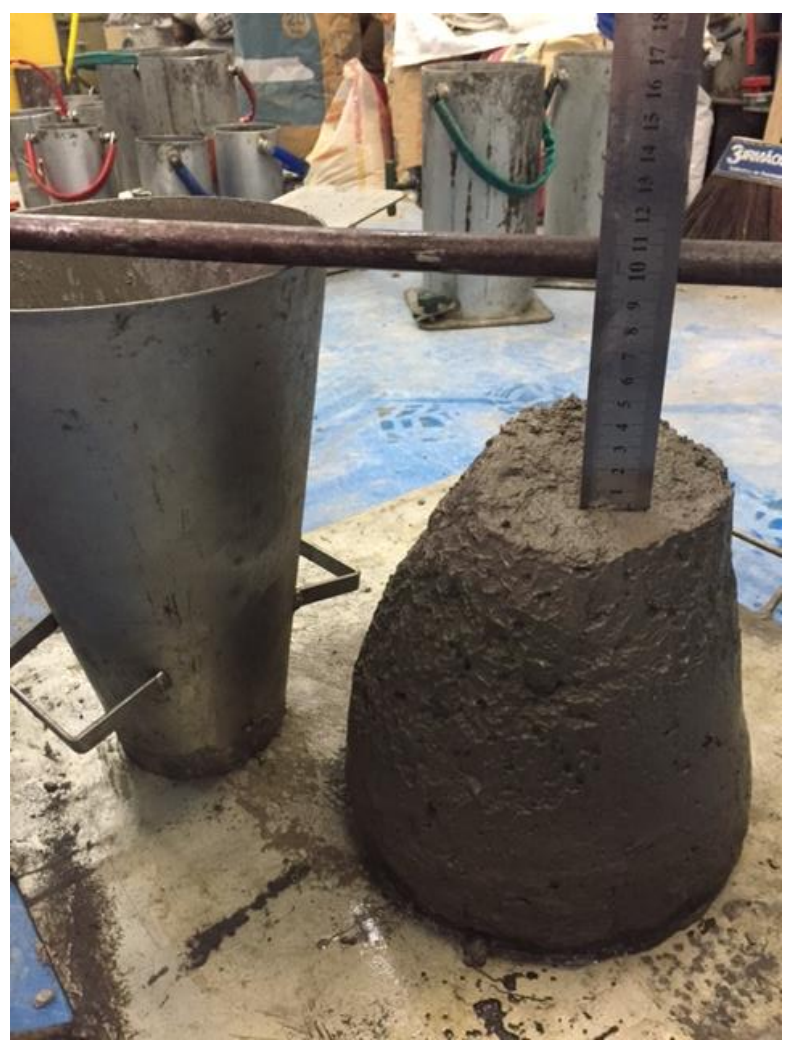

Figura 4.3 - Abatimento de tronco de cone para série 8. 


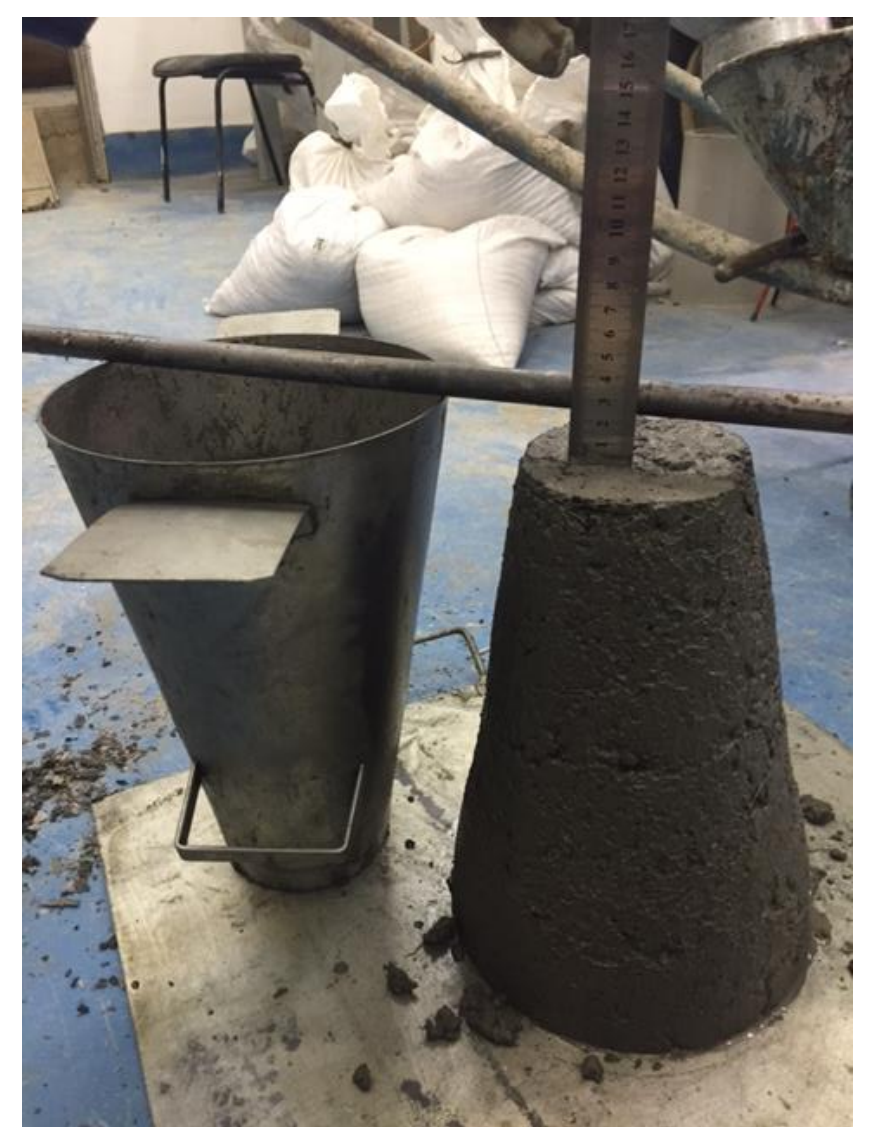

Figura 4.4 - Abatimento de tronco de cone para série 9.

As peças concretadas foram divididas em séries. A concretagem seguiu a padronização apresentada pela Tabela 4.3.

Para o controle tecnológico do concreto utilizado na pesquisa, durante as concretagens foram moldados quatro corpos de prova de $10 \mathrm{~cm}$ x $20 \mathrm{~cm}$ em cada concretagem seguindo as recomendações da NBR-5738 - 2003. Esses corpos de prova foram usados para determinar a resistência à compressão simples e módulo de elasticidade do concreto. O ensaio de resistência à tração indireta do concreto foi realizado em 54 corpos de prova.

Os ensaios de caracterização que geraram as informações utilizadas na pesquisa foram realizados entre os dias 17/09/2015 e 20/10/2015. Os mesmos são descritos nas seções 4.2.1.2 a 4.2.1.4. 
Tabela 4.3 - Programa de concretagem.

\begin{tabular}{|c|c|c|c|c|c|c|c|}
\hline Série & CP ensaio & CP controle & Data & Série & CP ensaio & CP controle & Data \\
\hline \multirow{8}{*}{1} & I-D5-F20-1 & CON-1-1 & \multirow{8}{*}{ 18/ago } & \multirow{8}{*}{6} & II-D5-F60-1 & CON-6-1 & \multirow{8}{*}{ 08/set } \\
\hline & I-D10-F20-1 & CON-1-2 & & & II-D10-F60-1 & CON-6-2 & \\
\hline & I-D15-F20-1 & CON-1-3 & & & II-D15-F60-1 & CON-6-3 & \\
\hline & I-D5-F20-2 & CON-1-4 & & & II-D5-F60-2 & CON-6-4 & \\
\hline & I-D10-F20-2 & & & & II-D10-F60-2 & & \\
\hline & I-D15-F20-2 & & & & II-D15-F60-2 & & \\
\hline & I-TD-F20-1 & & & & II-TD-F60-1 & & \\
\hline & I-TD-F20-2 & & & & II-TD-F60-2 & & \\
\hline \multirow{8}{*}{2} & I-D5-F40-1 & CON-2-1 & \multirow{8}{*}{ 21/ago } & \multirow{8}{*}{7} & III-D5-F20-1 & CON-7-1 & \multirow{8}{*}{$11 /$ set } \\
\hline & I-D10-F40-1 & CON-2-2 & & & III-D10-F20-1 & CON-7-2 & \\
\hline & I-D15-F40-1 & CON-2-3 & & & III-D15-F20-1 & CON-7-3 & \\
\hline & I-D5-F40-2 & CON-2-4 & & & III-D5-F20-2 & CON-7-4 & \\
\hline & I-D10-F40-2 & & & & III-D10-F20-2 & & \\
\hline & I-D15-F40-2 & & & & III-D15-F20-2 & & \\
\hline & I-TD-F40-1 & & & & III-TD-F20-1 & & \\
\hline & I-TD-F40-2 & & & & III-TD-F20-2 & & \\
\hline \multirow{8}{*}{3} & I-D5-F60-1 & CON-3-1 & \multirow{8}{*}{ 25/ago } & \multirow{8}{*}{8} & III-D5-F40-1 & CON-8-1 & \multirow{8}{*}{$15 /$ set } \\
\hline & I-D10-F60-1 & CON-3-2 & & & III-D10-F40-1 & CON-8-2 & \\
\hline & I-D15-F60-1 & CON-3-3 & & & III-D15-F40-1 & CON-8-3 & \\
\hline & I-D5-F60-2 & CON-3-4 & & & III-D5-F40-2 & CON-8-4 & \\
\hline & I-D10-F60-2 & & & & III-D10-F40-2 & & \\
\hline & I-D15-F60-2 & & & & III-D15-F40-2 & & \\
\hline & I-TD-F60-1 & & & & III-TD-F40-1 & & \\
\hline & I-TD-F60-2 & & & & III-TD-F40-2 & & \\
\hline \multirow{8}{*}{4} & II-D5-F20-1 & CON-4-1 & \multirow{8}{*}{ 27/ago } & \multirow{8}{*}{9} & III-D5-F60-1 & CON-9-1 & \multirow{8}{*}{$17 /$ set } \\
\hline & II-D10-F20-1 & CON-4-2 & & & III-D10-F60-1 & CON-9-2 & \\
\hline & II-D15-F20-1 & CON-4-3 & & & III-D15-F60-1 & CON-9-3 & \\
\hline & II-D5-F20-2 & CON-4-4 & & & III-D5-F60-2 & CON-9-4 & \\
\hline & II-D10-F20-2 & & & & III-D10-F60-2 & & \\
\hline & II-D15-F20-2 & & & & III-D15-F60-2 & & \\
\hline & II-TD-F20-1 & & & & III-TD-F60-1 & & \\
\hline & II-TD-F20-2 & & & & III-TD-F60-2 & & \\
\hline \multirow{8}{*}{5} & II-D5-F40-1 & CON-5-1 & \multirow{8}{*}{$01 /$ set } & & & & \\
\hline & II-D10-F40-1 & CON-5-2 & & & & & \\
\hline & II-D15-F40-1 & CON-5-3 & & & & & \\
\hline & II-D5-F40-2 & CON-5-4 & & & & & \\
\hline & II-D10-F40-2 & & & & & & \\
\hline & II-D15-F40-2 & & & & & & \\
\hline & II-TD-F40-1 & & & & & & \\
\hline & II-TD-F40-2 & & & & & & \\
\hline
\end{tabular}




\subsubsection{1}

\section{Resistência à tração direta}

Foi utilizada a máquina da MTS do Laboratório de Estruturas e Materiais (LEM) da PUC-Rio com capacidade para $1000 \mathrm{kN}$ para realização dos ensaios. Para cada série foram ensaiados dois corpos de prova de dimensões a seguir (Figura 4.6) de acordo com a Figura 4.5.

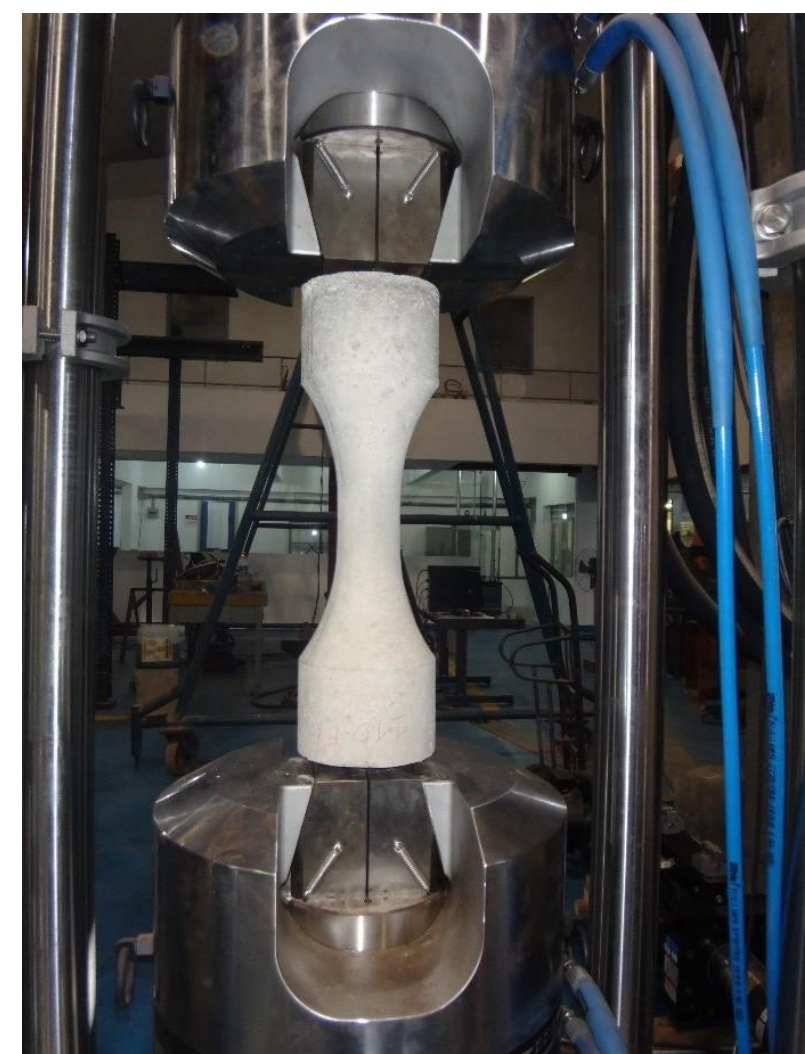

Figura 4.5 - Ensaio de tração direta.

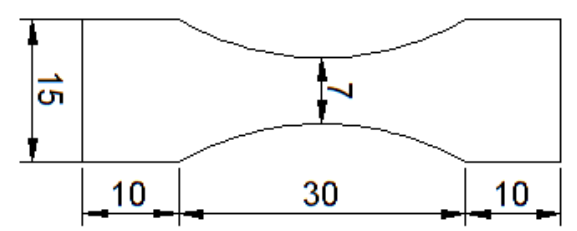

Figura 4.6 - Corpo de prova de tração direta

A Tabela 4.4 mostra os resultados dos ensaios dos corpos de prova submetidos à tração direta. 
Tabela 4.4 - Valores da resistência à tração direta do concreto

\begin{tabular}{|c|c|c|c|}
\hline $\begin{array}{c}\text { Corpo de } \\
\text { prova }\end{array}$ & $\begin{array}{l}\text { Idade } \\
\text { (dias) }\end{array}$ & $\begin{array}{c}f_{d i r} \\
(\mathrm{MPa})\end{array}$ & $\begin{array}{c}f_{\text {dir,médio }} \\
\text { (MPa) }\end{array}$ \\
\hline I-TD-F20-1 & 30 & 2,28 & \multirow{2}{*}{2,34} \\
\hline I-TD-F20-2 & 30 & 2,39 & \\
\hline I-TD-F40-1 & 32 & 1,39 & \multirow{2}{*}{1,86} \\
\hline I-TD-F40-2 & 32 & 2,34 & \\
\hline I-TD-F60-1 & 28 & 0,0 & \multirow{2}{*}{1,35} \\
\hline I-TD-F60-2 & 28 & 1,35 & \\
\hline II-TD-F20-1 & 28 & 3,34 & \multirow{2}{*}{3,01} \\
\hline II-TD-F20-2 & 28 & 2,68 & \\
\hline II-TD-F40-1 & 28 & 3,02 & \multirow{2}{*}{2,58} \\
\hline II-TD-F40-2 & 28 & 2,13 & \\
\hline II-TD-F60-1 & 28 & 3,78 & \multirow{2}{*}{3,56} \\
\hline II-TD-F60-2 & 28 & 3,33 & \\
\hline III-TD-F20-1 & 32 & 4,19 & \multirow{2}{*}{4,19} \\
\hline III-TD-F20-2 & 32 & 0,00 & \\
\hline III-TD-F40-1 & 28 & 3,24 & \multirow{2}{*}{2,81} \\
\hline III-TD-F40-2 & 28 & 2,37 & \\
\hline III-TD-F60-1 & 33 & 3,26 & \multirow{2}{*}{3,65} \\
\hline III-TD-F60-2 & 33 & 4,03 & \\
\hline
\end{tabular}

Os corpos de prova I-TD-F60-1 e III-TD-F20-2 já estavam rompidos antes de serem submetidos aos ensaios, por esse motivo eles foram descartados.

Os gráficos gerados a partir dos dados dos ensaios de tração direta se encontram no anexo $\mathrm{C}$.

\subsubsection{2 \\ Resistência à compressão}

A determinação da resistência à compressão do concreto utilizado na pesquisa foi obtida em obediência à norma NBR 5739-1994. Para cada série foram ensaiados dois corpos de prova cilíndricos de dimensões $10 \mathrm{~cm}$ x $20 \mathrm{~cm}$.

Foi utilizada a máquina da MTS do Laboratório de Estruturas e Materiais (LEM) da PUC-Rio com capacidade para $500 \mathrm{kN}$ para realização dos ensaios. Os valores obtidos nos ensaios são mostrados na Tabela 4.5.

Os gráficos gerados a partir dos dados de cada ensaio realizado para compressão simples se encontram no anexo B. 
Tabela 4.5 - Resultados dos ensaios de resistência à compressão do concreto.

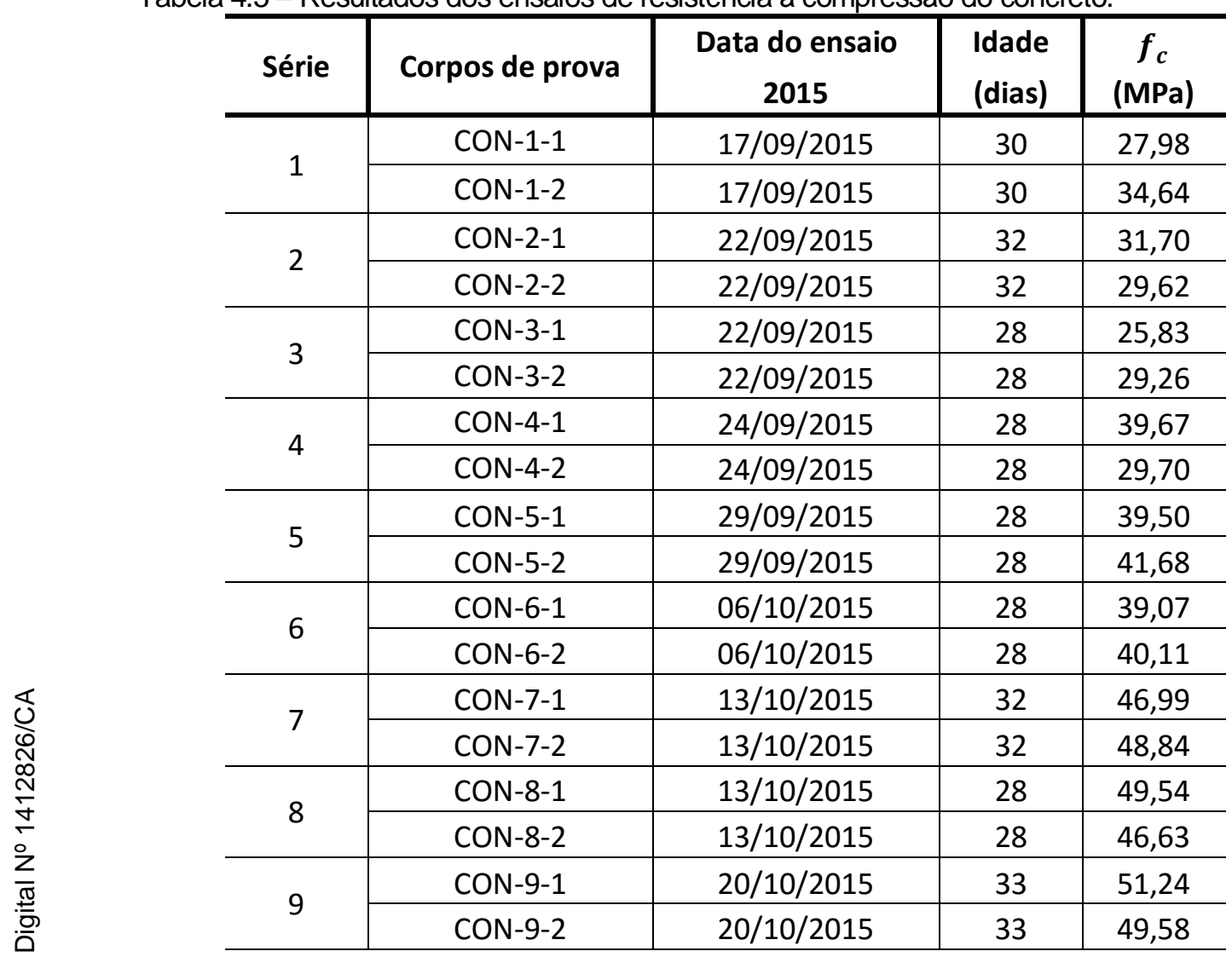

As resistências à compressão médias são mostradas na Tabela 4.6:

Tabela 4.6 - Resultados dos ensaios de resistência a compressão.

\begin{tabular}{c|c|c}
\hline $\begin{array}{c}\text { Ensaios dos Corpos } \\
\text { de prova aos 28 dias }\end{array}$ & $\begin{array}{c}\text { Quantidade de } \\
\text { corpos de prova }\end{array}$ & $\begin{array}{c}\boldsymbol{f}_{\boldsymbol{c}} \\
(\mathbf{M P a})\end{array}$ \\
\hline Série 1 & 2 & 31,31 \\
\hline Série 2 & 2 & 30,66 \\
\hline Série 3 & 2 & 27,55 \\
\hline Série 4 & 2 & 34,69 \\
\hline Série 5 & 2 & 40,59 \\
\hline Série 6 & 2 & 39,59 \\
\hline Série 7 & 2 & 47,91 \\
\hline Série 8 & 2 & 48,09 \\
\hline Série 9 & 2 & 50,41 \\
\hline
\end{tabular}

A Figura 4.6 mostra a execução do ensaio de resistência à compressão do concreto. 
Figura 4.7 - Ensaio de compressão simples.

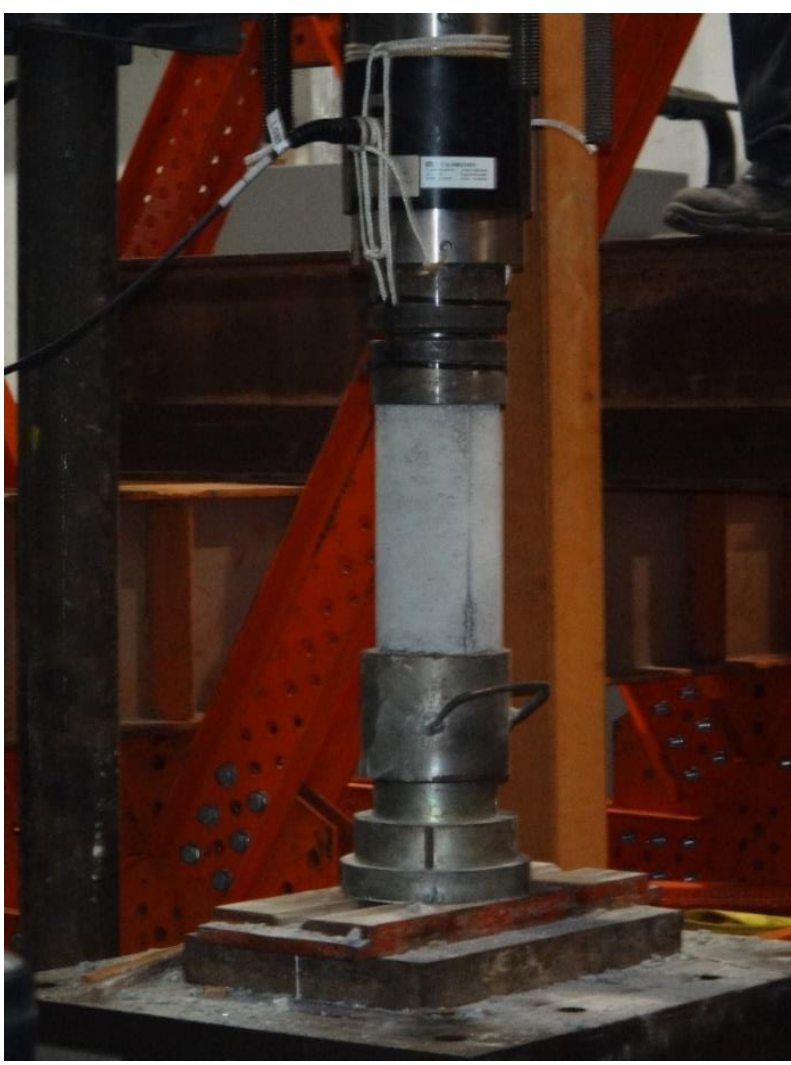

\subsubsection{3}

\section{Resistência à tração por compressão diametral}

Para todos os corpos de prova foram realizados ensaios de tração por compressão diametral seguindo as recomendações da NBR 7222-1994. Os corpos de prova foram ensaiados na máquina da MTS do Laboratório de Estruturas e Materiais (LEM) da PUC-Rio com capacidade para $500 \mathrm{kN}$. O ensaio de compressão diametral são mostrados nas Figura 4.8 e Figura 4.9.

A resistência à tração indireta de um corpo de prova cilíndrico de concreto é dada por:

$$
f_{t D, i}=\frac{2 F}{\pi d L}
$$

onde

$f_{t D, i}$ - resistência à tração do $\mathrm{CP}$ de concreto por compressão diametral (MPa);

$F$ - força máxima aplicada, equivalente à carga de ruptura $(\mathrm{kN})$;

$d$-diâmetro do corpo de prova (mm);

$L$ - altura do corpo de prova (mm). 


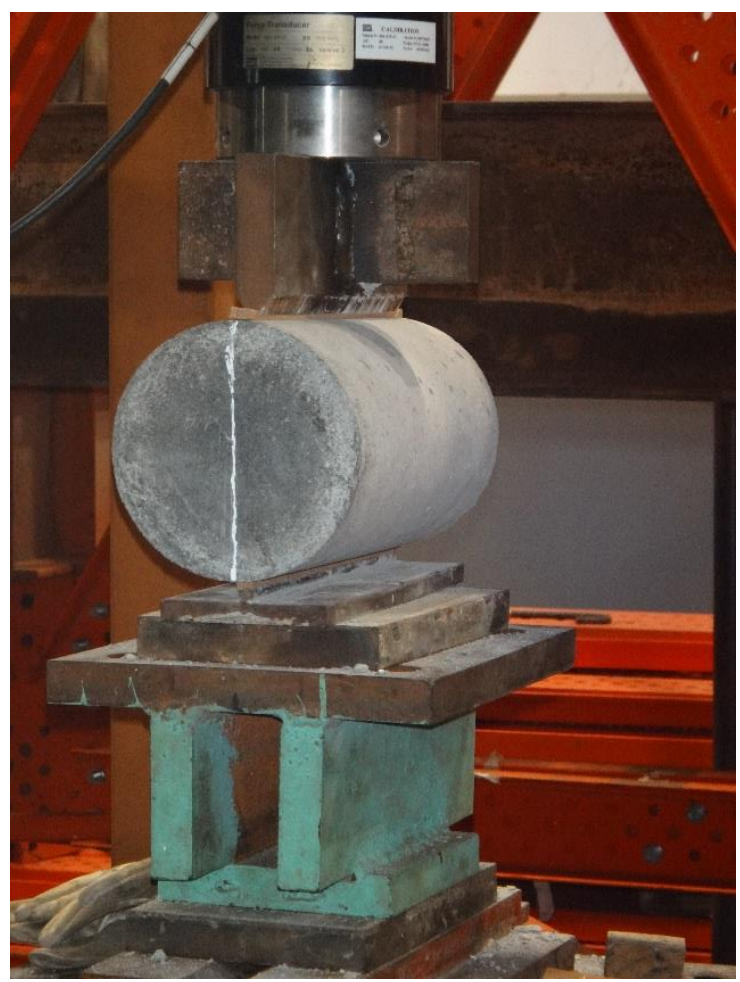

Figura 4.8 - Vista frontal do ensaio de compressão diametral.

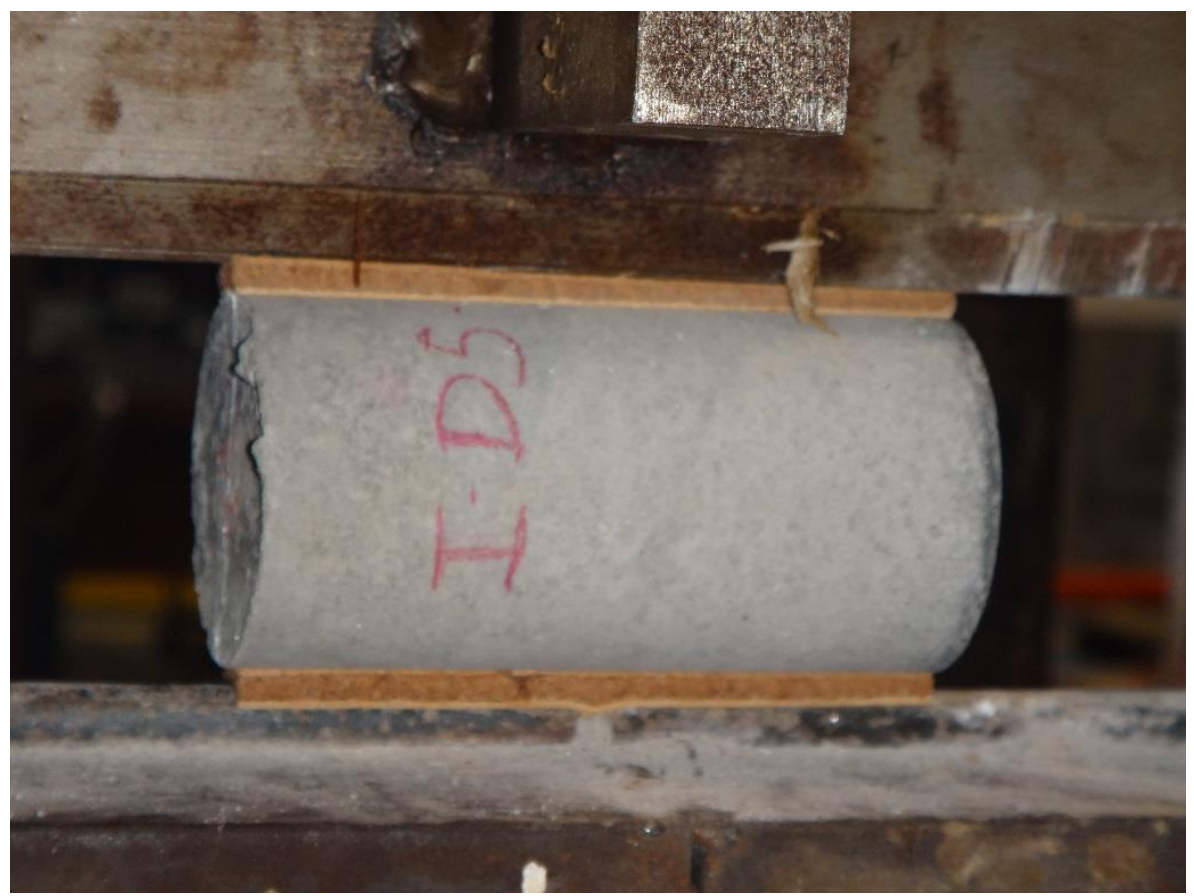

Figura 4.9 - Vista lateral do ensaio de compressão diametral.

Os valores dos ensaios de resistência à tração por compressão diametral são mostrados na Tabela 4.7.

Os gráficos gerados a partir dos dados de cada ensaio realizado se encontram no anexo A. 
Tabela 4.7- Resultados dos ensaios de resistência à tração por compressão diametral.

\begin{tabular}{|c|c|c|c|c|c|c|c|}
\hline Série & Corpo de prova & $\begin{array}{l}\text { Idade } \\
\text { (dias) }\end{array}$ & $\begin{array}{c}f_{t D, i} \\
(\mathrm{MPa})\end{array}$ & Série & Corpo de prova & $\begin{array}{l}\text { Idade } \\
\text { (dias) }\end{array}$ & $\begin{array}{c}f_{t D, i} \\
(\mathrm{MPa})\end{array}$ \\
\hline \multirow{6}{*}{1} & I-D5-F20-1 & 30 & 3,29 & \multirow{3}{*}{5} & II-D10-F40-2 & 28 & 2,3 \\
\hline & I-D5-F20-2 & 30 & 2,77 & & II-D15-F40-1 & 28 & 2,45 \\
\hline & I-D10-F20-1 & 30 & 1,70 & & II-D15-F40-2 & 28 & 2,73 \\
\hline & I-D10-F20-2 & 30 & 2,48 & \multirow{6}{*}{6} & II-D5-F60-1 & 28 & 3,59 \\
\hline & I-D15-F20-1 & 30 & 2,13 & & II-D5-F60-2 & 28 & 4,45 \\
\hline & I-D15-F20-2 & 30 & 1,73 & & II-D10-F60-1 & 28 & 3,06 \\
\hline \multirow{6}{*}{2} & I-D5-F40-1 & 32 & 4,28 & & II-D10-F60-2 & 28 & 2,69 \\
\hline & I-D5-F40-2 & 32 & 4,87 & & II-D15-F60-1 & 28 & 2,74 \\
\hline & I-D10-F40-1 & 32 & 2,86 & & II-D15-F60-2 & 28 & 2,18 \\
\hline & I-D10-F40-2 & 32 & 3,04 & \multirow{6}{*}{7} & III-D5-F20-1 & 32 & 4,46 \\
\hline & I-D15-F40-1 & 32 & 2,43 & & III-D5-F20-2 & 32 & 4,92 \\
\hline & I-D15-F40-2 & 32 & 2,1 & & III-D10-F20-1 & 32 & 3,61 \\
\hline \multirow{6}{*}{3} & I-D5-F60-1 & 28 & 4,08 & & III-D10-F20-2 & 32 & 3,77 \\
\hline & I-D5-F60-2 & 28 & 4,01 & & III-D15-F20-1 & 32 & 3,52 \\
\hline & I-D10-F60-1 & 28 & 2,4 & & III-D15-F20-2 & 32 & 2,5 \\
\hline & I-D10-F60-2 & 28 & 2,53 & \multirow{6}{*}{8} & III-D5-F40-1 & 28 & 5,02 \\
\hline & I-D15-F60-1 & 28 & 2,33 & & III-D5-F40-2 & 28 & 5,97 \\
\hline & I-D15-F60-2 & 28 & 2,36 & & III-D10-F40-1 & 28 & 3,62 \\
\hline \multirow{6}{*}{4} & II-D5-F20-1 & 28 & 4,43 & & III-D10-F40-2 & 28 & 4,09 \\
\hline & II-D5-F20-2 & 28 & 4,52 & & III-D15-F40-1 & 28 & 3,08 \\
\hline & II-D10-F20-1 & 28 & 2,36 & & III-D15-F40-2 & 28 & 3,26 \\
\hline & II-D10-F20-2 & 28 & 2,57 & \multirow{6}{*}{9} & III-D5-F60-1 & 33 & 6,18 \\
\hline & II-D15-F20-1 & 28 & 3,25 & & III-D5-F60-2 & 33 & 6,12 \\
\hline & II-D15-F20-2 & 28 & 2,11 & & III-D10-F60-1 & 33 & 4,43 \\
\hline \multirow{3}{*}{5} & II-D5-F40-1 & 28 & 4,4 & & III-D10-F60-2 & 33 & 4,41 \\
\hline & II-D5-F40-2 & 28 & 4,34 & & III-D15-F60-1 & 33 & 2,81 \\
\hline & II-D10-F40-1 & 28 & 3,18 & & III-D15-F60-2 & 33 & 3,28 \\
\hline
\end{tabular}

As resistências à tração médias são mostradas na Tabela 4.8 , onde estão separadas por série e por diâmetro. 
Tabela 4.8 - Resistência à tração média.

\begin{tabular}{|c|c|c|c|c|c|}
\hline CP & $\begin{array}{l}\text { Quantidade de } \\
\text { corpo de prova }\end{array}$ & $\begin{array}{c}f_{t D, i} \\
(\mathrm{MPa})\end{array}$ & CP & $\begin{array}{l}\text { Quantidade de } \\
\text { corpo de prova }\end{array}$ & $\begin{array}{c}f_{t D, i} \\
(\mathrm{MPa})\end{array}$ \\
\hline Série 1-D5 & 2 & 3,03 & Série 6-D5 & 2 & 4,02 \\
\hline Série 1-D10 & 2 & 2,09 & Série 6-D10 & 2 & 2,88 \\
\hline Série 1-D15 & 2 & 1,93 & Série 6-D15 & 2 & 2,46 \\
\hline Série 2-D5 & 2 & 4,58 & Série 7-D5 & 2 & 4,69 \\
\hline Série 2-D10 & 2 & 2,95 & Série 7-D10 & 2 & 3,69 \\
\hline Série 2-D15 & 2 & 1,93 & Série 7-D15 & 2 & 3,17 \\
\hline Série 3-D5 & 2 & 4,05 & Série 8-D5 & 2 & 5,50 \\
\hline Série 3-D10 & 2 & 2,47 & Série 8-D10 & 2 & 3,86 \\
\hline Série 3-D15 & 2 & 2,35 & Série 8-D15 & 2 & 3,17 \\
\hline Série 4-D5 & 2 & 4,48 & Série 9-D5 & 2 & 6,15 \\
\hline Série 4-D10 & 2 & 2,47 & Série 9-D10 & 2 & 4,42 \\
\hline Série 4-D15 & 2 & 2,68 & Série 9-D15 & 2 & 3,05 \\
\hline Série 5-D5 & 2 & 4,37 & & & \\
\hline Série 5-D10 & 2 & 2,74 & & & \\
\hline Série 5-D15 & 2 & 2,59 & & & \\
\hline
\end{tabular}

\subsubsection{4}

Módulo de elasticidade

O módulo de elasticidade longitudinal do concreto foi obtido por meio de ensaios de acordo com as recomendações da NBR 8522-2008 (Figura 4.10). Para cada concretagem foram moldados dois corpos de prova cilíndrico de dimensão 10 $\mathrm{cm}$ x $20 \mathrm{~cm}$ de acordo com a NBR 5738-1994. Os ensaios foram realizados no Laboratório de Estruturas e Materiais (LEM) da PUC-Rio com o mesmo equipamento utilizado nos experimentos descritos nas seções 4.2.2.2 e 4.2.2.3

A fim de se avaliar as deformações específicas do concreto durante o ensaio foram utilizados dois extensômetros elétricos de resistência (EER) com comprimento de $5 \mathrm{~cm}$ cada (Figura 4.9). Os EER foram colados à meia altura do corpo de prova em posições diametralmente opostas.

O procedimento adotado para se determinar o módulo de elasticidade do concreto foi a metodologia "A" prescrita na NBR 8522-2008, que simula a estrutura em seu primeiro carregamento, fornece o módulo de deformação secante e permite que se trace o diagrama tensão-deformação específica.

A previsão da força de ruptura foi obtida para cada série por meio de ensaios de resistência à compressão. 
Primeiramente foi realizada a centralização do corpo de prova, seguida da aplicação de um carregamento crescente à velocidade de $0,50 \mathrm{MPa} / \mathrm{s}$, com variação máxima de $\pm 0,05 \mathrm{MPa}$, efetuando pausas de 60 segundos entre cada estágio de carregamento alternando entre a aplicação de carga de 0,3 $f_{c}$ e 0,5 $\mathrm{MPa}$, como orienta a NBR 8522 - 2008, fazendo-se quatro leituras para a primeira carga e três para a segunda, prosseguiu-se o carregamento do corpo de prova até atingir a ruptura.

O módulo de deformação secante é dado por:

$$
E_{c i}=\frac{\sigma_{b}-\sigma_{0,5}}{\varepsilon_{b}-\varepsilon_{0,5}} 10^{-3}
$$

onde

$E_{c i}-$ módulo de elasticidade $(\mathrm{GPa}) ;$

$\sigma_{\mathrm{b}}$ - tensão correspondente a $0,3 f_{c}(\mathrm{MPa})$;

$\sigma_{0,5}$ - tensão mais próxima de $0,5 M P a$ no corpo de prova;

$\varepsilon_{\mathrm{b}}$ - deformação específica média dos corpos de prova sob tensão maior $(\mathrm{m} / \mathrm{m})$;

$\varepsilon_{0,5}$ - deformação específica média dos corpos de prova sob a tensão básica de $0,5 \mathrm{MPa}(\mathrm{m} / \mathrm{m})$.

A NBR 8522 - 2008 determina que a resistência à compressão $f_{c, e f}$ obtida ao fim dos ensaios para obtenção do módulo de elasticidade não deve diferir em mais de $20 \%$ da resistência à compressão calculada no item 4.2.1.2. A Tabela 4.9 apresenta os valores de $f_{c, e f}$ calculados.

$\mathrm{O}$ valor de $f_{c, \text { ef }}$ obtido no corpo de prova $\mathrm{CP} 1$ da série 6 não atende às especificações exigidas pela NBR 8522 - 2008, apresentando valor menor que $80 \%$ da resistência à compressão calculada previamente, portanto este corpo de prova será descartado para obtenção do módulo de elasticidade. A Tabela 4.10 apresenta os valores dos módulos de elasticidade calculados a partir da equação 4.2 para cada série. 
Tabela 4.9 - Valores de resistência à compressão obtidos nos ensaios para obtenção do módulo de elasticidade.

\begin{tabular}{|c|c|c|c|}
\hline Grupo & Corpo de Prova & $\begin{array}{c}\text { Força Máxima } \\
(\mathrm{kN})\end{array}$ & $f_{c, e f}(\mathrm{MPa})$ \\
\hline \multirow{2}{*}{1} & CP1 & 210,83 & 26,84 \\
\hline & $\mathrm{CP} 2$ & 267,70 & 34,08 \\
\hline \multirow{2}{*}{2} & $\mathrm{CP} 1$ & 254,70 & 32,43 \\
\hline & $\mathrm{CP} 2$ & 242,58 & 30,89 \\
\hline \multirow{2}{*}{3} & $\mathrm{CP} 1$ & 214,52 & 27,31 \\
\hline & $\mathrm{CP} 2$ & 198,01 & 25,21 \\
\hline \multirow{2}{*}{4} & CP1 & 337,00 & 42,91 \\
\hline & $\mathrm{CP} 2$ & 271,75 & 34,60 \\
\hline \multirow{2}{*}{5} & $\mathrm{CP} 1$ & 300,00 & 38,20 \\
\hline & $\mathrm{CP} 2$ & 307,39 & 39,14 \\
\hline \multirow{2}{*}{6} & CP1 & 221,50 & 28,20 \\
\hline & $\mathrm{CP} 2$ & 318,50 & 40,55 \\
\hline \multirow{2}{*}{7} & $\mathrm{CP} 1$ & 378,08 & 48,14 \\
\hline & $\mathrm{CP} 2$ & 349,41 & 44,49 \\
\hline \multirow{2}{*}{8} & $\mathrm{CP} 1$ & 397,23 & 50,58 \\
\hline & $\mathrm{CP} 2$ & 378,98 & 48,25 \\
\hline \multirow{2}{*}{9} & $\mathrm{CP} 1$ & 394,10 & 50,18 \\
\hline & $\mathrm{CP} 2$ & 420,13 & 53,49 \\
\hline
\end{tabular}

Tabela 4.10 - Módulo de elasticidade.

\begin{tabular}{c|c|c|c|c|c|c|c|c|c}
\hline Série & $\mathbf{1}$ & $\mathbf{2}$ & $\mathbf{3}$ & $\mathbf{4}$ & $\mathbf{5}$ & $\mathbf{6}$ & $\mathbf{7}$ & $\mathbf{8}$ & $\mathbf{9}$ \\
\hline $\boldsymbol{E}_{\boldsymbol{c} \boldsymbol{i}}$ (Gpa) & 32,34 & 29,84 & 19,84 & 23,19 & 27,58 & 25,60 & 31,49 & 27,08 & 29,98 \\
\hline
\end{tabular}

Figura 4.10 - Extensômetro. 


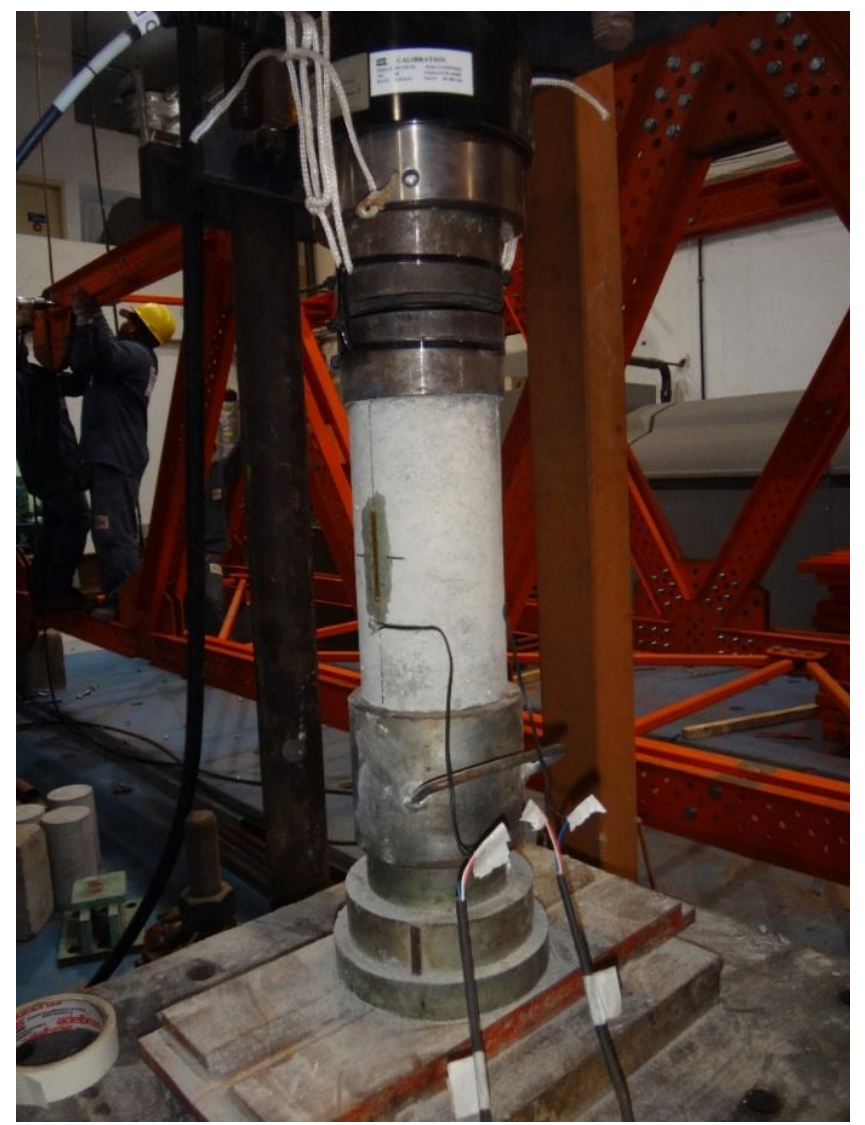

Figura 4.11 - Ensaio de módulo de elasticidade.

\section{3}

\section{Confecção dos corpos de prova}

\subsection{1 \\ Formas}

Os corpos de prova cilíndricos foram confeccionados em formas metálicas e untadas com óleo para facilitar a retirada do concreto da forma. (Figura 4.12).

Os corpos de prova de tração direta foram confeccionados em formas de silicones e também foram untadas com óleo (Figura 4.13). 


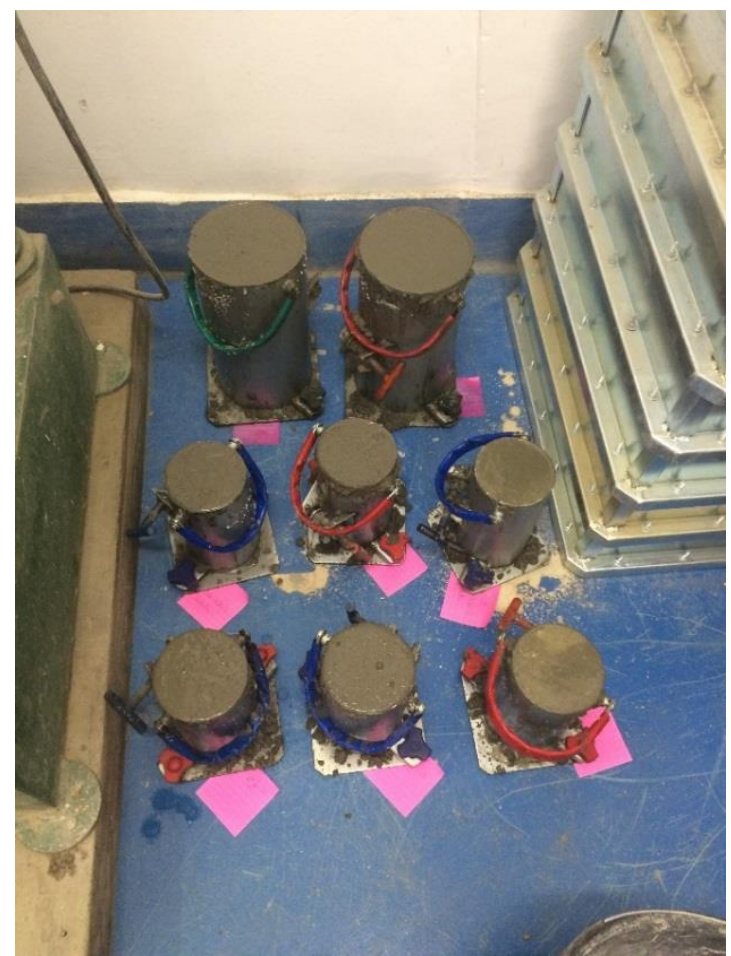

Figura 4.12 - Formas metálicas.

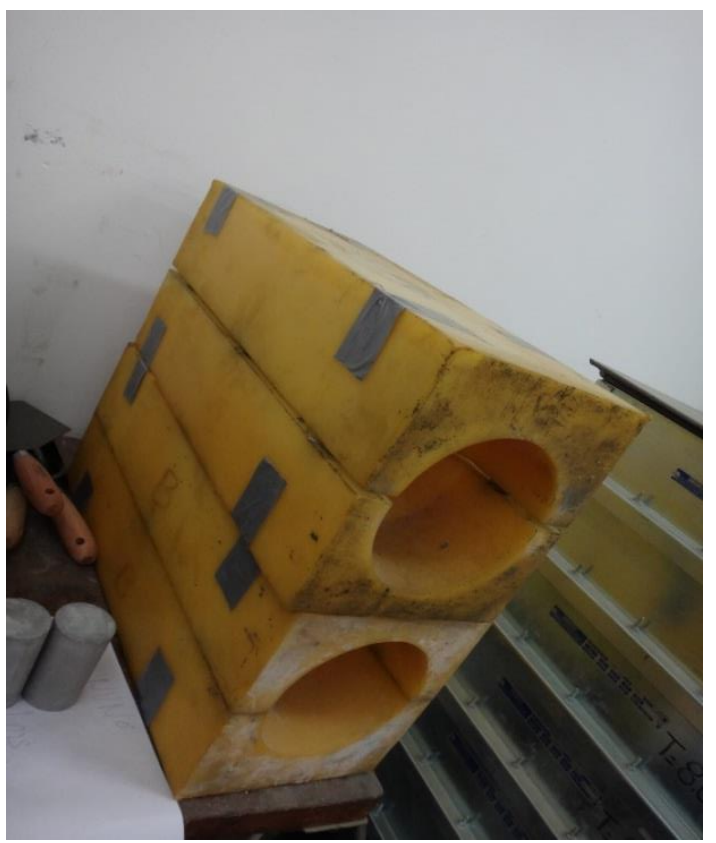

Figura 4.13 - Forma de silicone.

\subsection{2}

Corpos de prova de concreto

Os corpos de prova de compressão diametral tinham as seguintes dimensões: $5 \mathrm{~cm} \times 10 \mathrm{~cm}$ (Figura 4.14a), $10 \mathrm{~cm}$ x $20 \mathrm{~cm}$ (Figura 4.14b) e $15 \mathrm{~cm}$ x $30 \mathrm{~cm}$ (Figura 4.14c) e o corpo de prova de tração direta tinha as dimensões mostradas na Figura 4.15 . 


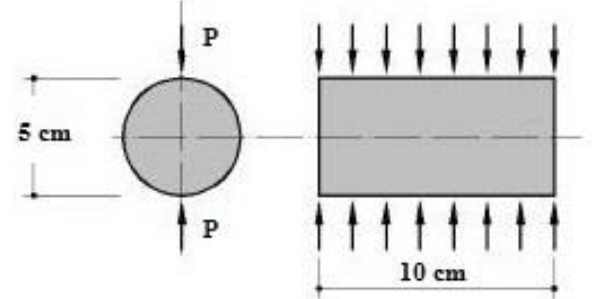

a)

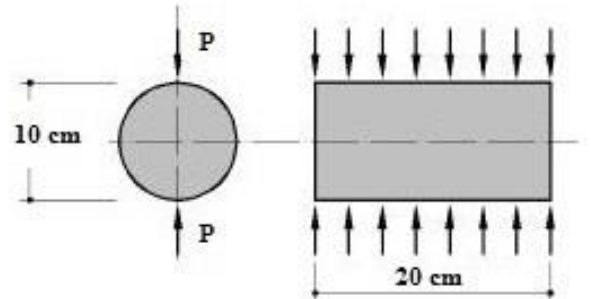

b)

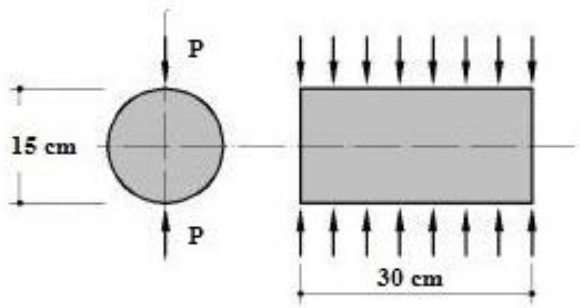

c)

Figura 4.14 - Corpos de prova: a) CP $5 \mathrm{~cm} \times 10 \mathrm{~cm}$; b) CP $10 \mathrm{~cm} \times 20 \mathrm{~cm}$; c) CP $15 \mathrm{~cm} \mathrm{x}$ $30 \mathrm{~cm}$.

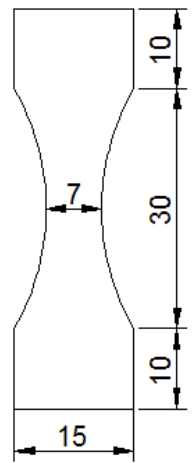

Figura 4.15 - Corpo de prova para o ensaio de tração direta.

\subsection{3}

\section{Concretagem}

As concretagens dos corpos de prova ocorreram no Laboratório de Estruturas e Materiais da PUC-Rio (LEM) nos meses de agosto e setembro.

O concreto foi lançado manualmente.

Os corpos de prova foram retirados das formas dois dias após cada concretagem e ficaram em condições ambientes no laboratório até as datas dos ensaios. 


\section{4 \\ Esquema dos ensaios}

Para realização do programa experimental foram ensaiados 72 corpos de prova de concreto, os quais foram divididos em nove séries, cada uma delas composta por dois corpos de prova de dimensões $5 \mathrm{~cm}$ x $10 \mathrm{~cm}$, dois de $10 \mathrm{~cm}$ x 20 $\mathrm{cm}$, dois de $15 \mathrm{~cm}$ x $30 \mathrm{~cm}$ e dois corpos de prova para tração direta.

No ensaio de tração direta é obtida a tração do concreto mostrada na Tabela 4.4 descrita no item 4.2.1.1. O equipamento utilizado nesse ensaio foi a máquina da MTS com capacidade máxima de 1000 kN (Figura 4.16).

No ensaio de compressão diametral é obtida a tração indireta dos corpos de prova por meio da expressão 4.1 descrita no item 4.2.1.3. O equipamento utilizado nesse ensaio foi a máquina da MTS com capacidade máxima de 500 kN (Figura 4.17).

Todos os ensaios foram realizados no Laboratório de Estruturas e Materiais do Departamento de Engenharia Civil da PUC-Rio.

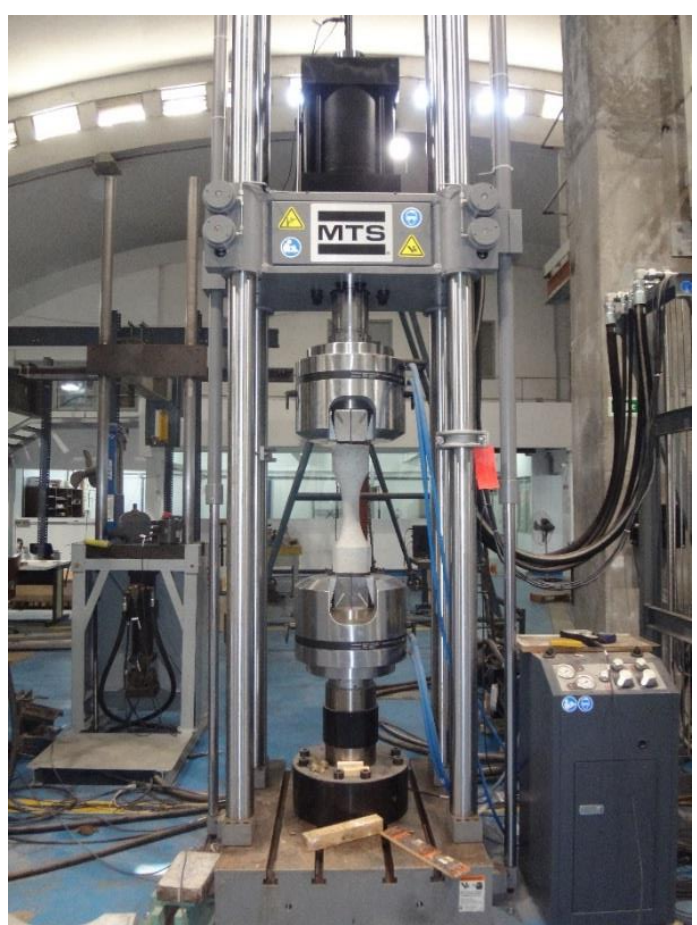

Figura 4.16 - Máquina da MTS com capacidade máxima de 1000 kN. 


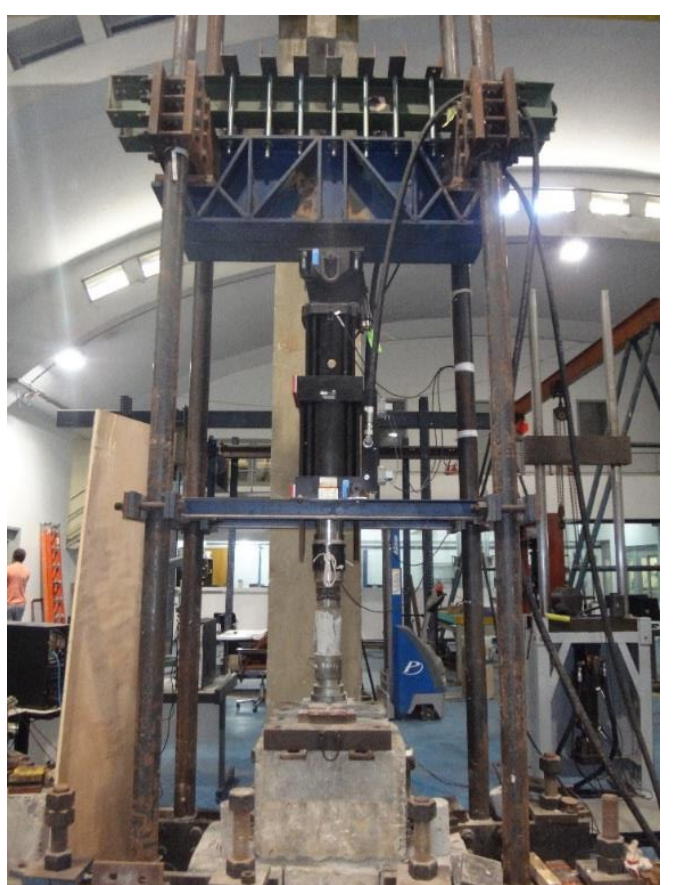

Figura 4.17 - Máquina da MTS com capacidade máxima de 500 kN.

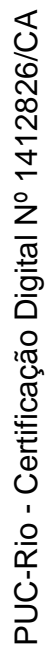




\section{Apresentação e análise dos resultados}

\section{1}

Introdução

Neste capítulo são apresentados e analisados os resultados experimentais obtidos nos ensaios descritos no Capítulo 4.

\section{2 \\ Apresentação dos grupos}

\section{2 .1}

\section{Grupo I}

O Grupo I é composto por três séries de concretagem divididas de acordo com o consumo de fibras. A primeira tem $20 \mathrm{~kg} / \mathrm{m}^{3}$ de fibras em sua composição, assim como as séries 2 e 3 têm $40 \mathrm{~kg} / \mathrm{m}^{3}$ e $60 \mathrm{~kg} / \mathrm{m}^{3}$ respectivamente. Todas têm a mesma dosagem calculada para atingir uma $f_{c}$ de $20 \mathrm{MPa}$ aos 28 dias. As datas das betonadas e seus respectivos ensaios, assim como suas resistências à compressão aos 28 dias são mostrados na Tabela 5.1.

Tabela 5.1 - Data dos ensaios séries 1, 2 e 3.

\begin{tabular}{c|c|c|c|c}
\hline Série & $\begin{array}{c}\text { Data } \\
\text { concreto }\end{array}$ & $\begin{array}{c}\text { Data } \\
\text { ensaio }\end{array}$ & Idade & $\begin{array}{c}\boldsymbol{f}_{\boldsymbol{c}} \\
(\mathbf{M P a})\end{array}$ \\
\hline 1 & $18 /$ ago & $17 /$ set & 30 & 31,31 \\
\hline 2 & $21 /$ ago & $22 /$ set & 32 & 30,66 \\
\hline 3 & $25 /$ ago & $22 /$ set & 28 & 27,55 \\
\hline
\end{tabular}

Considerando-se a média das três séries têm-se para o grupo I uma resistência à compressão de 29,84 MPa. Essa será a resistência considerada para o grupo I para as análises de resultados. 


\section{2 .2}

\section{Grupo II}

O Grupo II é composto por três séries de concretagem divididas de acordo com o consumo de fibras. Para dar continuidade as séries anteriores, são denominadas de séries 4,5 e 6 . A série 4 tem $20 \mathrm{~kg} / \mathrm{m}^{3}$ de fibras em sua composição, assim como as séries 5 e 6 têm $40 \mathrm{~kg} / \mathrm{m}^{3}$ e $60 \mathrm{~kg} / \mathrm{m}^{3}$, respectivamente. Todas têm a mesma dosagem calculada para atingir uma $f_{c}$ de $30 \mathrm{MPa}$ aos 28 dias. As datas das betonadas e seus respectivos ensaios, assim como suas resistências à compressão aos 28 dias são mostrados na Tabela 5.2.

Tabela 5.2 - Data dos ensaios séries 4, 5 e 6.

\begin{tabular}{c|c|c|c|c}
\hline Série & $\begin{array}{c}\text { Data } \\
\text { concreto }\end{array}$ & $\begin{array}{c}\text { Data } \\
\text { ensaio }\end{array}$ & Idade & $\begin{array}{c}\boldsymbol{f}_{\boldsymbol{c}} \\
(\mathbf{M P a})\end{array}$ \\
\hline 4 & $27 / \mathrm{ago}$ & $24 /$ set & 28 & 34,69 \\
\hline 5 & $01 /$ set & $29 /$ set & 28 & 40,59 \\
\hline 6 & $08 /$ set & $06 /$ out & 28 & 39,59 \\
\hline
\end{tabular}

Considerando-se a média das três séries têm-se para o grupo II uma resistência à compressão de 38,29 $\mathrm{MPa}$. Essa será a resistência considerada para o grupo II para as análises de resultados.

\section{2 .3 \\ Grupo III}

O Grupo III é composto por três séries de concretagem divididas de acordo com o consumo de fibras. Dando continuidade as séries anteriores, são denominadas de séries 7,8 e 9 . A série 7 tem $20 \mathrm{~kg} / \mathrm{m}^{3}$ de fibras em sua composição, assim como as séries 8 e 9 têm $40 \mathrm{~kg} / \mathrm{m}^{3}$ e $60 \mathrm{~kg} / \mathrm{m}^{3}$, respectivamente. Todas têm a mesma dosagem calculada para atingir uma $f_{c}$ de $50 \mathrm{MPa}$ aos 28 dias. As datas das betonadas e seus respectivos ensaios, assim como as suas resistências à compressão são mostrados na Tabela 5.3.

Tabela 5.3 - Data dos ensaios séries 7, 8 e 9.

\begin{tabular}{c|c|c|c|c}
\hline Série & $\begin{array}{c}\text { Data } \\
\text { concreto }\end{array}$ & $\begin{array}{c}\text { Data } \\
\text { ensaio }\end{array}$ & Idade & $\begin{array}{c}\boldsymbol{f}_{\mathbf{c}} \\
(\mathbf{M P a})\end{array}$ \\
\hline 7 & $11 /$ set & 13/out & 32 & 47,91 \\
\hline 8 & $15 /$ set & 13/out & 28 & 48,09 \\
\hline 9 & $17 /$ set & $20 /$ out & 33 & 50,41 \\
\hline
\end{tabular}


Considerando-se a média das três séries têm-se para o grupo III uma resistência à compressão de 48,80 MPa. Essa será a resistência considerada para o grupo III para as análises de resultados.

O acréscimo de resistência do grupo I para o II foi de $28,31 \%$ e do grupo II para o III foi de $27,44 \%$.

\section{3}

\section{Apresentação dos resultados}

\subsection{1}

\section{Compressão}

Como mencionado o grupo I foi dosado para uma $f_{c}$ de $20 \mathrm{MPa}$ aos 28 dias, porém, atingiu 29,84 MPa. O mesmo ocorre para o grupo II, a dosagem foi realizada para um concreto de $30 \mathrm{MPa}$ e atingiu 38,29 MPa, acréscimo de 27,63\%. O grupo III que foi dosado para $50 \mathrm{MPa}$ ficou com 48,80 MPa, mesmo assim bem próximo do esperado. Isso pode estar relacionado a dois fatores:

- o cimento utilizado foi o CP II-32 o que dificulta uma dosagem para $50 \mathrm{MPa}$;

- segundo Helene (93) mesmo com um fator água cimento bem reduzido é difícil alcançar uma resistência de $50 \mathrm{MPa}$ com o cimento CP II-32 .

Não se pode relacionar o aumento da resistência à compressão com o consumo de fibras pois não foi feita uma série de referência para comparação.

\section{3 .2}

\section{Tensão de tração por compressão diametral}

Tabela 5.4 - Razão da tensão de tração por compressão diametral.

\begin{tabular}{c|c|c|c|c|c|c|c|c|c|c|c}
\hline \multicolumn{4}{c|}{ CONSUMO } & \multicolumn{4}{c|}{ Grupos } & \multicolumn{4}{c|}{ Diâmetro } \\
\hline & $\Delta \mathrm{a}$ & $\Delta \mathrm{b}$ & $\Delta \mathrm{c}$ & & $\Delta \mathrm{d}$ & $\Delta \mathrm{e}$ & $\Delta \mathrm{f}$ & & $\Delta \mathrm{g}$ & $\Delta \mathrm{h}$ & $\Delta \mathrm{i}$ \\
\hline I-D5 & 1,51 & 0,88 & 1,34 & D5-F20 & 1,48 & 1,05 & 1,55 & I-F20 & 0,69 & 0,92 & 0,64 \\
\hline I-D10 & 1,41 & 0,84 & 1,18 & D10-F20 & 1,18 & 1,50 & 1,77 & I-F40 & 0,64 & 0,77 & 0,50 \\
\hline I-D15 & 1,17 & 1,04 & 1,22 & D15-F20 & 1,39 & 1,12 & 1,56 & I-F60 & 0,61 & 0,95 & 0,58 \\
\hline II-D5 & 0,98 & 0,92 & 0,90 & D5-F40 & 0,96 & 1,26 & 1,20 & II-F20 & 0,55 & 1,09 & 0,60 \\
\hline II-D10 & 1,11 & 1,05 & 1,17 & D10-F40 & 0,93 & 1,41 & 1,31 & II-F40 & 0,63 & 0,95 & 0,59 \\
\hline II-D15 & 0,97 & 0,95 & 0,92 & D15-F40 & 1,14 & 1,22 & 1,40 & II-F60 & 0,72 & 0,86 & 0,61 \\
\hline III-D5 & 1,17 & 1,12 & 1,31 & D5-F60 & 0,99 & 1,53 & 1,52 & III-F20 & 0,79 & 0,82 & 0,64 \\
\hline III-D10 & 1,04 & 1,15 & 1,20 & D10-F60 & 1,17 & 1,54 & 1,79 & III-F40 & 0,70 & 0,82 & 0,58 \\
\hline III-D15 & 1,05 & 0,96 & 1,01 & D15-F60 & 1,05 & 1,24 & 1,30 & III-F60 & 0,72 & 0,69 & 0,50 \\
\hline
\end{tabular}


Na Tabela 5.4 tem-se a razão das tensões médias de tração, comparadas entre consumo, grupo e diâmetro, considerando-se que:

- $\Delta a=F_{40} / F_{20}$ - razão entre as tensões de tração de 40 e $20 \mathrm{~kg} / \mathrm{m}^{3}$;

- $\Delta b=F_{60} / F_{40}$ - razão entre as tensões de tração de 60 e $40 \mathrm{~kg} / \mathrm{m}^{3}$;

- $\Delta c=F_{60} / F_{20}$ - razão entre as tensões de tração de 60 e $20 \mathrm{~kg} / \mathrm{m}^{3}$;

- $\Delta d=I I / I$ - razão entre as tensões de tração dos grupos II e I;

- $\Delta e=I I I / I I-$ razão entre as tensões de tração dos grupos III e II;

- $\Delta f=I I I / I-$ razão entre as tensões de tração dos grupos III e I;

- $\Delta g=D_{10} / D_{5}$ - razão entre as tensões de tração dos diâmetros 10 e 5;

- $\Delta h=D_{15} / D_{10}$ - razão entre as tensões de tração dos diâmetros 15 e 10;

- $\Delta i=D_{15} / D_{5}-$ razão entre as tensões de tração dos diâmetros 15 e 5.

Da Tabela 5.7 tem-se:

- a $\Delta a$ do grupo I teve grande aumento da tensão de tração, sendo mais significativo em diâmetros menores, já $\Delta b$ houve uma redução para os D5 e D10, e um aumento de somente $4 \%$ para a D15, o $\Delta c$ teve um aumento significativo da tensão de tração;

- a $\Delta a$ do grupo II não teve aumento significativo da tensão de tração para os D5 e D15, o D10 teve $11 \%$ de aumento, já a $\Delta b$ houve decréscimo para D5 e D10, aumentando somente $5 \%$ no D15, a $\Delta c$ somente aumentou no D10, aumento de 17\%;

- a $\Delta a$ do grupo III nota-se um aumento de $17 \%$ da tensão de tração para o D5 ficando o D15 e o D10 na faixa de 5\% de aumento, já a $\Delta b$ houve decréscimo para D15 e aumento de $12 \%$ e $15 \%$ para D5 e D10 respectivamente, a $\Delta c$ teve acréscimo maior para diâmetros menores;

- $\Delta d$ - para F20 nota-se um acréscimo significativo sendo maior no D5, para F40 e F60 houve comportamentos similares;

- $\Delta e$-houve um aumento significativo para todos os consumos de fibra, o mesmo aconteceu com o $\Delta f$;

- $\Delta h>\Delta g$ é maior em todos os casos exceto no III-F60.

Uma comparação com a tensão de compressão axial utilizando-se a mesma legenda dos $\Delta^{*}$ (mesmos índices referindo-se à tensão de compressão) tem-se os 
dados da Tabela 5.5. Os ensaios de compressão simples só ocorreram no corpo de prova de $10 \mathrm{~cm}$ de diâmetro, portanto, só é possível comparar o efeito do consumo e dos grupos.

Tabela 5.5 - Razão entre as tensões de compressão diametral e axial.

\begin{tabular}{|c|c|c|c|c|c|c|c|}
\hline \multicolumn{4}{|c|}{ CONSUMO } & \multicolumn{4}{|c|}{ Grupos } \\
\hline \multicolumn{8}{|c|}{ Compressão simples } \\
\hline & $\Delta \mathrm{a}$ & $\Delta \mathrm{b}$ & $\Delta \mathrm{c}$ & & $\Delta \mathrm{d}$ & $\Delta \mathrm{e}$ & $\Delta \mathrm{f}$ \\
\hline I-D10 & 0,98 & 0,90 & 0,88 & D10-F20 & 1,11 & 1,38 & 1,53 \\
\hline II-D10 & 1,17 & 0,98 & 1,14 & D10-F40 & 1,32 & 1,18 & 1,57 \\
\hline III-D10 & 1,00 & 1,05 & 1,05 & D10-F60 & 1,44 & 1,27 & 1,83 \\
\hline
\end{tabular}

$\mathrm{Na}$ Tabela 5.5, nota-se que para todos os grupos os $\Delta a$, b e c, na compressão simples, não tiveram alterações significativa. As razões $\Delta d$ e $f$ aumentaram de acordo com o consumo. A razão $\Delta e$ é maior que 1 para todos os casos, porém, não aumenta com o consumo.

\subsection{3 \\ Gráficos $f_{t} \times$ consumo de fibras}

Os gráficos das Figuras 5.1 a 5.14 ilustram os resultados dos corpos de prova nos ensaios realizados de acordo com o item 4.2.1.2 e 4.2.1.3.

Os parâmetros que são analisados são o diâmetro e o grupo. A resistência à tração por compressão diametral é estudada em função do aumento do consumo de fibra. A nomenclatura dos gráficos das Figuras 5.1 a 5.14 é:

- I, II ou III - resistência à compressão;

- D5, D10 e D15 - diâmetro do corpo de prova.

Todas as siglas utilizadas são descritas no Capítulo 4.

Por exemplo o gráfico da Figura 5.1 apresenta o comportamento da resistência à tração por compressão diametral em corpos de prova de diâmetro $5 \mathrm{~cm}$ do grupo I (29,84 MPa), em função do consumo de fibras. 


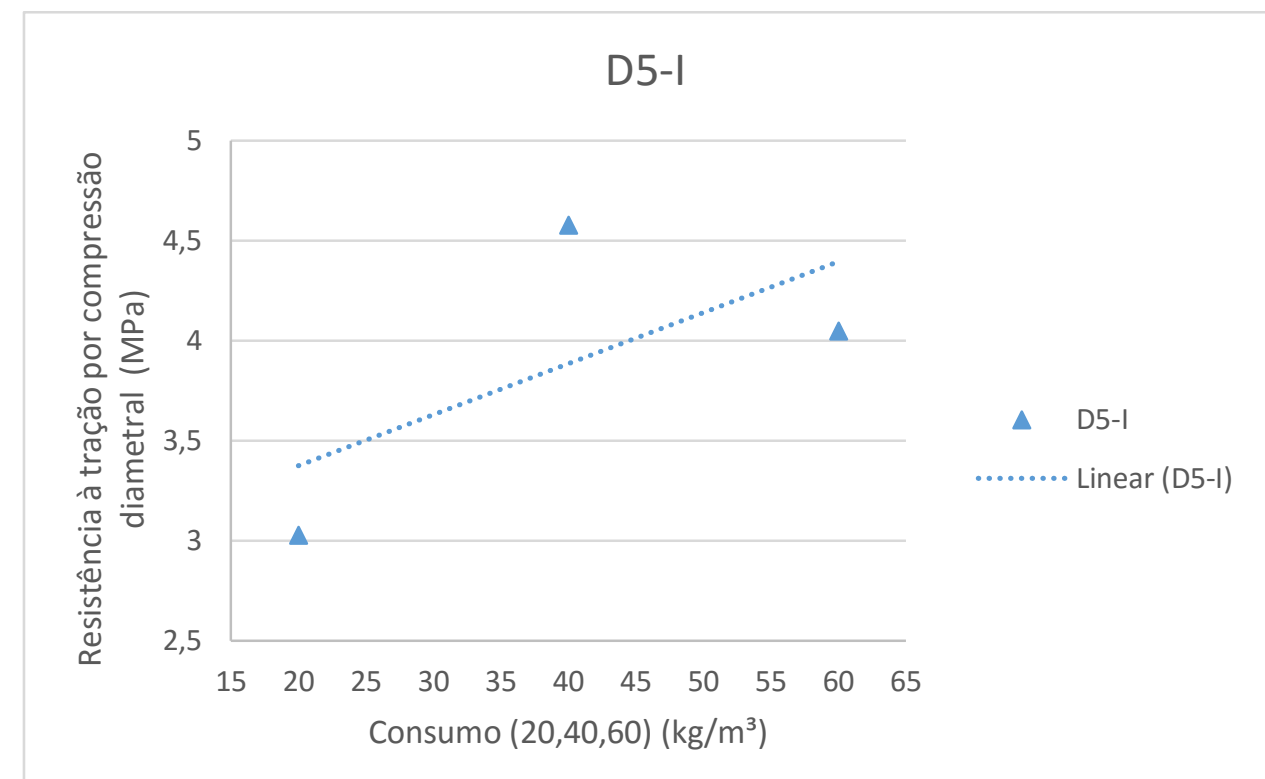

Figura 5.1 - Resistência à tração por compressão diametral x consumo, D5-I.

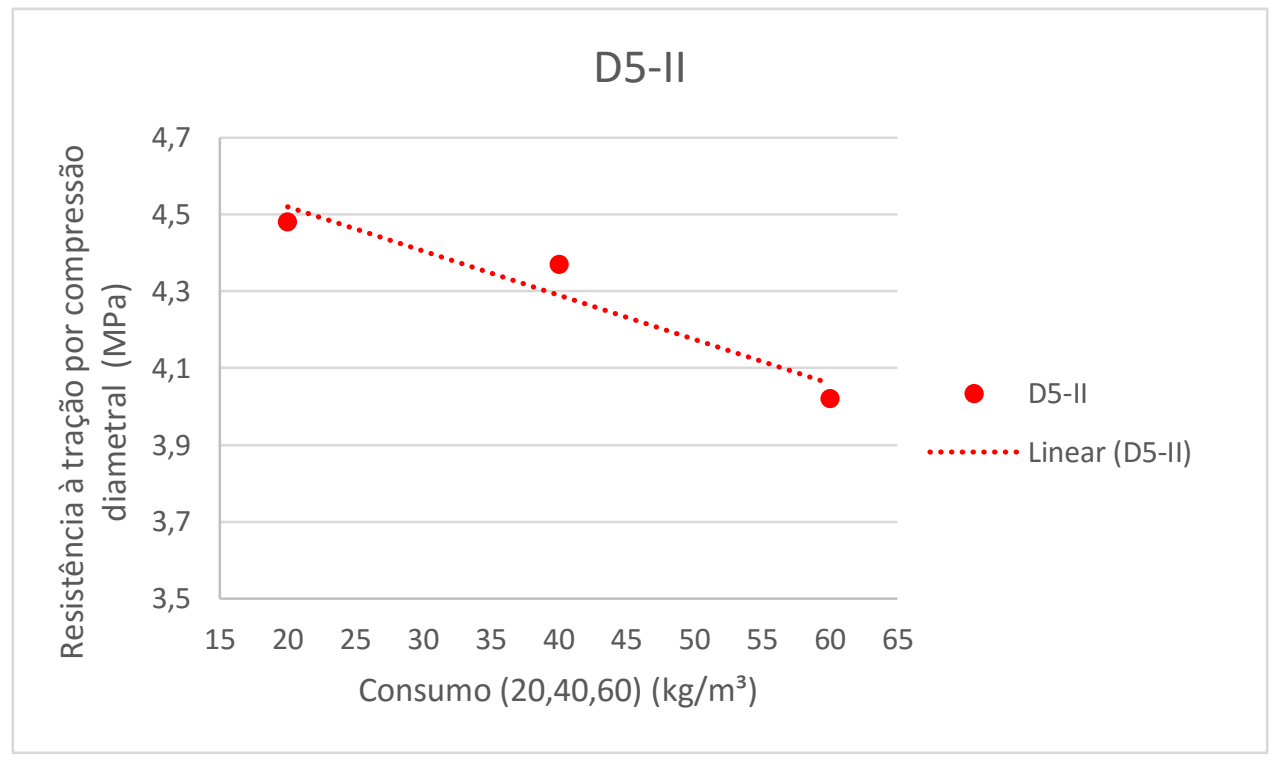

Figura 5.2 - Resistência à tração por compressão diametral x consumo, D5-II. 


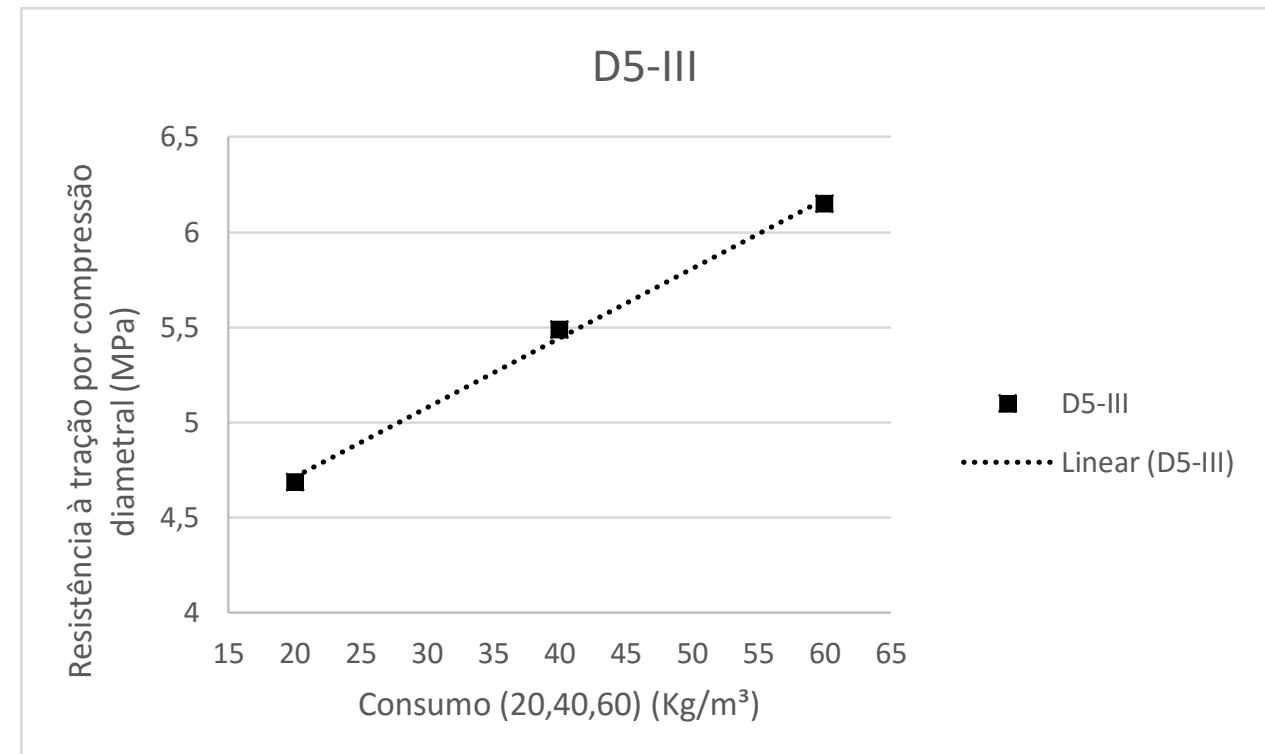

Figura 5.3 - Resistência à tração por compressão diametral x consumo, D5-III.

Nas Figuras 5.1 e 5.3 observa-se que o acréscimo de resistência é praticamente linear, principalmente no gráfico da Figura 5.3, com bom ajuste das curvas de tendências.

Na Figura 5.2 não se pode afirmar que a curva de ajuste tenha uma tendência decrescente, já que a variação de resistência é de 0,46 MPa entre o primeiro e o último corpo de prova com $20 \mathrm{~kg} / \mathrm{m}^{3}$ e $60 \mathrm{~kg} / \mathrm{m}^{3}$, respectivamente. Levando-se em conta apenas um corpo de prova ensaiado de cada consumo, sem retirar a média, esse ajuste apresenta um comportamento praticamente linear e crescente igualmente dos outros diâmetros. Observa-se esse ajuste na Figura 5.4. Verifica-se que somente dois corpos de cada diâmetro em cada betonada foi insuficiente para obter um resultado satisfatório.

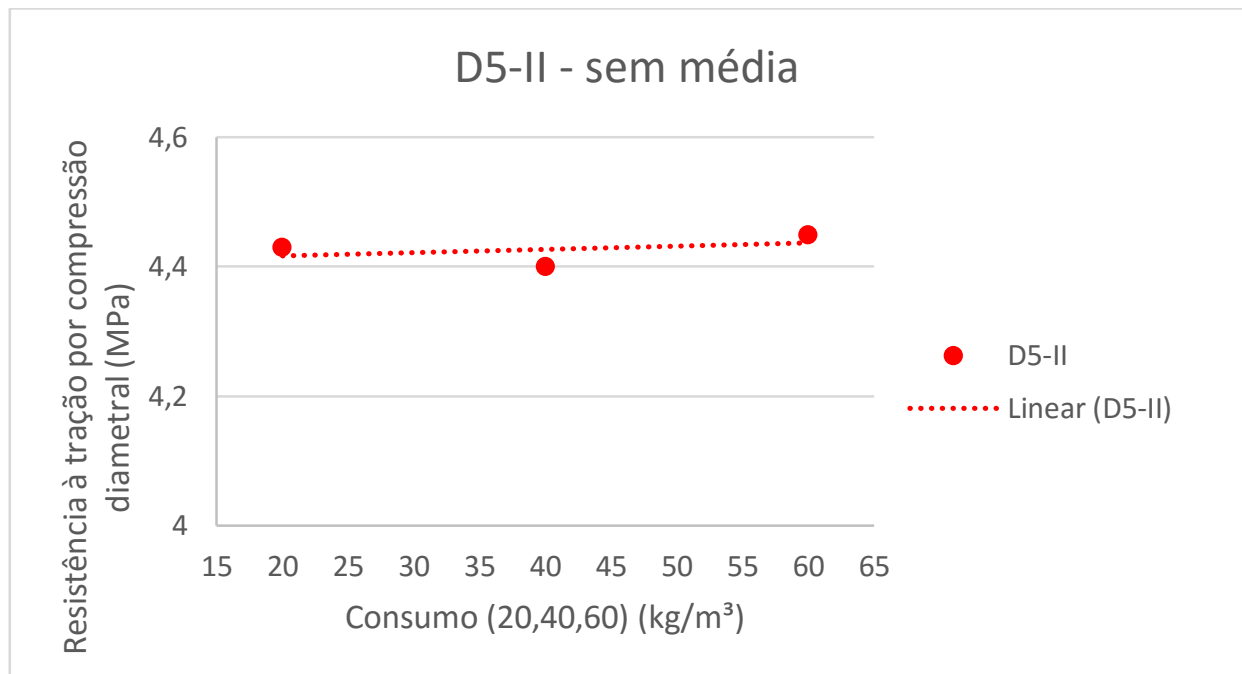

Figura 5.4 - Resistência à tração por compressão diametral x consumo, D5-II - sem média. 


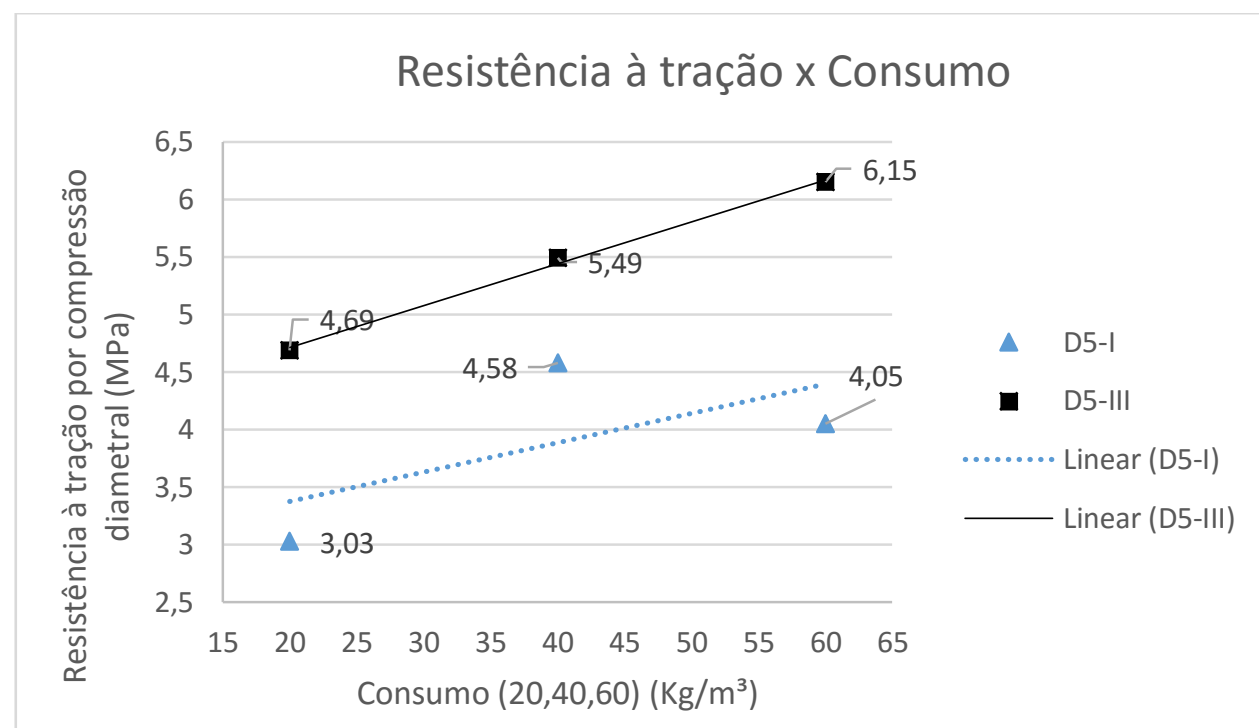

Figura 5.5 - Resistência à tração por compressão diametral x consumo, comparativo D5 grupos I e III.

No gráfico da Figura 5.5 tem-se a comparação entre os grupos, sem a comparação com o grupo II devido ao decréscimo que ocorreu na Figura 5.2. Observa-se que quanto maior é a $f_{c}$ maior é a resistência à tração por compressão diametral resistida pelo corpo de prova. Do grupo I para o III houve um acréscimo de 63,53\% de resistência à compressão, 54,78 \% para F20, de 19,86\% para F40 e $51,85 \%$ para F60 de resistência à tração.

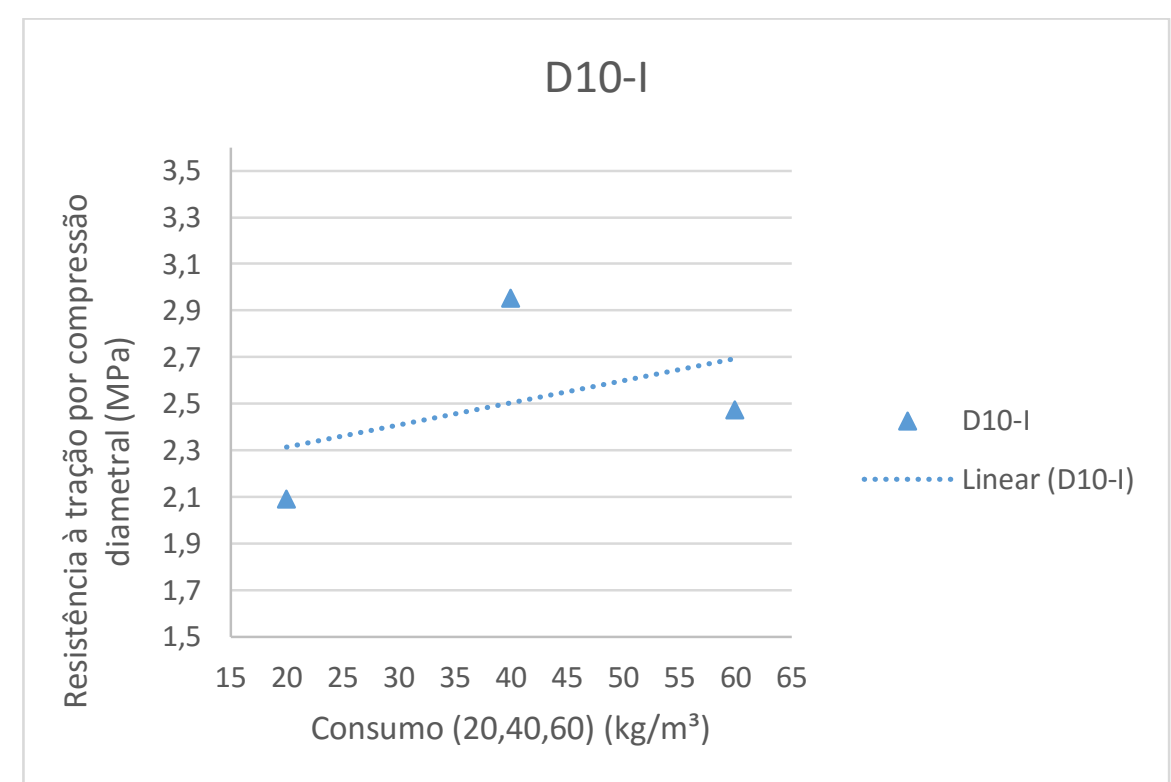

Figura 5.6 - Resistência à tração por compressão diametral x consumo, D10-I. 


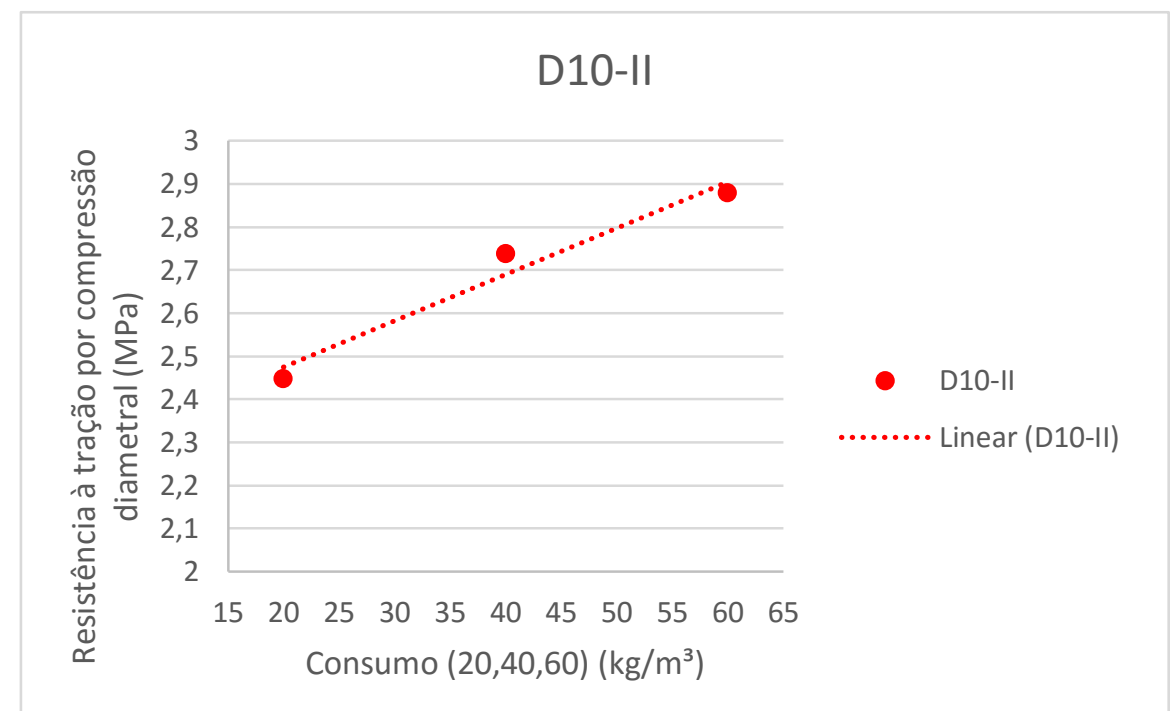

Figura 5.7 - Resistência à tração por compressão diametral x consumo, D10-II.

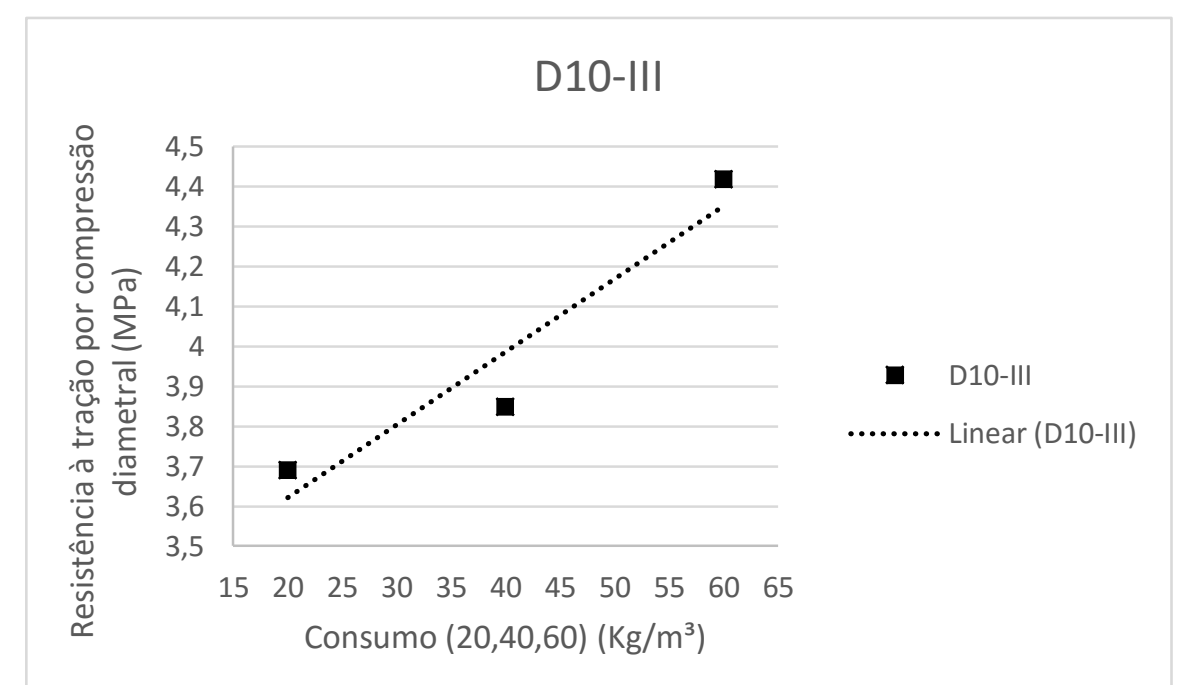

Figura 5.8 - Resistência à tração por compressão diametral x consumo, D10-III.

Nos gráficos das Figuras 5.6 a 5.8 pode-se observar que acréscimo de resistência é praticamente linear, com bom ajuste da curva de tendência.

Os resultados mostrados na Figura 5.7 foram obtidos com corpos de prova cujas betonadas foram as mesmas dos corpos de prova cujos resultados constam na Figura 5.2, porém, não ocorreram as discrepâncias observadas. 


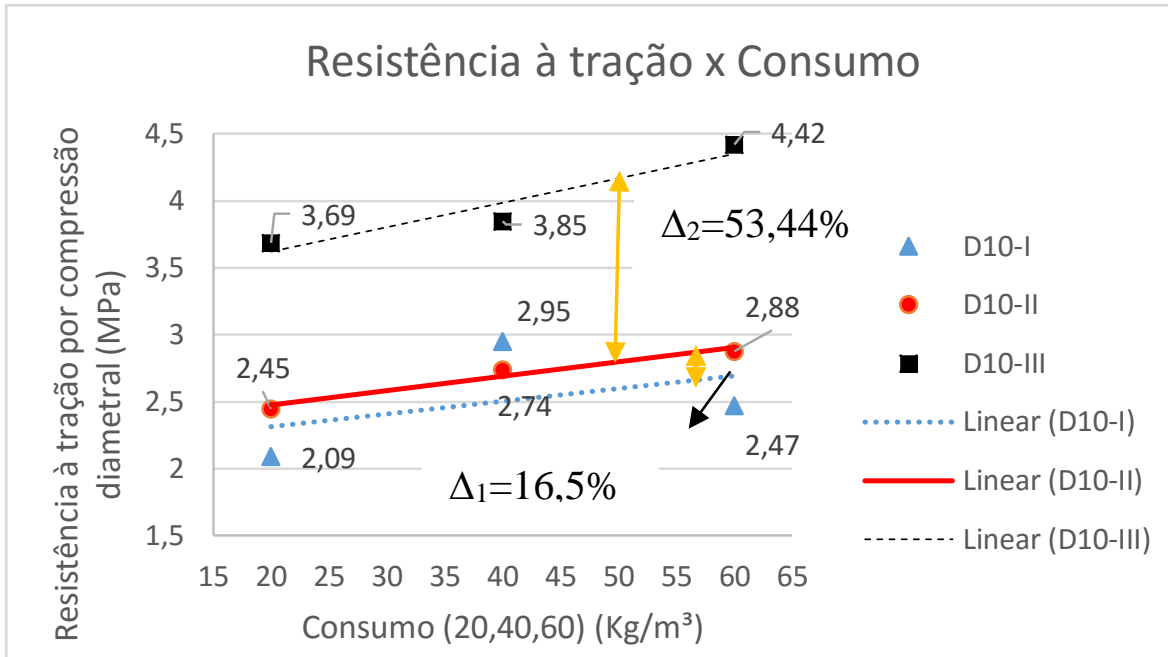

Figura 5.9 - Resistência à tração por compressão diametral x consumo, comparativo D10 grupos I, II e III.

No gráfico da Figura 5.9 tem-se uma comparação dos corpos de prova D10, entre os grupos I, II e III. Observa-se que quanto maior é a $f_{c}$ maior é a resistência à tração por compressão diametral resistida pelo corpo de prova. $\mathrm{O}$ acréscimo de resistência foi praticamente linear. Observou-se que o aumento de resistência é mais acentuado a partir da $f_{c}=38,29 \mathrm{MPa}$ (grupo II). Do grupo I para o II o aumento foi de $16,5 \%$ já do II para o III a resistência à tração mais que dobrou, tendo um aumento de 53,44\%, ambos para o consumo F60. Nesse caso a fibra influenciou o ganho de resistência, quanto maior foi o consumo de fibras maior o delta.

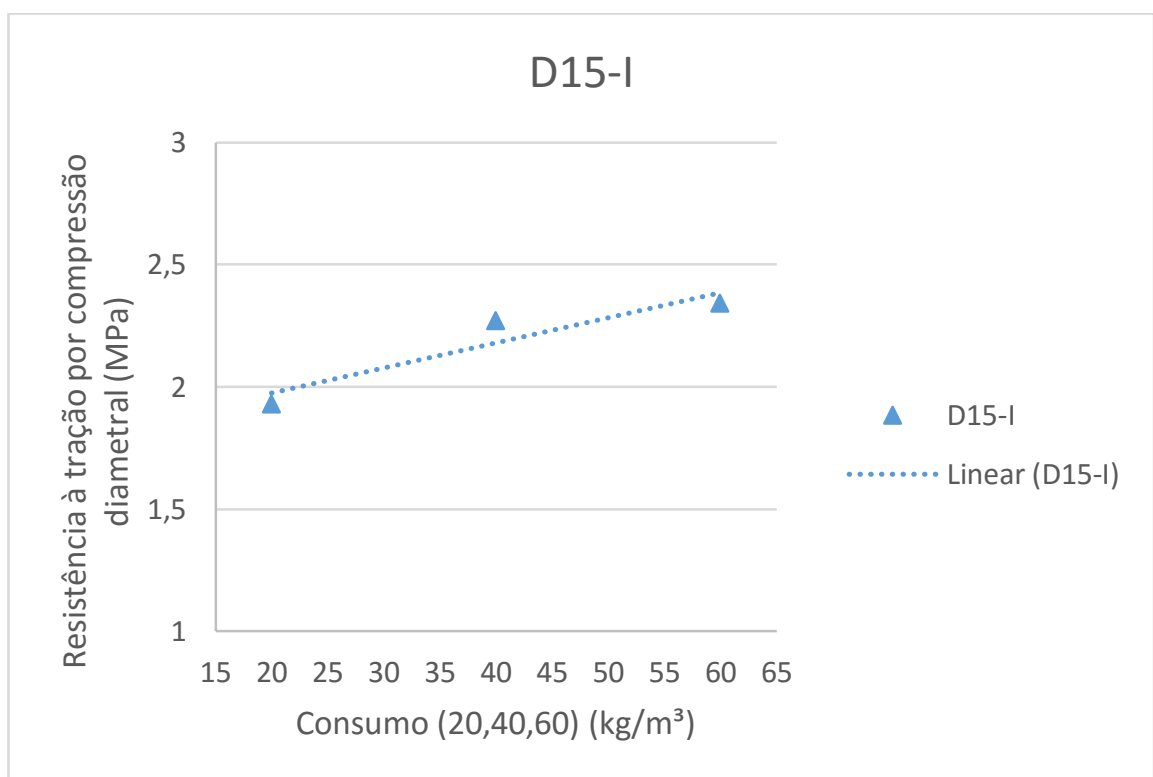

Figura 5.10 - Resistência à tração por compressão diametral x consumo, D15-I. 


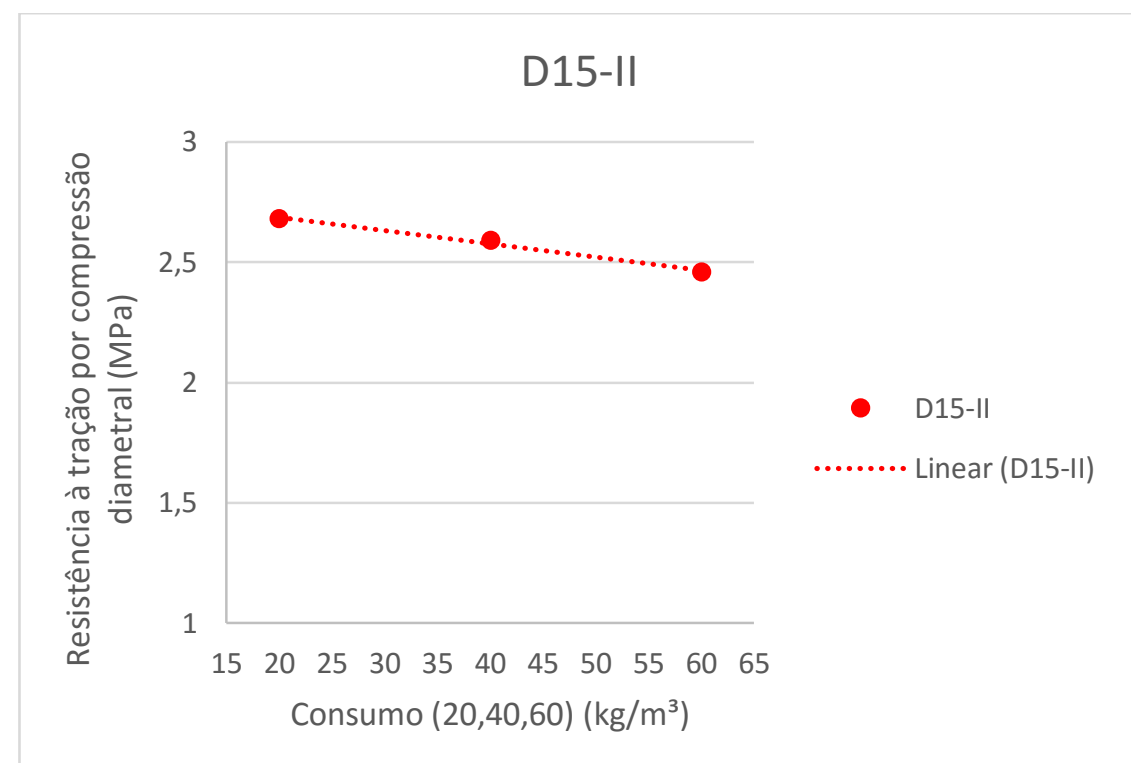

Figura 5.11 - Resistência à tração por compressão diametral x consumo, D15-II.

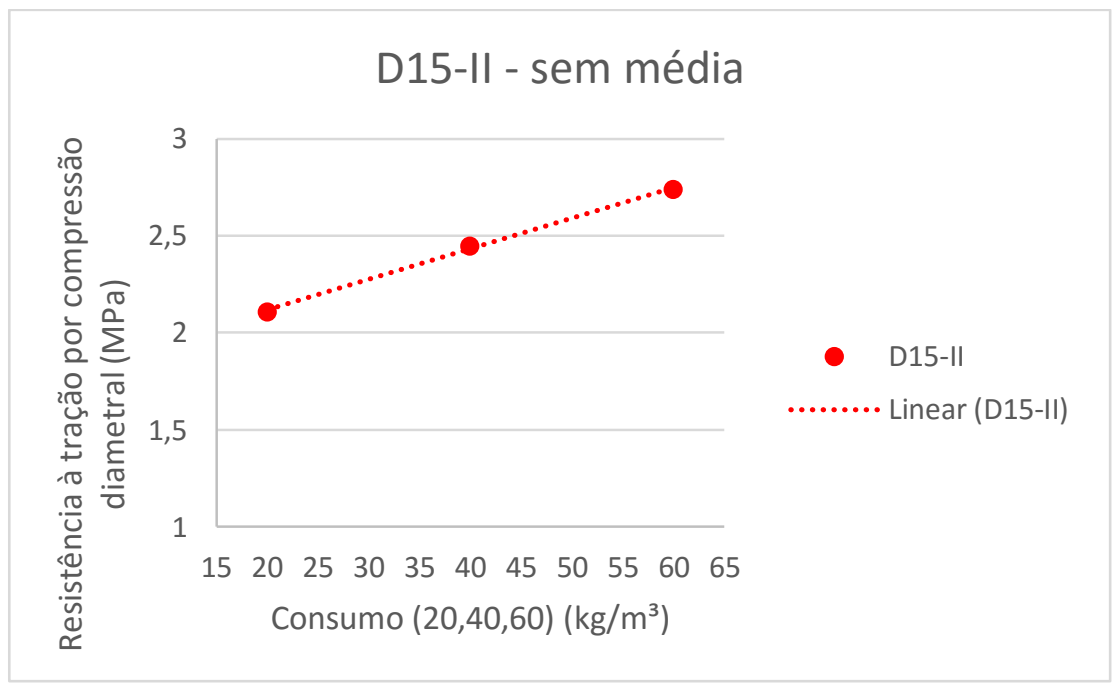

Figura 5.12 - Resistência à tração por compressão diametral x consumo, D15-II - sem média. 


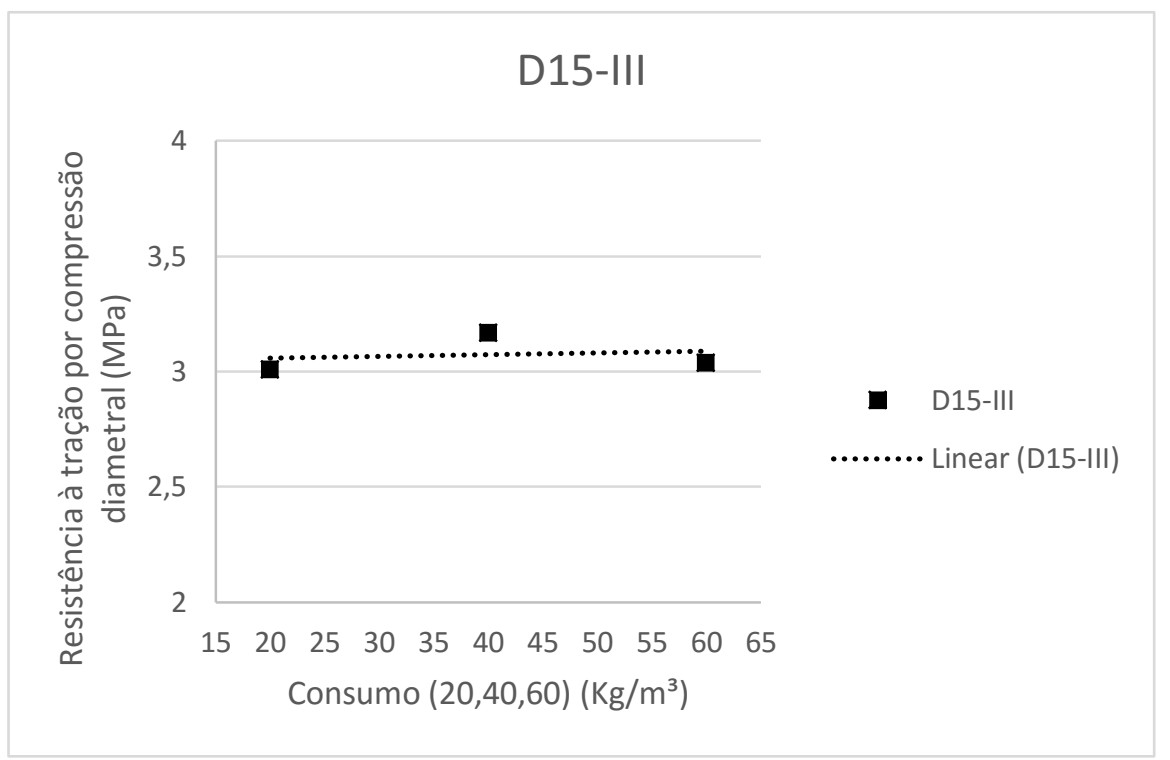

Figura 5.13 - Resistência à tração por compressão diametral x consumo, D15-III.

Nos gráficos das Figuras 5.10 e 5.12 observa-se um bom ajuste da curva de tendência. Na Figura 5.11 ocorreu o mesmo problema relativo aos dados mostrados na Figura 5.2, não se pode afirmar que a curva de ajuste tenha uma tendência decrescente, já que a variação de resistência é de 0,22 MPa entre o primeiro e o último corpo de prova com $20 \mathrm{~kg} / \mathrm{m}^{3}$ e $60 \mathrm{~kg} / \mathrm{m}^{3}$, respectivamente. Esse decréscimo pode ter sido ocasionado devido às diferentes betonadas de cada corpo de prova.

Sem utilizar a média dos corpos de prova como já feito anteriormente, temse o comportamento da Figura 5.12. Constata-se que é preciso mais corpos de prova para poder tirar a média e ter um bom resultado.

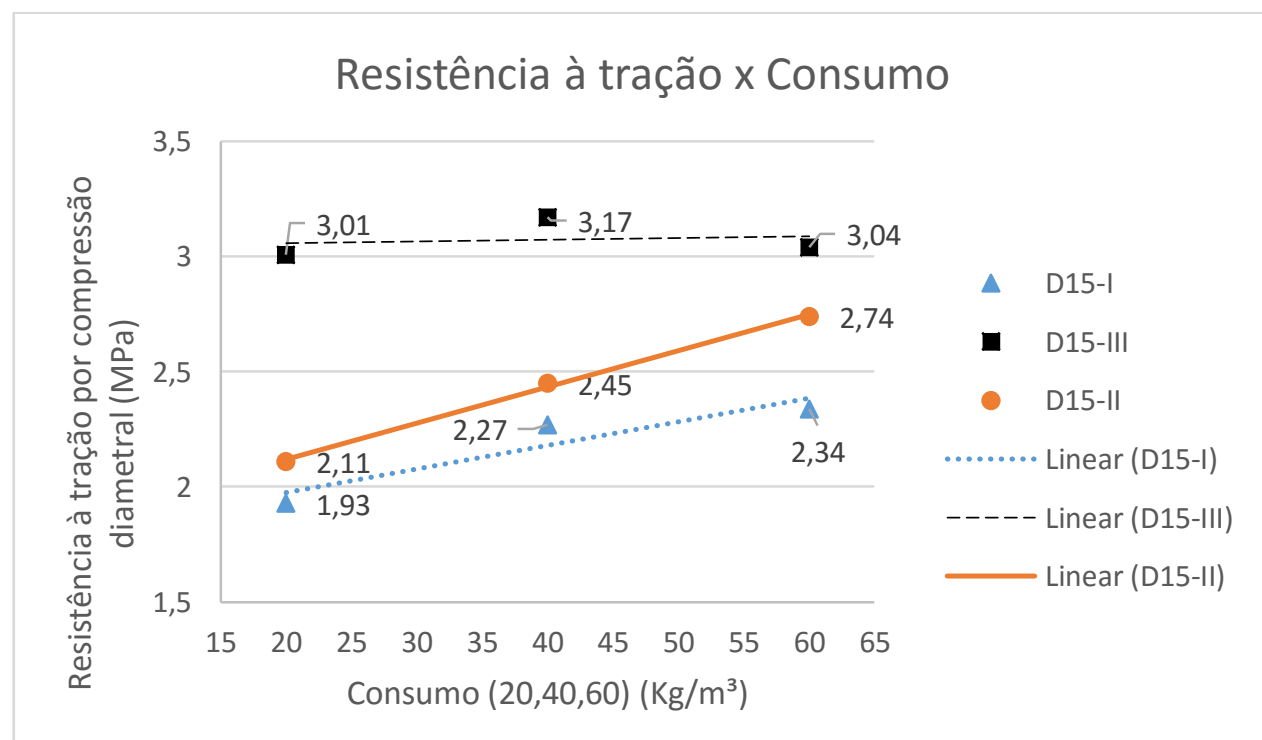

Figura 5.14 - Resistência à tração por compressão diametral $x$ consumo, comparativo D15 grupos I e III. 
No gráfico da Figura 5.14 tem-se uma comparação entre os grupos. Observase que quanto maior é a $f_{c}$ maior é a resistência à tração por compressão diametral resistida pelo corpo de prova. Do grupo I para o III houve um acréscimo de resistência à tração de 55,95 \% para F20, de 39,64\% para F40 e 29,91 \% para F60. O acréscimo de resistência à tração do grupo I para o III foi maior com menor quantidade de fibras, ou seja, para resistência à compressão mais alta o consumo elevado de fibra começa a não ter tanta influência na resistência à tração, nesse caso do corpo de prova de diâmetro $15 \mathrm{~cm}$.

\subsection{4}

\section{Gráficos $f_{t} \times$ grupos}

Os gráficos das Figuras 5.15 a 5.26 apresentam os resultados dos corpos de prova dos ensaios realizados de acordo com o item 4.2.1.2 e 4.2.1.3.

Os parâmetros que são analisados são o diâmetro e o consumo de fibras. É estudada a resistência à tração por compressão diametral versus o grupo à qual pertence. A nomenclatura dos gráficos das Figuras 5.15 a 5.26 é:

- F20, F40 e F60 - Consumo de fibras;

- D5, D10 e D15 - diâmetro do corpo de prova.

Todas as siglas utilizadas são descritas no Capítulo 4.

A Figura 5.15 ilustra os dados obtidos para a resistência à tração por compressão diametral em corpos de prova de diâmetro $5 \mathrm{~cm}$ com $20 \mathrm{~kg} / \mathrm{m}^{3}$ de fibras, variando a resistência à compressão (grupos I, II e III).

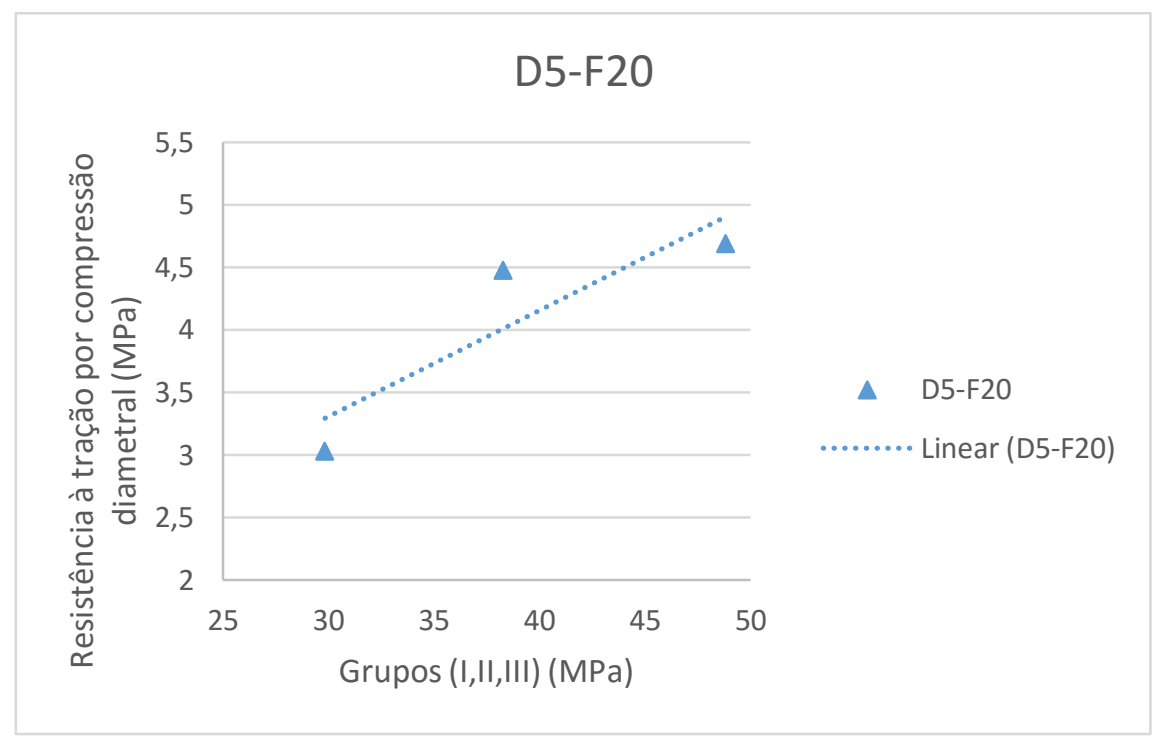

Figura 5.15 - Resistência à tração por compressão diametral x grupos, D5-F20. 


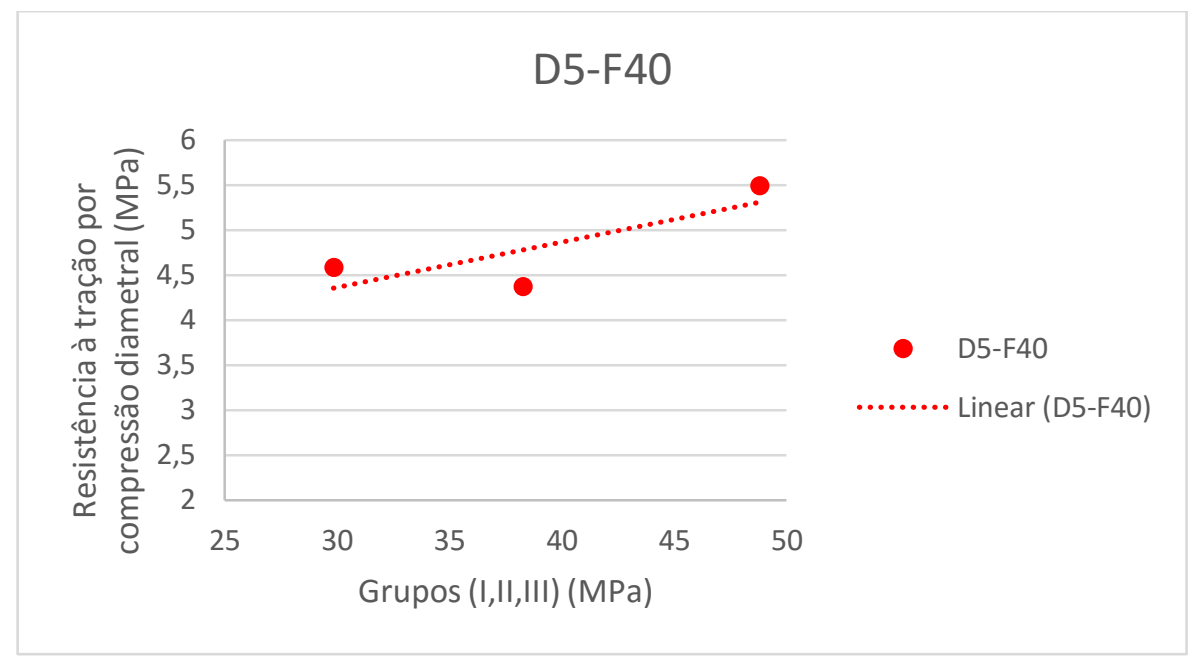

Figura 5.16 - Resistência à tração por compressão diametral x grupos, D5-F40.

Nos gráficos das Figuras 5.15 a 5.17 observa-se uma relação quase linear para todos os gráficos. Para um mesmo diâmetro e mesmo consumo de fibras quanto maior é a resistência à compressão maior é a resistência à tração por compressão diametral.

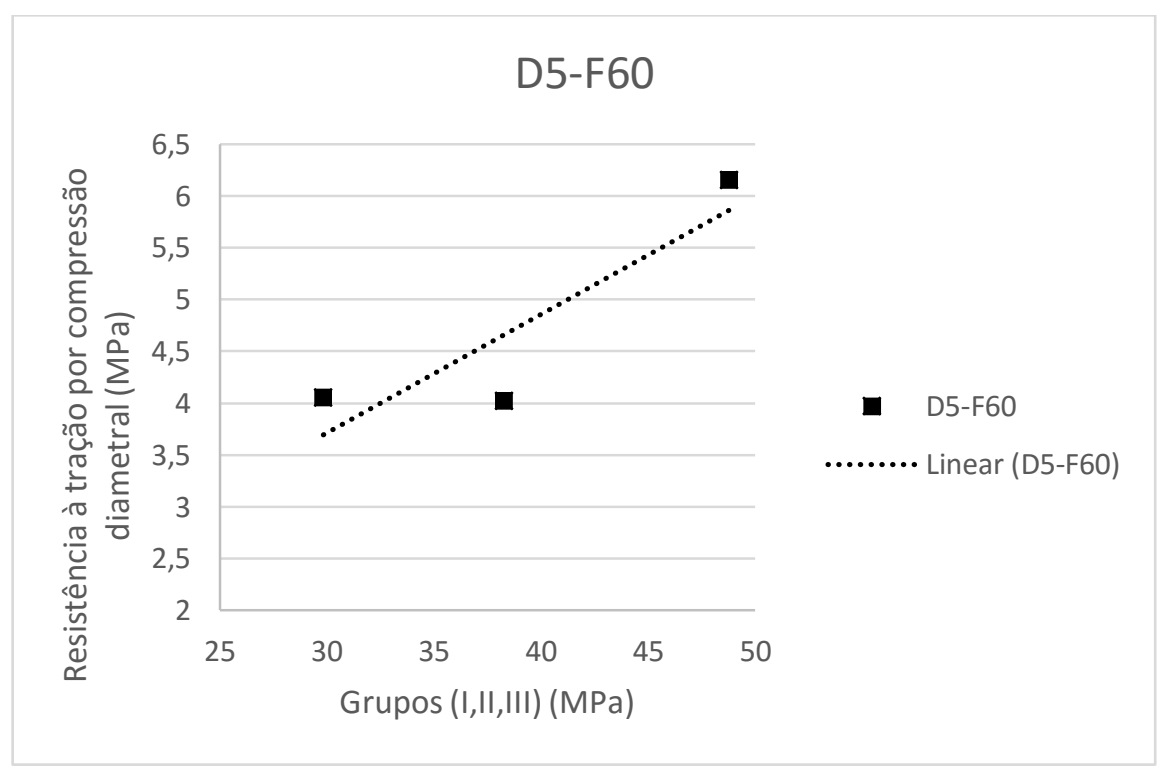

Figura 5.17 - Resistência à tração por compressão diametral x grupos, D5-F60. 


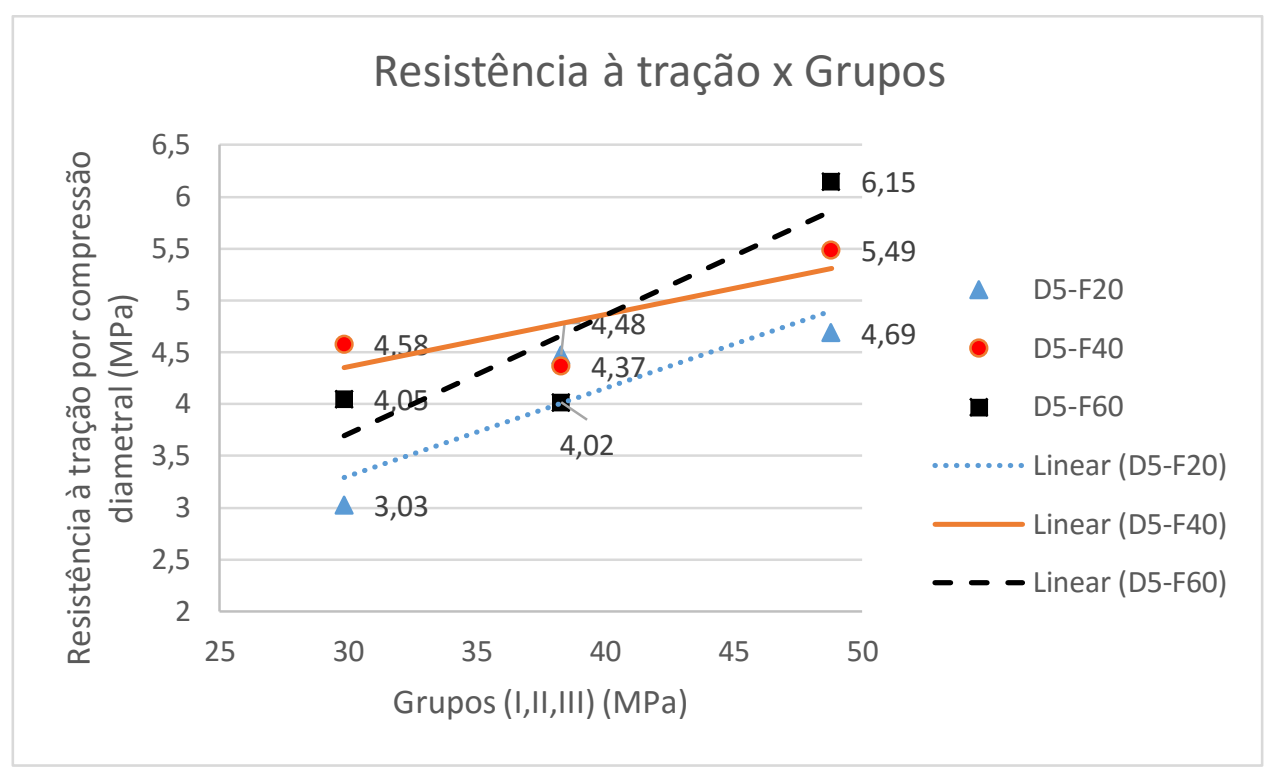

Figura 5.18 - Resistência à tração por compressão diametral x grupos, comparativo D5 consumo F20, 40 e 60.

Na Figura 5.18 observa-se que para o corpo de prova de $5 \mathrm{~cm}$ de diâmetro o consumo de fibras F20 gerou uma maior variação de resistência à tração com o aumento da resistência à compressão. Esse aumento foi de 54,78\%. Para o grupo I, tem-se que a $f_{t}$ de $\mathrm{F} 40$ é $10 \%$ maior que o F60, e 51,15 \% maior que o F20, porém para o grupo III ocorre ao contrário, o F60 é 12\% maior que o de F40 e 31,11\% maior que o de F20.

Para o grupo II, observa-se que para os consumos de fibra houve uma variação de $11 \%$ somente. Nesse caso conclui-se que a resistência à compressão influenciou mais as curvas nos pontos F20 e F60. 


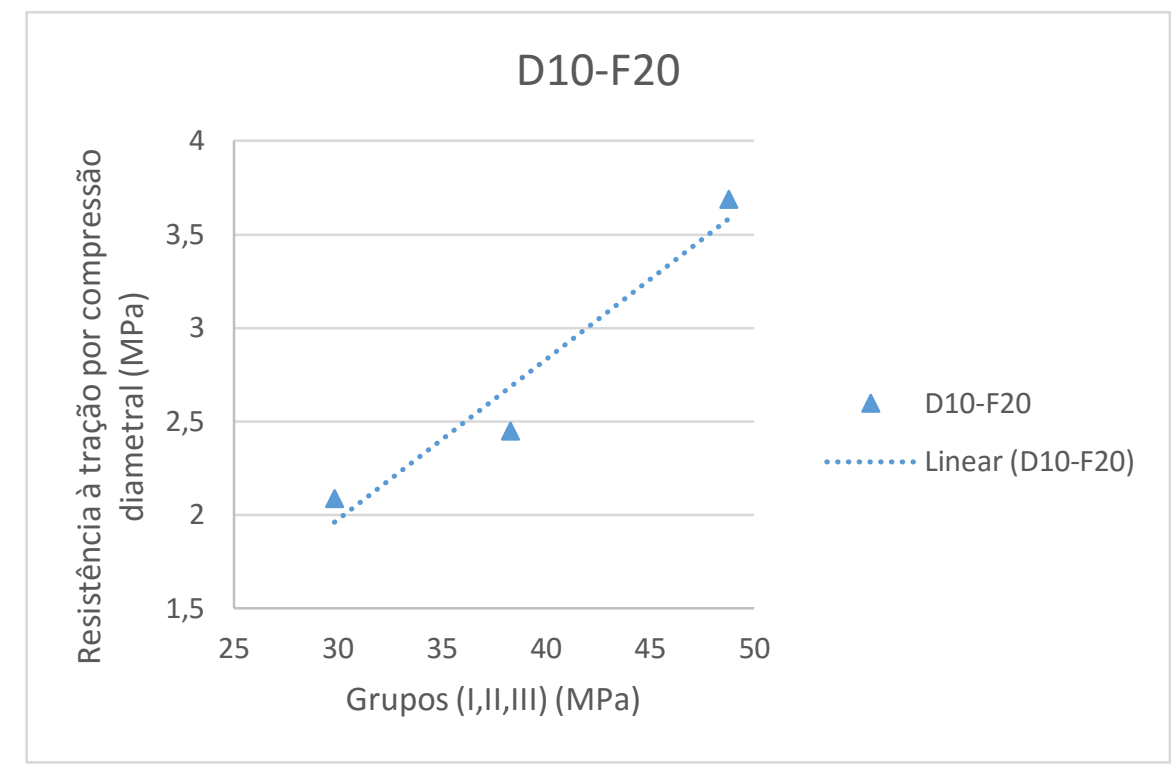

Figura 5.19 - Resistência à tração por compressão diametral x grupos, D10-F20.

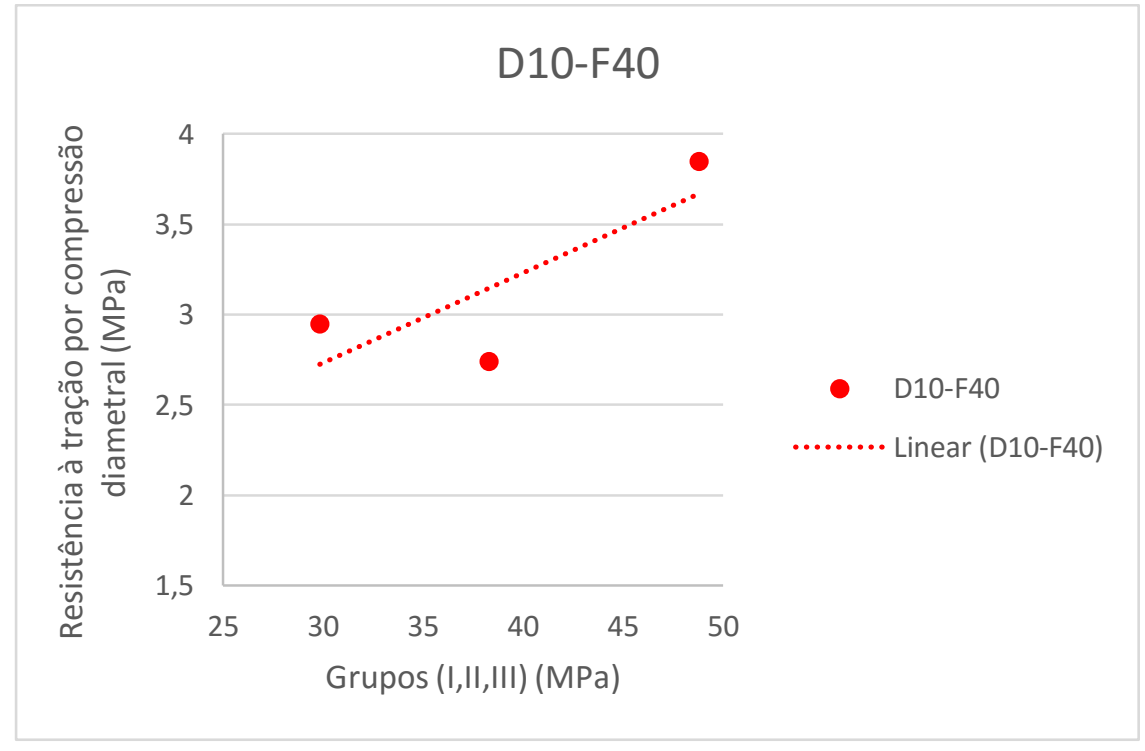

Figura 5.20 - Resistência à tração por compressão diametral x grupos, D10-F40. 


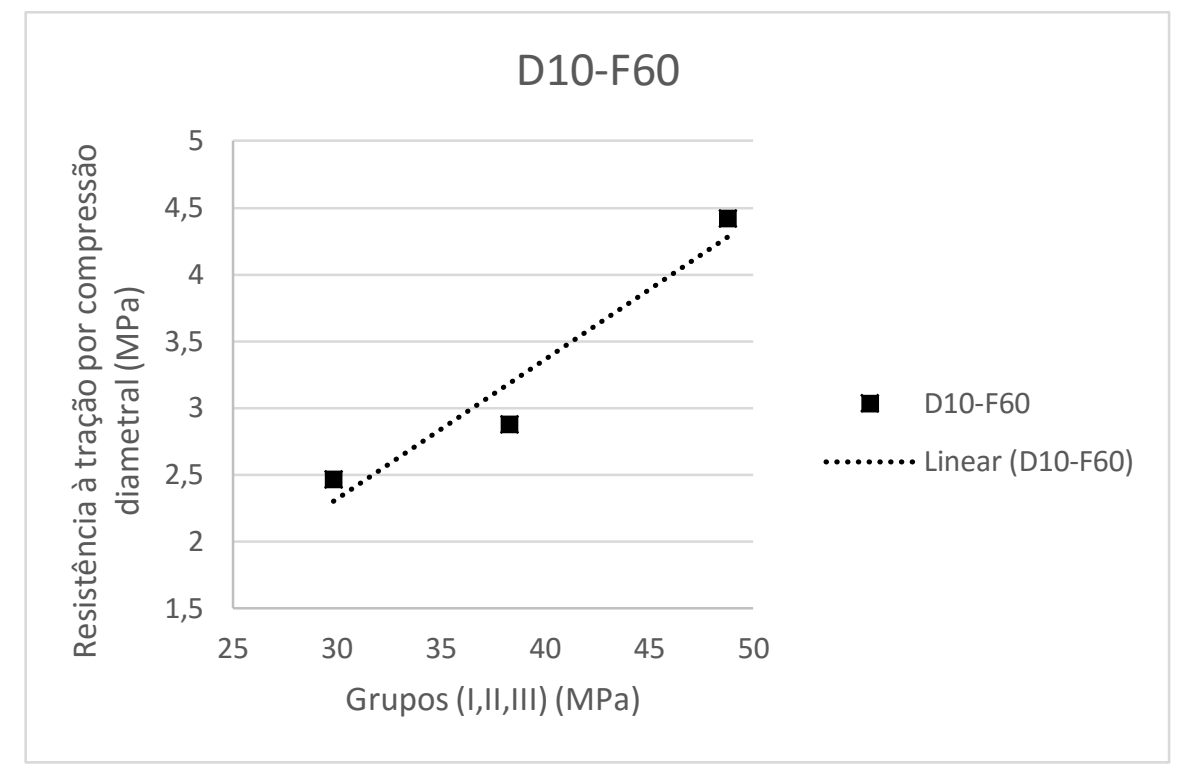

Figura 5.21 - Resistência à tração por compressão diametral x grupos, D10-F60.

Nos gráficos das Figuras 5.19 a 5.21 observa-se uma relação quase linear para todos os gráficos. Para um mesmo diâmetro e um mesmo consumo de fibras quanto maior é a resistência à compressão maior é a resistência à tração.

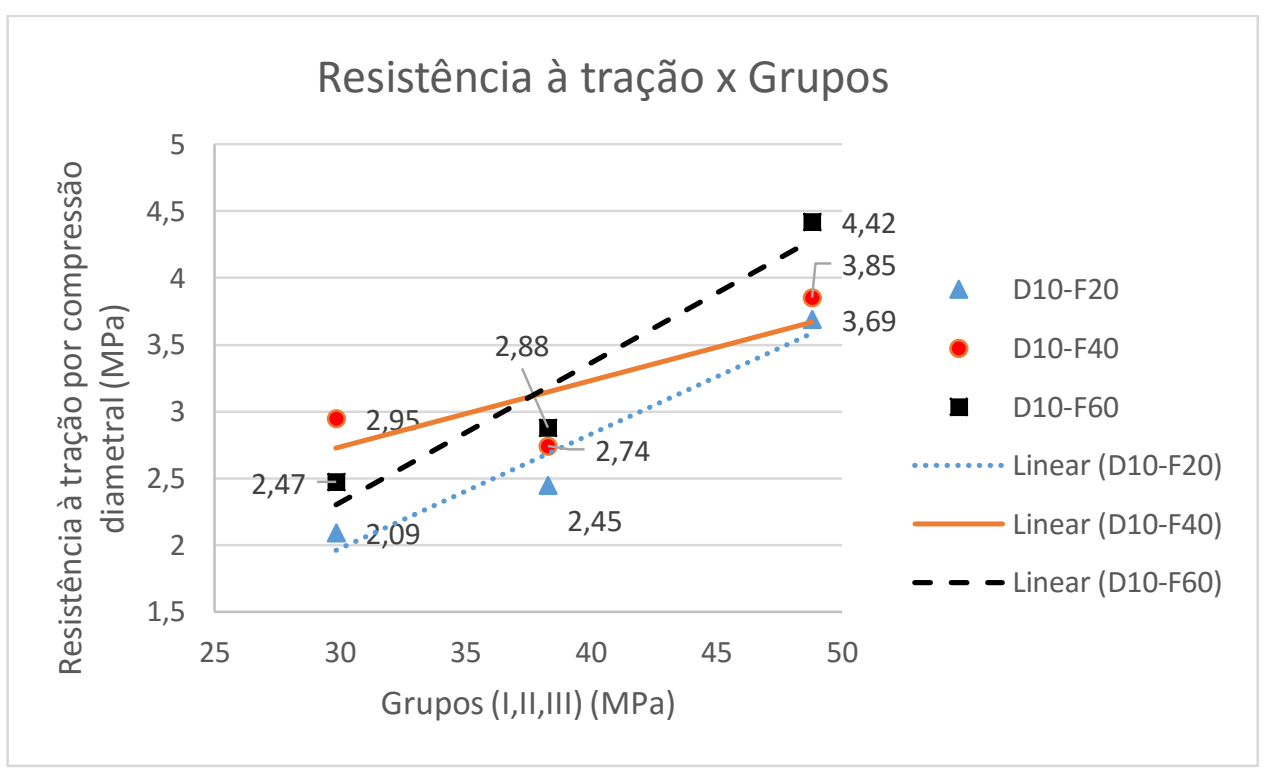

Figura 5.22 - Resistência à tração por compressão diametral x grupos, comparativo D10 consumo 20, 40 e 60.

Na Figura 5.22 verifica-se que para o corpo de prova de $10 \mathrm{~cm}$ de diâmetro o consumo de fibras F40 gerou uma menor variação de resistência à tração com o aumento da resistência à compressão. Esse aumento foi de 30\%, os consumos F20 e F60 tiveram acréscimo de $76 \%$ e $78 \%$, respectivamente. 
Para o grupo I, observa-se que a $f_{t}$ de F40 é 19\% maior que o F60 e 41,14 \% maior que o F20, porém, para o grupo III, o F60 é 14,80\% maior que o F40 e 19,78\% maior que o F20. Para o grupo II, tem-se que para os consumos de fibra houve somente uma variação de $17 \%$.

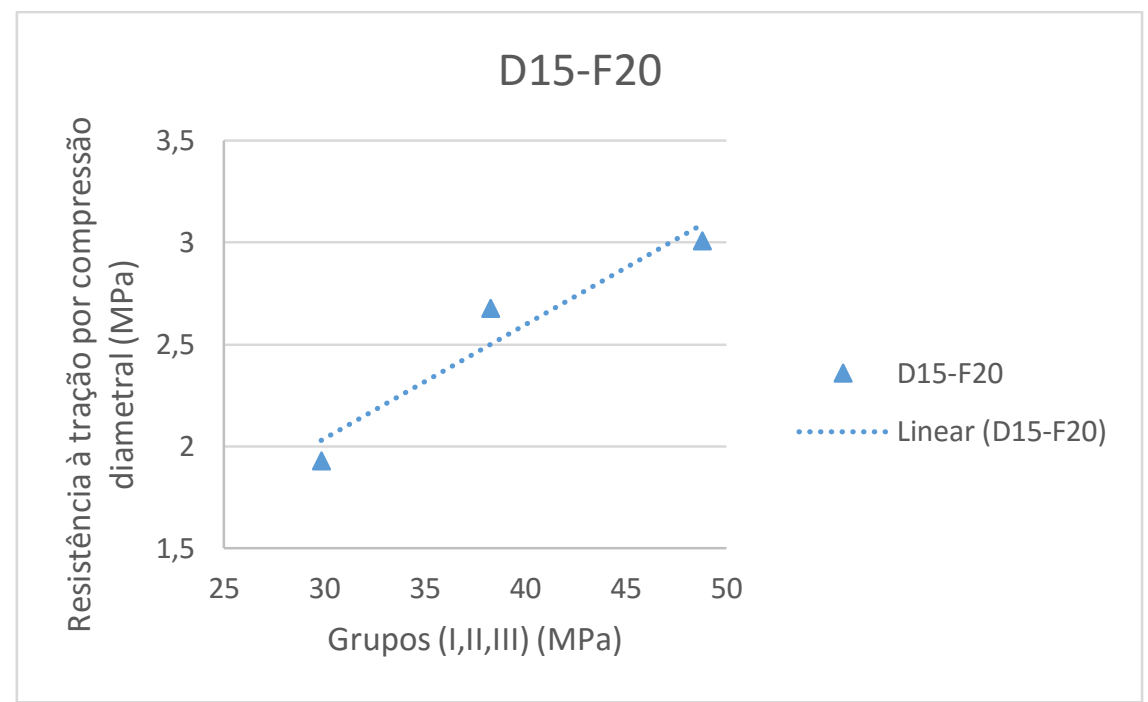

Figura 5.23 - Resistência à tração por compressão diametral x grupos, D15-F20.

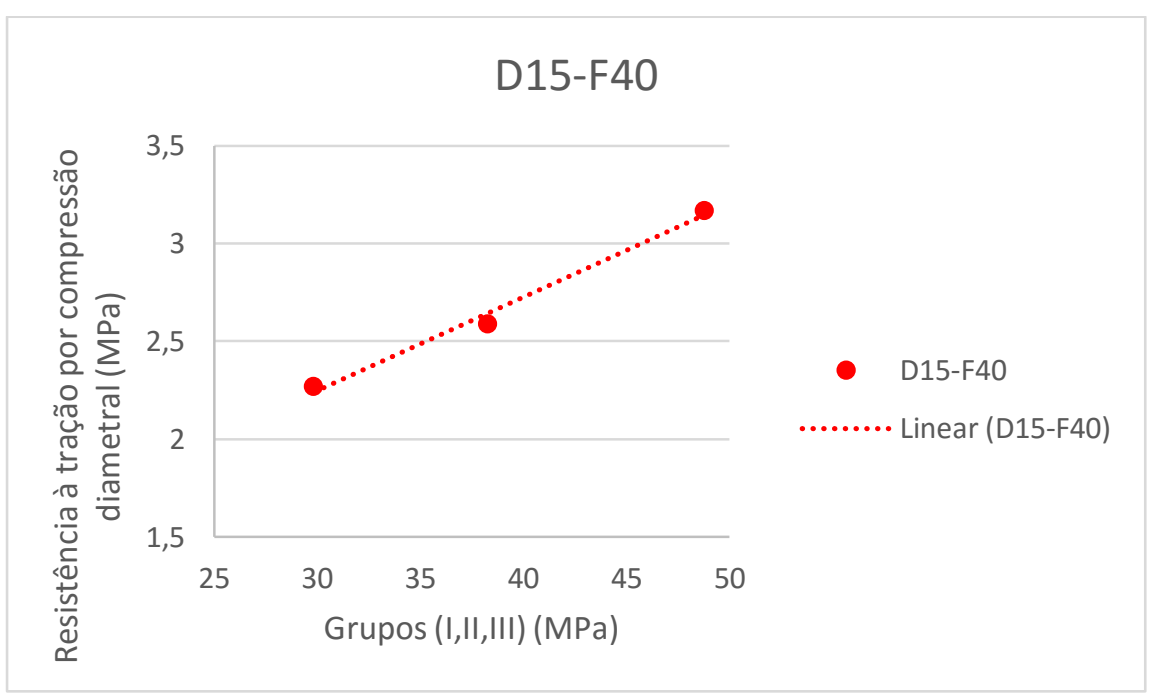

Figura 5.24 - Resistência à tração por compressão diametral x grupos, D15-F40.

Nos gráficos das Figuras 5.23 a 5.25 observa-se uma relação quase linear para todos os gráficos. Para um mesmo diâmetro e um mesmo consumo de fibras quanto maior é a resistência à compressão maior é a resistência à tração. A maior variação de resistência ocorre no consumo de fibras F20, que entre o grupo I e III houve um acréscimo da $f_{t}$ de 55,95\%, enquanto para os consumos de F40 e F60 o acréscimo da $f_{t}$ foi de $39,64 \%$ e $29,91 \%$, respectivamente. 


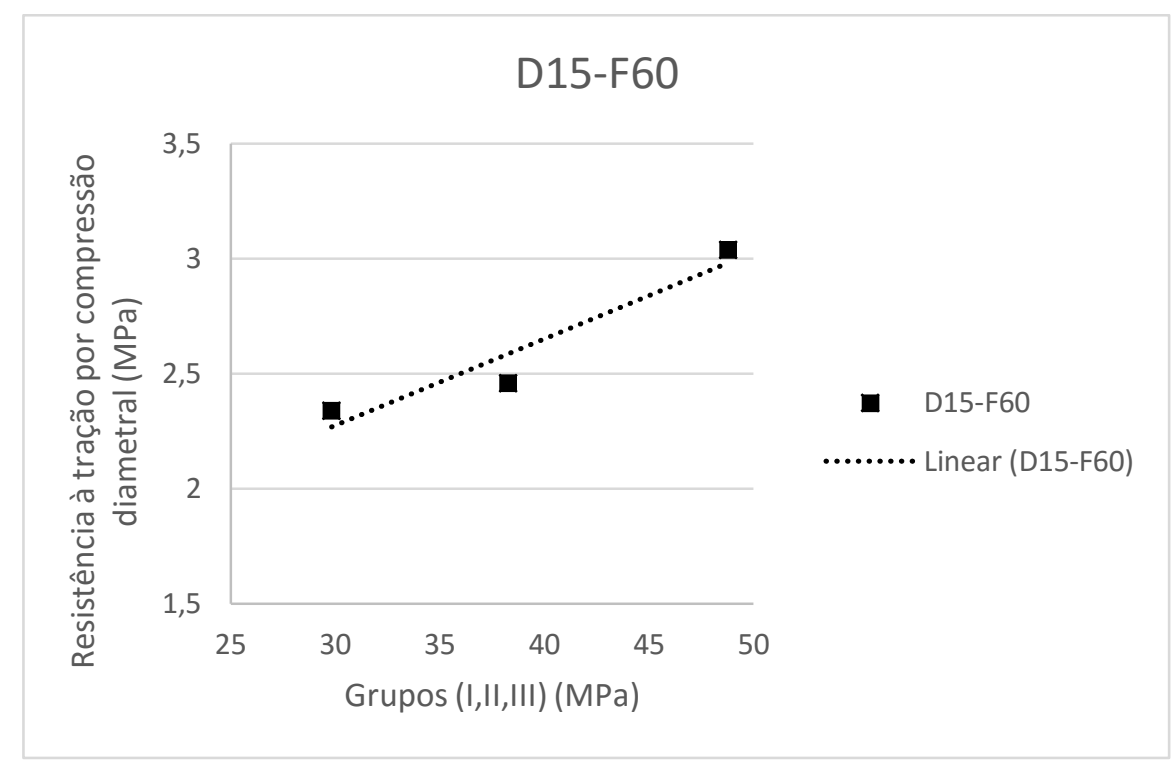

Figura 5.25 - Resistência à tração por compressão diametral x grupos, D15-F60.

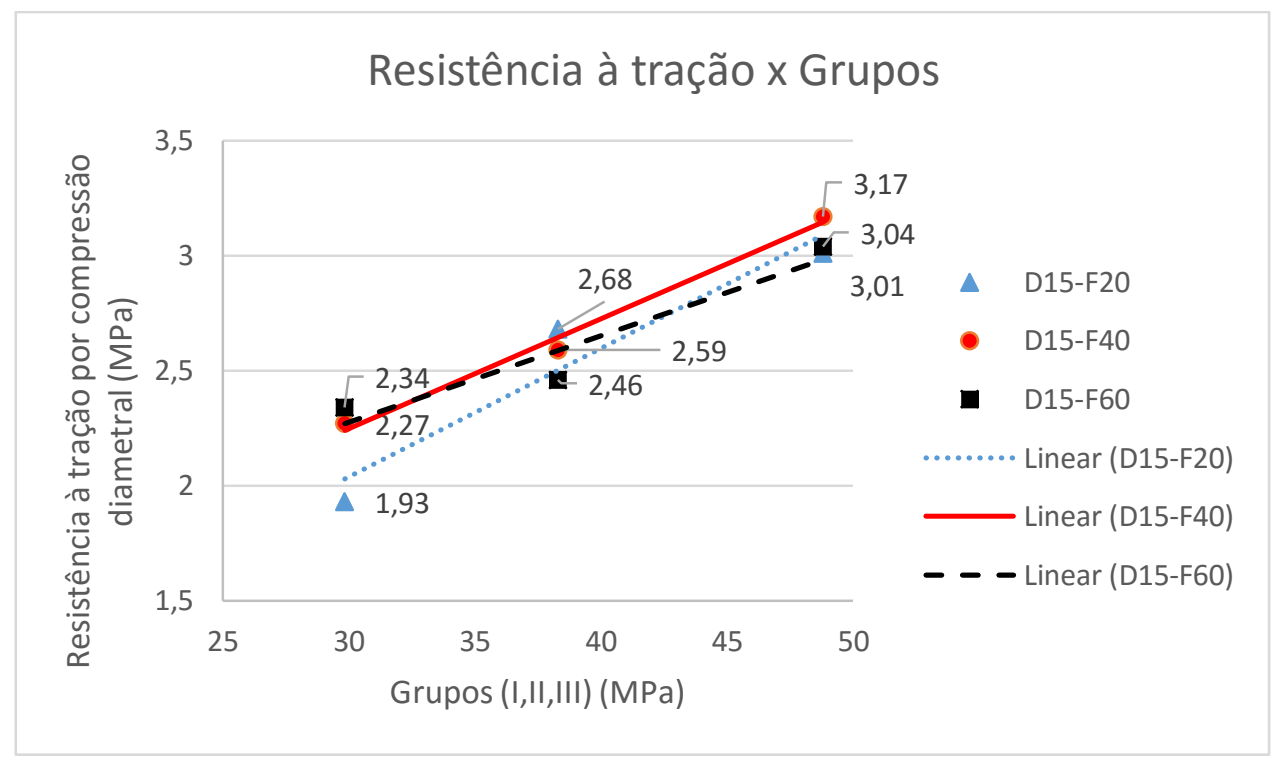

Figura 5.26 - Resistência à tração por compressão diametral x grupos, comparativo D15 consumo F20, 40 e 60.

Na Figura 5.26 tem-se que os valores de $f_{t}$ não variam significativamente com o aumento do consumo, por exemplo, no consumo F60 para o grupo III $(48,80 \mathrm{MPa})$, a resistência à tração é praticamente a mesma para os outros consumos (F20 e F40).

Comparando-se os gráficos das Figuras 5.18, 5.22 e 5.26 observam-se que o consumo de fibras se comparando nos grupos tem mais significância quando se refere ao corpo de prova de menor diâmetro. Para o corpo de prova de maior diâmetro (D15) a influência das fibras quase não foi representativa para a mesma 
$f_{c}$, ou seja, o consumo de fibras tem menor influência na resistência à tração quando o corpo de prova tem maiores dimensões.

\subsection{5}

\section{Gráficos $f_{t} \times$ diâmetro}

Os gráficos das Figuras 5.27 a 5.38 apresentam os dados dos corpos de prova dos ensaios realizados de acordo com o item 4.2.1.2 e 4.2.1.3.

Os parâmetros que são analisados são o grupo e o consumo de fibras. A Resistência à tração por compressão diametral é estudada em função do diâmetro dos corpos de prova. A nomenclatura dos gráficos das Figuras 5.27 a 5.38 é:

- F20, F40 e F60 - consumo de fibras;

- I, II e III - grupos.

Todas as siglas utilizadas são descritas no Capítulo 4.

Por exemplo a Figura 5.27 ilustra o comportamento da Resistência à tração por compressão diametral versus o diâmetro de corpos de prova com consumo de $20 \mathrm{~kg} / \mathrm{m}^{3}$ de fibras e com resistência à compressão de 29,84 MPa.

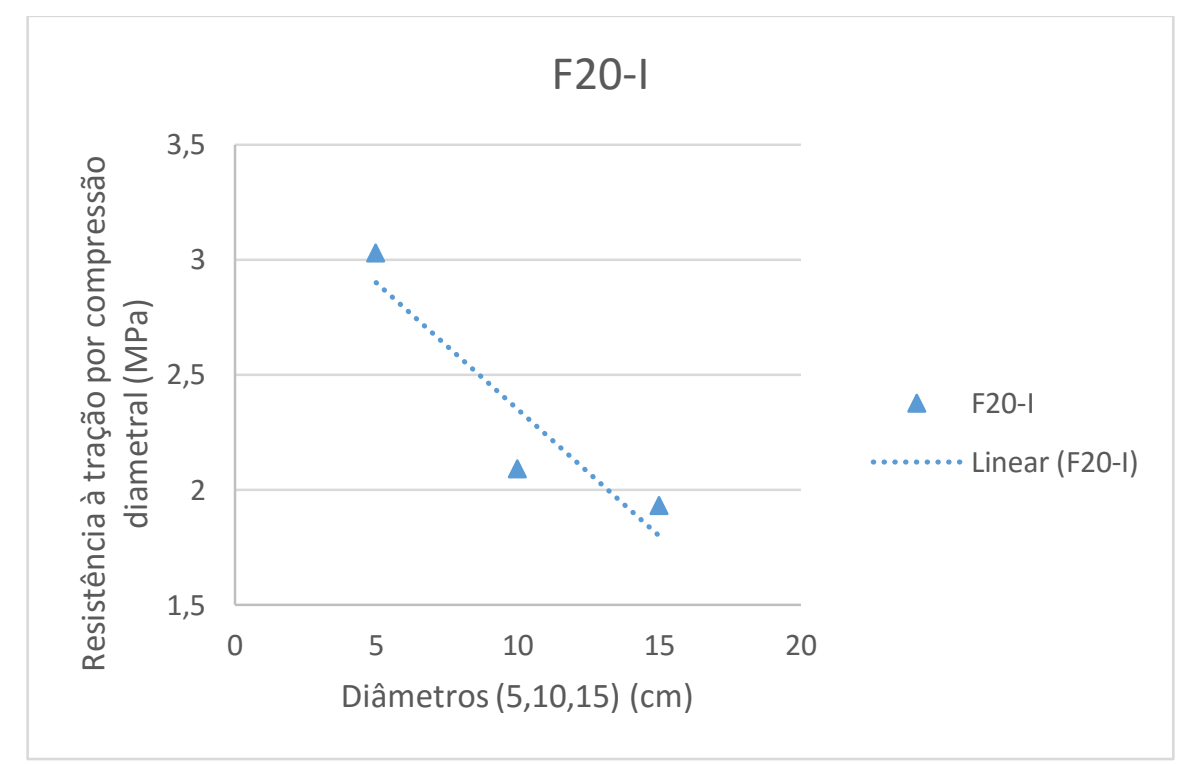

Figura 5.27 - Resistência à tração por compressão diametral x diâmetro, F20-I.

Observa-se nas Figuras 5.27 a 5.29 um decréscimo da resistência a tração com o acréscimo do diâmetro. 


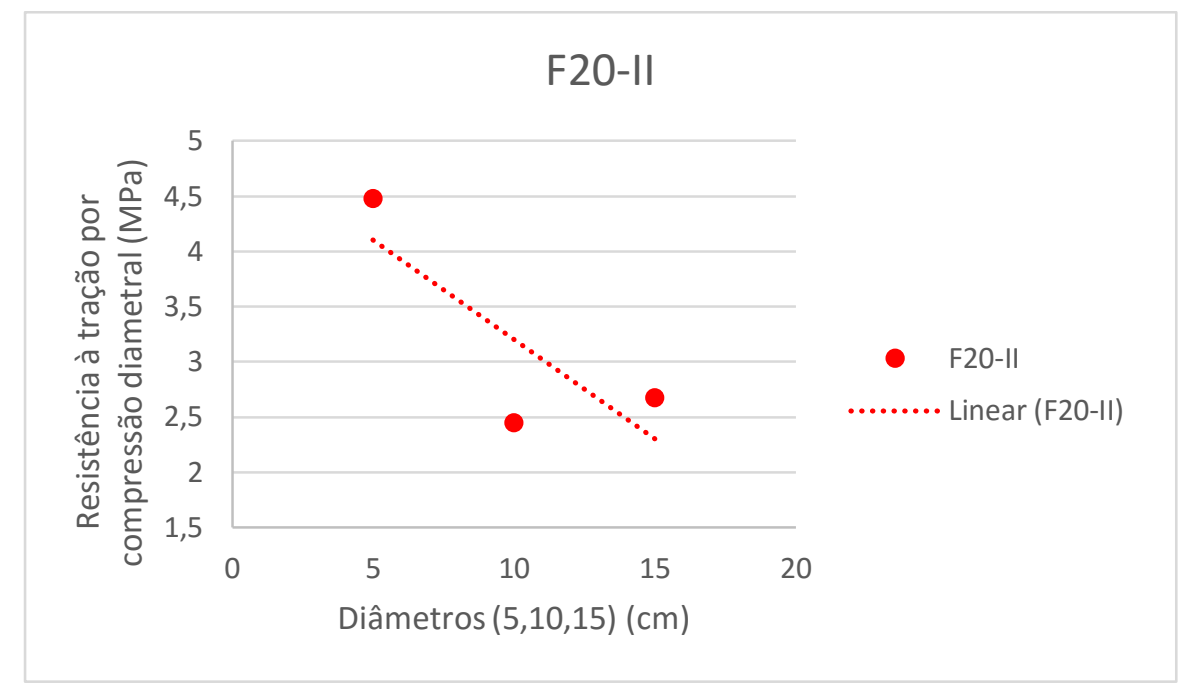

Figura 5.28 - Resistência à tração por compressão diametral x diâmetro, F20-II.

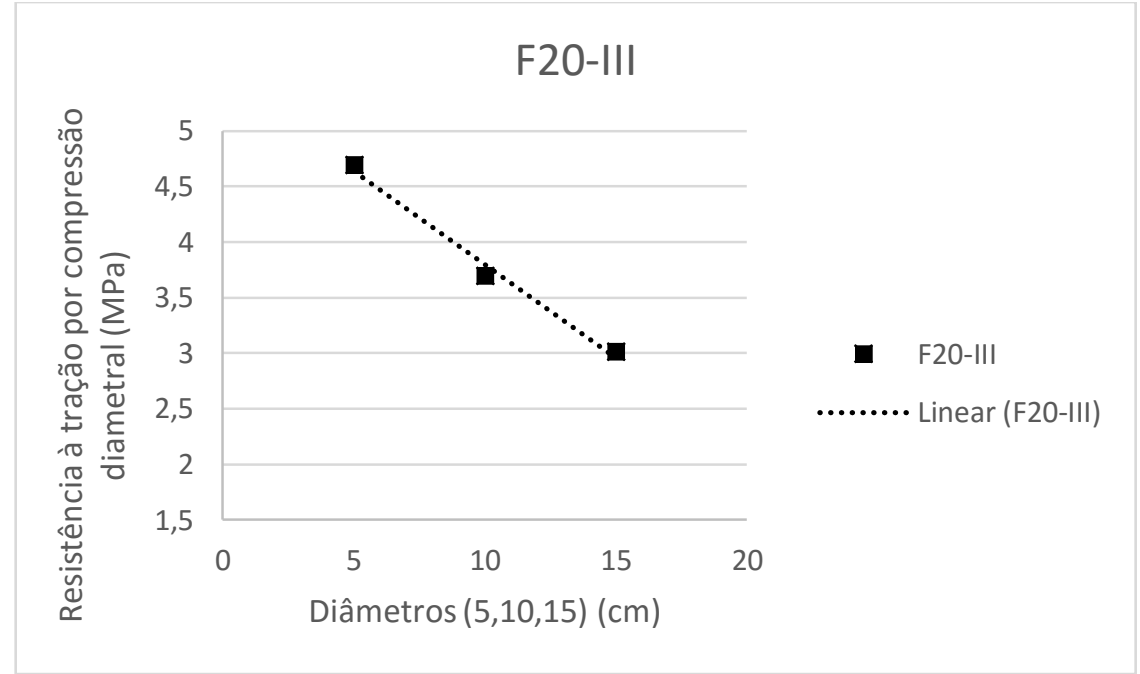

Figura 5.29 - Resistência à tração por compressão diametral x diâmetro, F20-III.

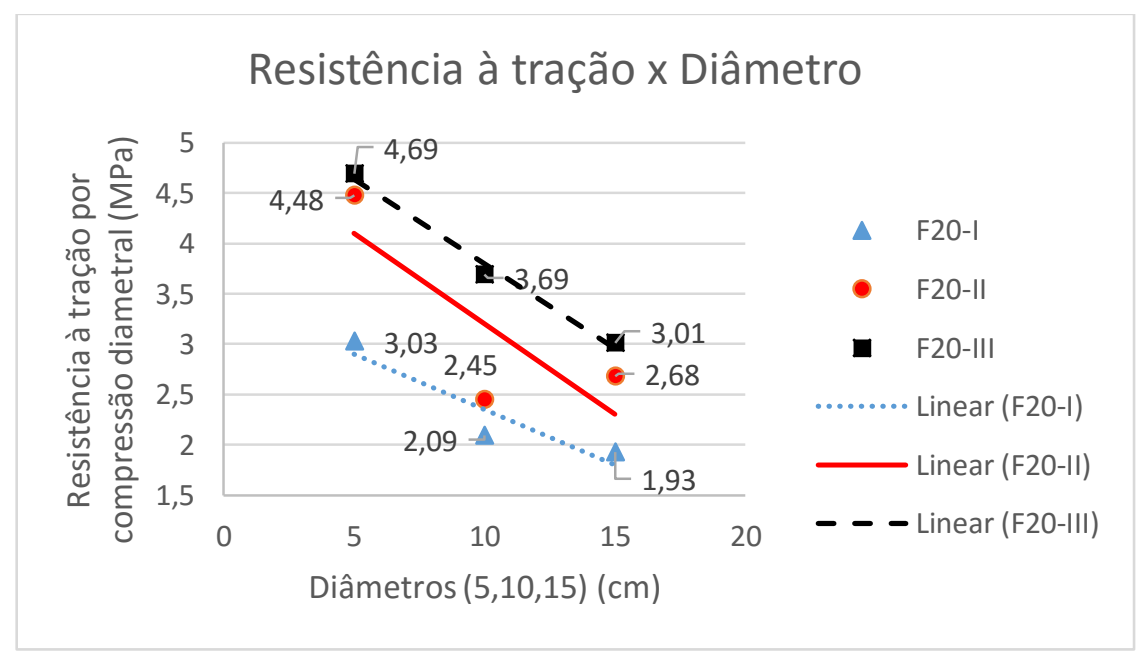

Figura 5.30 - Resistência à tração por compressão diametral x diâmetro, comparação F20 com os grupos I, II, III. 
Na Figura 5.30 observa-se que com o acréscimo do diâmetro há decréscimo da resistência à tração da ordem de 36,30\% para o grupo I, 40,70\% e 35,82\% para os grupos II e III, respectivamente.

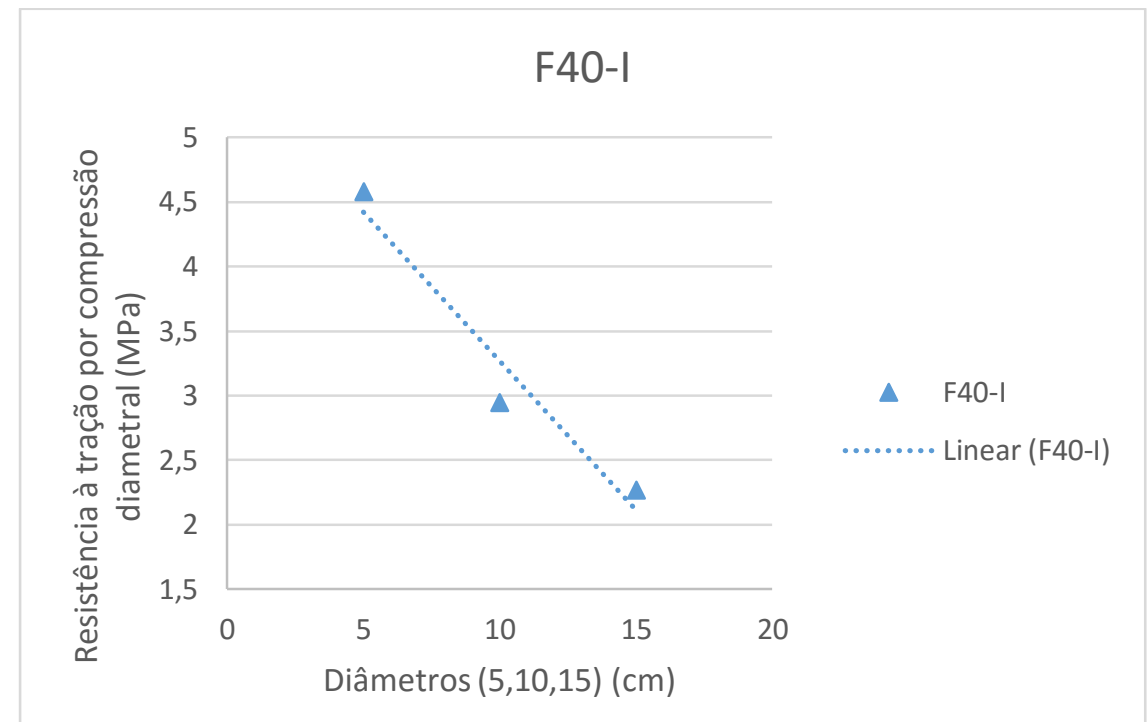

Figura 5.31 - Resistência à tração por compressão diametral x diâmetro, F40-I.

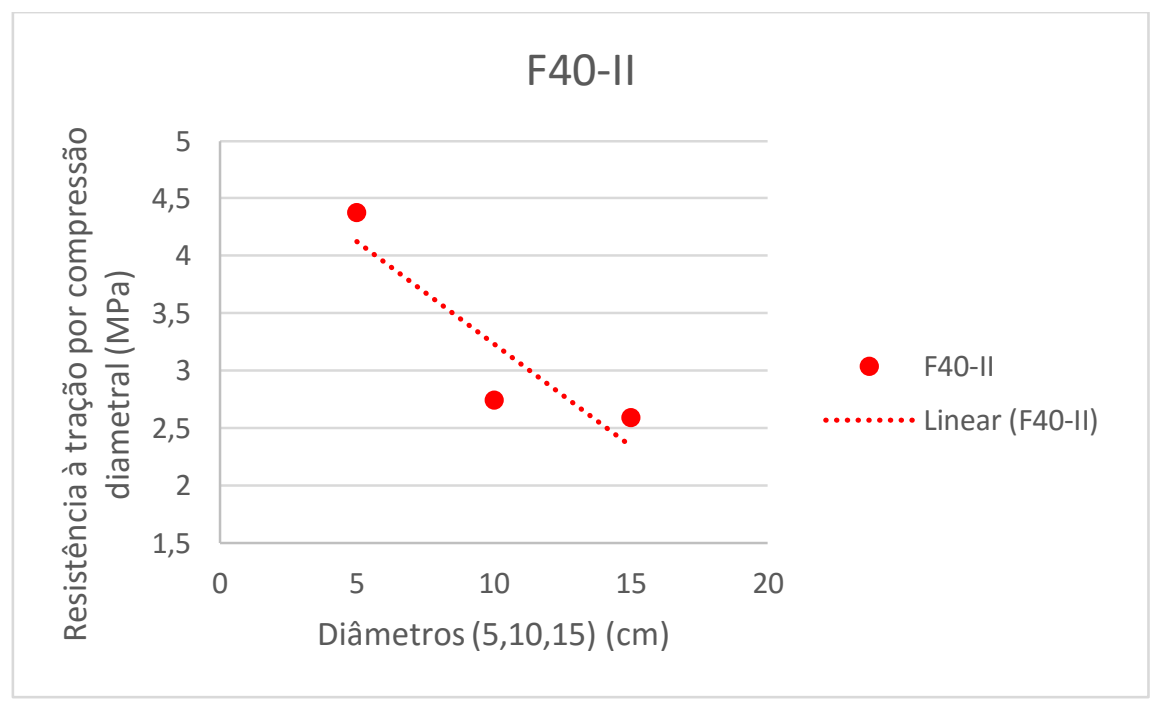

Figura 5.32 - Resistência à tração por compressão diametral x diâmetro, F40-II.

Nas Figuras 5.31 a 5.33 tem-se um decréscimo da resistência à tração com o acréscimo do diâmetro. 


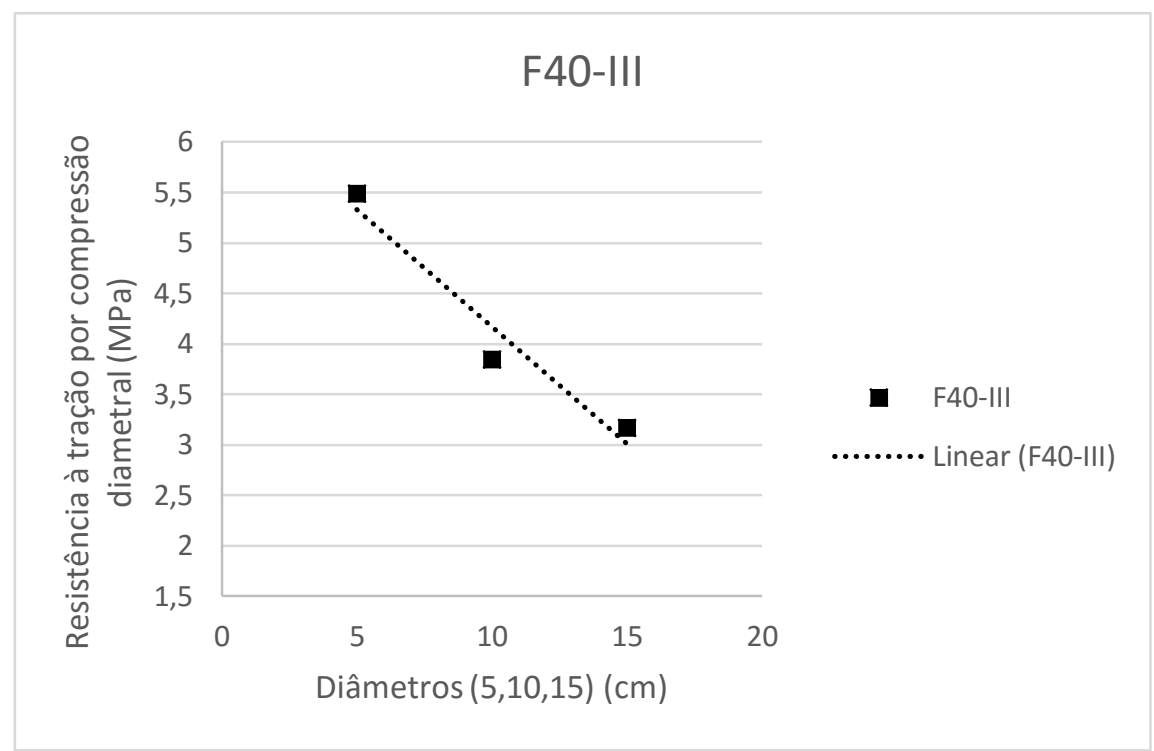

Figura 5.33 - Resistência à tração por compressão diametral x diâmetro, F40-III.

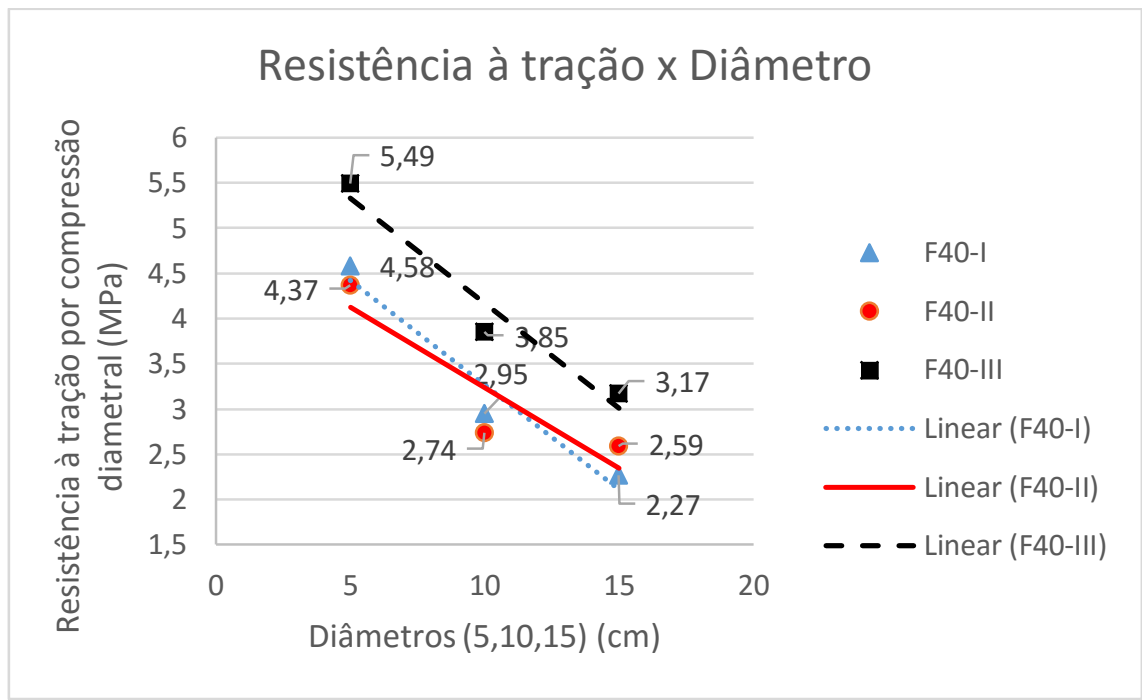

Figura 5.34 - Resistência à tração por compressão diametral x diâmetro, comparação F40 com os grupos I, II e III.

Na Figura 5.34 observa-se que com o acréscimo do diâmetro há decréscimo da resistência à tração da ordem de 50,43\% para o grupo I, 40,73\% para o grupo II, e um decréscimo de $42,25 \%$ para o grupo III. 


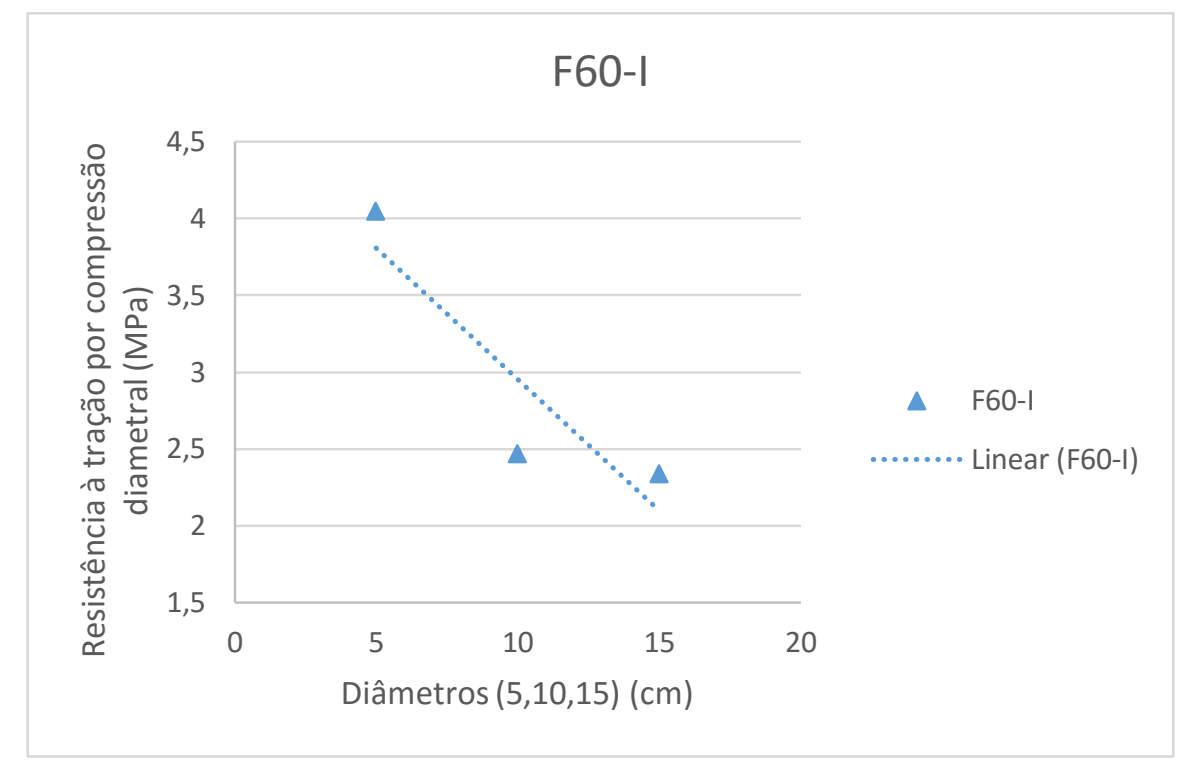

Figura 5.35 - Resistência à tração por compressão diametral x diâmetro, F60-I.

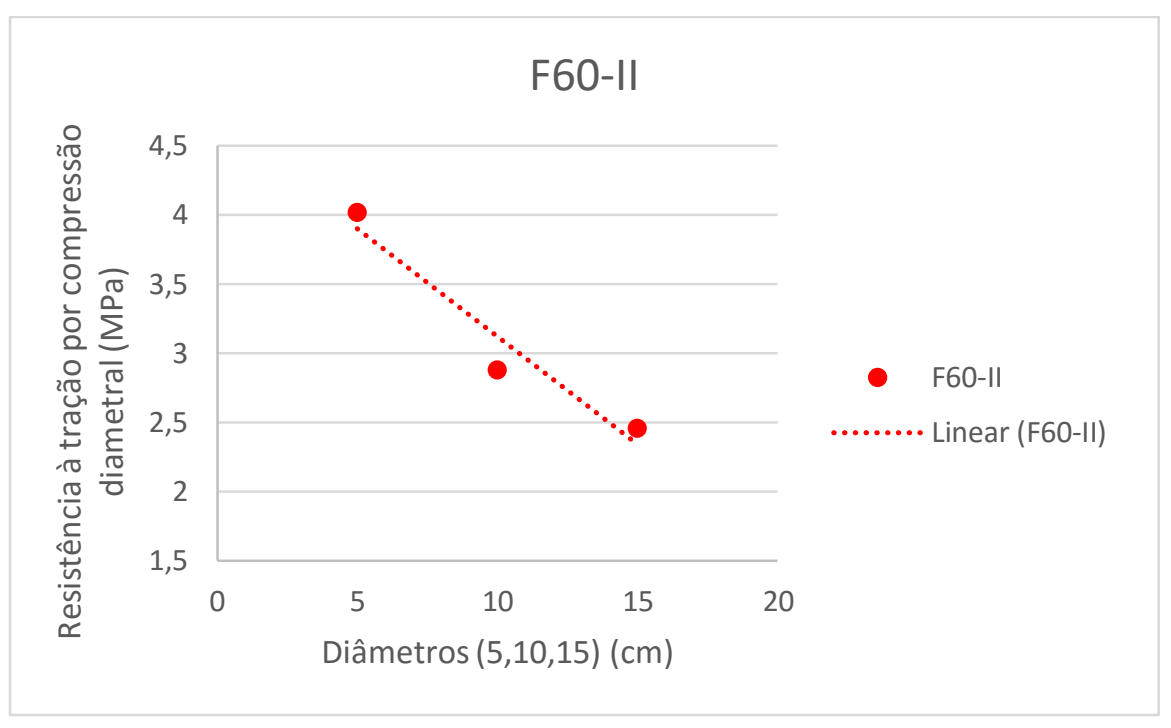

Figura 5.36 - Resistência à tração por compressão diametral x diâmetro, F60-II.

Nas Figuras 5.35 a 5.37 observa-se um decréscimo da resistência à tração com o acréscimo do diâmetro. 


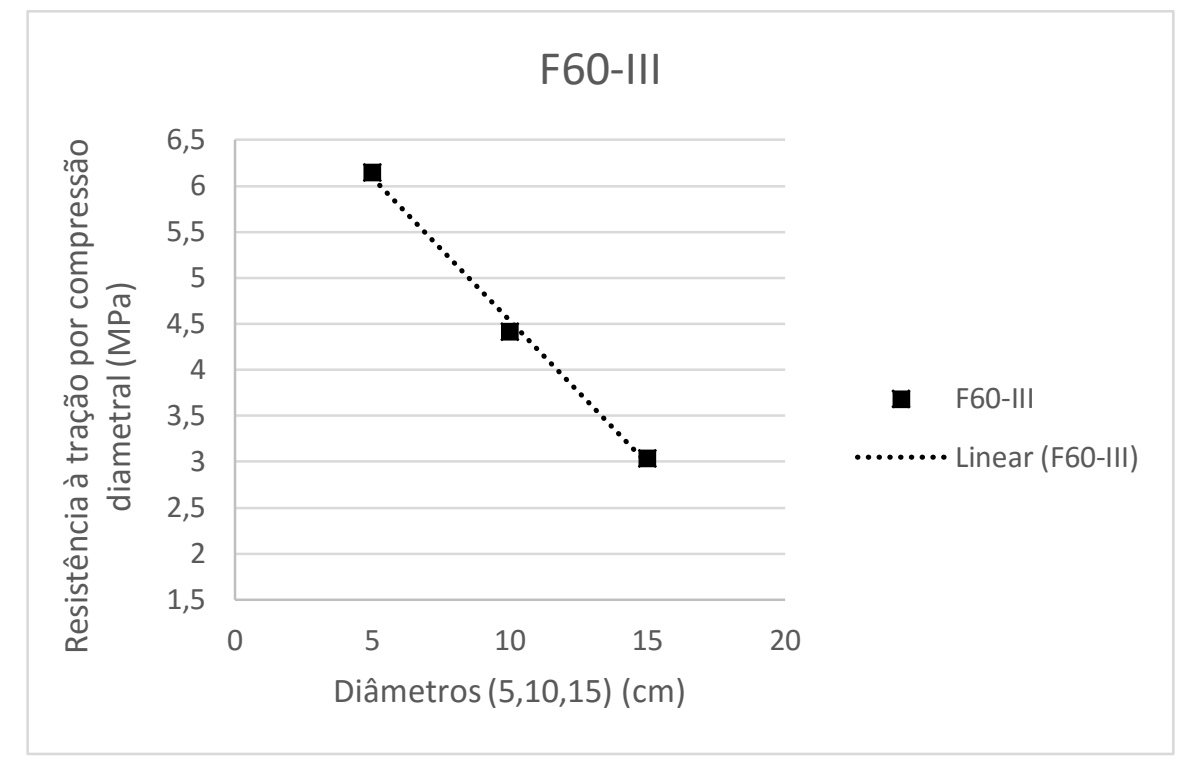

Figura 5.37 - Resistência à tração por compressão diametral x diâmetro, F60-III.

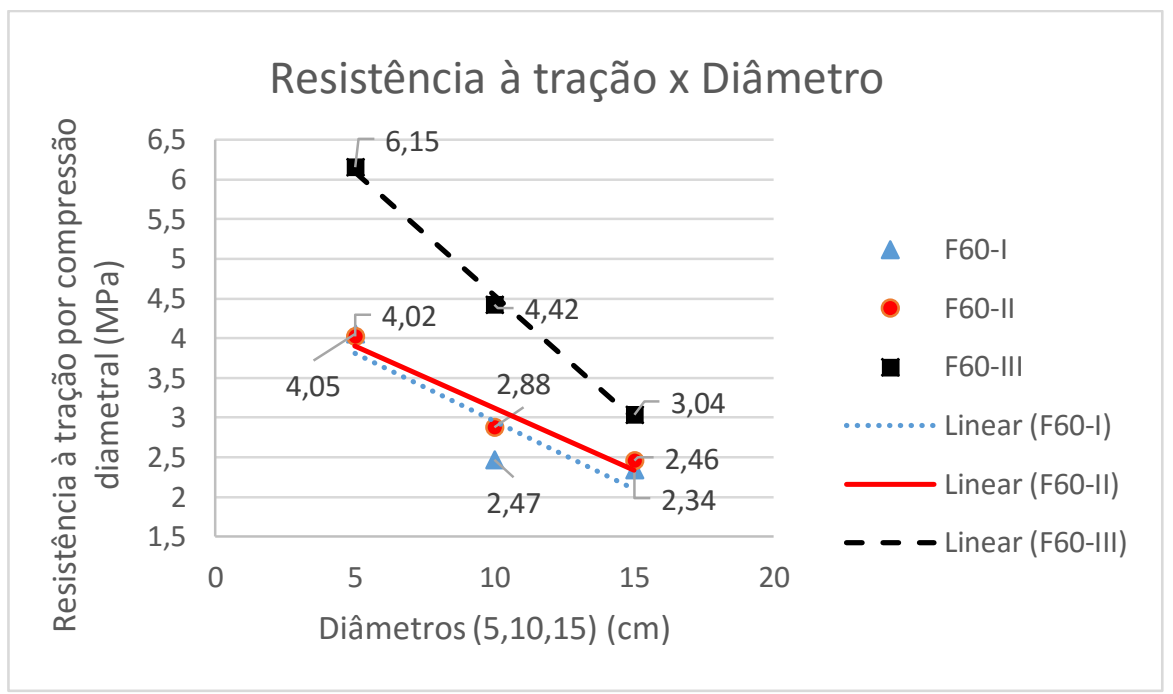

Figura 5.38 - Resistência à tração por compressão diametral x diâmetro, comparação F40 com os grupos I, II e III.

$\mathrm{Na}$ Figura 5.38, como visto nas Figuras 5.30 e 5.34, o decréscimo da resistência à tração ocorre devido ao acréscimo do diâmetro. Esse decréscimo é da ordem de $42,22 \%$ para o grupo I, 38,8\% para o grupo II e 50,56\% para o grupo III.

A Tabela 5.6 mostra resumidamente os decréscimos da resistência à tração de cada série de acordo com o aumento do diâmetro do corpo de prova. 
Tabela 5.6 - Decréscimo da resistência a tração por compressão diametral.

\begin{tabular}{c|c|c|c|c|c}
\cline { 2 - 6 } & Decréscimo \% & & Decréscimo \% & & Decréscimo \% \\
\hline F20-I & 36,30 & F40-I & 50,43 & F60-I & 42,22 \\
\hline F20-II & 40,17 & F40-II & 40,73 & F60-II & 38,80 \\
\hline F20-III & 35,82 & F40-III & 42,25 & F60-III & 50,56 \\
\hline
\end{tabular}

Para a resistência de 29,84 MPa o maior decréscimo de $f_{t}$ foi para o consumo de $40 \mathrm{~kg} / \mathrm{m}^{3}$. Para a resistência de 38,29 MPa esse decréscimo se manteve próximo para as três quantidades de consumo. Para a $f_{c}=48,80 \mathrm{MPa}$ o maior decréscimo observado foi para o consumo de $60 \mathrm{~kg} / \mathrm{m}^{3}$.

\subsection{6}

\section{Gráficos $\Psi$ x consumo}

Nas Figuras 5.39 a 5.50 denomina-se $\Psi$ a razão entre a resistência à tração por compressão diametral obtida no ensaio do item 4.2.1.3 pela resistência à tração direta obtida no ensaio do 4.2.1.1.

$$
\Psi=\frac{f_{t D, i}}{f_{\text {dir }, \text { médio }}}
$$

As Figuras 5.39 a 5.41 mostram a variação da razão $\Psi$ em função do consumo de fibras de cada diâmetro do grupo I.

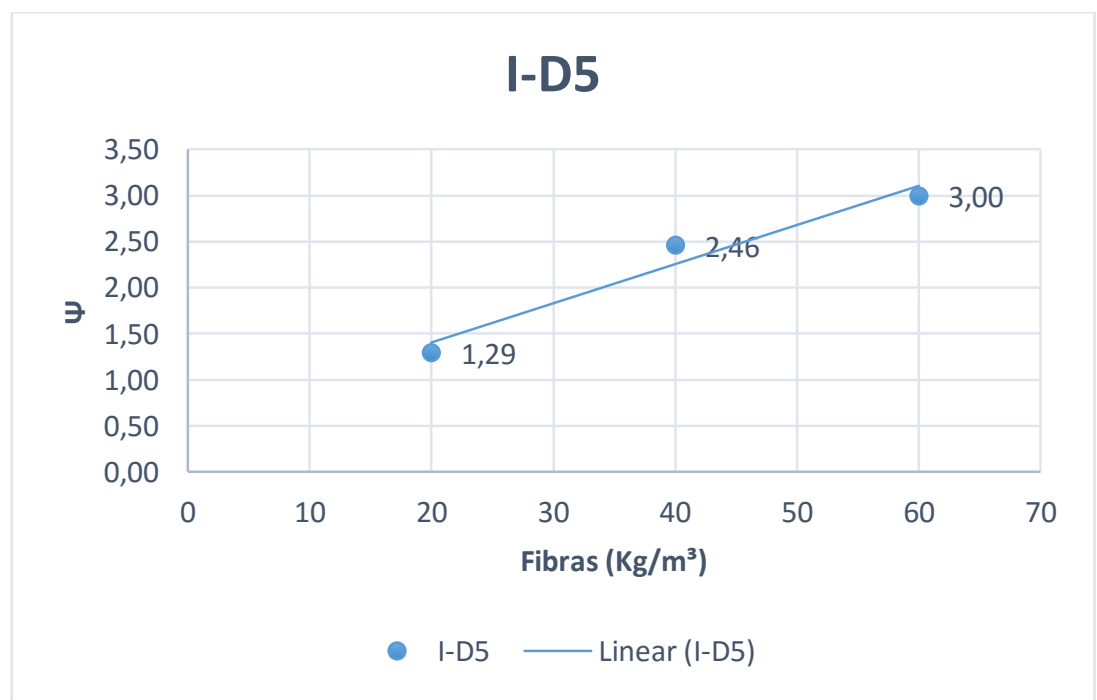

Figura $5.39-\Psi \times$ consumo, I-D5. 


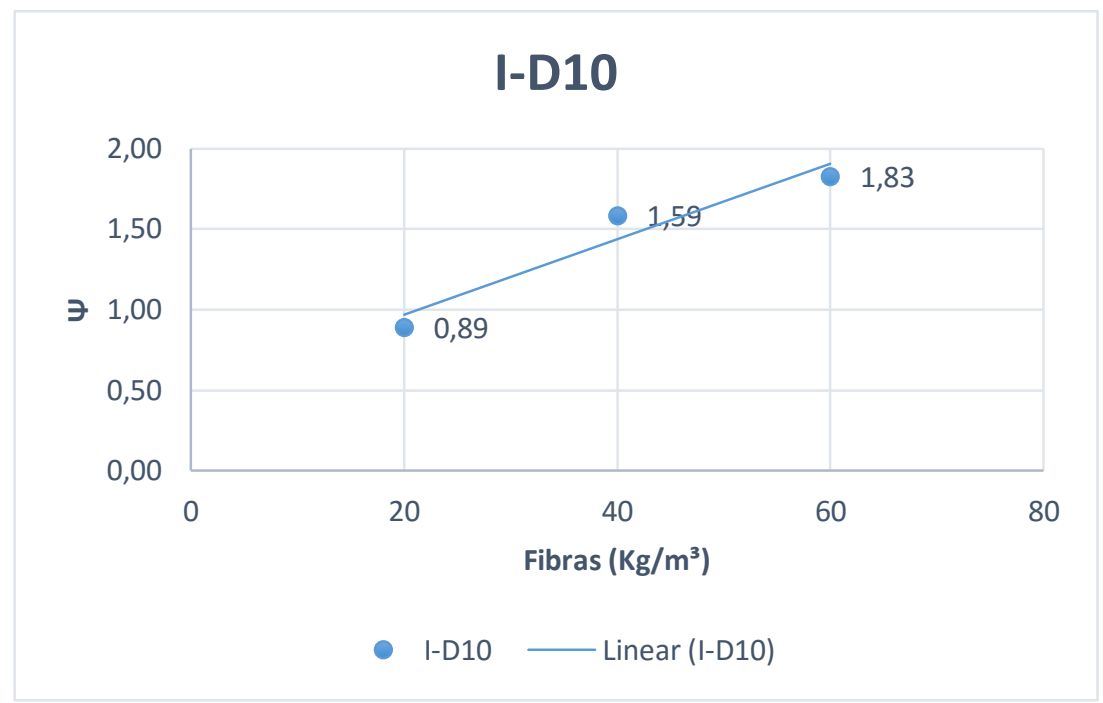

Figura $5.40-\Psi \times$ consumo, I-D10.

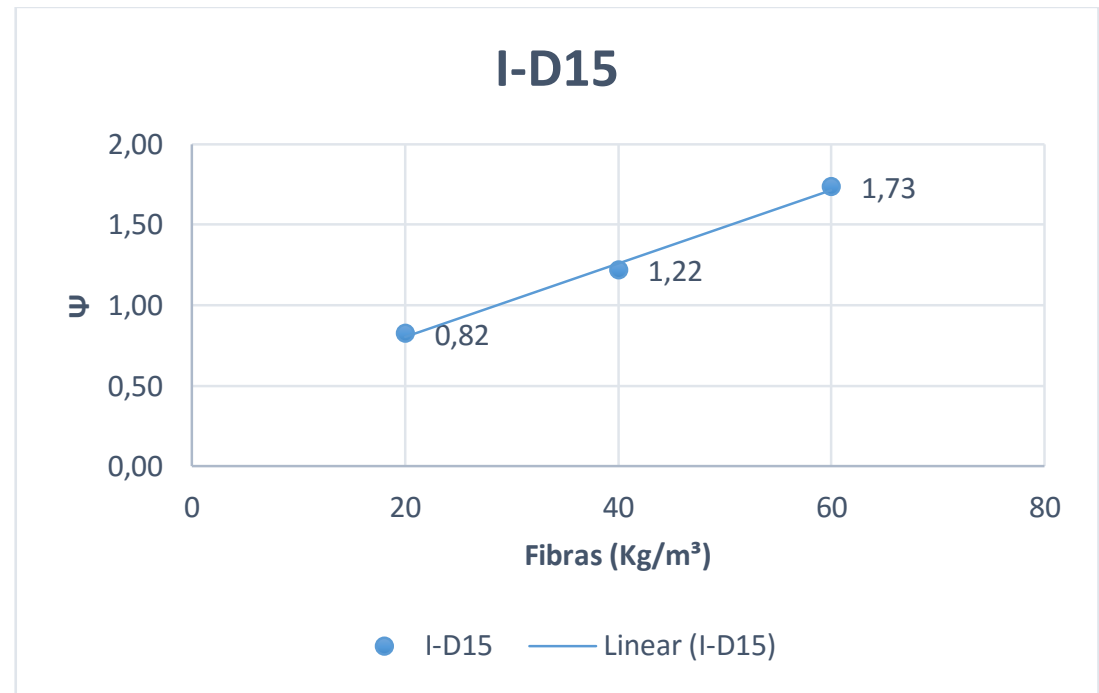

Figura $5.41-\Psi \times$ consumo, I-D15.

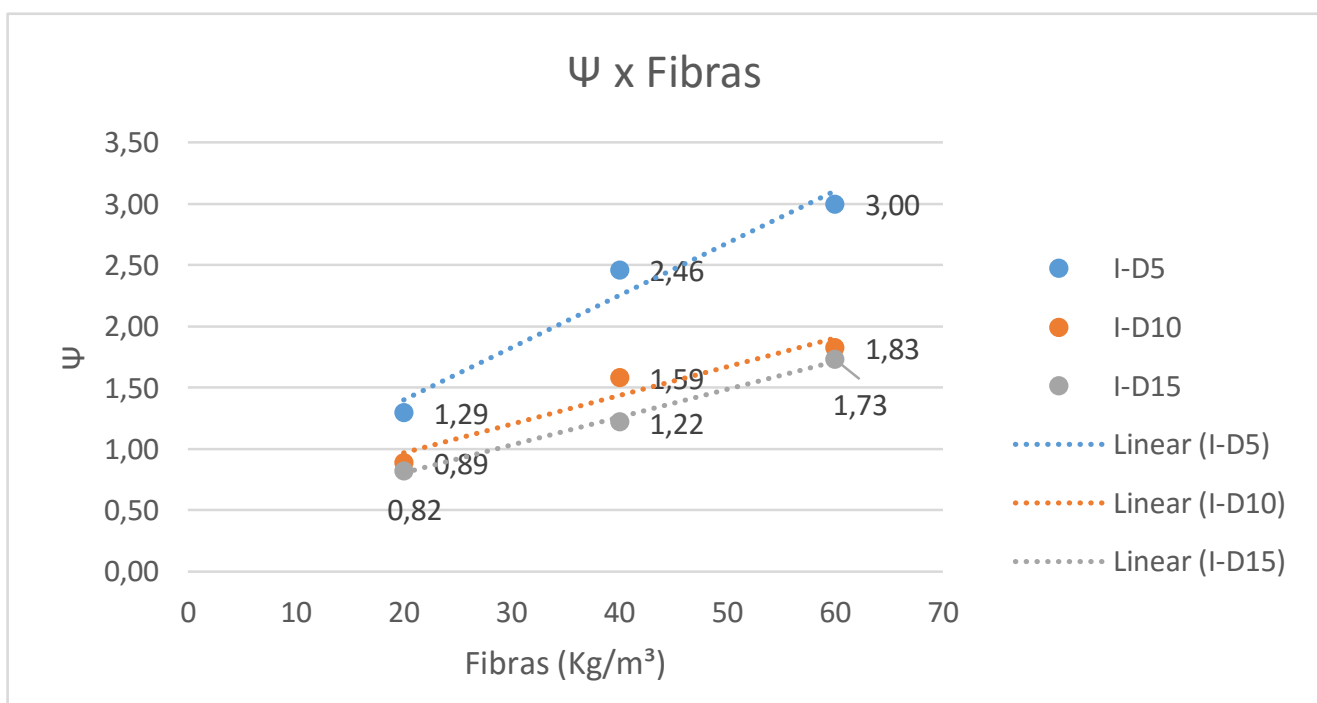

Figura 5.42 - Gráficos comparativos de $\Psi$ x consumo, grupo I. 
Os gráficos da Figura 5.42 apresentam as seguintes características:

- quanto maior é o consumo de fibras maior é $\Psi$;

- o maior acréscimo de $\Psi$ em relação ao consumo de fibras F20 para F40 foi do diâmetro D5, que teve um aumento de $90,69 \%$, enquanto os D10 e D15 tiverem aumentos de 78,65\% e 48,78\%, respectivamente;

- o maior acréscimo de $\Psi$ em relação ao consumo de fibras F40 para F60 foi do diâmetro D15, que teve um aumento de $41,80 \%$, enquanto os D5 e D10 aumentaram em 21,95\% e 15,09 \%, respectivamente;

- o maior acréscimo de $\Psi$ em relação ao consumo de fibras F20 para F60 foi do diâmetro D5, que teve um aumento de 132,55\%, enquanto os D10 e D15 aumentaram em 105,61\% e 110,97 \%, respectivamente;

- com o diâmetro menor do corpo de prova, $\Psi$ é maior para todos os valores de consumo de fibras adotados.

As Figuras 5.43 a 5.45 apresentam a razão de $\Psi$ pelo consumo de fibras de cada diâmetro do grupo II.

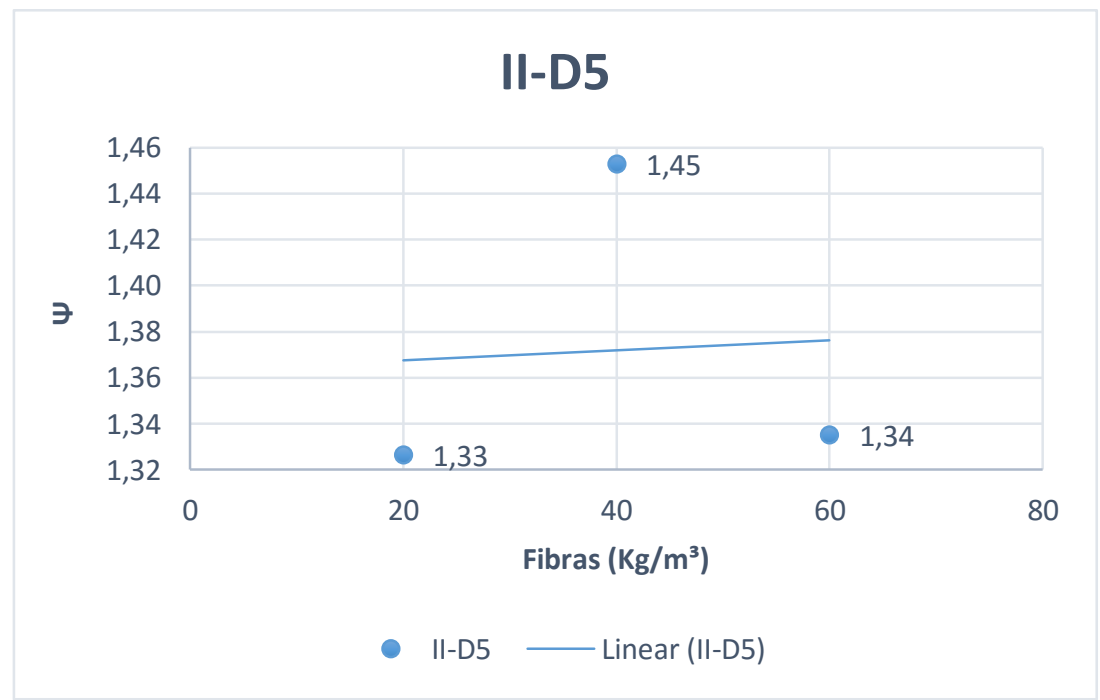

Figura $5.43-\Psi$ x consumo, II-D5. 


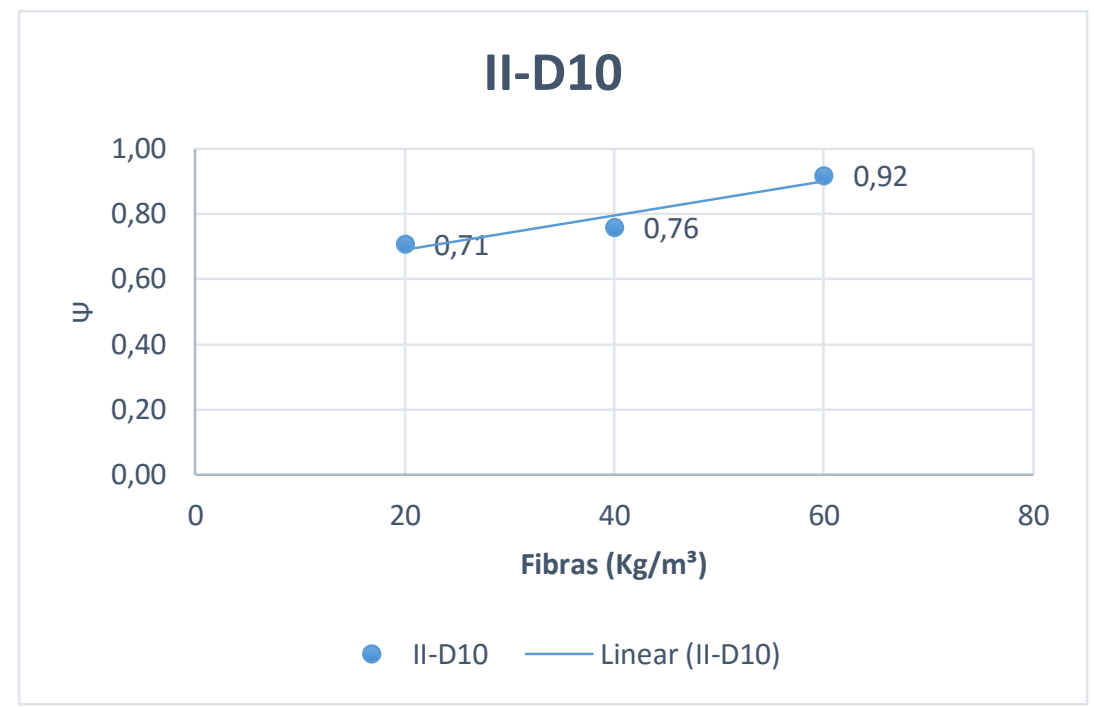

Figura $5.44-\Psi \times$ consumo, II-D10.

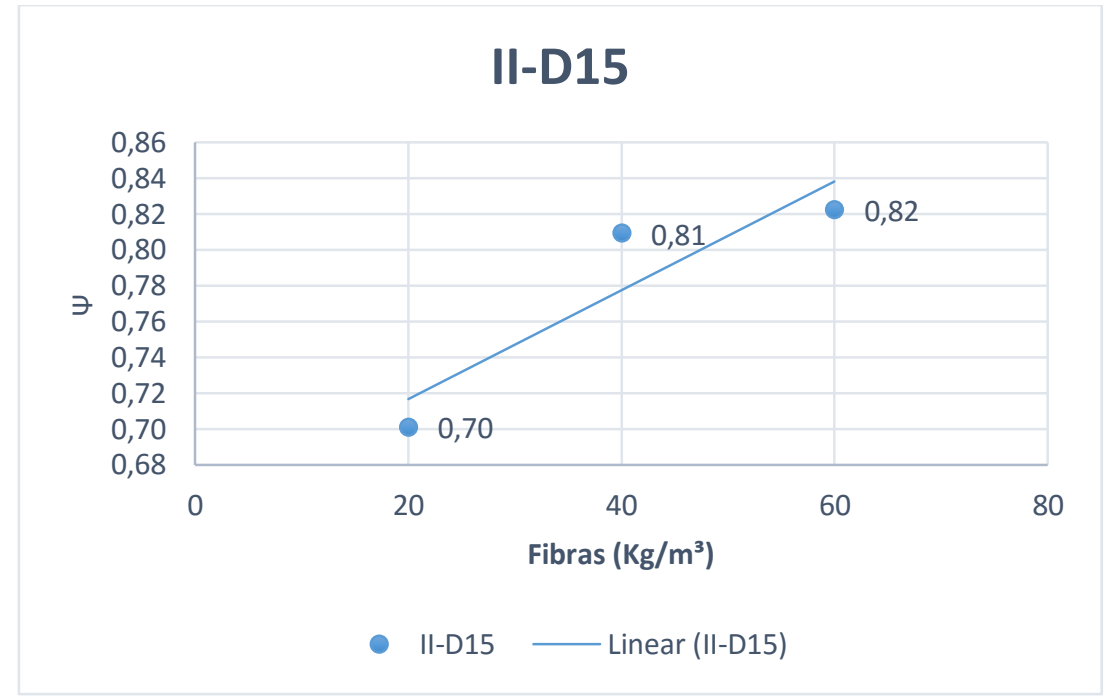

Figura $5.45-\Psi \times$ consumo, II-D15.

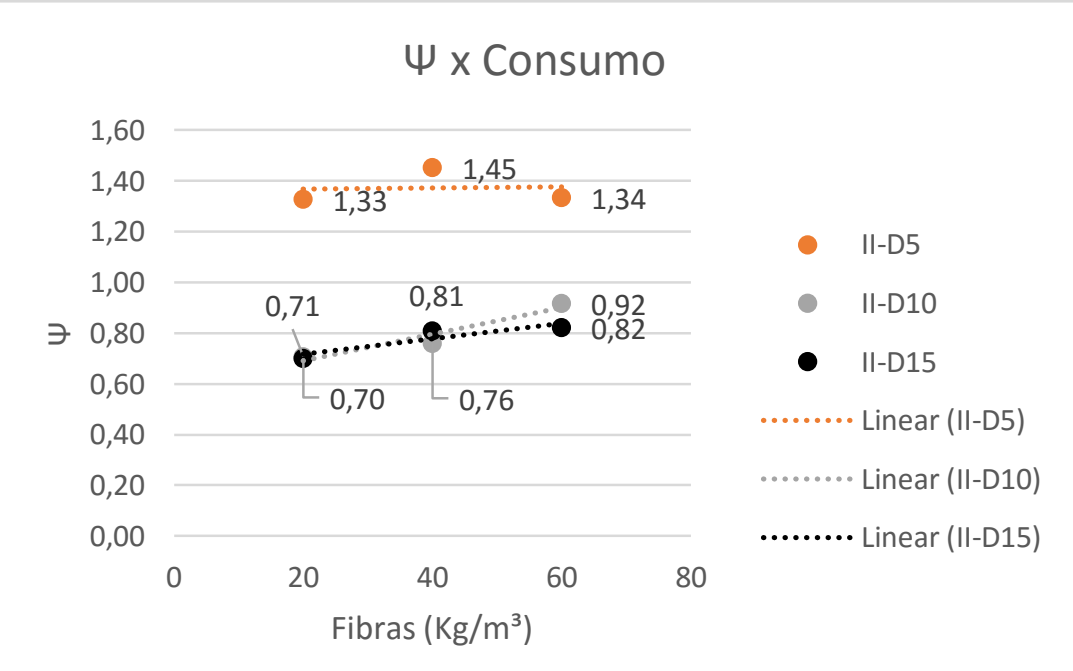

Figura 5.46 - Gráficos comparativos de $\Psi$ x consumo, grupo II. 
Os gráficos das Figura 5.46 apresentam as seguintes características:

- com o diâmetro menor do corpo de prova, $\Psi$ é maior para todos os valores de consumo de fibras adotados;

- as curvas de tendência de $\Psi$ tiverem acréscimo com o aumento de fibras.

As Figuras 5.47 a 5.49 apresentam a razão $\Psi$ pelo consumo de fibras de cada diâmetro do grupo III.

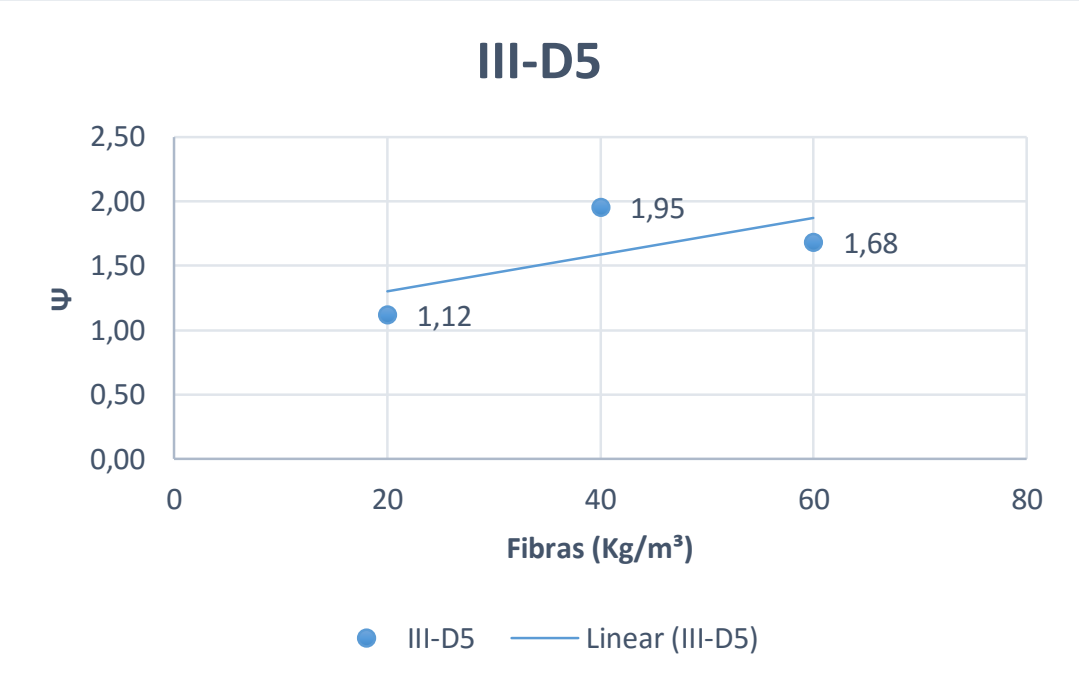

Figura $5.47-\Psi$ x consumo, III-D5.

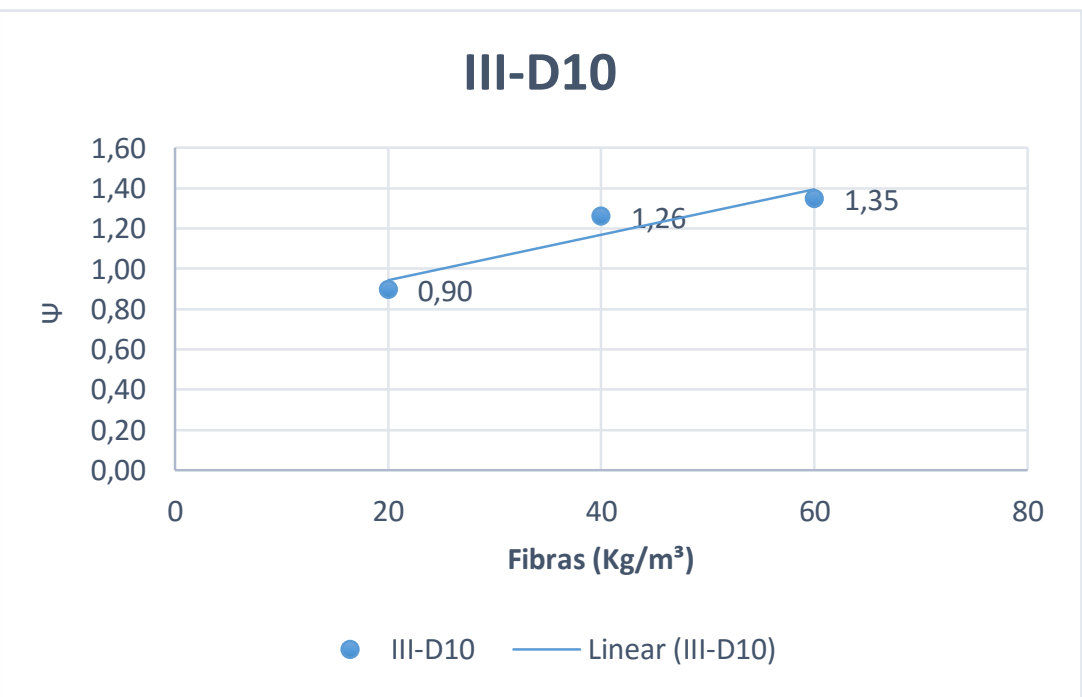

Figura $5.48-\Psi$ x consumo, III-D10. 


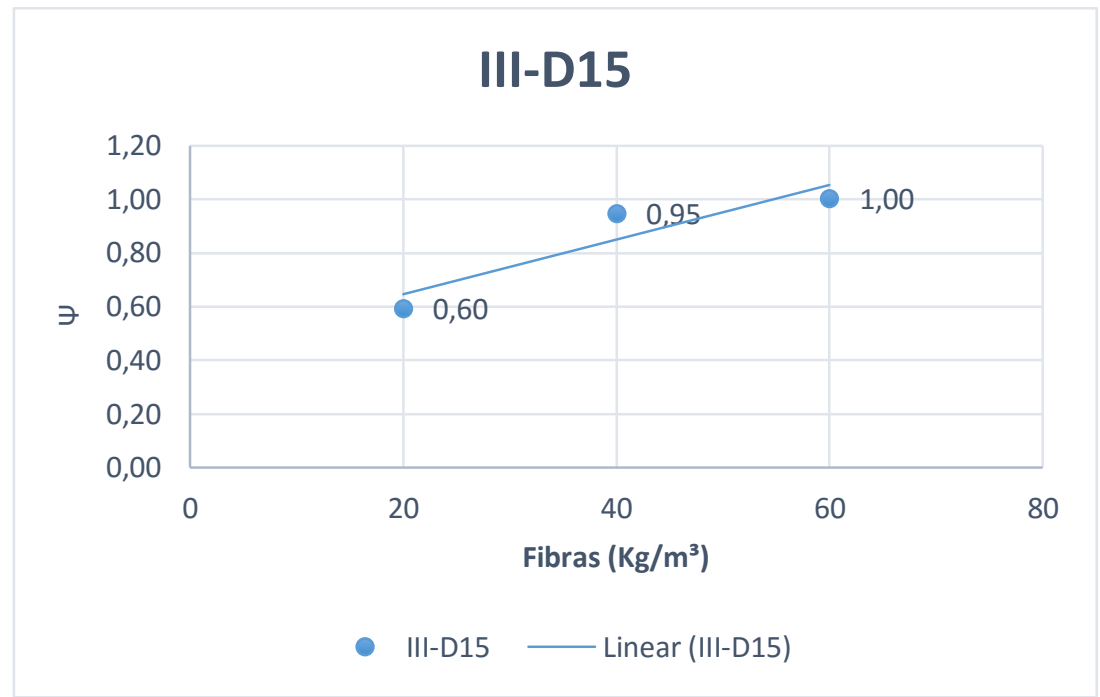

Figura $5.49-\Psi \times$ consumo, III-D15.

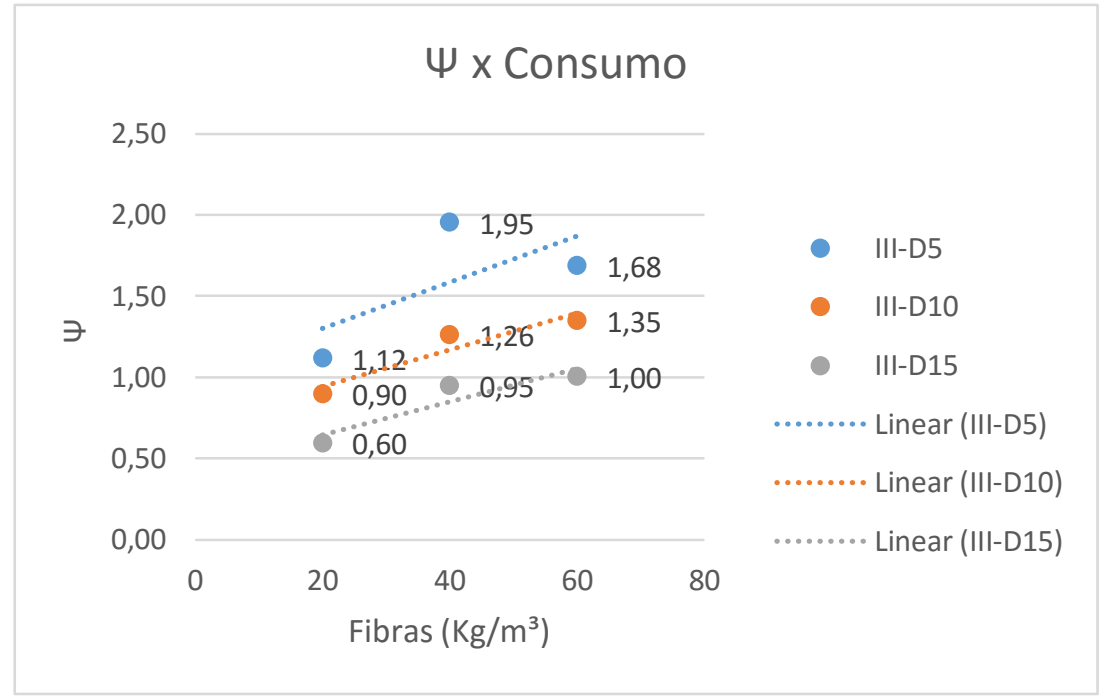

Figura 5.50 - Gráficos comparativos de $\Psi$ x consumo, grupo III.

\subsection{7}

Gráficos $\Psi$ x diâmetro

Nas Figuras 5.51 a 5.62 tem para a razão $\Psi$ os resultados encontrados no item anterior por meio da equação 5.1.

As Figuras 5.51 a 5.53 mostram a variação da razão $\Psi$ em função do diâmetro de cada consumo de fibras no grupo I. 


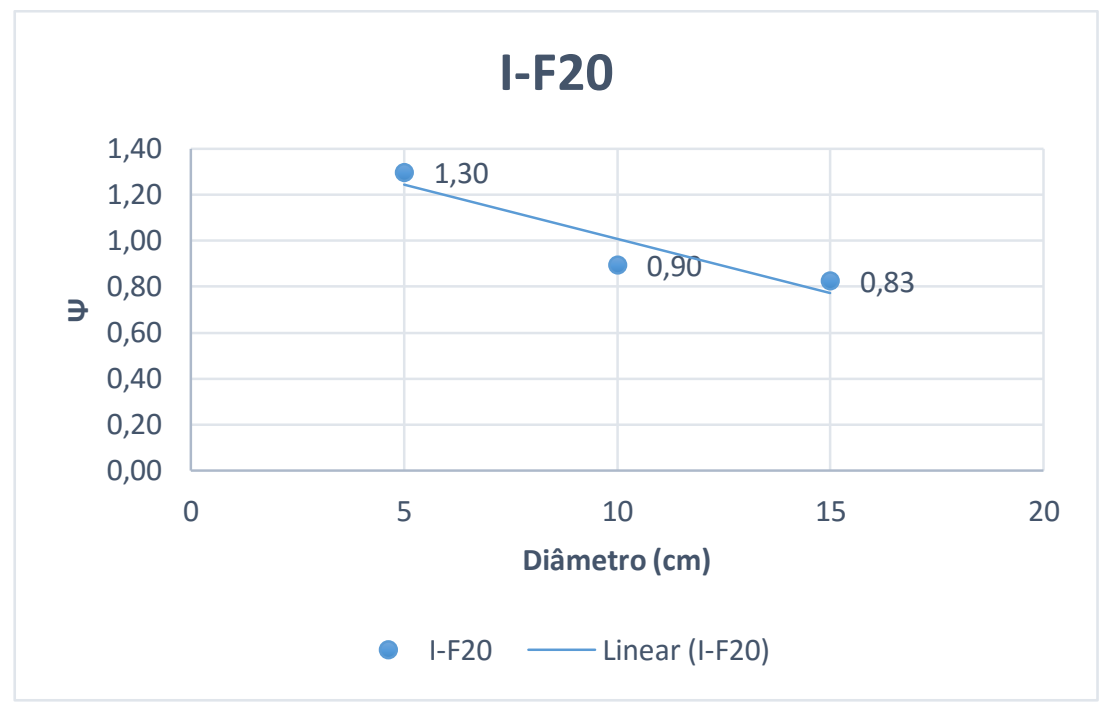

Figura $5.51-\Psi \times$ diâmetro, I-F20.

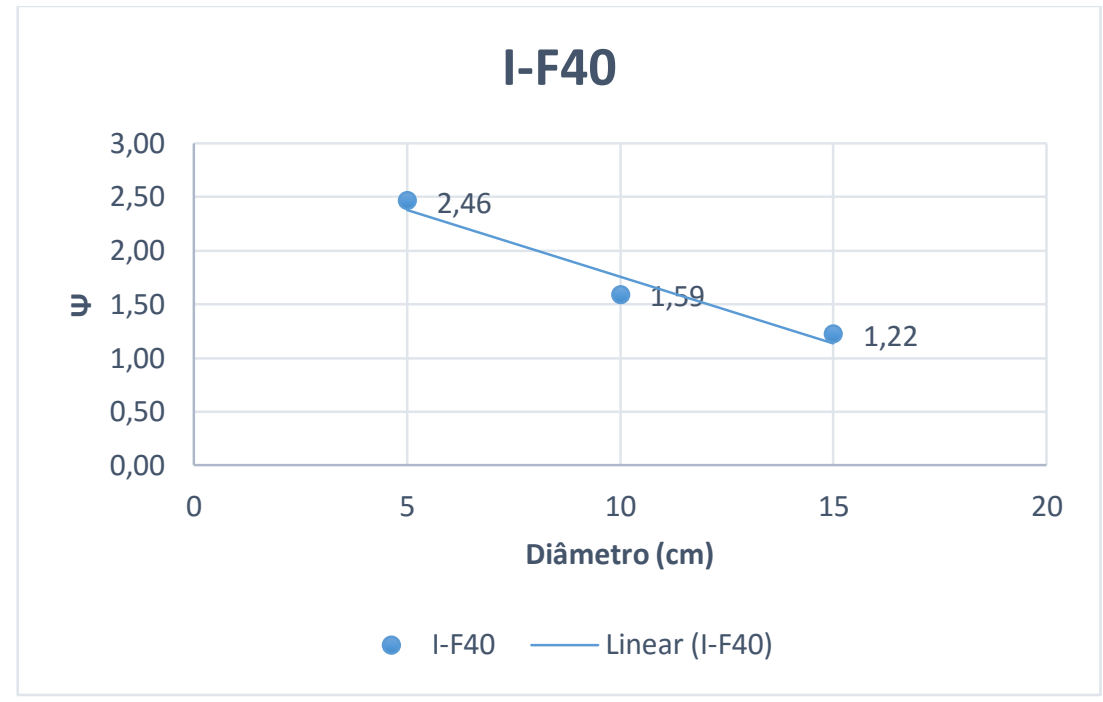

Figura $5.52-\Psi$ x diâmetro, I-F40.

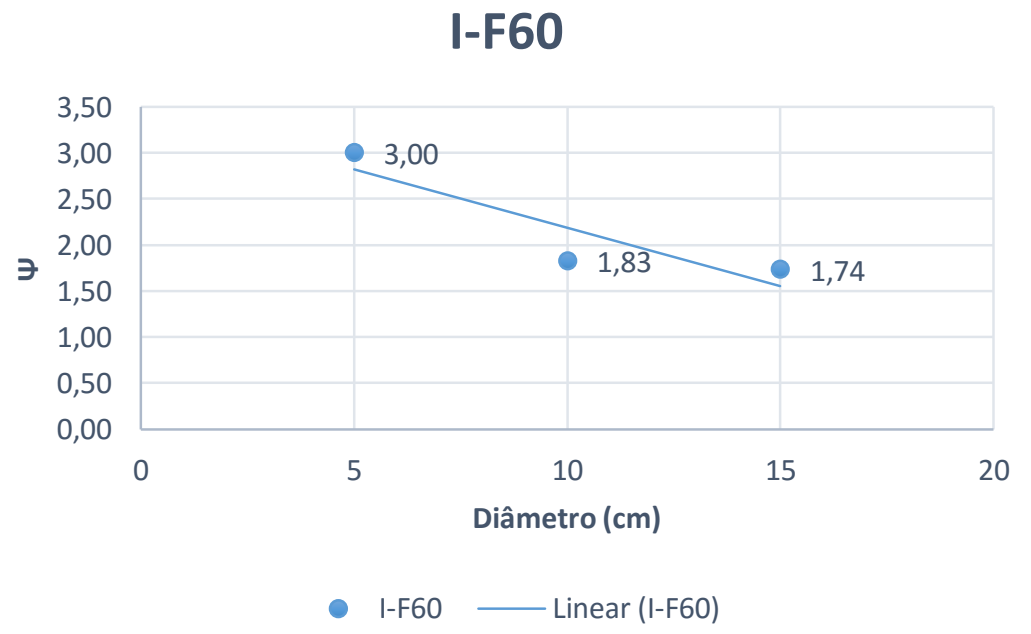

Figura $5.53-\Psi \times$ diâmetro, I-F60. 


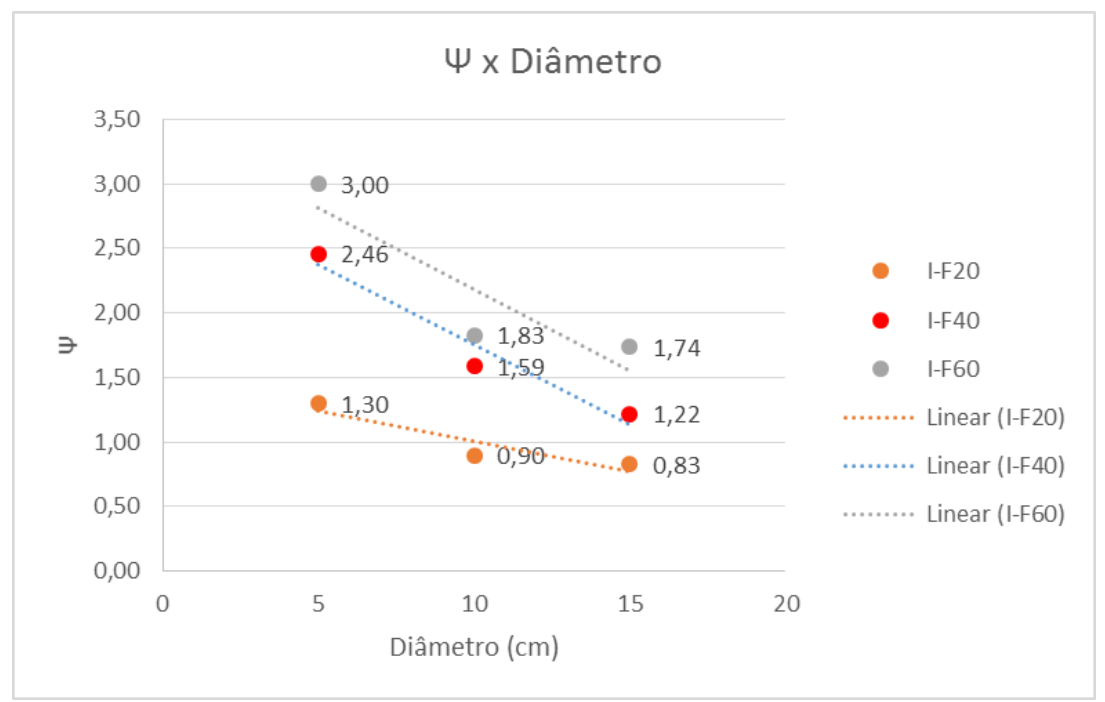

Figura 5.54 - Gráficos comparativos de $\Psi$ x diâmetro, grupo I.

Os gráficos da Figura 5.54 apresentam as seguintes características:

- nos três gráficos houve redução de $\Psi$ com o aumento do diâmetro;

- no consumo F40 essa redução foi mais acentuada;

- no consumo F60 os valores de $\Psi$ são maiores para todos os diâmetros;

- houve aumento de $\Psi$ para todos os diâmetros quando o consumo de fibra aumentou.

As Figuras 5.55 a 5.57 apresentam a razão $\Psi$ pela variação do diâmetro de cada consumo de fibras no grupo II.

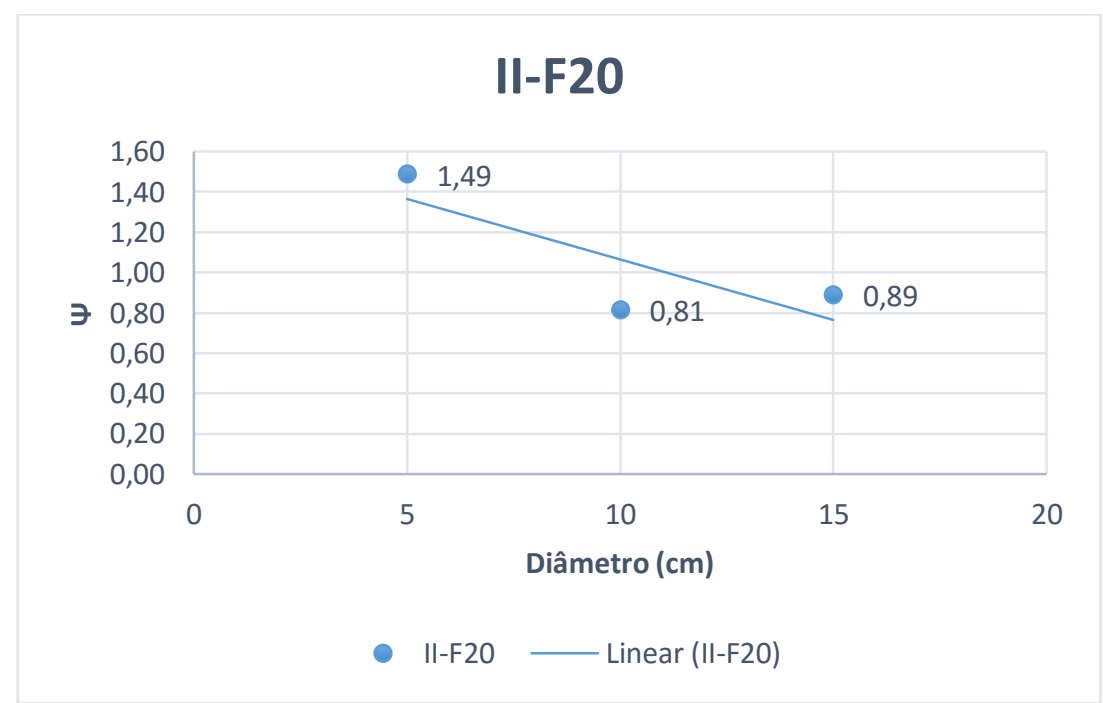

Figura $5.55-\Psi \times$ diâmetro, II-F20. 


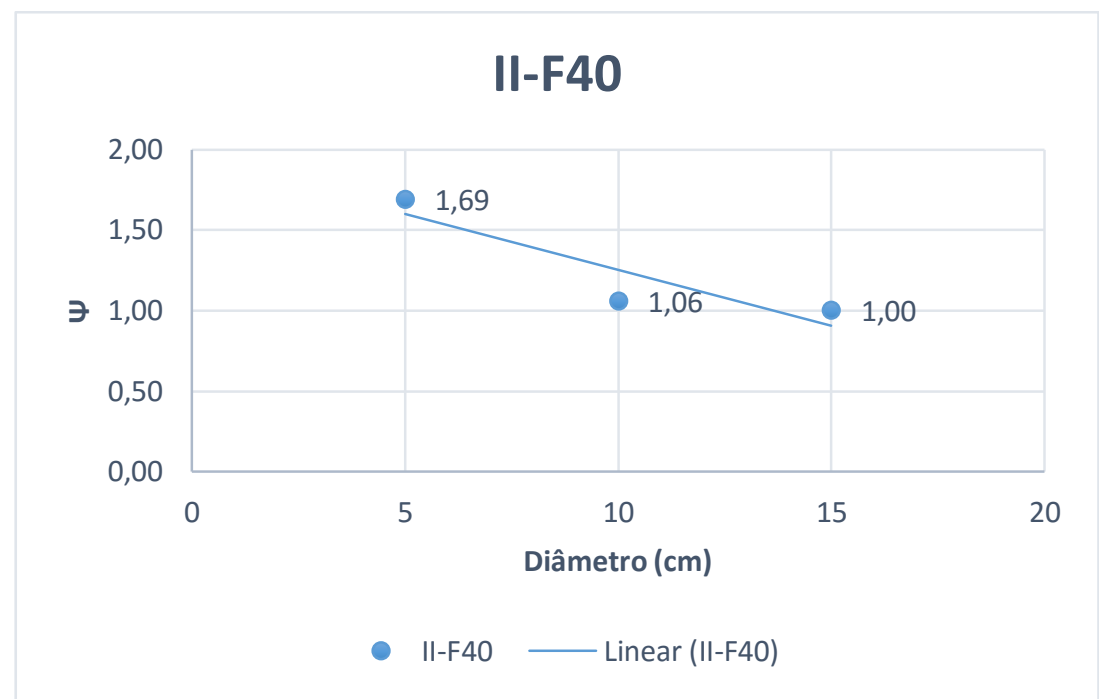

Figura $5.56-\Psi \times$ diâmetro, II-F40.

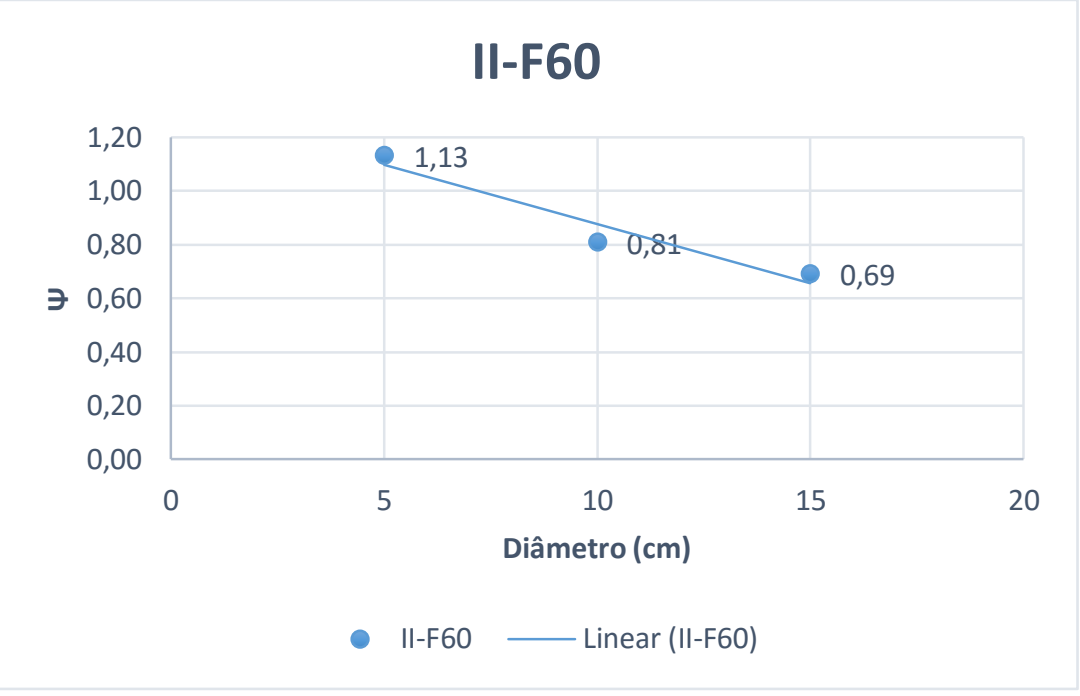

Figura $5.57-\Psi$ x diâmetro, II-F60.

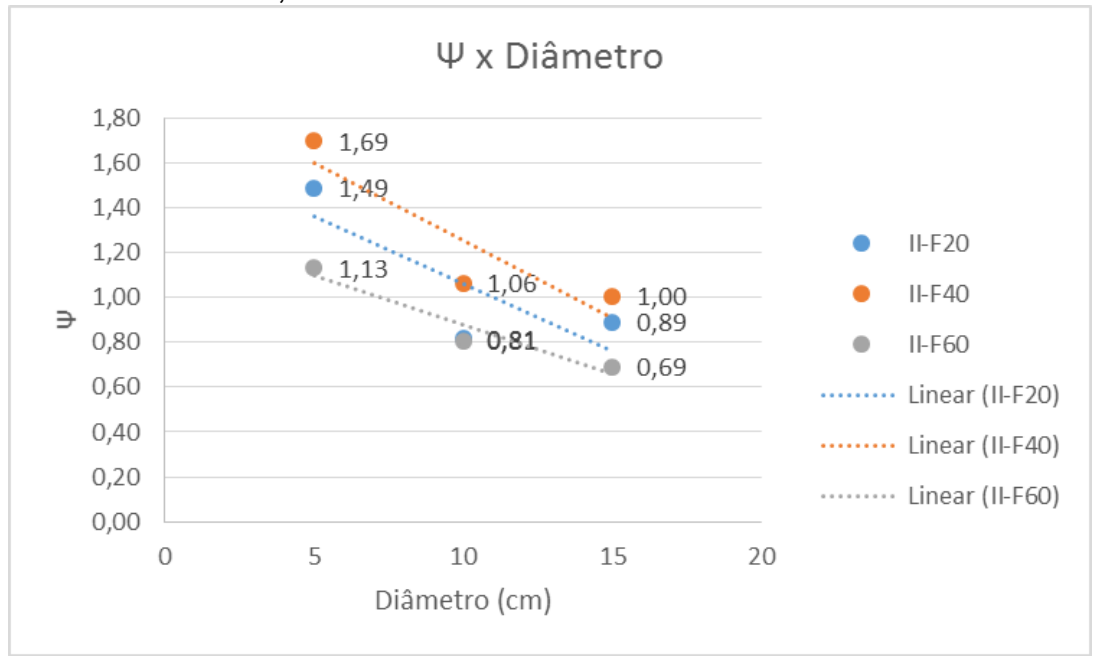

Figura 5.58 - Gráficos comparativos de $\Psi$ x diâmetro, grupo II.

Os gráficos das Figura 5.58 apresentam as seguintes características: 
- nos três gráficos houve redução de $\Psi$ com aumento do diâmetro;

- no consumo F40 essa redução foi mais acentuada;

- no consumo F40 os valores de $\Psi$ são maiores para todos os diâmetros

- houve aumento de $\Psi$ para todos os diâmetros quando a fibra aumentou de F20 para F40, porém, houve uma diminuição de $\Psi$ quando o consumo de fibras aumentou de F40 para F60.

As Figuras 5.59 e 5.61 apresentam a razão $\Psi$ pela variação do diâmetro de cada consumo de fibras no grupo III.

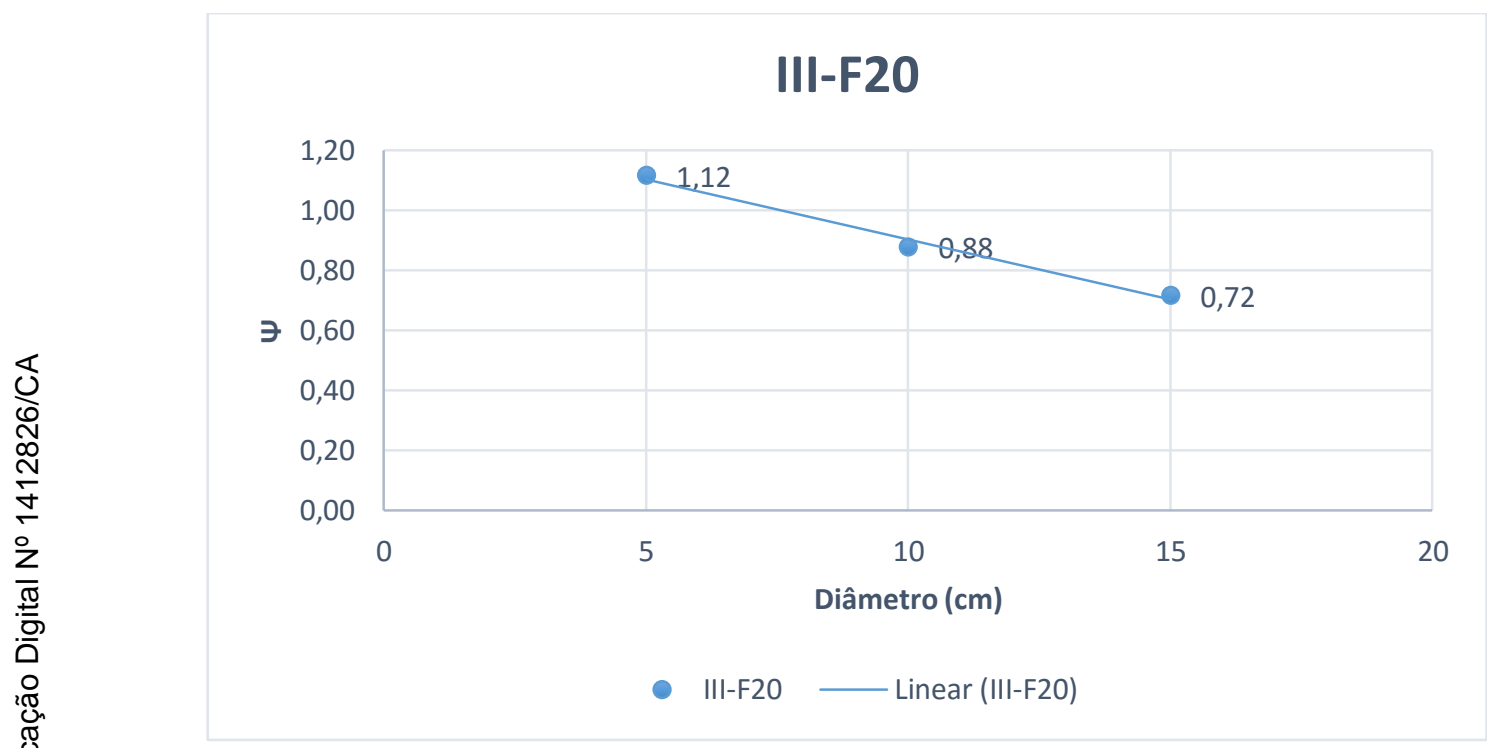

Figura $5.59-\Psi \times$ diâmetro, III-F20.

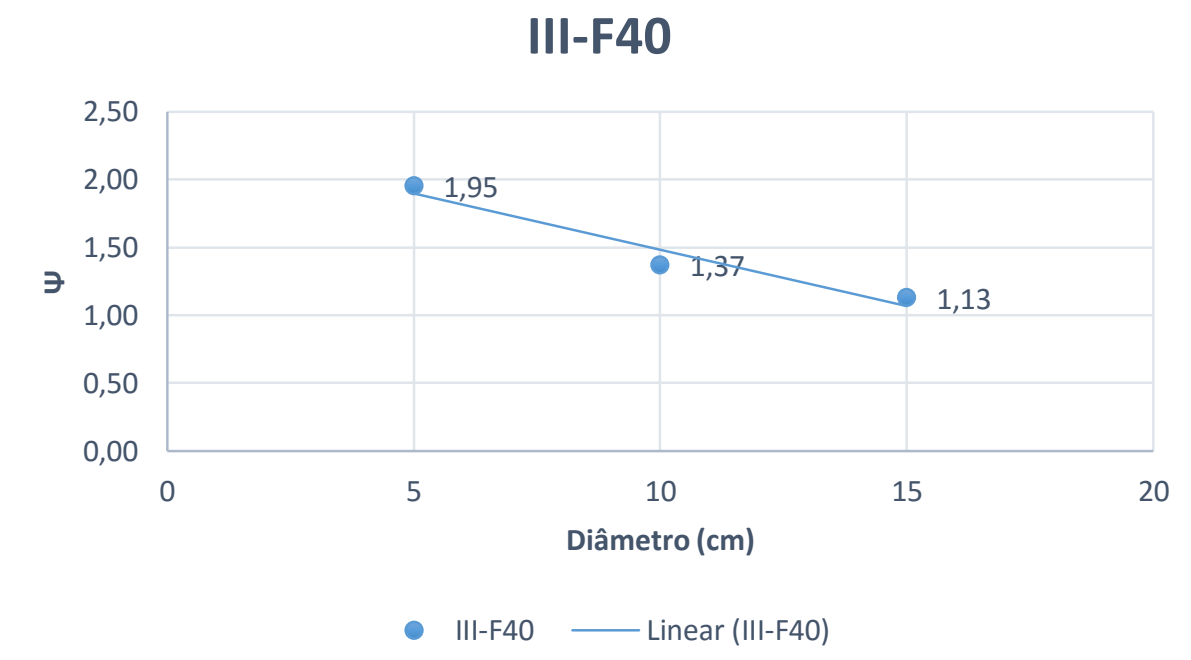

Figura $5.60-\Psi \times$ diâmetro, III-F40. 


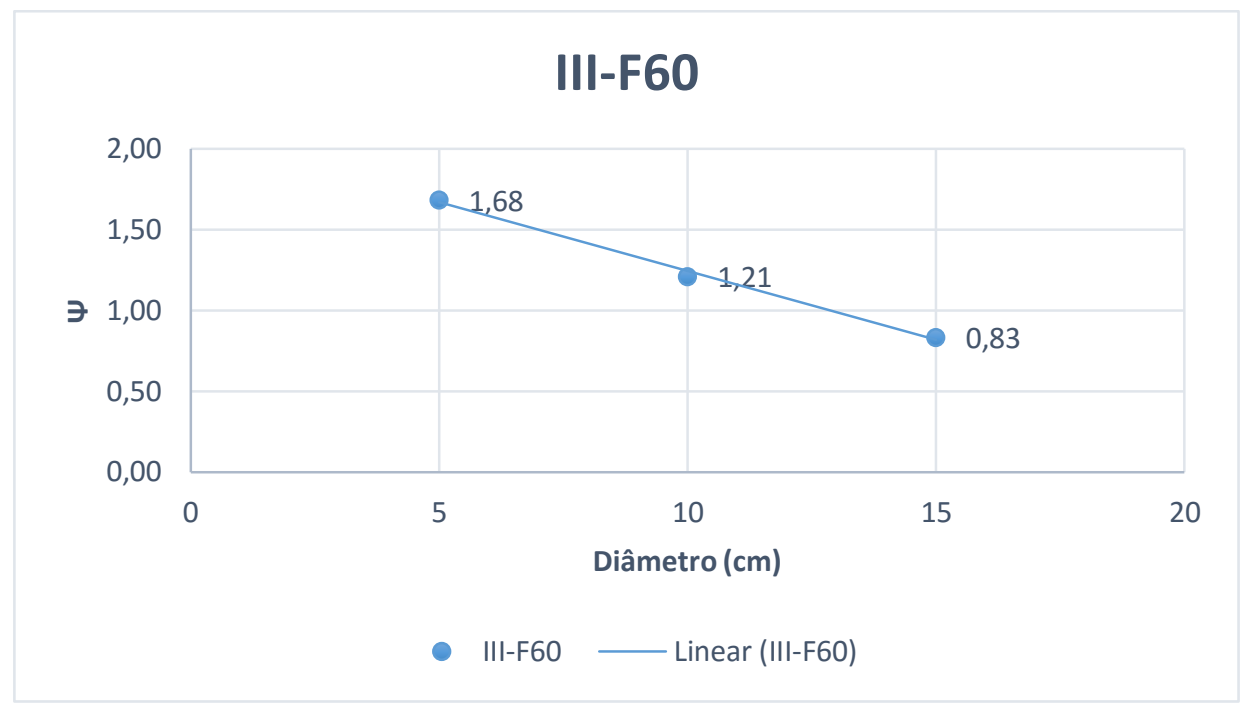

Figura $5.61-\Psi \times$ diâmetro, III-F60.

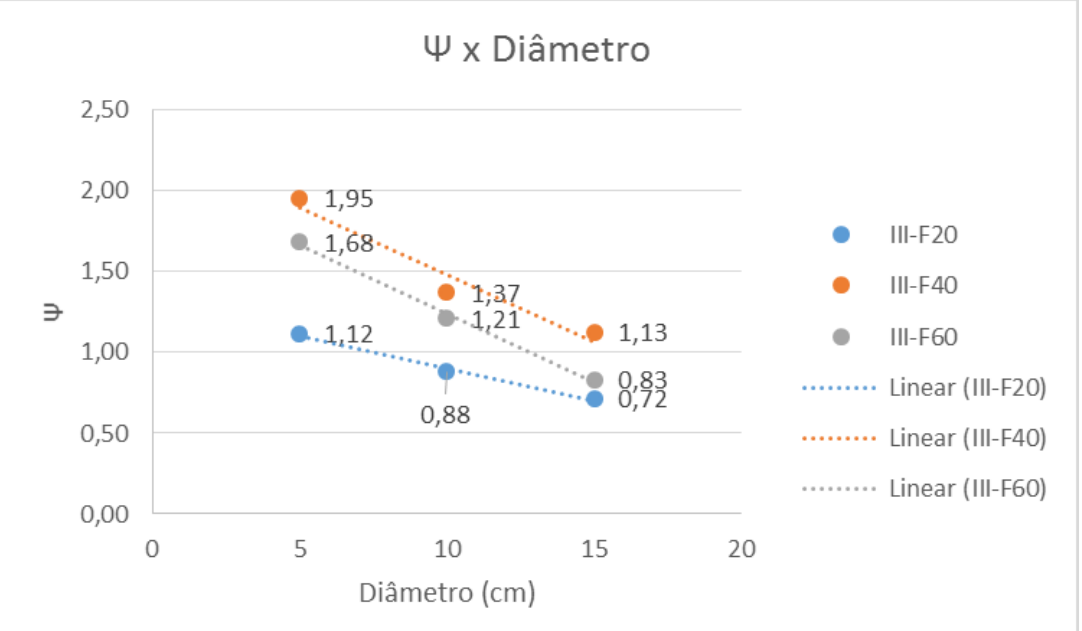

Figura 5.62 - Gráficos comparativos de $\Psi$ x diâmetro, grupo III.

Os gráficos das Figura 5.62 apresentam as seguintes características:

- nos três gráficos houve redução de $\Psi$ com aumento do diâmetro;

- no consumo F60 essa redução foi mais acentuada;

- no consumo F40 os valores de $\Psi$ são maiores para todos os diâmetros em relação aos consumos F20 e F60.

Para todos os gráficos apresentados neste capitulo observa-se que o consumo de fibras influenciou no acréscimo de $\Psi$ em todos os diâmetros quando a $f_{c}$ aumentou de 29,84 MPa, para valores de resistências acima de 38,29 $\mathrm{MPa}$. O aumento do consumo de fibras influenciou o acréscimo de $\Psi$ até certo ponto, depois esse aumento de consumo não foi significativo. 


\subsection{8}

\section{Força de tração direta $x$ deslocamento}

\subsubsection{1}

Grupos

As Figuras 5.63 a 5.68 mostram os dados dos ensaios do item 4.2.1.1. A força de tração direta é estudada em função do aumento do consumo de fibras.

\section{Grupo I}

O ensaio relativo ao corpo de prova I-TD-F20-1 e I-TD-F60-1 não foram mostrados, pois os corpos de prova já estavam rompidos quando foram submetidos ao ensaio.

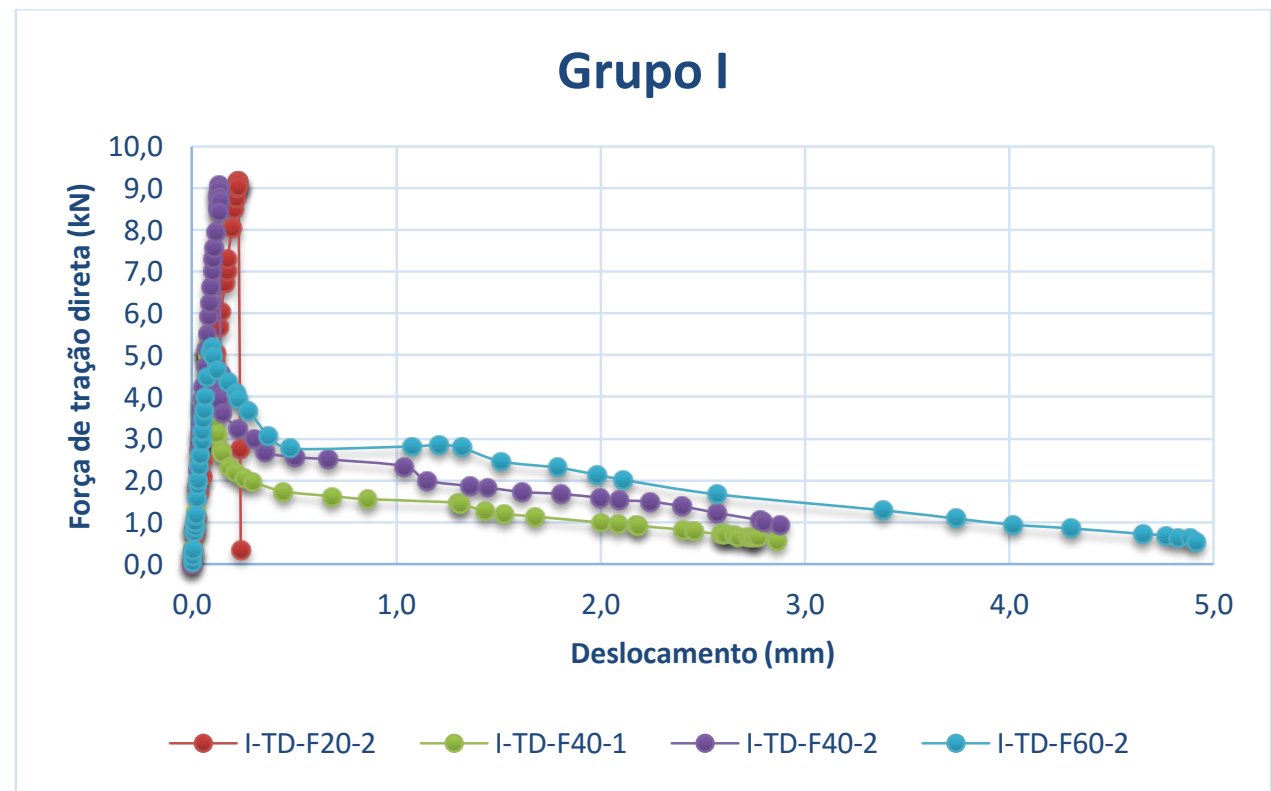

Figura 5.63 - Força x deslocamento, Grupo I.

\section{Grupo II}

Todos os corpos de prova foram tiveram sucesso no ensaio. 


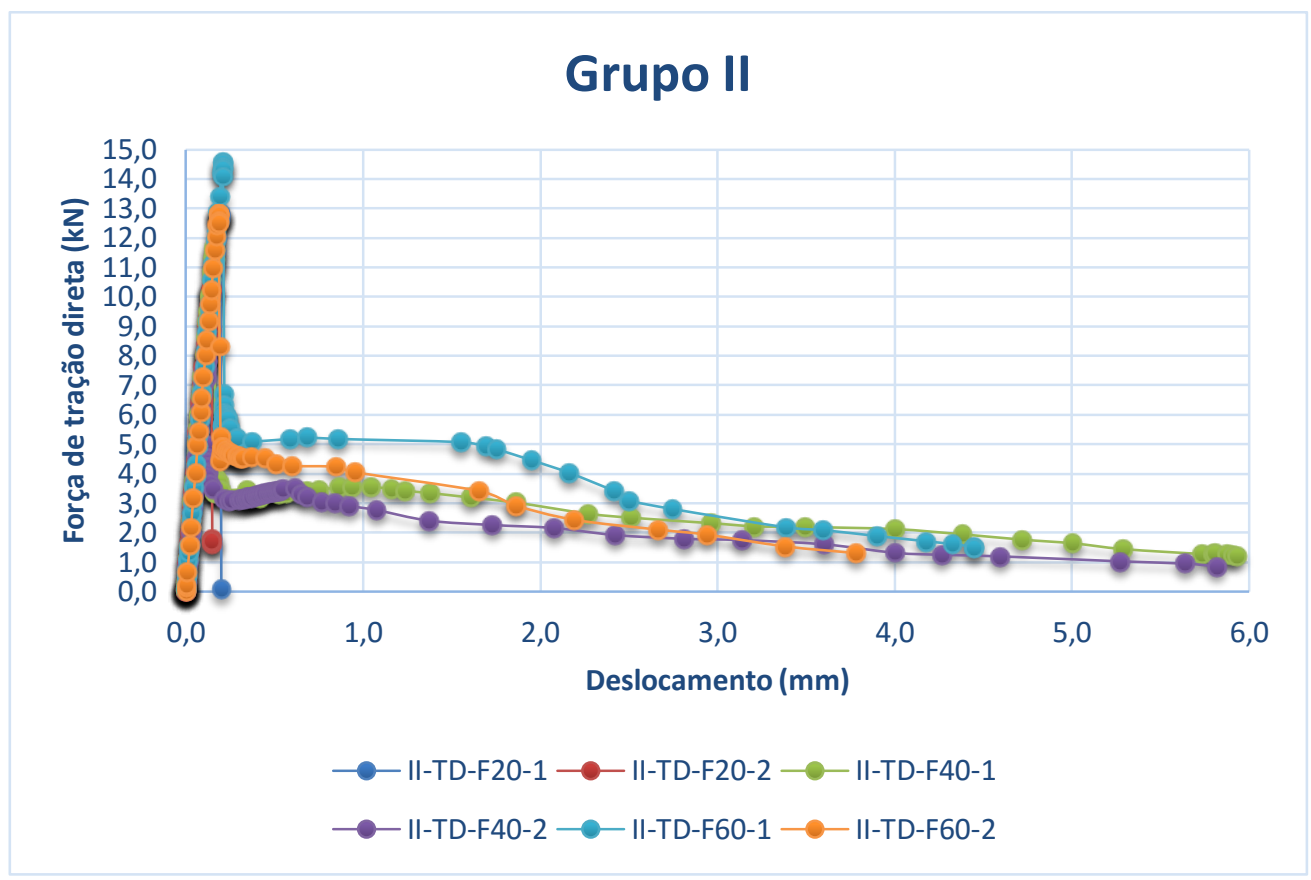

Figura 5.64 - Força x deslocamento, Grupo II.

\section{Grupo III}

O ensaio relativo ao corpo de prova III-TD-F20-2 não foi mostrado, pois o corpo de prova já estava rompido quando foi submetido ao ensaio.

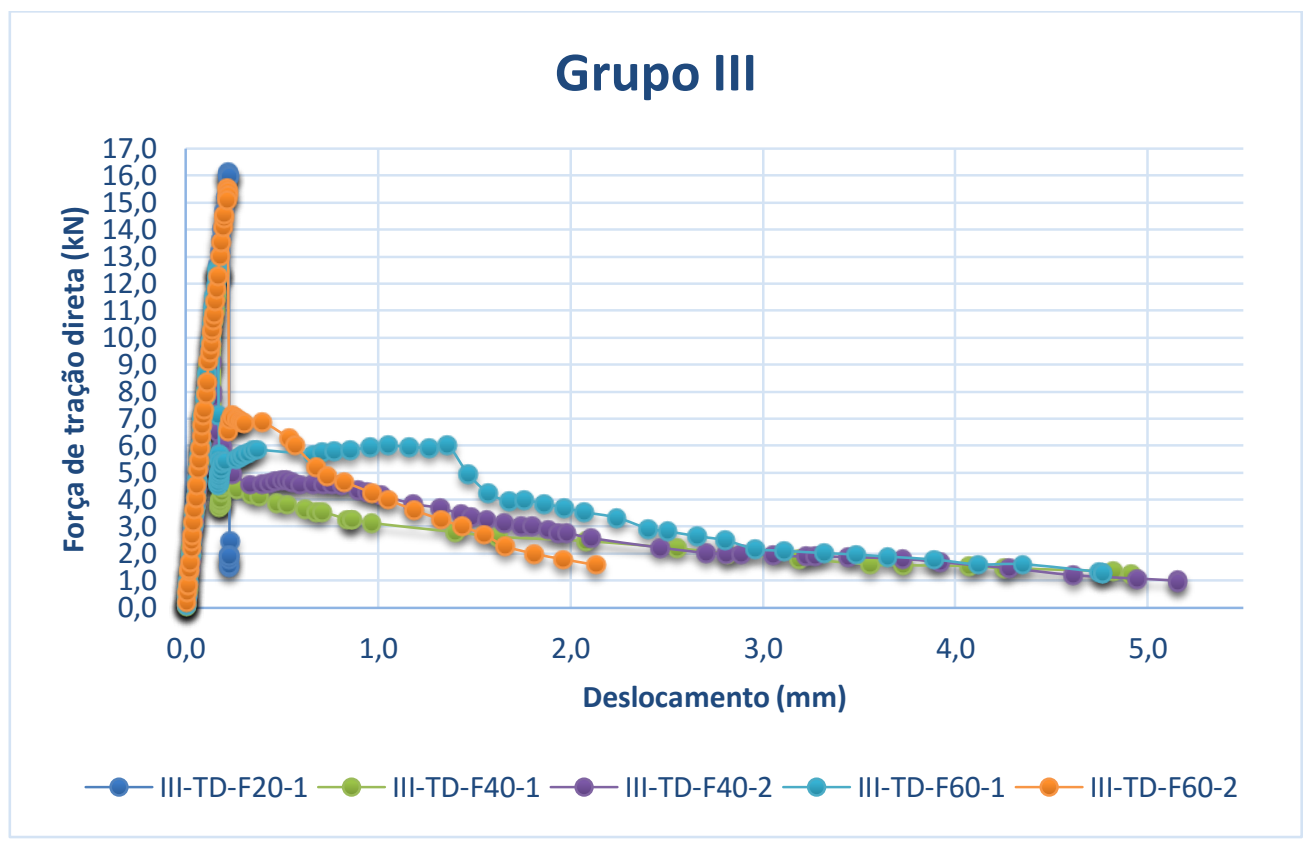

Figura 5.65 - Força x deslocamento, Grupo III.

Os gráficos das Figuras 5.63 a 5.65 apresentam as seguintes características: 
- os corpos de prova com menor consumo de fibras tiveram uma carga de ruptura maior, porém, romperam em seguida;

- no gráfico da Figura 5.63 o corpo de prova com maior consumo de fibras apresenta a menor força de ruptura, porém, apresenta maior resistência no regime plástico após a ruptura;

- todos os corpos de prova com $20 \mathrm{~kg} / \mathrm{m}^{3}$ de fibras, nos três grupos, não apresentaram energia plástica de deformação;

- na Figura 5.64 o corpo de prova com maior consumo de fibras (F60) apresenta maior força de ruptura em relação ao F40, porém, um deslocamento final menor. Todavia, observando-se a Tabela 5.7 temse que mesmo com um deslocamento final menor o corpo de prova F60 apresenta maior energia plástica de deformação. Observa-se no gráfico em questão que as linhas laranja e azul suportam uma carga maior durante mais tempo entre os deslocamentos de $1 \mathrm{~mm}$ a $3 \mathrm{~mm}$. O mesmo ocorre para o gráfico da Figura 5.65 do grupo III;

- a queda de força após o pico de carga diminui com o aumento do consumo de fibras.

Os gráficos gerados para a obtenção das energias de deformação plástica e elástica se encontram no anexo A.

Tabela 5.7 - Energias plásticas e elásticas de deformação.

\begin{tabular}{c|c|c|c|c|c|c|c|c}
\hline $\mathbf{F 2 0}$ & $\mathbf{E}_{\text {elástica }}$ & $\mathbf{E}_{\text {plástica }}$ & $\mathbf{F 4 0}$ & $\mathbf{E}_{\text {elástica }}$ & $\mathbf{E}_{\text {plástica }}$ & $\mathbf{F 6 0}$ & $\mathbf{E}_{\text {elástica }}$ & $\mathbf{E}_{\text {plástica }}$ \\
\hline I-TD-F20 & 1,08 & - & I-TD-F40 & 0,46 & 4,49 & I-TD-F60 & 0,31 & 9,03 \\
\hline II-TD-F20 & 1,29 & - & II-TD-F40 & 0,78 & 12,40 & II-TD-F60 & 1,415 & 12,84 \\
\hline III-TD-F20 & 1,88 & - & III-TD-F40 & 0,90 & 13,08 & III-TD-F60 & 1,455 & 15,67 \\
\hline
\end{tabular}

\subsubsection{2}

\section{Consumo de fibras}

As Figuras 5.66 a 5.68 mostram os dados dos ensaios de tração direta. A força de tração direta é estudada para um mesmo consumo de fibras em função dos grupos (I, II, III). Os mesmos corpos de prova ausentes no item anterior devido a falha no ensaio também não serão mostrados nesse item. 


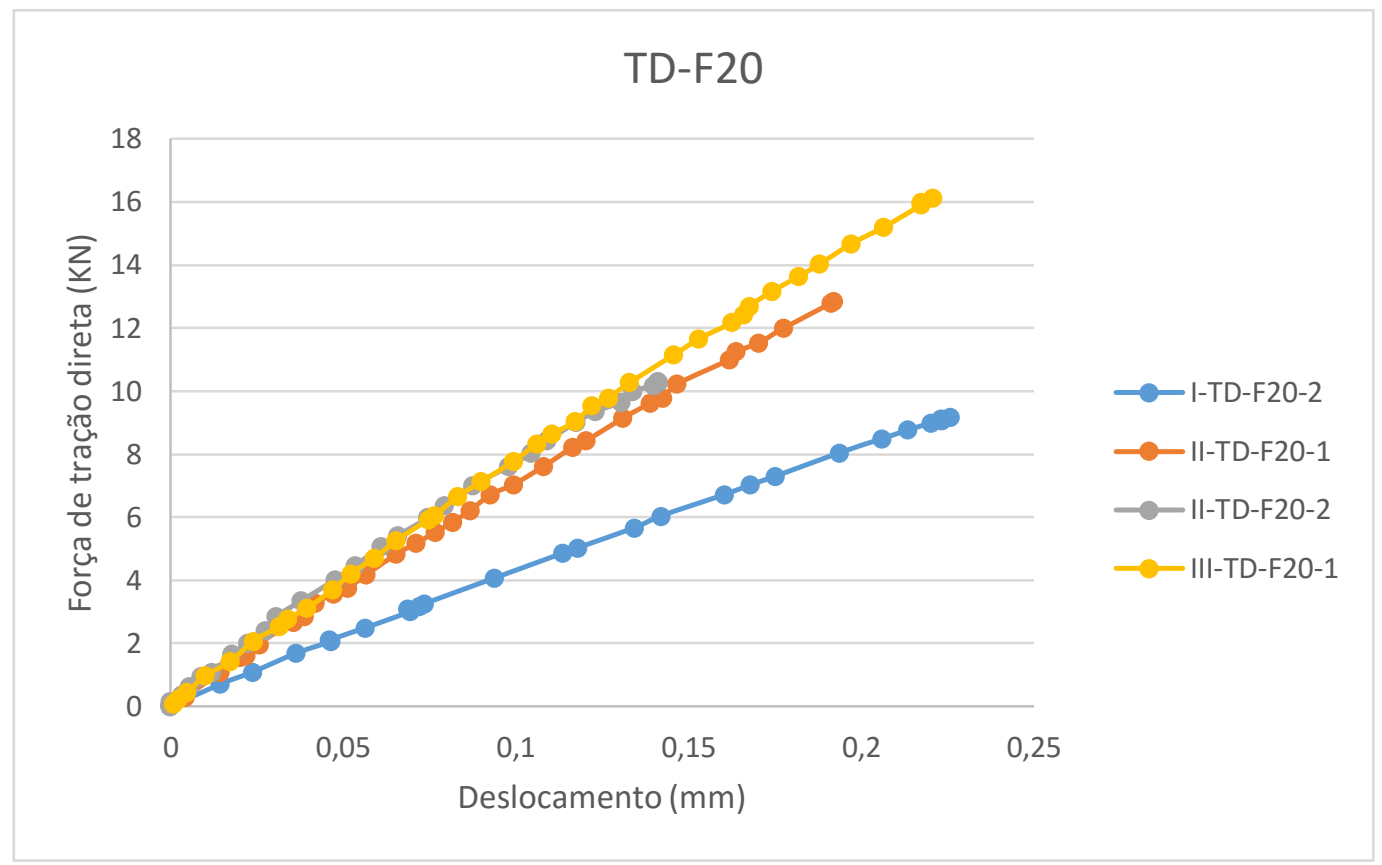

Figura 5.66 - Força x deslocamento, TD-F20.

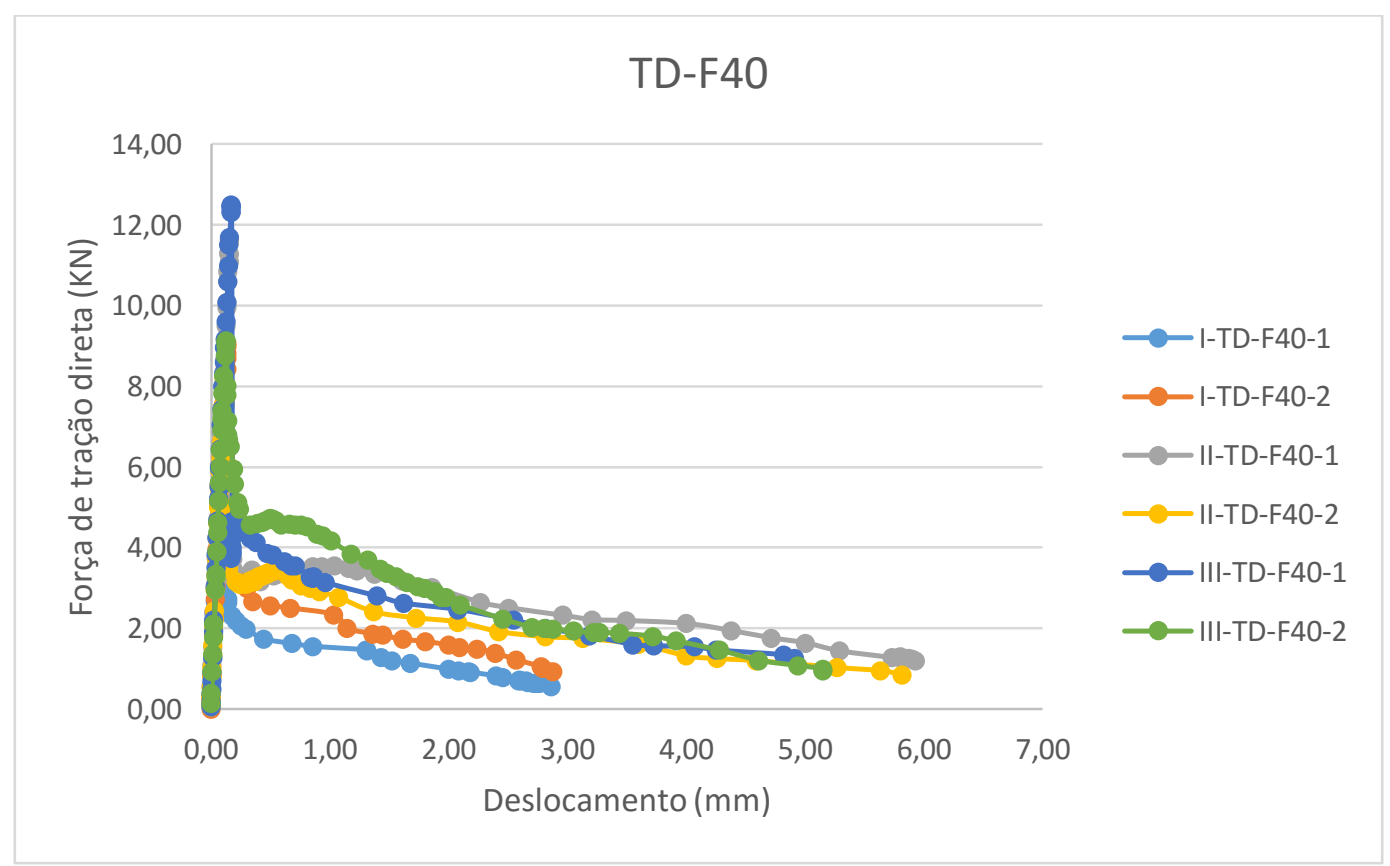

Figura 5.67 - Força x deslocamento, TD-F40. 


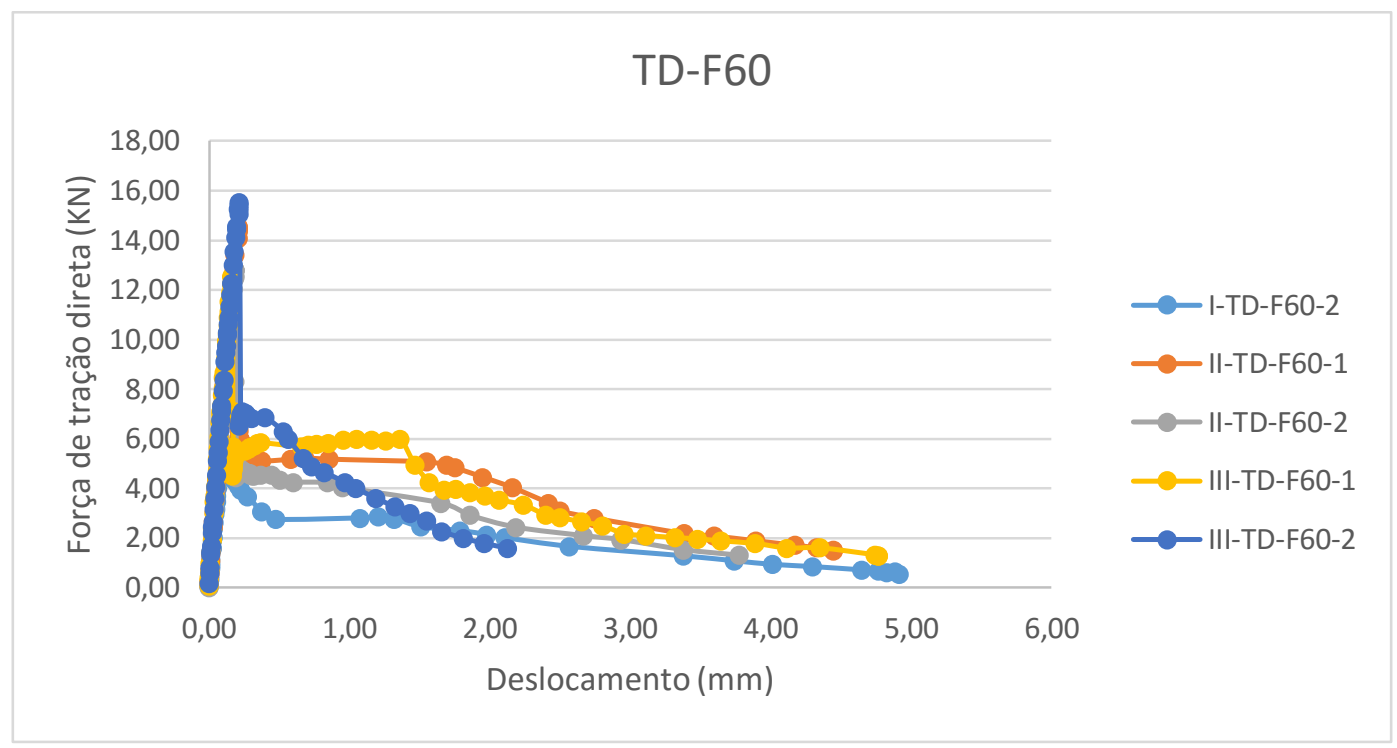

Figura 5.68 - Força x deslocamento, TD-F60.

No gráfico da Figura 5.66 observa-se que nenhum corpo de prova apresentou energia de deformação plástica. Pode-se ver que para o mesmo consumo de fibras (F20) os corpos de prova dos grupos I e III apresentaram praticamente o mesmo deslocamento final, porém, o corpo de prova do grupo III suportou maior carga de ruptura. Constata-se que quanto maior é a resistência à compressão do corpo de prova maior é sua carga de ruptura.

No gráfico da Figura 5.67 observa-se que todos os corpos de prova apresentaram energia plástica de deformação. Houve um menor deslocamento final e carga de ruptura para os corpos de prova do grupo I. O grupo II obteve o maior deslocamento final, porém o grupo III teve a maior carga de ruptura. Mesmo o grupo II apresentando maior deslocamento final, observa-se na Tabela 5.10 que o grupo III apresentou maior energia plástica de deformação.

No gráfico da Figura 5.68 observa-se que os corpos de prova com menor resistência à compressão apresentaram maior deslocamento final, porém, menor carga de ruptura. Mesmo o grupo I apresentando maior deslocamento final os grupos II e III apresentaram maior energia de deformação plástica (Tabela 5.10)

De acordo com a Tabela 5.7 observa-se:

- nenhum corpo de prova com $20 \mathrm{~kg} / \mathrm{m}^{3}$ de fibras apresentou regime plástico;

- quanto maior era a resistência à compressão maior era a energia de deformação elástica para um mesmo consumo de fibras. 
- a energia de deformação elástica reduz do F20 para o F40 e aumenta do F40 para o F60;

- a partir do consumo de F40, todos os corpos de prova apresentaram energia de deformação plástica.

- as energias de deformação plástica F40 e F60 são próximos nos grupos II e III;

- para o grupo I, quanto maior o consumo de fibras, menor a energia de deformação elástica e maior a plástica, tendo diferença significativa da energia de deformação elástica do F40 para F60;

- para o grupo II, quanto maior o consumo de fibras maior a energia de deformação plástica, porém, sem grande variação do F40 para o F60. Ocorre o mesmo para o grupo III;

- observa-se que para resistência à compressão menor as fibras influenciam mais a resistência à tração do que quando comparados a concretos de alta resistência.

- A queda de força após o pico de carga diminui com o aumento do consumo de fibras.

\section{3 .9 \\ Energia dissipada}

\subsubsection{1}

\section{Tração direta}

A área sob a curva força-deslocamento até o deslocamento último foram obtidas dos gráficos por meio do método de Simpson. Tem-se essas áreas na Tabela 5.7 do capitulo 5.3.8.1. Nos gráficos das Figuras 5.69 e 5.70 tem-se a energia dissipada versus o consumo de fibras. 


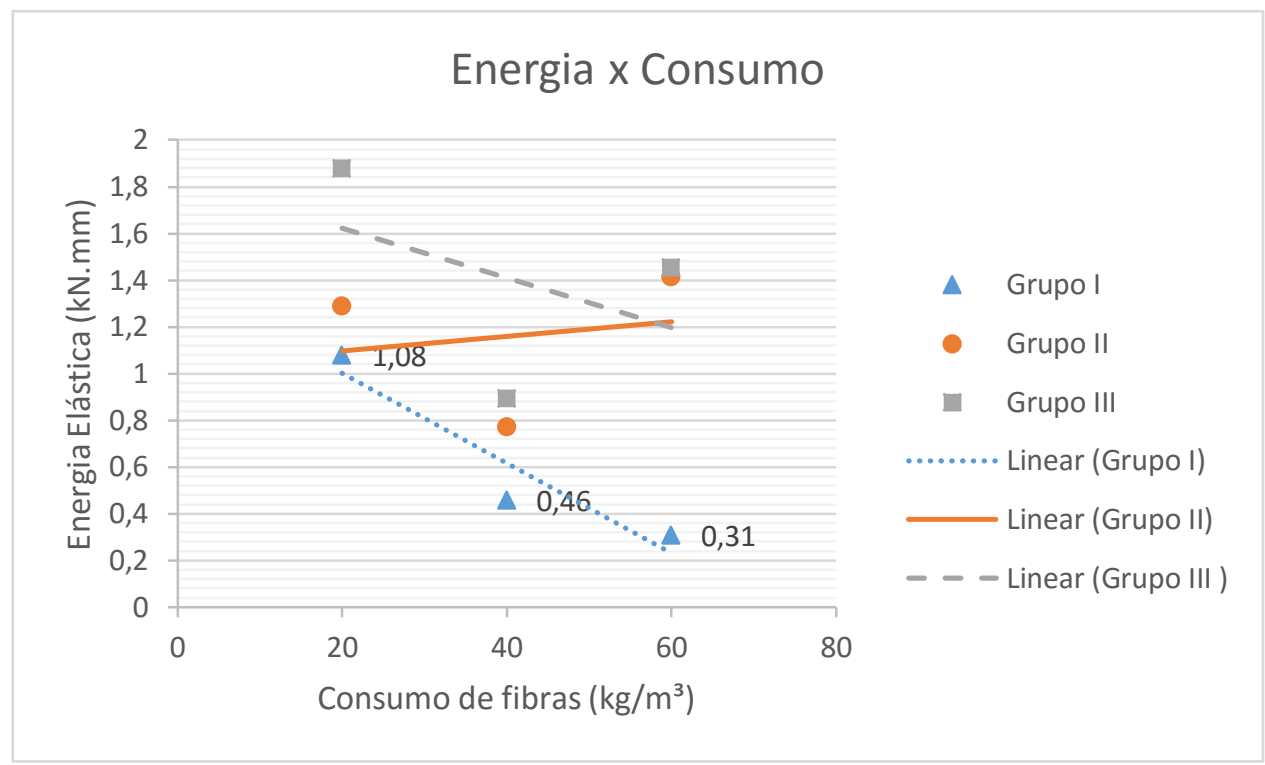

Figura 5.69 - Energia elástica x consumo de fibras.

O gráfico da Figura 5.69 apresenta as seguintes características:

- observa-se somente uma curva com tendência linear satisfatória;

- não há correlação entre os resultados ensaiados dos grupos II e III, requer mais ensaios;

- na curva do grupo I, quanto maior o consumo de fibras menor a energia elástica de deformação.

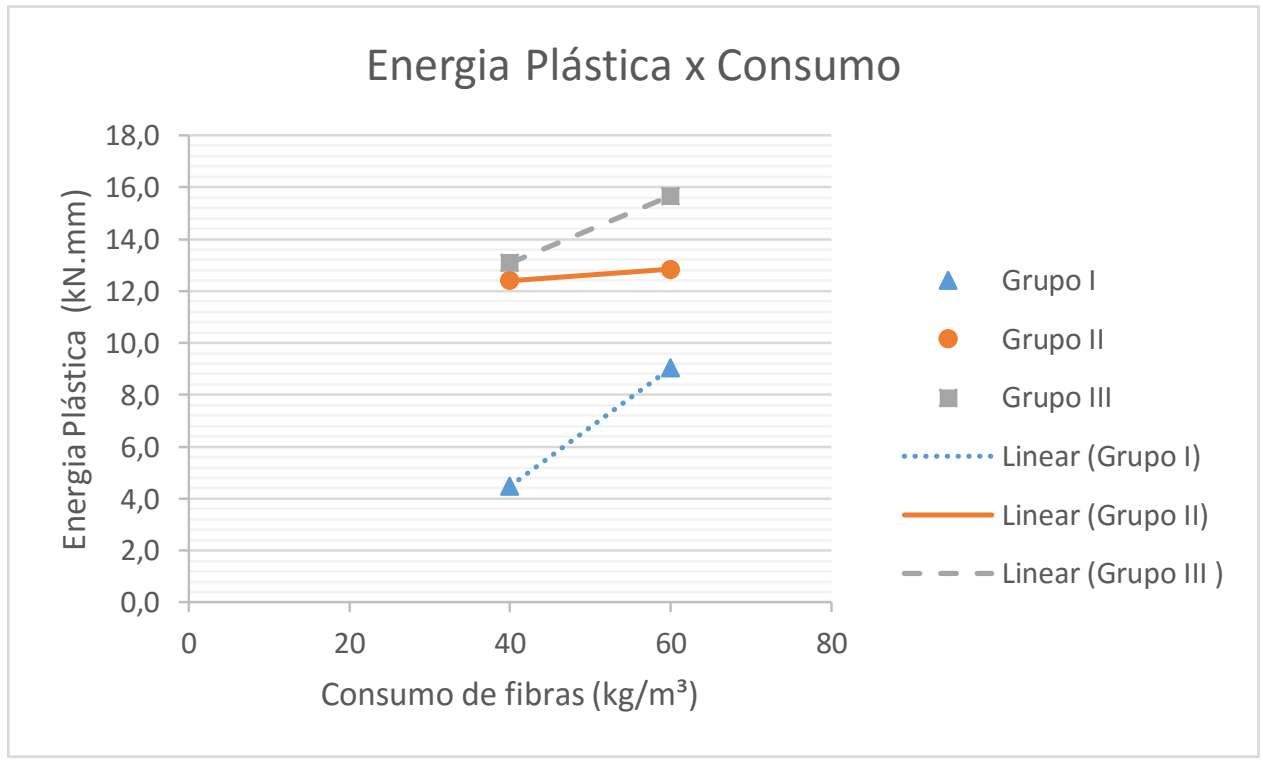

Figura 5.70 - Energia plástica x consumo de fibras. 
O gráfico da Figura 5.70 apresenta apenas um indicativo do comportamento da variação da energia plástica, pois se tem apenas dois corpos de prova por grupo, apresenta as seguintes características:

- para o consumo F20, nenhum grupo apresentou energia plástica de deformação, o concreto se comporta como concreto simples;

- a capacidade de absorção de energia plástica aumentou consideravelmente com o aumento do consumo de fibras;

- os concretos mais resistentes se comportam de maneira similar;

- o grupo com $f_{c}$ menor obteve o maior aumento da energia plástica de deformação, em cerca de mais de $100 \%$.

Nos gráficos das Figuras 5.71 e 5.72 tem-se a energia dissipada versus grupo de corpos de prova.

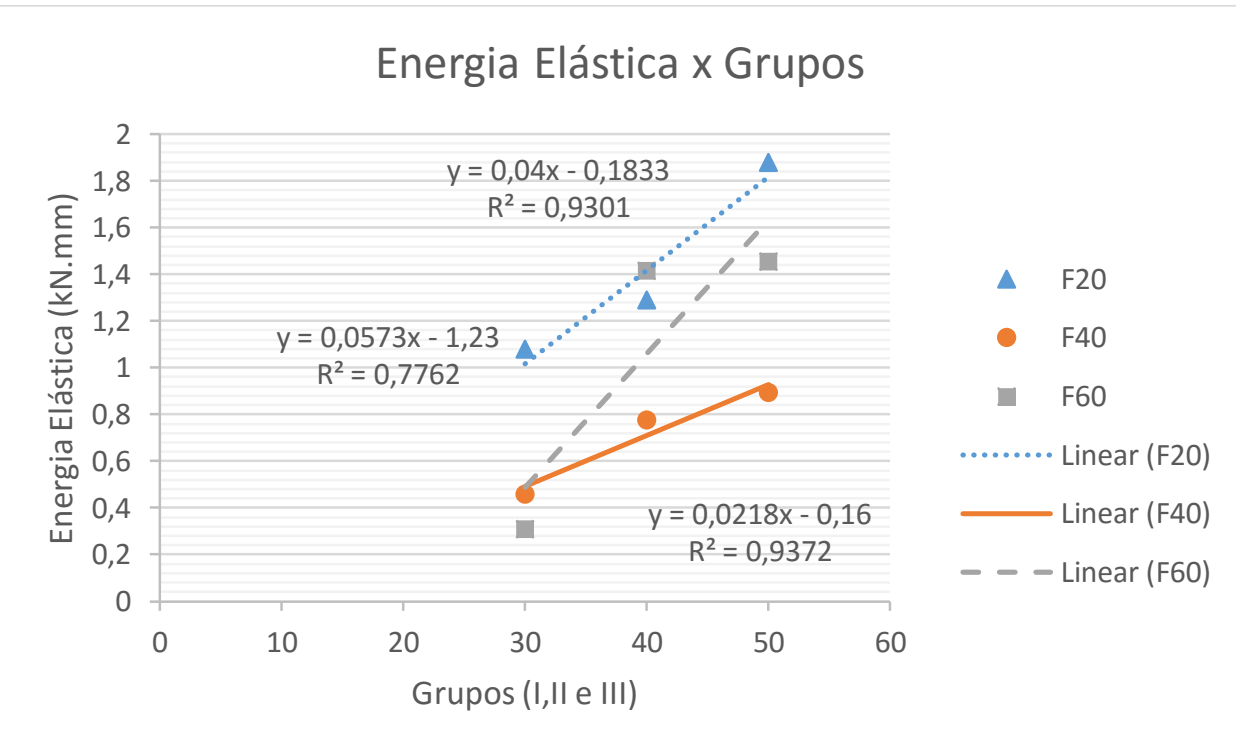

Figura 5.71 - Energia elástica x grupos.

O gráfico das Figura 5.71 apresenta as seguintes características:

- todas as curvas têm uma tendência linear;

- quanto maior o $f_{c}$ maior a energia elástica de deformação;

- para o grupo I, quanto menor o consumo maior a energia elástica de deformação. 


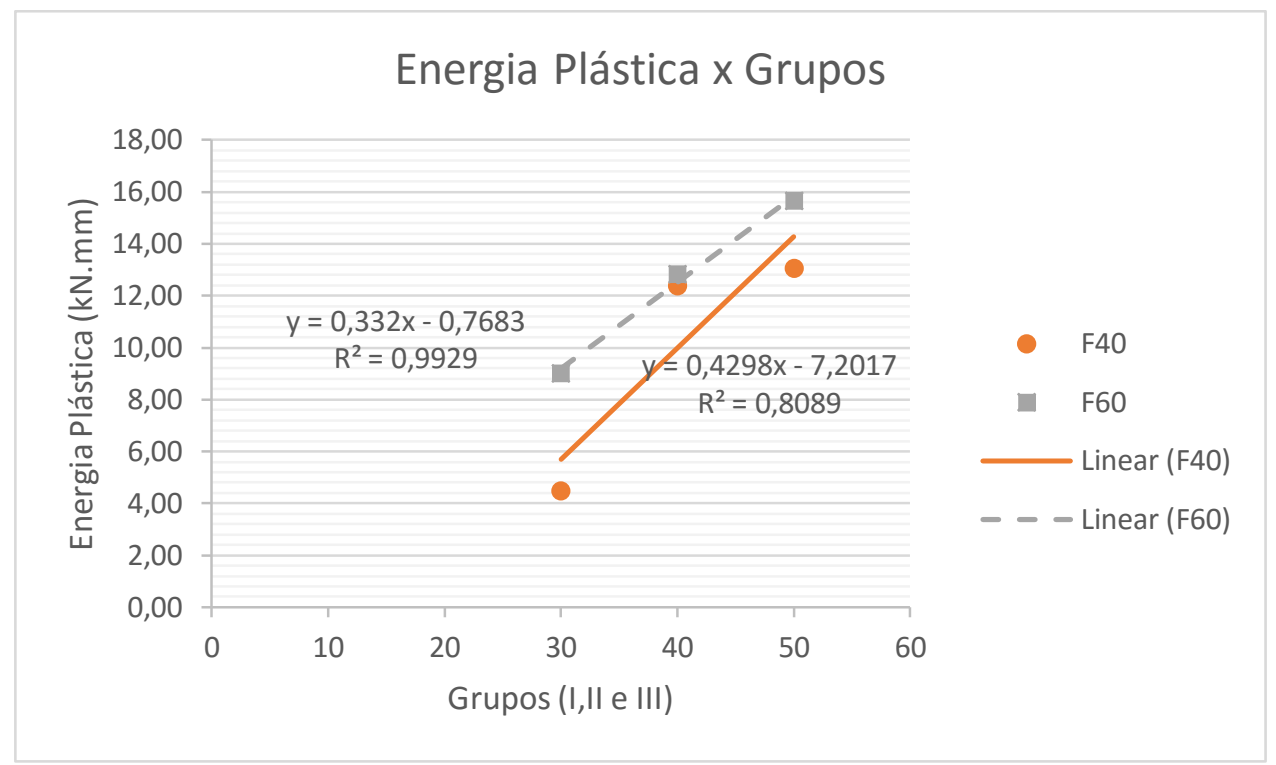

Figura 5.72 - Energia plástica x grupos.

O gráfico das Figura 5.72 apresenta as seguintes características:

- o concreto com consumo de fibras F20, não apresentou energia plástica, por esse motivo, não está representado no gráfico;

- quanto maior o consumo de fibras, maior a energia plástica;

- os consumos F40 e F60 apresentaram comportamento similar, nos três grupos de resistência à compressão.

\subsubsection{2}

\section{Compressão diametral}

$\mathrm{Na}$ Tabela 5.8 tem-se a média da energia total dissipada dos ensaios de compressão diametral, que é a área sob a curva força-deslocamento até o deslocamento último. Essas áreas foram obtidas dos gráficos por meio do método de Simpson. Todos os gráficos encontram-se no Anexo A. 
Tabela 5.8 - Energia total dissipada.

\begin{tabular}{c|c|c|c|c|c}
\hline Série 1 & E total & Série 2 & E total & Série 3 & E total \\
\hline I-D5-F20 & 68,78 & I-D5-F40 & 105,05 & I-D5-F60 & 129,78 \\
\hline I-D10-F20 & 139,83 & I-D10-F40 & 291,72 & I-D10-F60 & 252,28 \\
\hline I-D15-F20 & 389,22 & I-D15-F40 & 511,43 & I-D15-F60 & 407,00 \\
\hline Série 4 & E total & Série 5 & E total & Série 6 & E total \\
\hline II-D5-F20 & 120,36 & II-D5-F40 & 129,46 & II-D5-F60 & 110,72 \\
\hline II-D10-F20 & 270,60 & II-D10-F40 & 273,58 & II-D10-F60 & 279,30 \\
\hline II-D15-F20 & 555,97 & II-D15-F40 & 478,36 & II-D15-F60 & 442,72 \\
\hline Série 7 & E total & Série 8 & E total & Série 9 & E total \\
\hline III-D5-F20 & 134,42 & III-D5-F40 & 145,13 & III-D5-F60 & 145,93 \\
\hline III-D10-F20 & 348,52 & III-D10-F40 & 386,64 & III-D10-F60 & 457,50 \\
\hline III-D15-F20 & 660,38 & III-D15-F40 & 647,30 & III-D15-F60 & 740,90 \\
\hline
\end{tabular}

Na Tabela 5.9 tem-se a razão entre as energias totais dissipadas, comparadas considerando-se o consumo, o grupo e o diâmetro, sendo que:

- $\Delta a=F_{40} / F_{20}$ - razão entre a energia dissipada de 40 e $20 \mathrm{~kg} / \mathrm{m}^{3}$;

- $\Delta b=F_{60} / F_{40}$ - razão entre a energia dissipada de 60 e $40 \mathrm{~kg} / \mathrm{m}^{3}$;

- $\Delta c=F_{60} / F_{20}$ - razão entre a energia dissipada de 60 e $20 \mathrm{~kg} / \mathrm{m}^{3}$;

- $\Delta d=I I / I-$ razão entre a energia dissipada do grupo II e I;

- $\Delta e=I I I / I I$ - razão entre a energia dissipada do grupo III e II;

- $\Delta f=I I I / I$ - razão entre a energia dissipada do grupo III e I;

- $\Delta g=D_{10} / D_{5}$ - razão entre a energia dissipada do diâmetro 10 e 5;

- $\Delta h=D_{15} / D_{10}$ - razão entre a energia dissipada do diâmetro 15 e 10;

- $\Delta i=D_{15} / D_{5}$ - razão entre a energia dissipada do diâmetro 15 e 5 .

Tabela 5.9 - Razões entre as energias dissipadas.

\begin{tabular}{c|c|c|c|c|c|c|c|c|c|c|c}
\hline \multicolumn{4}{c}{ Consumo } & \multicolumn{4}{c|}{ Grupos } & \multicolumn{4}{c}{ Diâmetro } \\
\hline & $\Delta \mathrm{a}$ & $\Delta \mathrm{b}$ & $\Delta \mathrm{c}$ & & $\Delta \mathrm{d}$ & $\Delta \mathrm{e}$ & $\Delta \mathrm{f}$ & & $\Delta \mathrm{g}$ & $\Delta \mathrm{h}$ & $\Delta \mathrm{i}$ \\
\hline I-D5 & 1,53 & 1,24 & 1,89 & D5-F20 & 1,75 & 1,12 & 1,95 & I-F20 & 2,03 & 2,78 & 5,66 \\
\hline I-D10 & 2,09 & 0,86 & 1,80 & D10-F20 & 1,94 & 1,29 & 2,49 & I-F40 & 2,78 & 1,75 & 4,87 \\
\hline I-D15 & 1,31 & 0,80 & 1,05 & D15-F20 & 1,43 & 1,19 & 1,70 & I-F60 & 1,94 & 1,61 & 3,14 \\
\hline II-D5 & 1,08 & 0,86 & 0,92 & D5-F40 & 1,23 & 1,12 & 1,38 & II-F20 & 2,25 & 2,05 & 4,62 \\
\hline II-D10 & 1,01 & 1,02 & 1,03 & D10-F40 & 0,94 & 1,41 & 1,33 & II-F40 & 2,11 & 1,75 & 3,70 \\
\hline II-D15 & 0,86 & 0,93 & 0,80 & D15-F40 & 0,94 & 1,35 & 1,27 & II-F60 & 2,52 & 1,59 & 4,00 \\
\hline III-D5 & 1,08 & 1,01 & 1,09 & D5-F60 & 0,85 & 1,32 & 1,12 & III-F20 & 2,59 & 1,89 & 4,91 \\
\hline III-D10 & 1,11 & 1,18 & 1,31 & D10-F60 & 1,11 & 1,64 & 1,81 & III-F40 & 2,66 & 1,67 & 4,46 \\
\hline III-D15 & 0,98 & 1,14 & 1,12 & D15-F60 & 1,09 & 1,67 & 1,82 & III-F60 & 3,14 & 1,62 & 5,08 \\
\hline
\end{tabular}


Da Tabela 5.9 tem-se:

- $\Delta a$ do grupo I - grande aumento da energia total dissipada, o mesmo ocorreu no $\Delta c$ para todos os diâmetros, o $\Delta b$ somente teve aumento para o D5;

- $\Delta a, \Delta b$ e $\Delta c$ do grupo II - tiveram comportamento semelhante, não tendo aumento significativo de energia dissipada;

- $\Delta a, \Delta b e s c$ do grupo III - maior aumento foi $\Delta c$ para o D10;

- $\Delta d-$ a energia total dissipada quase dobrou para F20 no D10, porém, não foi tão significativa assim no F60;

- $\Delta e-$ a energia total dissipada aumentou para todos diâmetros, tendo um maior aumento no D15 do consumo F60;

- $\Delta f$ - para F20 o aumento foi muito grande chegando a ser mais que o dobro, para F40 e F60 também teve aumento;

- $\Delta i>\Delta g>\Delta h$ para todos os casos exceto, para o I-F20 que $\Delta h>\Delta g$.

\subsubsection{0 \\ Curva tensão vs. deformação específica}

A curva de tensão-deformação específica foi obtida para o ensaio de tração direta.

A medida que a força axial $\mathrm{F}$ aumentava gradualmente, o alongamento total $\Delta l$ era mensurado em cada incremento de carga até ocorrer a fratura do corpo de prova. Com a área inicial da secção transversal $A_{0}$ e o comprimento $l_{0}$ medidos no corpo de prova original de tração, foram obtidas a tensão normal $\sigma=F / A$ e deformação específica $\varepsilon=\Delta l / l_{0}$.

As Figuras 5.73 a 5.75 mostram os diagramas de tensão-deformação específica para três ensaios realizados do grupo I, todos os outros ensaios do grupo I, II e III encontram-se no Anexo D. Para cada material essa curva pode assumir formas muito distintas. 


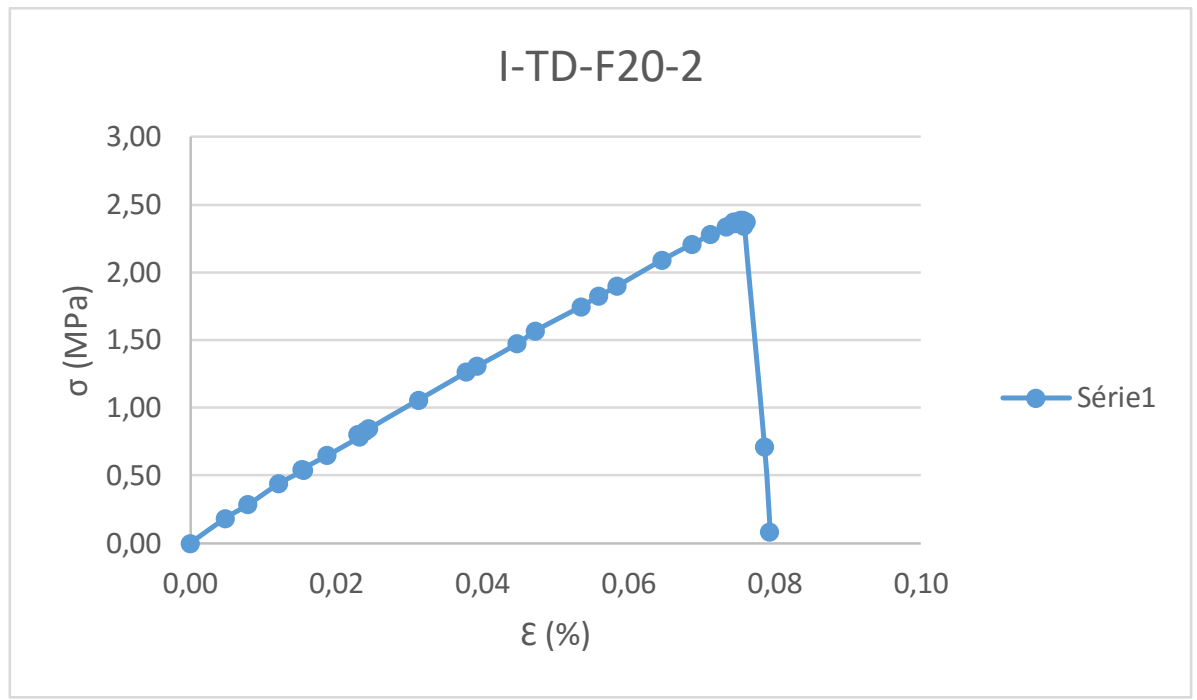

Figura 5.73 - Curva tensão-deformação específica, I-TD-F20-2.

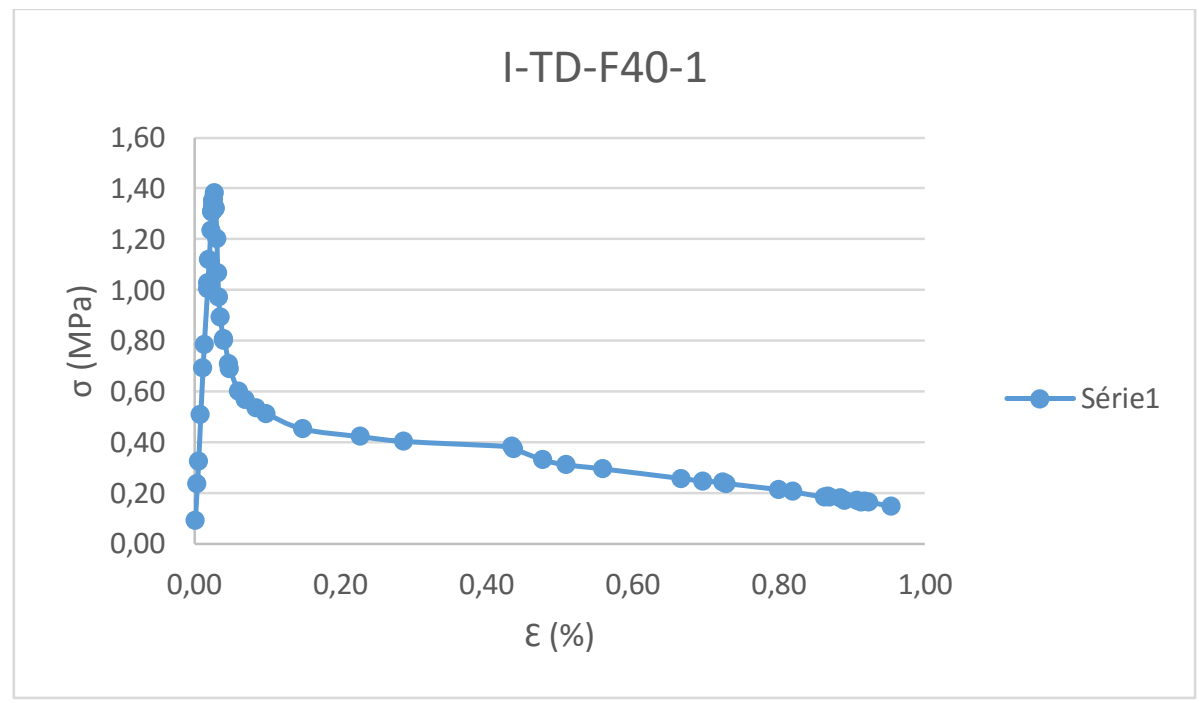

Figura 5.74 - Curva tensão-deformação específica, I-TD-F40-1.

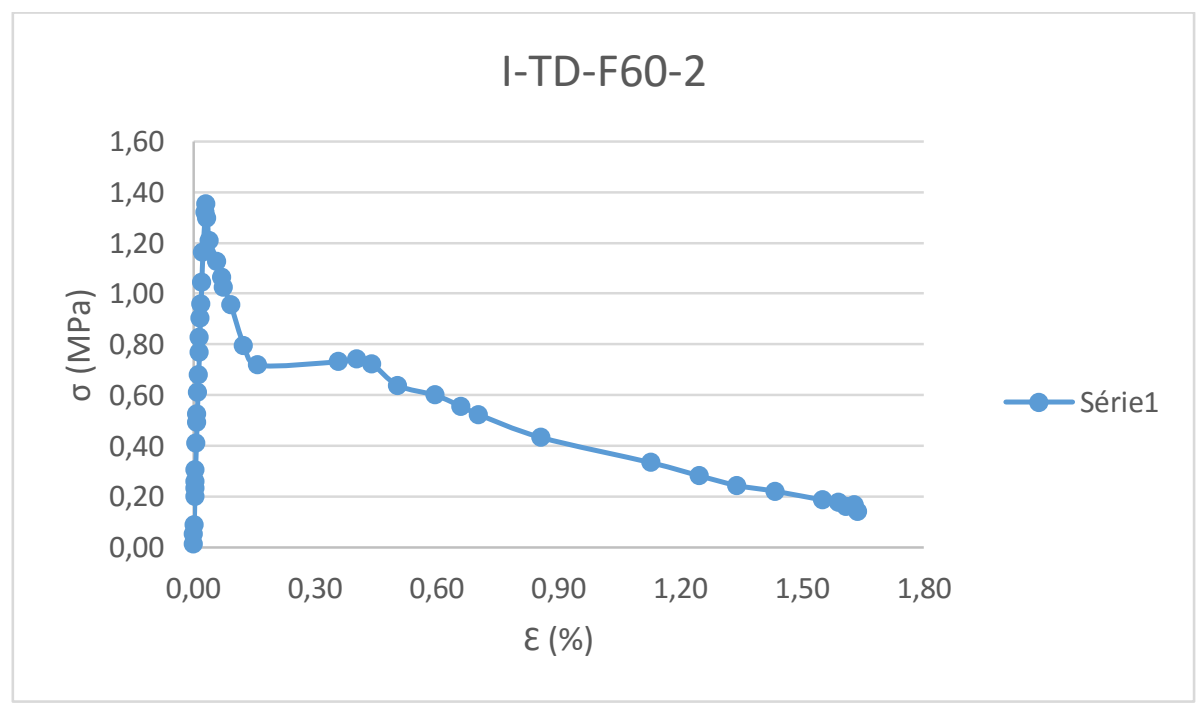

Figura 5.75 - Curva tensão-deformação específica, I-TD-F60-2. 
Das Figuras 5.73 a 5.75 observa-se que a deformação específica $\varepsilon$ aumenta para concretos com o consumo maior de fibras.

A ductilidade é a propriedade do material que indica o grau de deformação que o mesmo suporta até o momento de sua fratura. Os materiais frágeis são caracterizados por suportar pouca ou nenhuma deformação no processo de ensaio de tração. Já um material dúctil apresenta grande deformação.

Na Tabela 5.10 tem-se o percentual de deformação específica de cada corpo de prova definido por (SOCHOR,2001):

$$
\% \varepsilon=100 . \Delta l / l_{0}
$$

onde $\Delta l$ indica o quanto o corpo de prova deformou no ensaio de tração direta.

Observa-se nas Figuras 5.73 a 5.75 que a variação da tensão e deformação específica é linear para os pequenos valores de estágios de carregamento.

Tabela 5.10 - Percentual de deformação específica.

\begin{tabular}{c|c|c|c}
\hline $\begin{array}{c}\text { Corpo de } \\
\text { prova }\end{array}$ & $\begin{array}{c}100 * \frac{\Delta l}{l_{0}} \\
(\%)\end{array}$ & $\begin{array}{c}\text { Corpo de } \\
\text { prova }\end{array}$ & $\begin{array}{c}100 * \frac{\Delta l}{l_{0}} \\
(\%)\end{array}$ \\
\hline I-TD-F20-2 & 0,08 & II-TD-F40-2 & 1,93 \\
\hline I-TD-F40-1 & 0,95 & II-TD-F60-1 & 1,48 \\
\hline I-TD-F40-2 & 0,95 & II-TD-F60-2 & 1,26 \\
\hline I-TD-F60-2 & 1,63 & III-TD-F20-1 & 0,07 \\
\hline II-TD-F20-1 & 0,07 & III-TD-F40-1 & 1,63 \\
\hline II-TD-F20-2 & 0,05 & III-TD-F40-2 & 1,71 \\
\hline II-TD-F40-1 & 1,97 & III-TD-F60-1 & 1,59 \\
\hline II-TD-F40-2 & 1,93 & III-TD-F60-2 & 0,70 \\
\hline
\end{tabular}

\subsubsection{1}

\section{Relação da força de tração nos corpos de prova}

Na Tabela 5.11 tem-se a razão entre a força de tração do corpo de prova de $15 \mathrm{~cm}$ de diâmetro pela do corpo de prova de 5 e $10 \mathrm{~cm}$ de diâmetro e do corpo de prova de $10 \mathrm{~cm}$ pela do corpo de prova de $5 \mathrm{~cm}$, além das médias, desvio padrão e coeficiente de variação desses resultados. 
Tabela 5.11 - Razão da força de tração.

\begin{tabular}{|c|c|c|c|}
\hline & $\frac{f t_{15}}{f t_{5}}$ & $\frac{f t_{15}}{f t_{10}}$ & $\frac{f t_{10}}{f t_{5}}$ \\
\hline I-F20 & 0,64 & 0,92 & 0,69 \\
\hline I-F40 & 0,50 & 0,77 & 0,64 \\
\hline I- F60 & 0,58 & 0,95 & 0,61 \\
\hline II -F20 & 0,60 & 1,09 & 0,55 \\
\hline II-F40 & 0,59 & 0,95 & 0,63 \\
\hline II- F60 & 0,61 & 0,85 & 0,72 \\
\hline III -F20 & 0,64 & 0,82 & 0,79 \\
\hline III-F40 & 0,58 & 0,82 & 0,70 \\
\hline III- F60 & 0,49 & 0,69 & 0,72 \\
\hline Média & 0,581 & 0,873 & 0,67 \\
\hline DP & 0,054 & 0,119 & 0,07 \\
\hline cov & 9,241 & 13,620 & 10,64 \\
\hline
\end{tabular}

Para os ensaios realizados o coeficiente de variação é aceitável.

\subsubsection{2}

\section{Ruptura}

Em todos os corpos de prova submetidos ao ensaio de tração por compressão diametral houve o desenvolvimento de uma fissura na sua região central. Nas Figuras 5.76 a 5.79 observa-se a ruptura de alguns corpos de prova ensaiados.

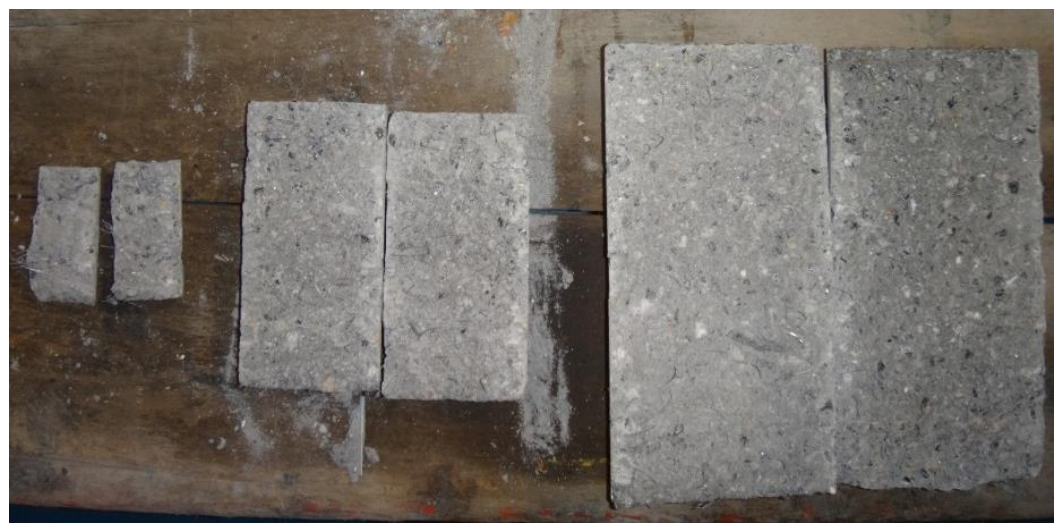

Figura 5.76 - Corpos de prova com consumo de fibra de $20 \mathrm{~kg} / \mathrm{m}^{3}$.

Nota-se que na Figura 5.76 os corpos de prova apresentaram ruptura frágil, resultando em duas metades imediatamente após a força atingir o valor máximo. Na Figura 5.77 os corpos de prova apresentaram ruptura dúctil, pois as fibras costuram a linha de ruptura, não deixando que o corpo de prova se parta totalmente. 
Nas Figuras 5.78 e 5.79 é possível ver a comparação entre os corpos de prova com $20 \mathrm{~kg} / \mathrm{m}^{3}$ e $60 \mathrm{~kg} / \mathrm{m}^{3}$.

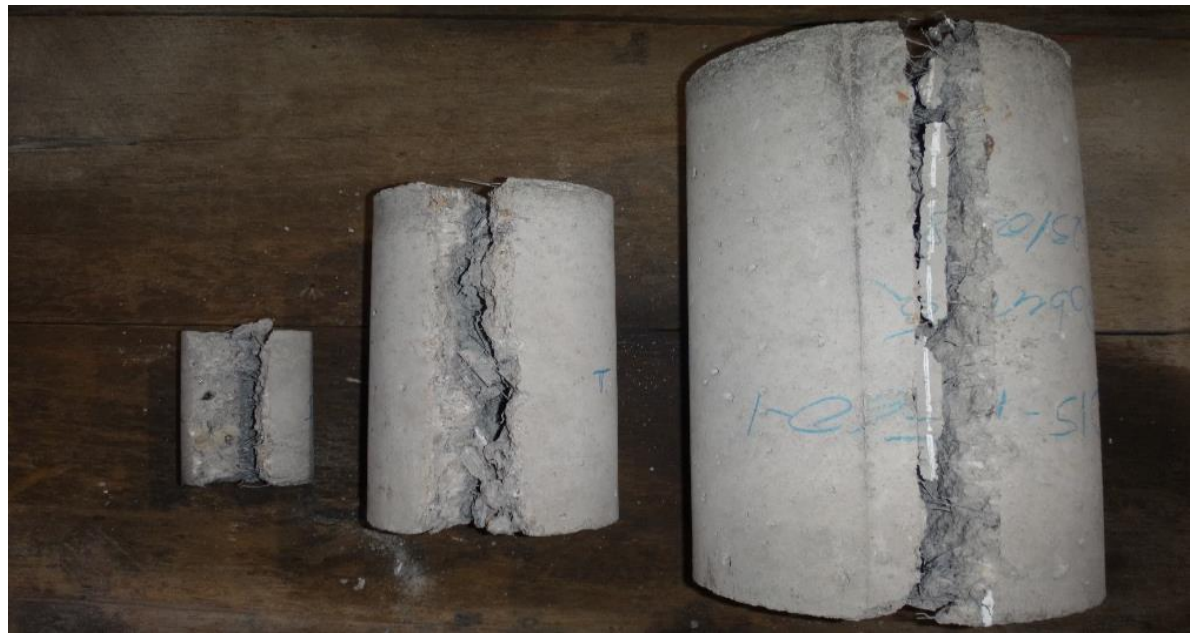

Figura 5.77 - Corpos de prova com consumo de fibra de $60 \mathrm{~kg} / \mathrm{m}^{3}$.

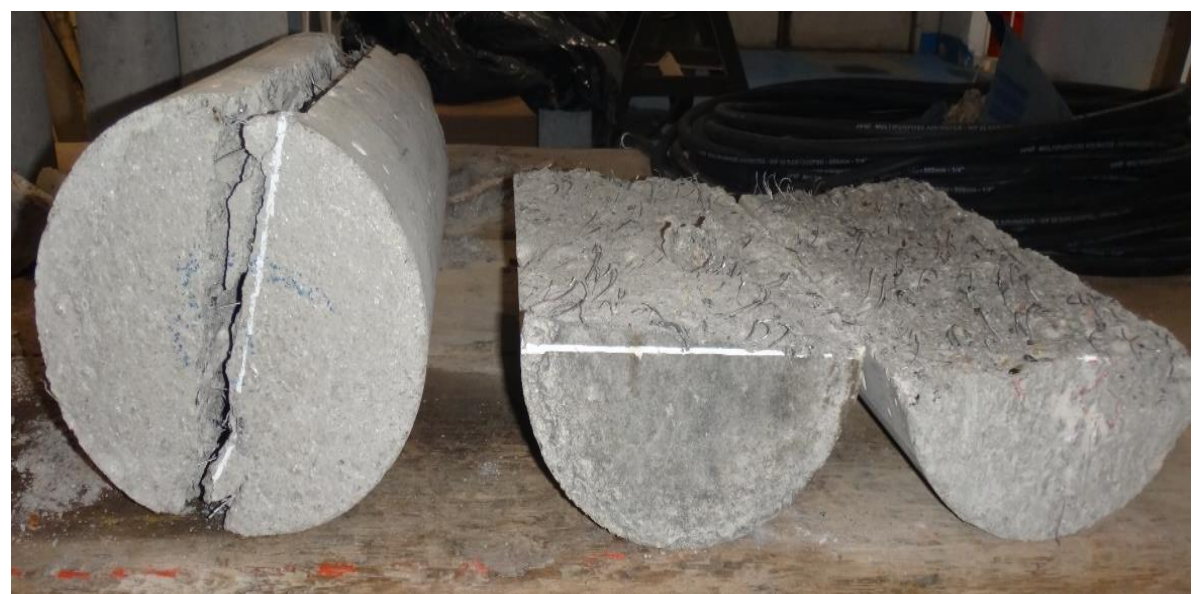

Figura 5.78 - Corpos de prova D10 com consumo de fibra de $20 \mathrm{~kg} / \mathrm{m}^{3}$ e $60 \mathrm{~kg} / \mathrm{m}^{3}$.

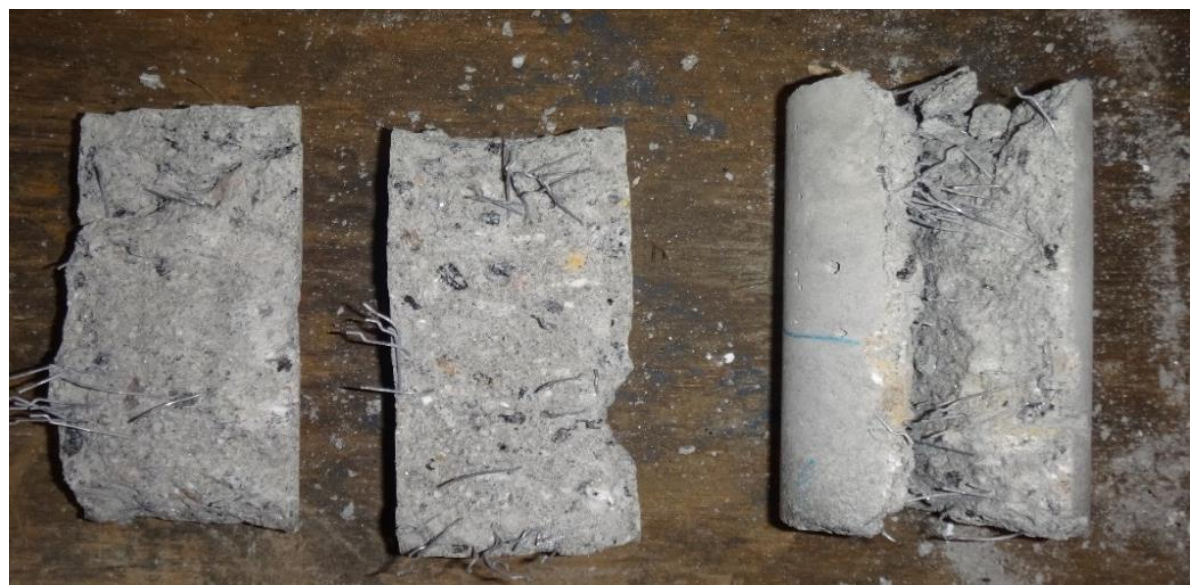

Figura 5.79 - Corpos de prova D5 com consumo de fibra de $20 \mathrm{~kg} / \mathrm{m}^{3}$ e $60 \mathrm{~kg} / \mathrm{m}^{3}$. 
5.3 .13

Ângulo interno

Segundo CHEN (1982):

$$
\frac{f_{c}}{f_{t}} \cong 2 \operatorname{tg}^{2}\left(\frac{\pi}{4}+\frac{\varphi}{2}\right)
$$

A partir dos valores experimentais de $f_{c}$ (resistência à compressão) e $f_{t}$ (resistência à tração por compressão diametral) obtém-se os seguintes ângulos (Tabela 5.12).

Tabela 5.12 - Ângulo de atrito interno.

\begin{tabular}{c|c|c}
\hline & $\frac{f_{c}}{f_{t}}$ & Ângulo \\
\hline Série 1 & 14,98 & 49,86 \\
\hline Série 2 & 10,39 & 42,63 \\
\hline Série 3 & 11,18 & 44,14 \\
\hline Série 4 & 14,07 & 48,69 \\
\hline Série 5 & 14,81 & 49,65 \\
\hline Série 6 & 13,77 & 48,27 \\
\hline Série 7 & 12,98 & 47,14 \\
\hline Série 8 & 12,47 & 46,36 \\
\hline Série 9 & 11,40 & 44,56 \\
\hline
\end{tabular}

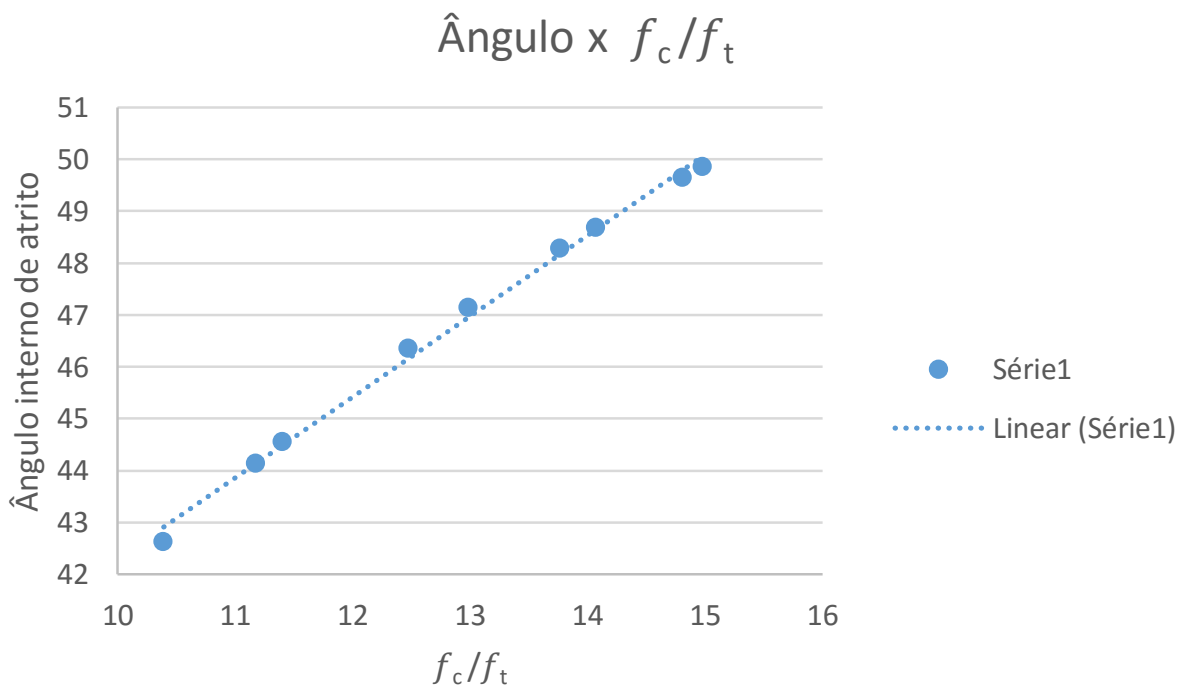

Figura 5.80 - Variação do ângulo de atrito interno em função de $\frac{f_{c}}{f_{t}}$. 
CHEN (1982) propôs a seguinte expressão teórica para o cálculo da carga última a partir do ensaio de compressão diametral:

$$
Q^{u}=\frac{a}{\operatorname{sen} \beta}\left\lfloor\frac{f_{c} l(1-\operatorname{sen} \varphi)}{\cos (\beta+\varphi)}-2 f_{t} \operatorname{lcos} \beta \operatorname{tg}(\beta+\varphi)\right\rfloor+f_{t} \operatorname{ldtg}(\beta+\varphi)
$$

onde

$$
\cot \beta=\operatorname{tg} \varphi+\sec \varphi\left[1+\frac{\left(\frac{d}{2 a}\right) \cos \varphi}{\left(\frac{f_{c}}{f_{t}}\right)[(1-\operatorname{sen} \varphi) / 2]-\operatorname{sen} \varphi}\right]^{1 / 2}
$$

e as constantes $d, 2 a, l, f_{c}$ e $f_{t}$ são as dimensões dos corpos de prova e dos resultados dos ensaios. A Tabela 5.13 mostra os valores de $Q^{u}$ calculados com a equação 5.4, os valores experimentais e a razão entre eles.

\begin{tabular}{|c|c|c|}
\hline CHEN & ENSAIO & CHEN/ENSAIO \\
\hline 115,65 & 77,86 & 1,49 \\
\hline 126,18 & 94,95 & 1,33 \\
\hline 110,99 & 79,42 & 1,40 \\
\hline 130,53 & 80,63 & 1,62 \\
\hline 150,42 & 100,03 & 1,50 \\
\hline 149,94 & 96,00 & 1,56 \\
\hline 184,66 & 118,54 & 1,56 \\
\hline 187,55 & 128,76 & 1,46 \\
\hline \multirow[t]{4}{*}{201,88} & 139,00 & 1,45 \\
\hline & Média & 1,48 \\
\hline & DP & 0,09 \\
\hline & $\operatorname{COV}(\%)$ & 6,00 \\
\hline
\end{tabular}

Tabela 5.13 - Razão entre valores teóricos e experimentais.

Constata-se que os valores fornecidos peça expressão 5.4 são em média $50 \%$ maiores do que os experimentais.

\subsubsection{4}

\section{Métodos comparativos}

De acordo com a expressão 3.5 do item 3.4 e com os dados obtidos nos ensaios experimentais tem-se a Tabela 5.14 e o gráfico da Figura 5.81. 


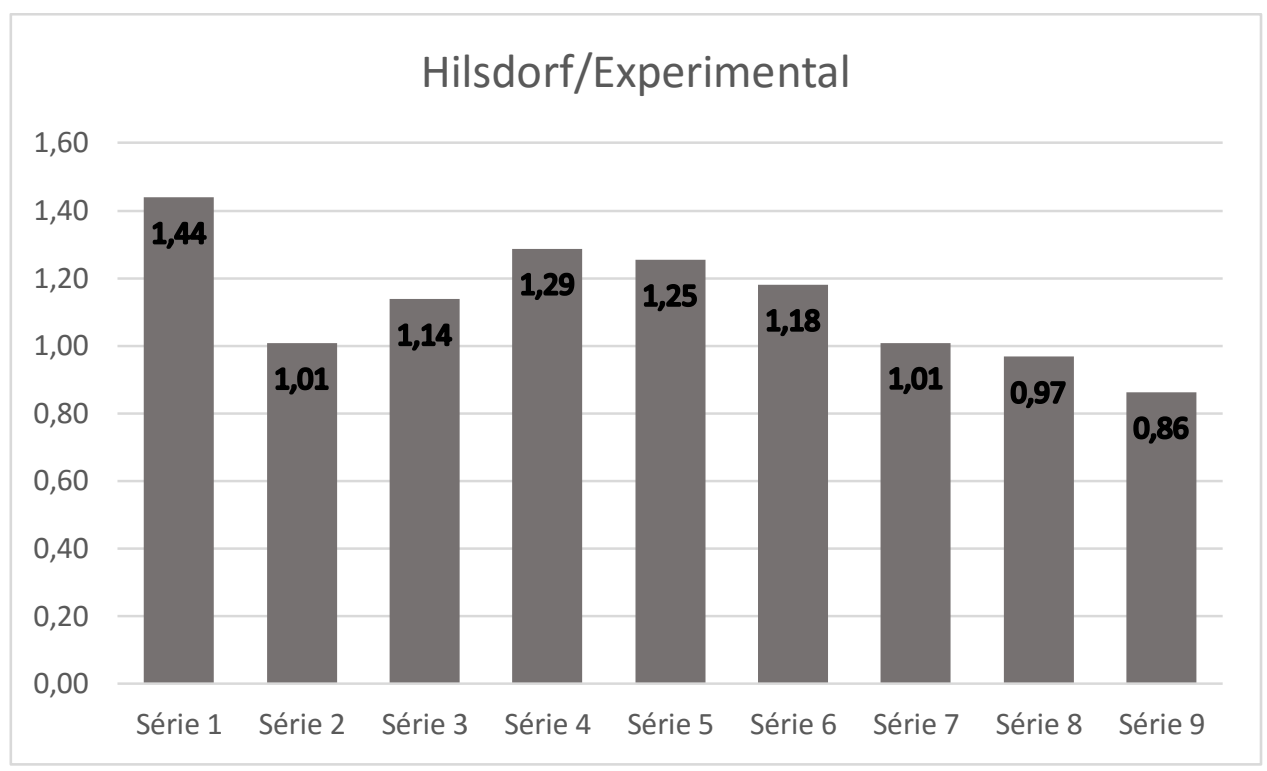

Figura 5.81 - Razão da força de tração pela fórmula proposta por HILSDORF pela obtida experimentalmente.

Tabela 5.14 - Resultados da expressão 3.5 e dados experimentais.

\begin{tabular}{c|c|c|c}
\cline { 2 - 4 } & HILSDORF & Experimental & Razão \\
\hline Série 1 & 3,01 & 2,09 & 1,44 \\
\hline Série 2 & 2,97 & 2,95 & 1,01 \\
\hline Série 3 & 2,80 & 2,47 & 1,14 \\
\hline Série 4 & 3,17 & 2,47 & 1,29 \\
\hline Série 5 & 3,44 & 2,74 & 1,25 \\
\hline Série 6 & 3,39 & 2,88 & 1,18 \\
\hline Série 7 & 3,72 & 3,69 & 1,01 \\
\hline Série 8 & 3,73 & 3,86 & 0,97 \\
\hline Série 9 & 3,81 & 4,42 & 0,86 \\
\hline & & Média & 1,13 \\
\cline { 3 - 4 } & & DP & 0,18 \\
\cline { 3 - 4 } & & COV (\%) & 16,16 \\
\cline { 3 - 4 } & & &
\end{tabular}

O coeficiente de variação é inferior a $25 \%$, donde se conclui que os resultados obtidos pelos dois métodos são aceitáveis.

\subsubsection{5}

\section{Efeito escala}

De acordo com o capítulo 3 verifica-se a razão entre a lei de Carpinteri e o estudo experimental realizado, a constante utilizada para a expressão 3.3 foi $\alpha_{0}=0,5$, obtendo-se as Figuras 5.82 a 5.84. Analisando-se essas figuras constatase que os resultados obtidos experimentalmente se assemelham aos estudos 
realizados por CARPINTERI (1995), devido a boa aproximação dos resultados experimentais.

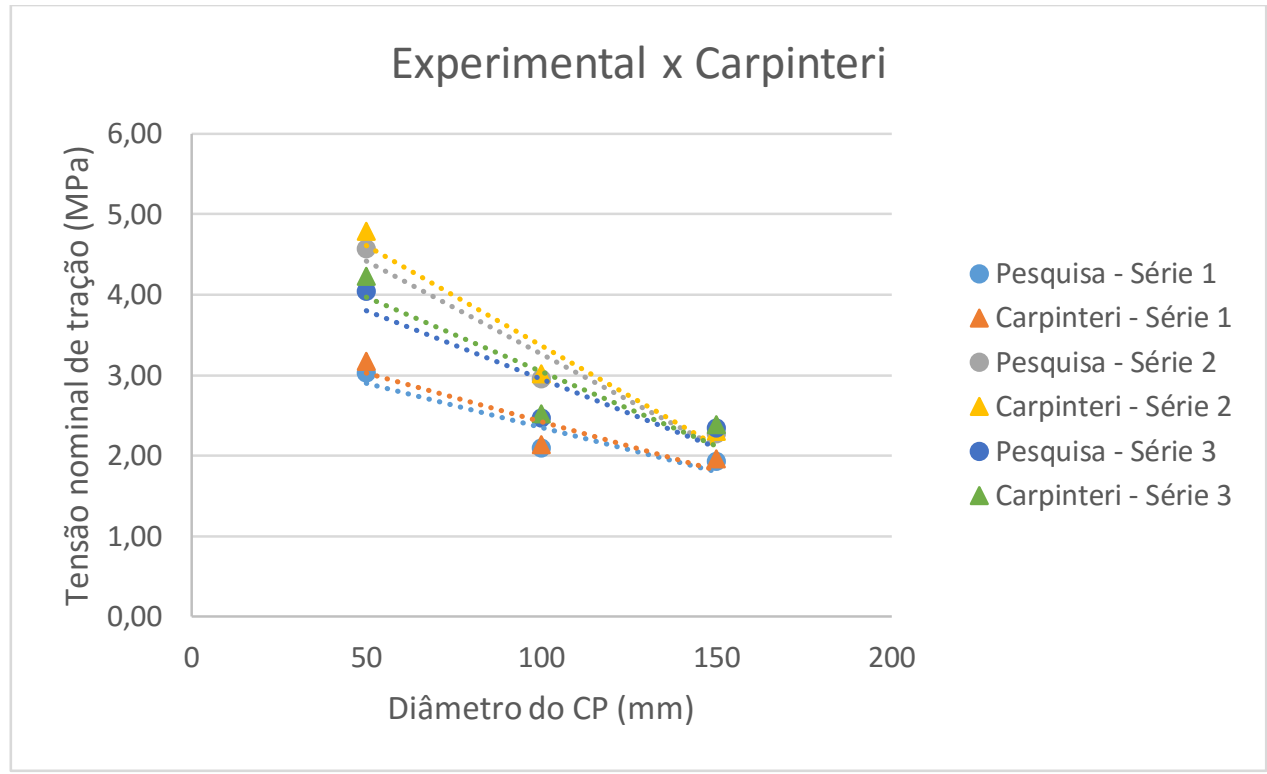

Figura 5.82 - Lei de Carpinteri x valores experimentais, Séries 1, 2 e 3.

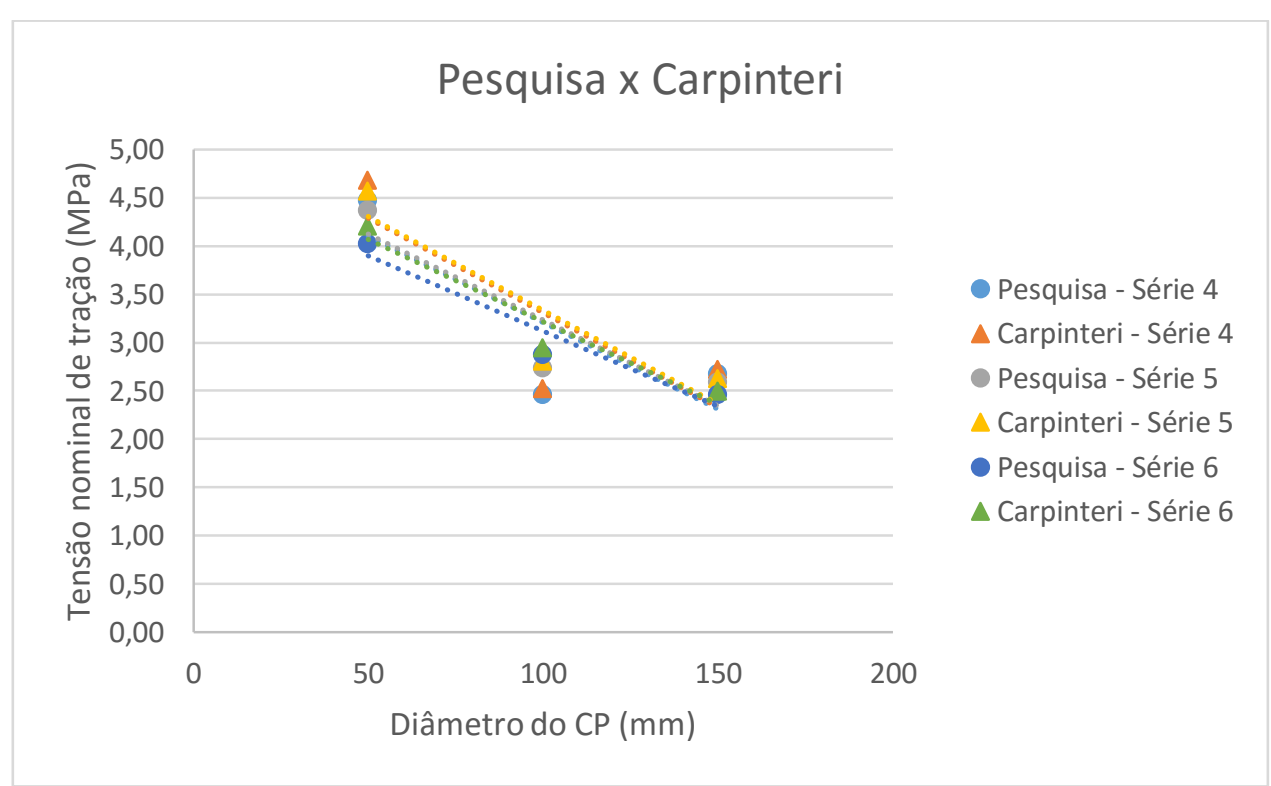

Figura 5.83 - Lei de Carpinteri x valores experimentais, Séries 4, 5 e 6. 


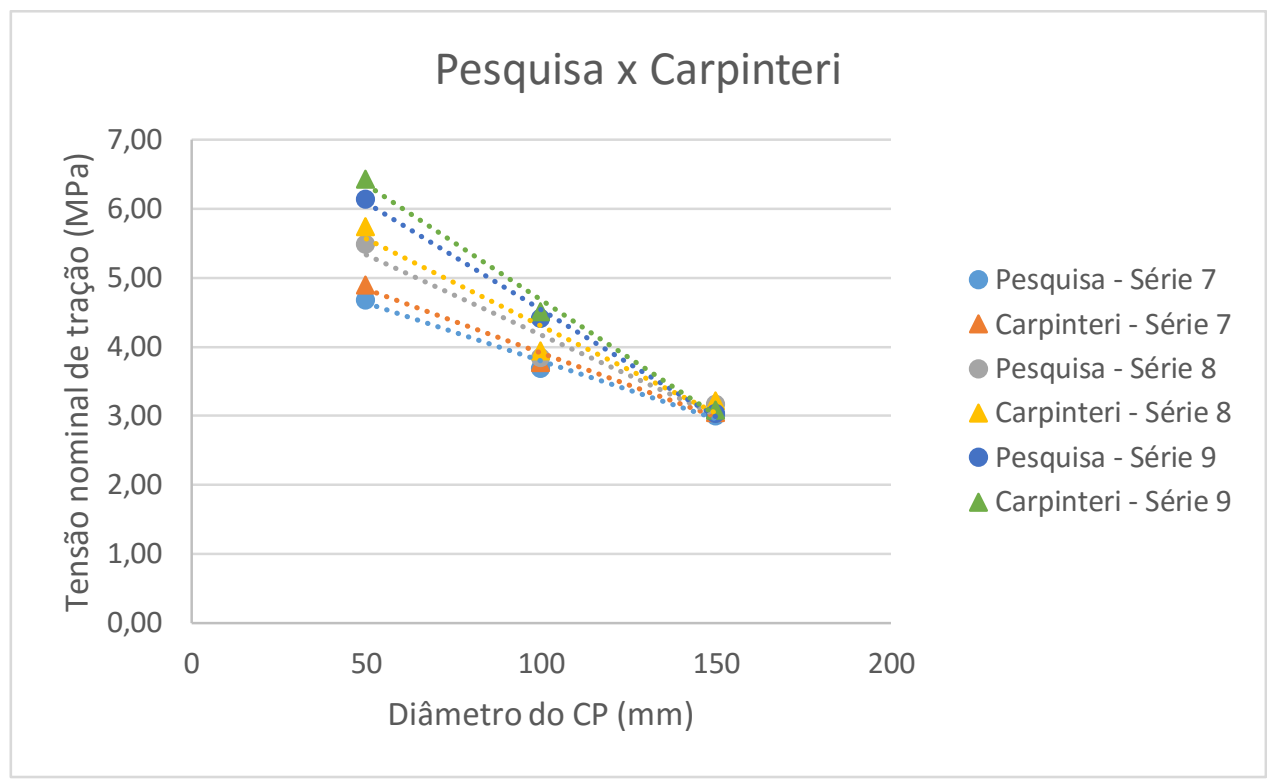

Figura 5.84 - Lei de Carpinteri x valores experimentais, Séries 7, 8 e 9.

Com os gráficos das Figuras 5.82 a 5.84 têm-se que quanto maior é a dimensão do corpo de prova, menor é sua tensão nominal de tração. Isto ocorre para todos os valores de consumo de fibra adotados. Para os diâmetros de $50 \mathrm{~mm}$ observa-se que as tensões de tração são diferentes para os consumos, porém, essa diferença tem uma redução com o aumento do diâmetro. Nos diâmetros de $150 \mathrm{~mm}$ a tensão de tração é praticamente igual para todos os consumos. 


\section{6 \\ Conclusões e sugestões para trabalhos futuros}

\section{1 \\ Conclusões}

O estudo realizado limita-se às características dos materiais utilizados, as dimensões dos corpos de prova, os teores de fibras de aço e de suas propriedades mecânicas. A partir da análise de resultados experimentais e teóricos pode-se concluir que:

\subsection{1}

\section{Ensaio de tração por compressão diametral}

1. Para um mesmo diâmetro e mesma resistência à compressão, quanto maior o consumo de fibras maior é a resistência à tração, sendo que o acréscimo de $f_{t}$ varia linearmente com o aumento de $f_{c}$, para todos os diâmetros e consumos de fibras analisados.

2. Existe influência significativa do consumo de fibras de aço na resistência à tração por compressão diametral dos CAFA. Para um mesmo diâmetro e mesma resistência à compressão, quanto maior o consumo de fibras maior é a resistência à tração, sendo que o acréscimo de $f_{t}$ varia linearmente com o aumento de $f_{c}$, para todos os diâmetros e consumos de fibras.

3. O consumo de fibras tem menor influência na resistência à tração quando o corpo de prova tem maiores dimensões.

4. Existe influência significativa das dimensões dos corpos de prova na resistência à tração por compressão diametral dos CAFA. Para um mesmo consumo de fibras e mesma resistência à compressão, quanto maior é o diâmetro do corpo de prova menor é a sua resistência de tração, sendo que o ensaio do corpo de prova de $5 \mathrm{~cm}$ de diâmetro só é válido com fibras pequenas, de até $3 \mathrm{~cm}$. 
5. Para os ensaios realizados a resistência à tração varia linearmente com o consumo e o diâmetro do corpo de prova.

6. A análise dos resultados dos ensaios utilizando-se a média dos valores obtidos para cada grupo apresenta anomalias, que foram corrigidas ao se considerar todos os resultados individuais.

7. A resistência à tração do D15 é em torno de $55 \%$ menor do que a resistência do D5.

8. O aumento da resistência à compressão de $30 \mathrm{MPa}$ para $40 \mathrm{MPa}$, acarreta um acréscimo de resistência à tração maior no concreto com consumo F20 do que nos consumos F40 e F60.

9. O aumento da resistência à compressão de $40 \mathrm{MPa}$ para $50 \mathrm{MPa}$ acarretou aumento da resistência à tração para todos os consumos de fibras.

10. O acréscimo da resistência à compressão tem maior influência na resistência à tração do que o maior consumo de fibras.

11. Os concretos de $30 \mathrm{MPa}$ apresentaram um acréscimo maior de resistência à tração com o aumento do consumo de fibras do que os concretos de $40 \mathrm{MPa}$ e $50 \mathrm{MPa}$.

12. O maior acréscimo de energia dissipada quando comparado os consumos F20 para F40 é quando o concreto apresenta menor resistência à compressão, o mesmo ocorre quando há variação de F20 para F60.

13. O acréscimo do consumo de fibras de F40 para F60 não teve influência significativa na energia dissipada.

14. A partir da Figura 5.80 conclui-se que quanto maior é a razão $\frac{f_{c}}{f_{t}}$, maior é o ângulo de atrito, pois são linearmente independentes.

\subsection{2}

\section{Razão $\Psi$}

15. A razão $\Psi$ sempre aumenta com o acréscimo do consumo de fibras para todos os diâmetros e $f_{c}$, e varia inversamente com o diâmetro para todos os corpos de prova. 


\subsection{3 \\ Ensaio de tração direta}

16. A região plástica não fica delineada para o consumo de $20 \mathrm{~kg} / \mathrm{m}^{3}$ (Figura 5.63).

17. A energia elástica de deformação aumenta com a resistência à compressão.

18. O comportamento do concreto com consumo de fibras reduzido é similar ao do concreto simples.

19. Com o aumento da resistência à compressão tem-se o aumento da energia plástica de deformação.

20. Os concretos com maiores resistências à compressão (a partir de 40 $\mathrm{MPa}$ ), têm comportamento similares para os consumos de F40 e F60.

21. O acréscimo do consumo de fibras acarreta uma diminuição da queda da força aplicada após o pico de carga.

22. O acréscimo do consumo de fibras acarreta uma diminuição da resistência à tração direta.

\subsection{4 \\ Efeito escala}

23. Quando a dimensão do agregado é pequena em relação às dimensões do corpo de prova $(15 \mathrm{~cm}$ x $30 \mathrm{~cm})$, o efeito escala tende a desaparecer devido a "homogeneidade" do material. Entretanto, no corpo de prova $(5 \mathrm{~cm} \times 10 \mathrm{~cm}) \mathrm{a}$ "heterogeneidade" do material faz com que o efeito escala fique evidente.

24. A configuração da curva representativa do comportamento da resistência à tração por compressão diametral do CAFA em função da variação do diâmetro do corpo de prova, aproxima-se da configuração da curva traçada com a equação de CARPINTERI et al. (1995).

25. Os resultados experimentais para resistência à tração por compressão diametral do concreto confirmam que o efeito escala está presente neste estudo, ou seja, há um decréscimo da resistência à tração com o incremento da dimensão do corpo de prova. 
26. Constata-se que os resultados obtidos experimentalmente sempre se assemelham aos estudos realizados por CARPINTERI (1992), mesmo com consumos de fibras diferentes.

27. O modelo de CARPINTERI (1992) é valido para CAFA, salientandose que é possível afirmar isso para os consumos estudados, ou seja, 20 $\mathrm{kg} / \mathrm{m}^{3}, 40 \mathrm{~kg} / \mathrm{m}^{3}$ e $60 \mathrm{~kg} / \mathrm{m}^{3}$.

28. As expressões para o efeito escala para a determinação da resistência mecânica do concreto devem ser reavaliadas para grandes estruturas, pois em grandes dimensões o efeito escala tende a diminuir.

29. Quanto maior é a dimensão do corpo de prova menor é a influência das fibras sobre a resistência à tração do concreto.

\section{2}

\section{Sugestões para trabalhos futuros}

Como sugestões para continuidade dessa pesquisa sugere-se:

i. realização de ensaios semelhantes aos realizados, porém, utilizandose um número maior de corpo de prova;

ii. realização de ensaios com consumo de fibras acima de $60 \mathrm{~kg} / \mathrm{m}^{3}$;

iii. realização de ensaios de tração direta com consumo de fibras de 25 , 30 e $35 \mathrm{~kg} / \mathrm{m}^{3}$, para analisar a partir de qual consumo o concreto começa a ter regime plástico;

iv. realização de ensaios semelhantes aos realizados, porém, com outros tipos de fibras;

v. realização de mais pesquisas para verificação do efeito tamanho, variando os diâmetros máximos dos agregados;

vi. na verificação do efeito escala sugere-se que se realize ensaios com maior variabilidade nos diâmetros de corpos de prova para determinação da resistência à tração por compressão diametral do CAFA;

vii. verificar o efeito escala devido às fibras, utilizando-se fibras de aço com diferentes dimensões e índice de esbeltez. 


\section{7}

\section{Referências bibliográficas}

ACI 544.4R-88; AMERICAN CONCRETE INSTITUTE. Manual of Concrete Practice: Design Considerations for Steel Fiber Reinforced Concrete. Detroit, v.85.1988.

ACI 544.1R-96; AMERICAN CONCRETE INSTITUTE. Manual of concrete practice: State of the art report on fiber reinforced concrete. Detroit. v.93.1996.

ASSOCIAÇÃO BRASILEIRA DE NORMAS TÉCNICAS - NBR-7222: Argamassa e Concreto - Determinação da Resistência à Tração por Compressão Diametral de Corpos de prova Cilíndrico. Brasil, 1994.

ASSOCIAÇÃO BRASILEIRA DE NORMAS TÉCNICAS - NBR-9937: Agregados - Determinação da absorção e da massa específica de agregado graúdo. Rio de Janeiro, 1987.

ASSOCIAÇÃO BRASILEIRA DE NORMAS TÉCNICAS - NBR-7217: Agregados - Determinação da composição granulométrica. Rio de Janeiro, 1987

ASSOCIAÇÃO BRASILEIRA DE NORMAS TÉCNICAS - NBR NM 67:1998. Concreto - Determinação da Consistência pelo Abatimento do Tronco de Cone. Rio de Janeiro, 1998.

ASSOCIAÇÃO BRASILEIRA DE NORMAS TÉCNICAS - NBR-8522: Concreto - Determinação dos módulos estáticos de elasticidade e de deformação e da curva tensão-deformação. Rio de Janeiro, 2008. 
ASSOCIAÇÃO BRASILEIRA DE NORMAS TÉCNICAS - NBR-5739: Concreto - Ensaio de Compressão de Corpos de prova de Concreto Cilíndricos - Método de Ensaio. Rio de Janeiro, 1994.

ASSOCIAÇÃO BRASILEIRA DE NORMAS TÉCNICAS - NBR-15530: Fibras de aço para concreto - Especificações. Brasil, 2007.

ASSOCIAÇÃO BRASILEIRA DE NORMAS TÉCNICAS - NBR-5738: Moldagem e Cura de Corpos de Prova Cilíndricos ou Prismáticos de Concreto. Rio de Janeiro, 2003.

AVESTON, J.; COOPER, G. A.; KELLY, A. Single and Multiple fracture. Conference on the Properties of Fiber Composites, p.15-26., London, 1971.

BARROS, J. A. O. Caracterização do comportamento do betão reforçado com fibras de aço por intermédio de ensaios experimentais. Jornadas de Estruturas de Betão, Betões de Elevado Desempenho, 151-170, 1996.

BARROS, J. A. O.; CRUZ, J. S.; UIRIX, E. Avaliação da Capacidade de Absorção de Energia de Betões Reforçados com Fibras de aço. Portugal, 1999.

BENTUR, A.; MINDESS, S. Fiber Reinforced Cementitious Composites. New York. Barking, Elsevier Science Publishers, 1990.

BAZANT, Z. P. Size Effect in Blunt Fracture. Concrete, Rock, Metal, Journal of Engeneering Mechanics, ASCE, 518-535, 1984.

BAZANT, Z. P.; KAZEMI, M. T.; HASEGAWA, T.; MAZARS, J. Size Effect in Brazilian Split-cylinder tests: Measurements and Fractura Analysis. ACI Journal, Vol 88, p 325-332, 1991. 
CARMONA, S.; GETTU, R.; HURTADO, C.; MARTíN, M. A. Use of Splitting-Tension Test To Characterize The Toughness Of Fiber-Reforced Concrete. Anales de mecanica de la fractura, v.12, p 233-238. 1995.

CARPINTERI, A. Fractal Nature of Material Microstructure and Size Effect on Apparent Mechanical Properties. Mechanics of Materials, 1992.

CARPINTERI, A.; CHIAIA, B.; FERRO, G. Size effects on nominal tensile strength of concrete structures: multifractality of material ligaments and dimensional transition from order to disorder. Materials and Structures. $p$ 311-317. 1995.

CASTRO, N. S. Influência Do Agregado Graúdo Na Trabalhabilidade Do Concreto Reforçado Com Fibra De Aço. Feira de Santana, 2010. 72p. Dissertação de Mestrado - Departamento de Tecnologia, Universidade Estadual de Feira de Santana.

CALLISTER, W. D. Ciência e Engenharia de materiais: uma introdução.8. ed. LTC. Rio de Janeiro, 2012.

CHEN. Plasticity in reinforced concrete. McGraw-Hill, 1982.

COURA, C. V. G., BARBOSA, M. T. G., DARWISH, F. A. I. Análise da Lei de Bazant e Carpinteri na Resistência à Compressão do Concreto. Rev. Int. De Desastres Naturales, Accidentes e Infraestrutura Civil. Vol 8(1), 2007.

COURA, C. V. G. Estudo da influência da Dimensão do Agregado e do Corpo de prova na Resistência à compressão do Concreto. Dissertação de Mestrado. Universidade Federal Fluminense, Brasil, 2006.

CUCCHIARA, C.; MENDOLA, L. L.; PAPIA, M. Effectiveness of strirrups and steel fibres as shear reinforcement. Cement and Concrete Composites, v.26, n.7, p.777-786, 2004. 
DENNEMAN, E.; KEARSLEY, E. P.; VISSER, A. T. Splitting tensile test for fibre reinforced concrete. Materials and Structures, 2011.

ELFAHAL, M. M; KRAUTHAMMER, T; OHNO, T; BEPPU, M; MINDESS, S. Size effect for normal strength concrete cylinders subjected to axial impact. International Journal of Impact Engineering. 2004.

ELFAHAL, M. M; KRAUTHAMMER, T; Dynamic Size effect in normal and High-Strength concrete cylinders. ACI Materials Journal. Vol 102, p 77-85, 2005.

FIGUEIREDO, A. D. CONCRETO COM FIBRAS DE AÇO. Escola Politécnica da Universidade de São Paulo. Boletim técnico. São Paulo, 2000.

FIGUEIREDO, A. D. Concreto com Fibras. Concreto Ensino, Pesquisa e Realizações. IBRACON, Ipisis Gráfica e Editora, São Paulo, 2005.

FIGUEIREDO, A. D.; CHAMA NETO, P. J.; FARIA, H. M. A nova normalização brasileira sobre fibras de aço. Concreto \& Construções. IBRACON. Ano XXXVI. № 50. ISSN 1809-7197. p. 67-75. 2008.

FIGUEIREDO, A. D.; CECCATO, M. R.; TORNERI, P. Influência do comprimento da fibra no desempenho do concreto reforçado com fibras de aço. Congresso Brasileiro do Concreto. São Paulo,1997.

HELENE, P. R. L.; TERZIAN, P. Manual de dosagem e controle do concreto. São Paulo: PINI, 1993.

MAIDL, B, R. Steel Fibre Reinforced Concrete. Ernst \& Sohn, Berlim, 1995. MARANGON, E. Desenvolvimento e Caracterização de Concretos Autoadensáveis Reforçados Com Fibras de Aço. Dissertação de mestrado, COPPE/Universidade Federal do Rio de Janeiro, Rio de Janeiro, 2006. 
MARANGON, E. Caracterização Material e Estrutural de Concretos Autoadensáveis Reforçados Com Fibras de Aço. Tese de Doutorado, COPPE/Universidade Federal do Rio de Janeiro, Rio de Janeiro, 2011.

MEHTA, P. K.; MONTEIRO, P. J. M. Concreto: Estrutura, propriedades e materiais. Editora Pini Ltda. São Paulo, novembro de 1994.

MINDESS, S. Fibre reinforced concrete: challenges and prospects. Second University-Industry Workshop on Fiber Reinforced Concrete and Other Advanced Materials. Canada. 1995.

NUNES, F. G. T.; ARAÚJO, D. L.; GUERRA, E. A. Influência da adição de fibras de aço nas propriedades mecânicas do concreto. Congresso Brasileiro de Concreto, Rio de Janeiro, 2006

NUNES, N. L. AGOPYAN, V. A Influência do Fator de Forma da Fibra na Tenacidade à Flexão do Concreto Reforçado com Fibras de Aço. Boletim Técnico, EPUSP, 18 p., São Paulo,1998.

RIOS, R. D.; RIERA, J. D.; ITURRIOZ, I. Uma Contribuição ao Entendimento do Efeito de Escala em Estruturas de Concreto. Programa de Pós-Graduação em Engenharia Civil - Universidade Federal do Rio Grande do Sul, Porto Alegre, 2002.

SILVA, F. A.; MOBASHER, B., TOLEDO FILHO, R.D. Recent Advances in High Perfomancem Natural (Sisal) Fiber Cement Composites. In: Seventh International Rilem Symposium on Fibre Reinforced Concrete: Design and Applications, pp. 105-113, Chenai. Rilem Publications S.A.R.L. 2008.

SOCHOR, M; Strength of Materials I. 2001.

TOLEDO FILHO, R. D. Materiais compósitos reforçados com fibras naturais: Caracterização experimental, Tese de Doutorado em Engenharia, DEC-PUC-Rio/DEC-Imperial College, Rio de Janeiro.1997. 


\section{A.Anexo A - Ensaios de compressão diametral}

Os gráficos desse anexo apresentam os resultados dos ensaios de compressão diametral.

\section{Série 1}

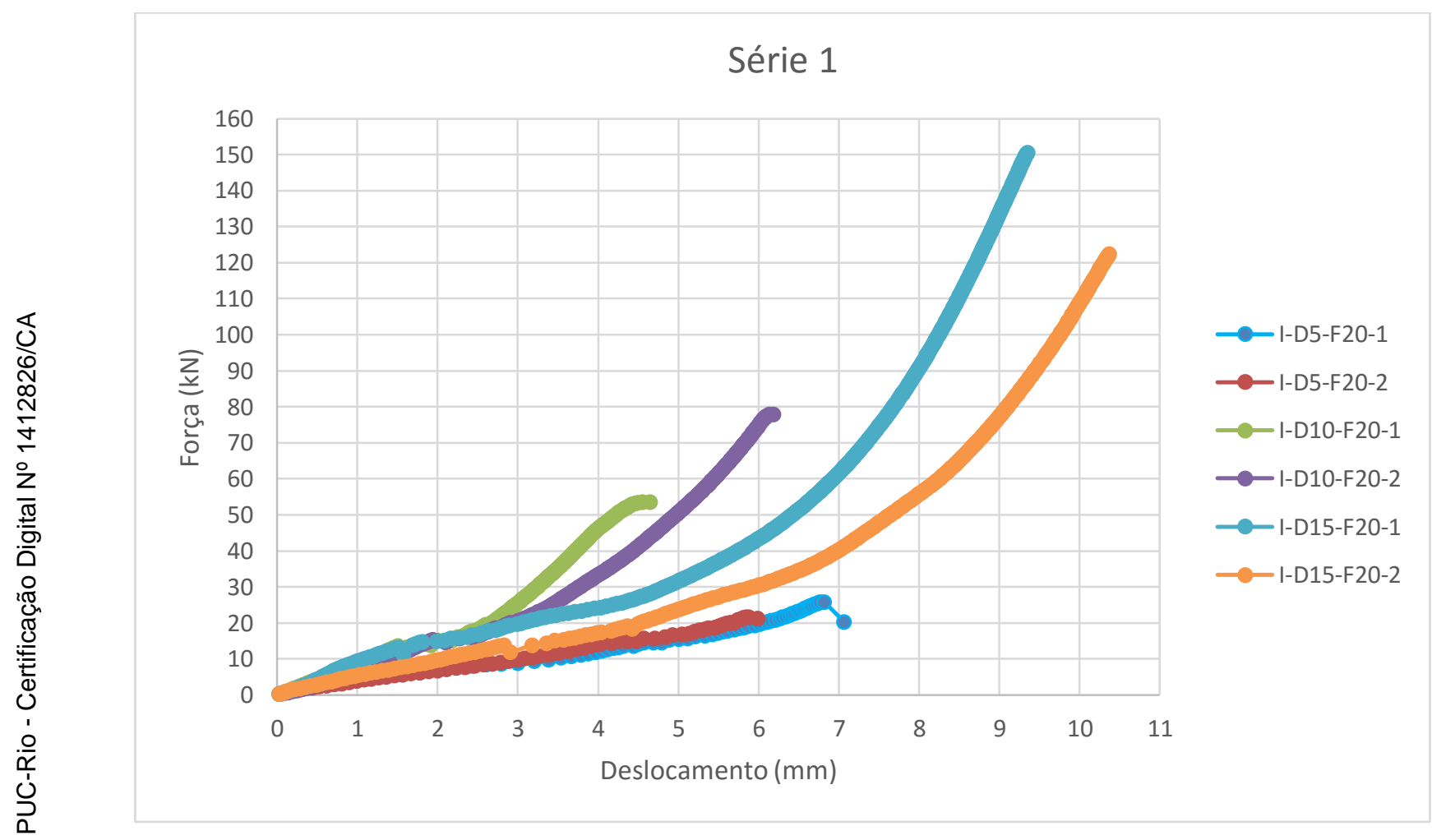

Figura A.1 - Força x deslocamento, Série 1. 


\section{Série 2}

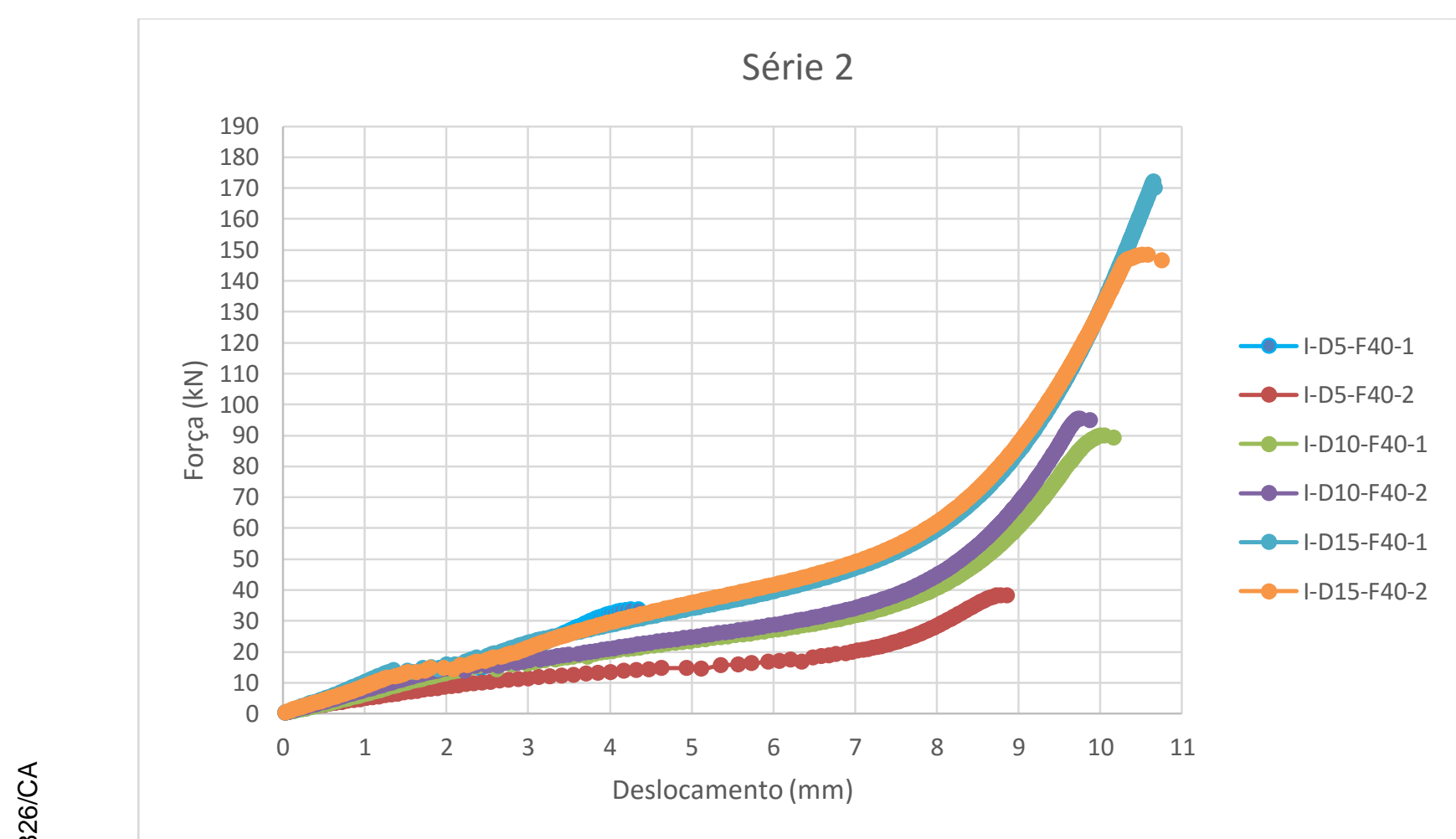

Figura A.2 - Força x deslocamento, Série 2.

\section{$\underline{\text { Série } 3}$}

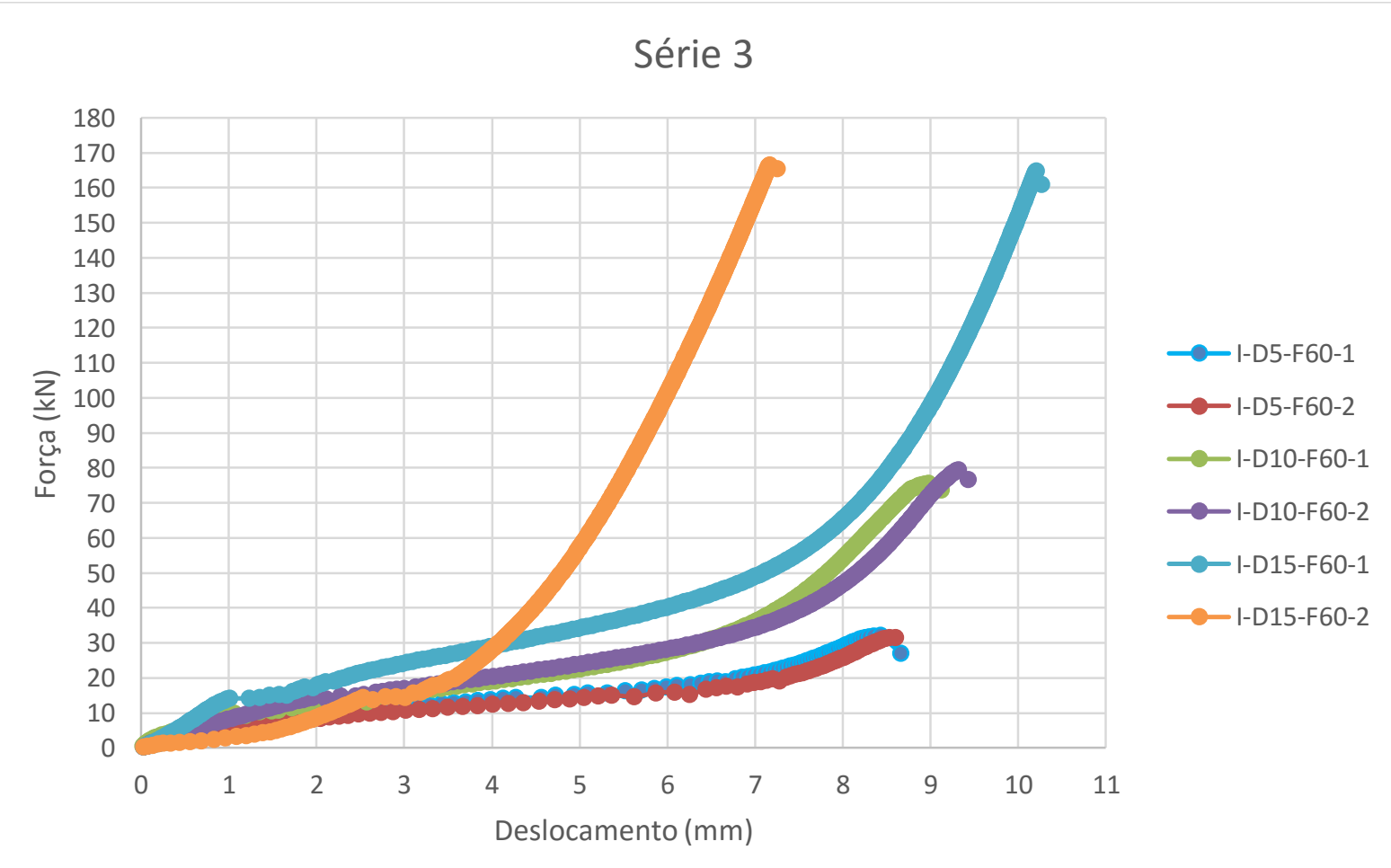

Figura A.3 - Força x deslocamento, Série 3. 


\section{Série 4}

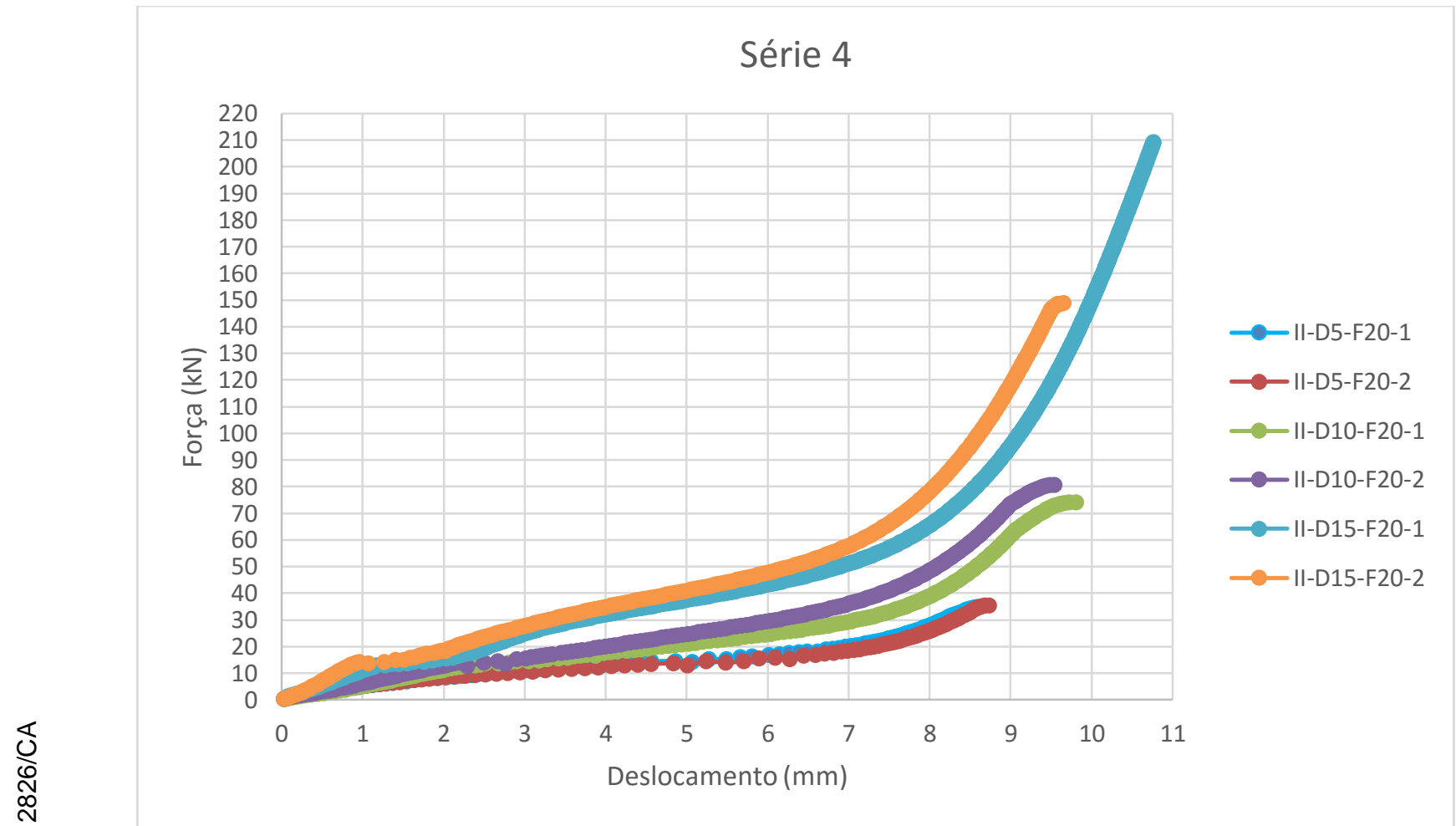

Figura A.4 - Força x deslocamento, Série 4.

\section{$\underline{\text { Série } 5}$}

\section{Série 5}
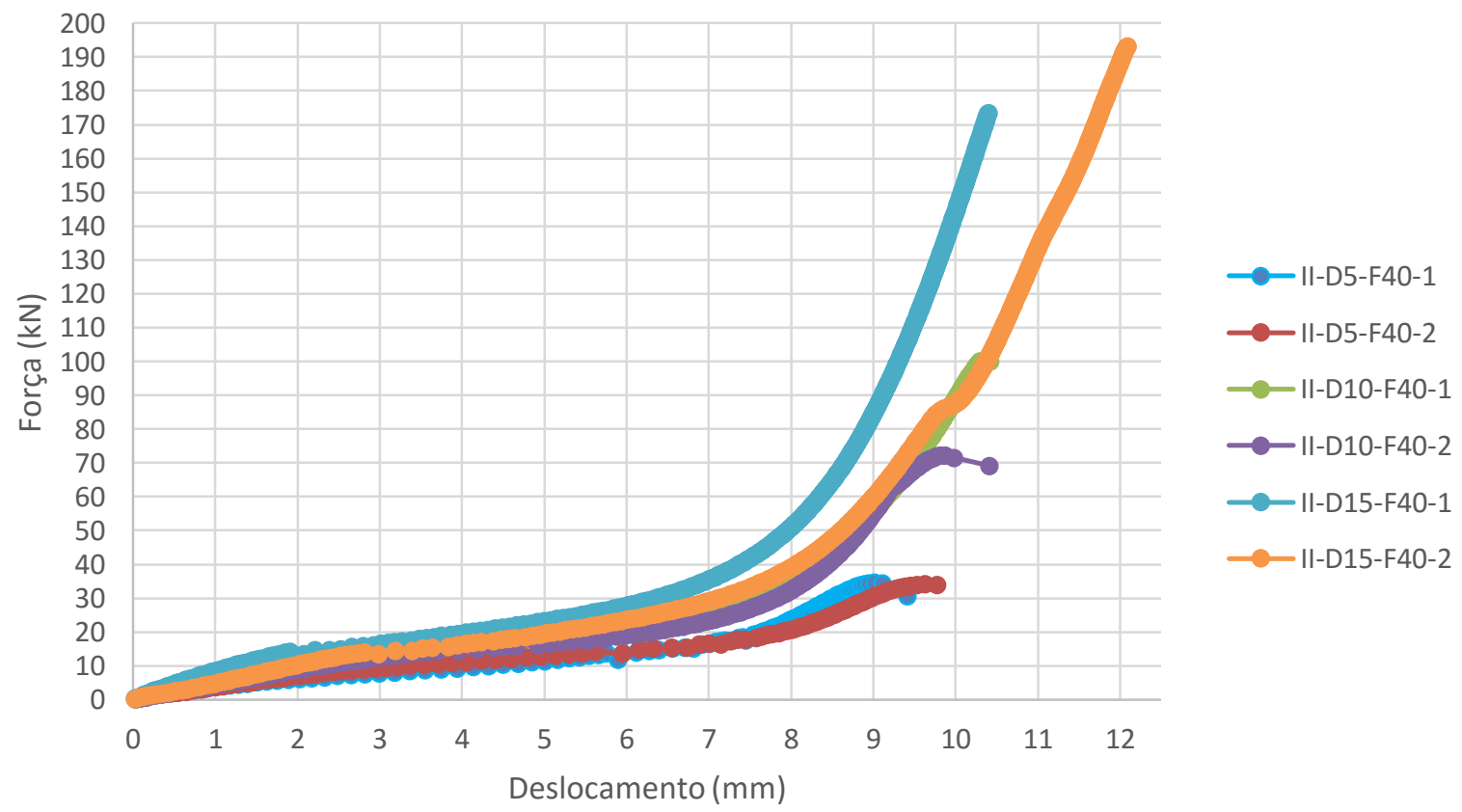

Figura A.5 - Força x deslocamento, Série 5. 


\section{Série 6}

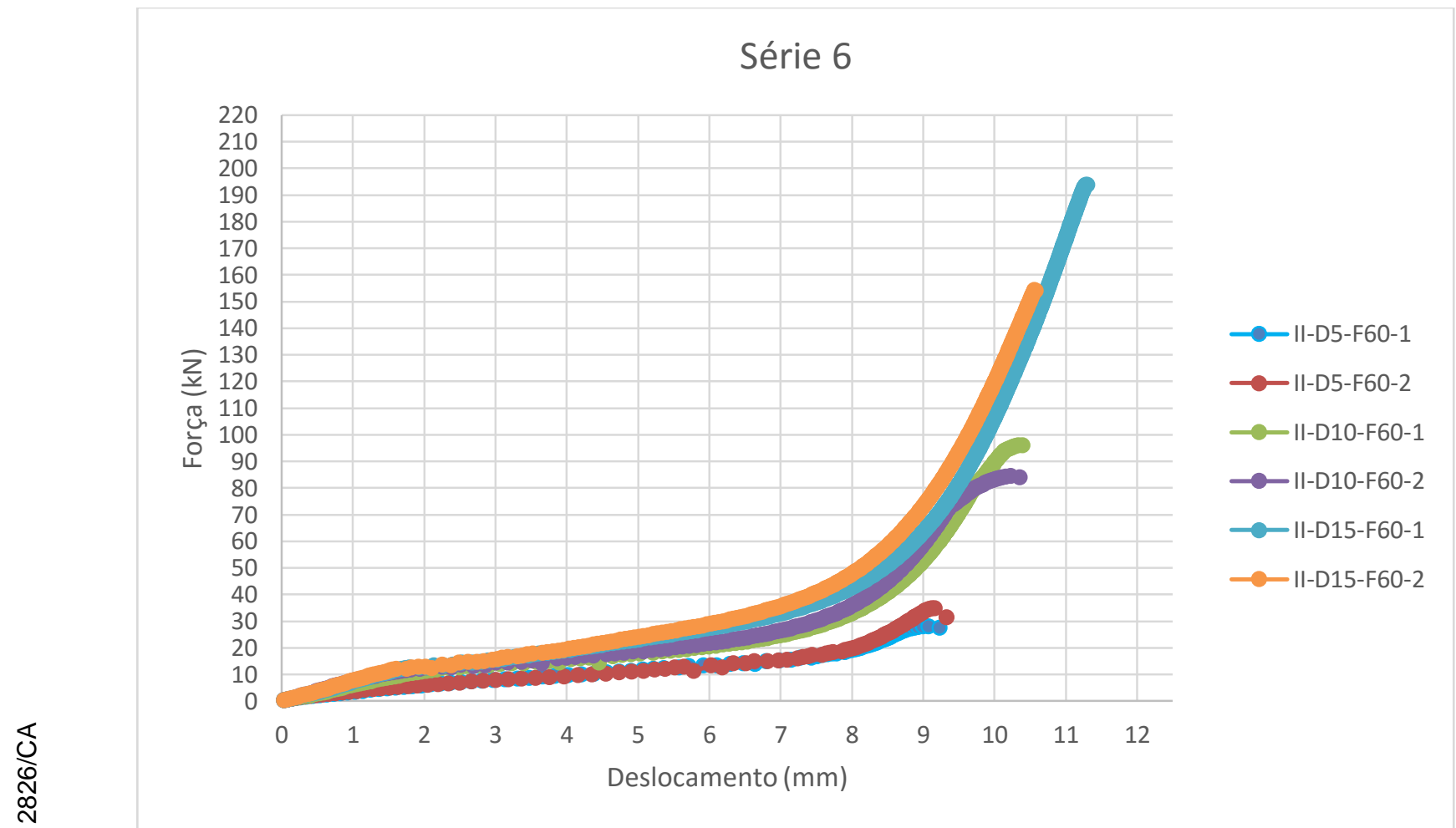

Figura A. 6 - Força x deslocamento, Série 6.

\section{$\underline{\text { Série } 7}$}

Série 7

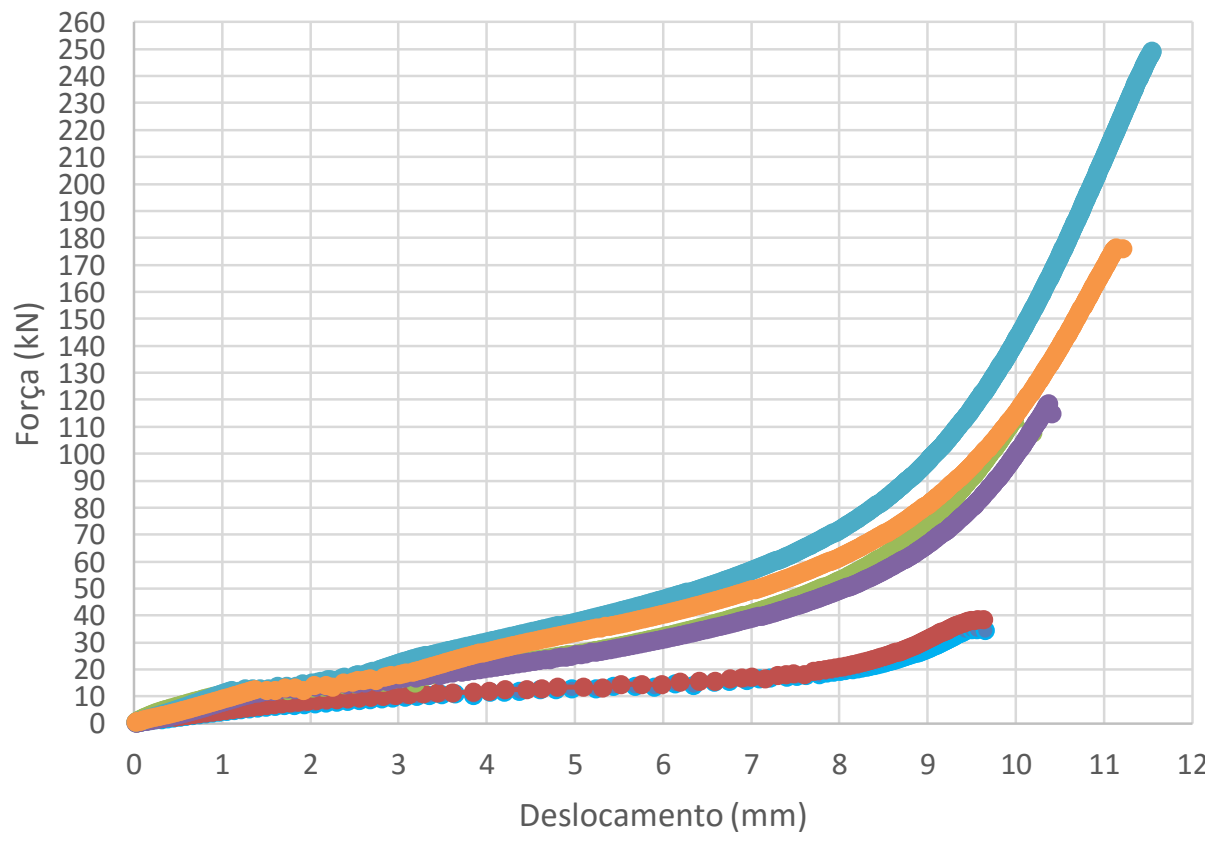

$\longrightarrow$ III-D5-F20-1

- —III-D5-F20-2

$\longrightarrow$ III-D10-F20-1

$\longrightarrow$ III-D10-F20-2

$\longrightarrow$ III-D15-F20-1

- III-D15-F20-2

Figura A.7 - Força x deslocamento, Série 7. 


\section{Série 8}

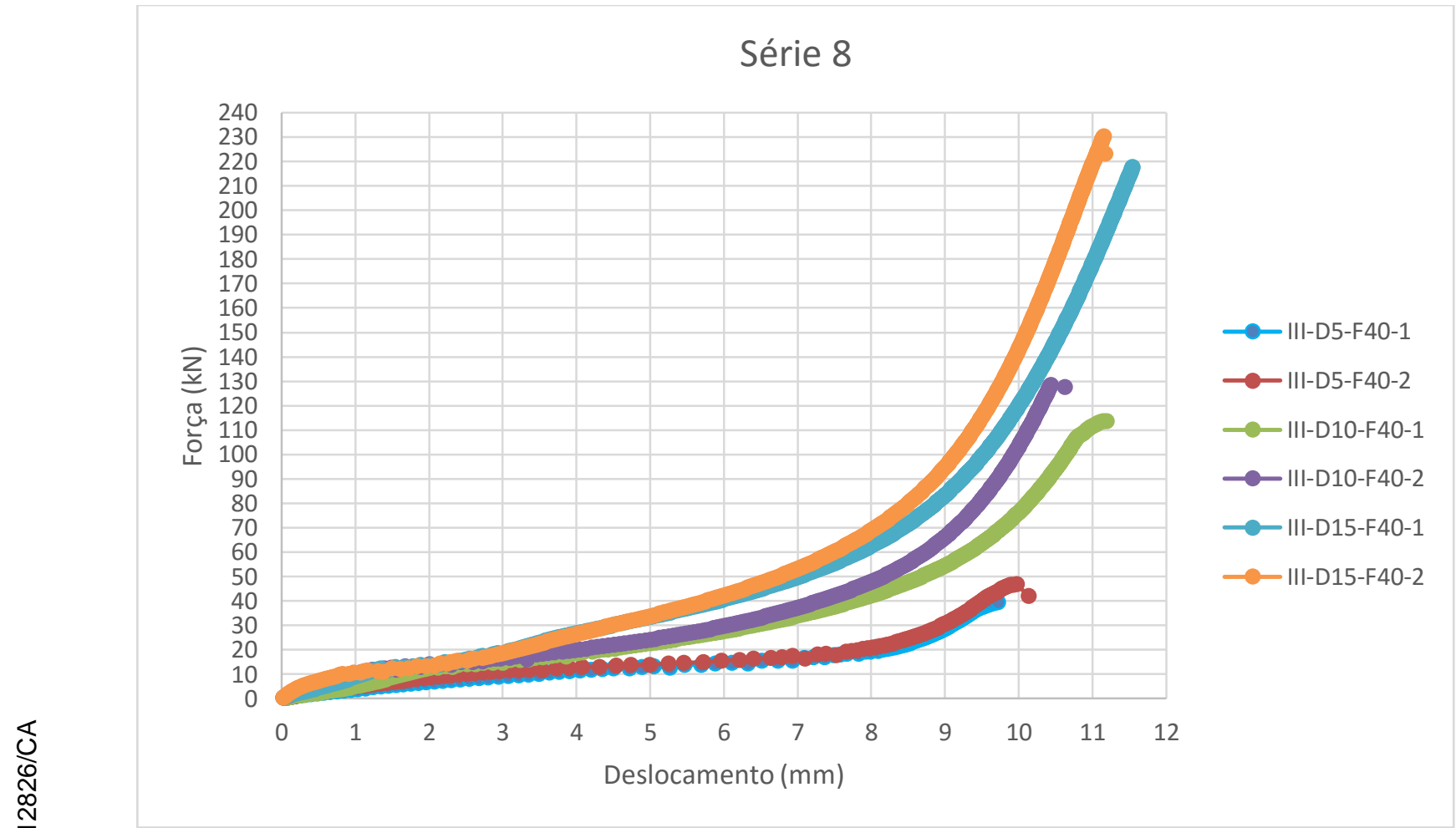

Figura A.8 - Força x deslocamento, Série 8.

\section{Série 9}

Série 9

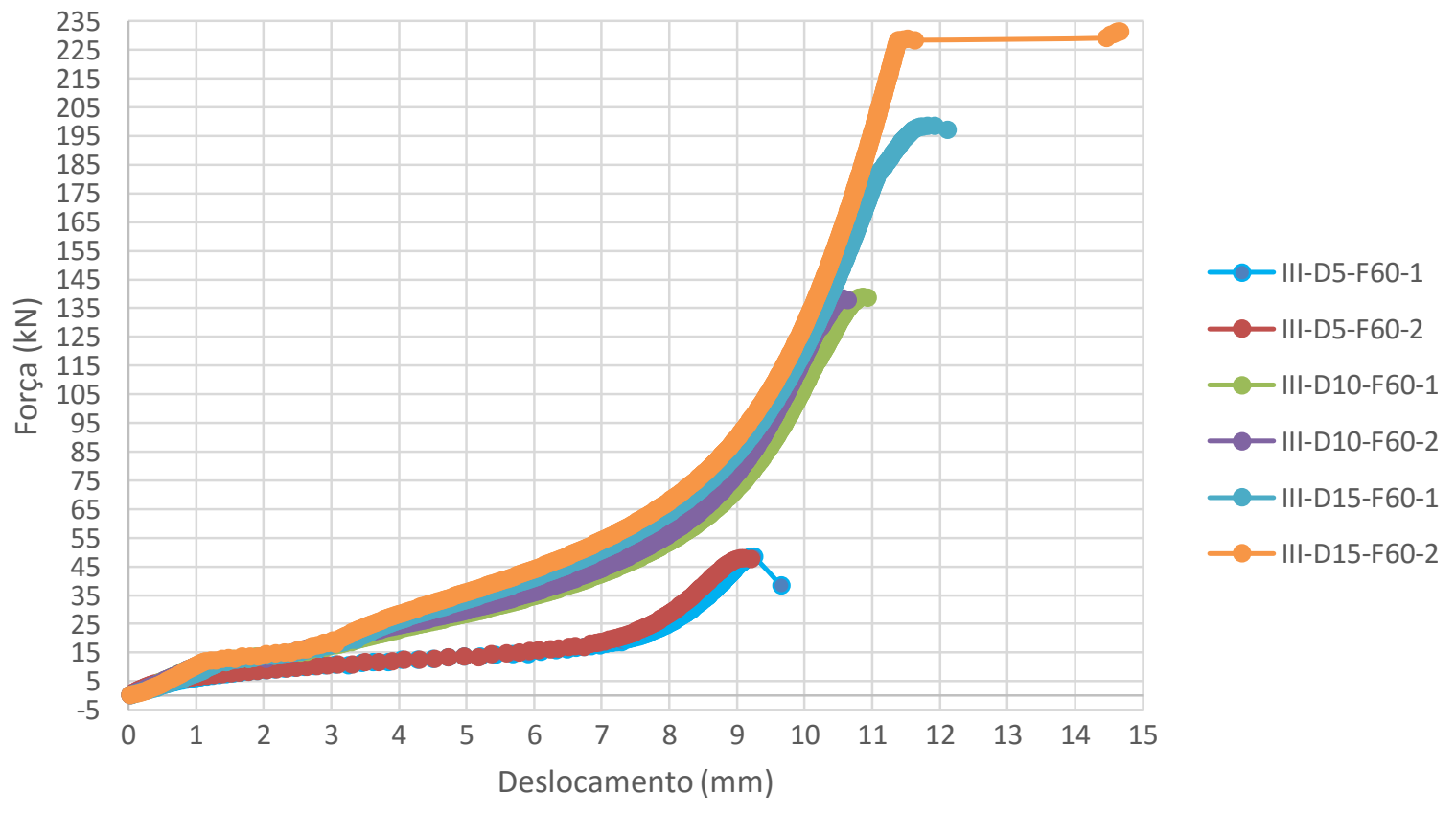

Figura A.9 - Força x deslocamento, Série 9 


\section{B.Anexo B - Ensaios de compressão simples}

Os gráficos desse anexo apresentam os resultados dos ensaios de compressão.

\section{Série 1}

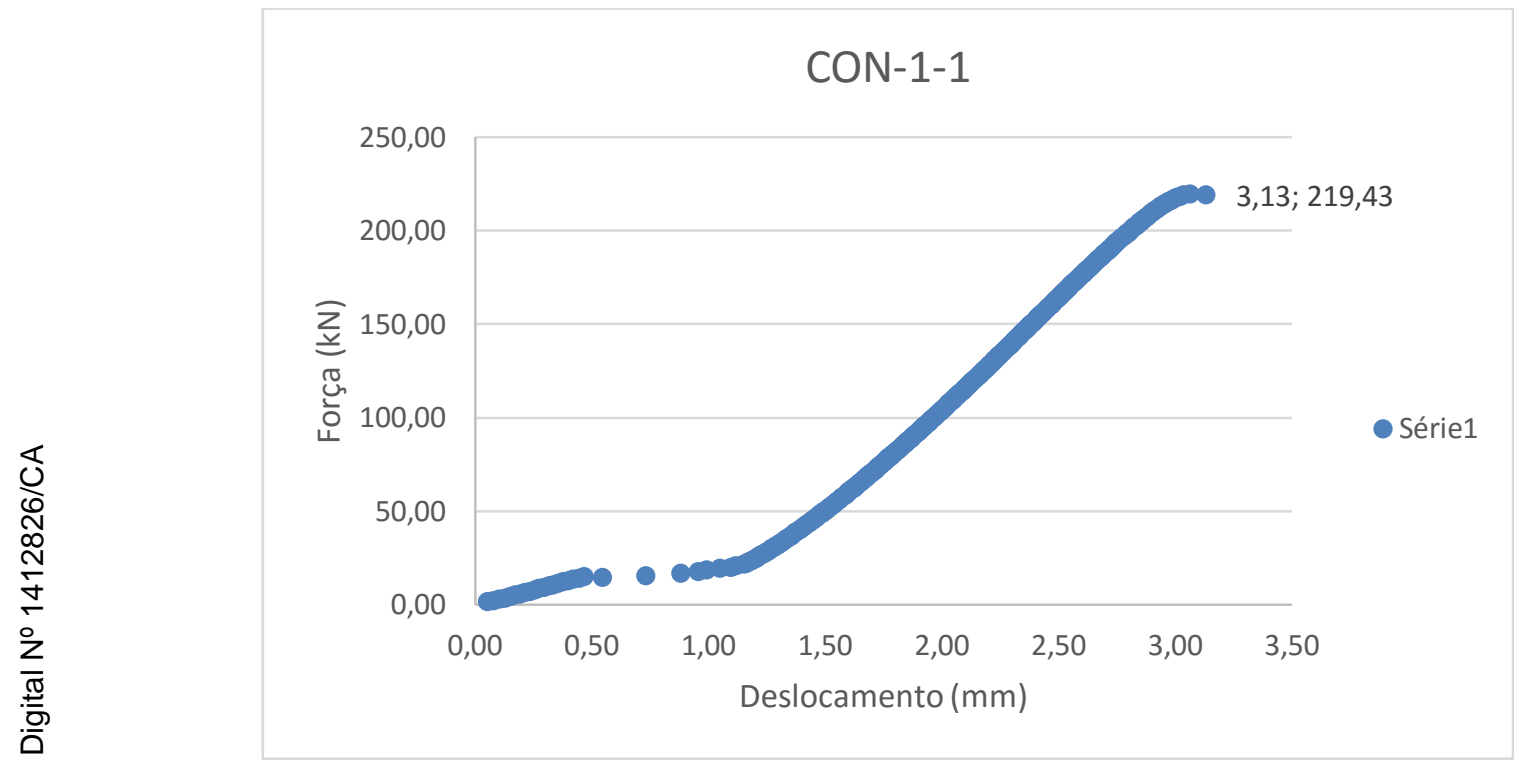

Figura B.1 - Força x deslocamento, CON-1-1.

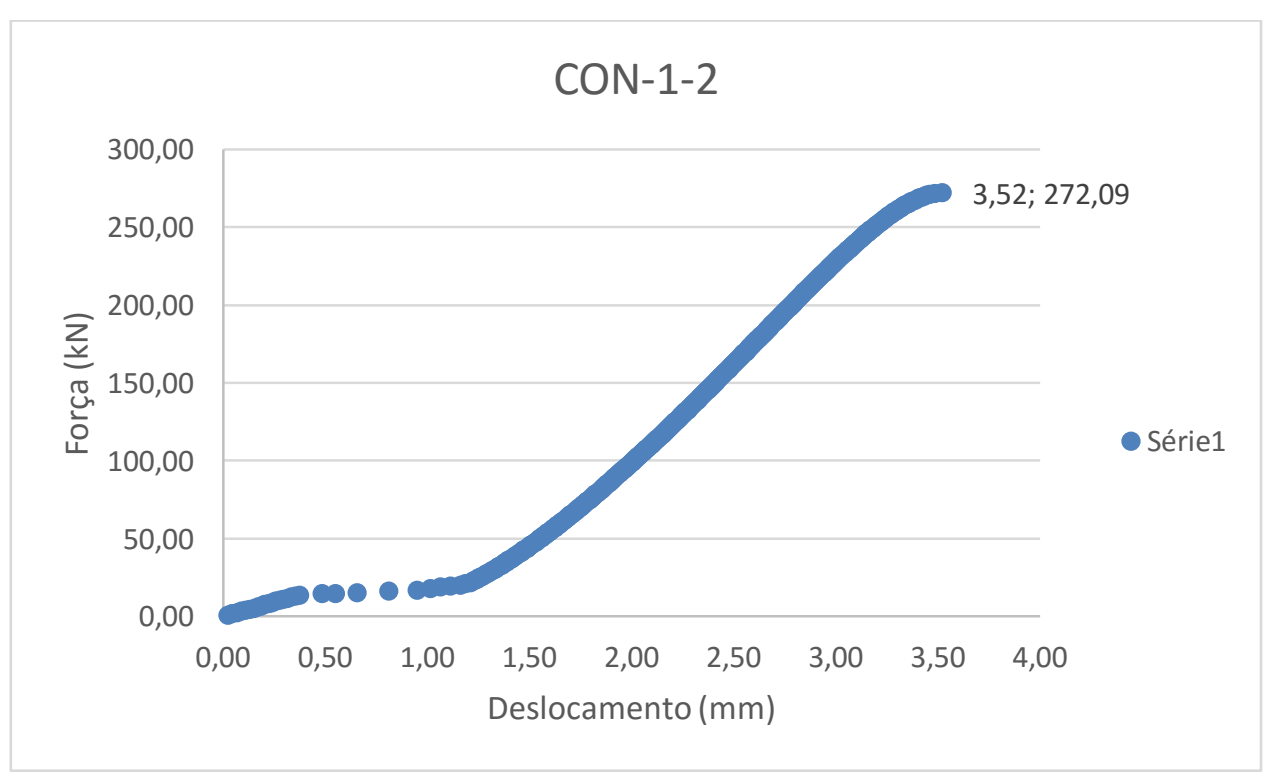

Figura B.2 - Força x deslocamento, CON-1-2. 


\section{Série 2}

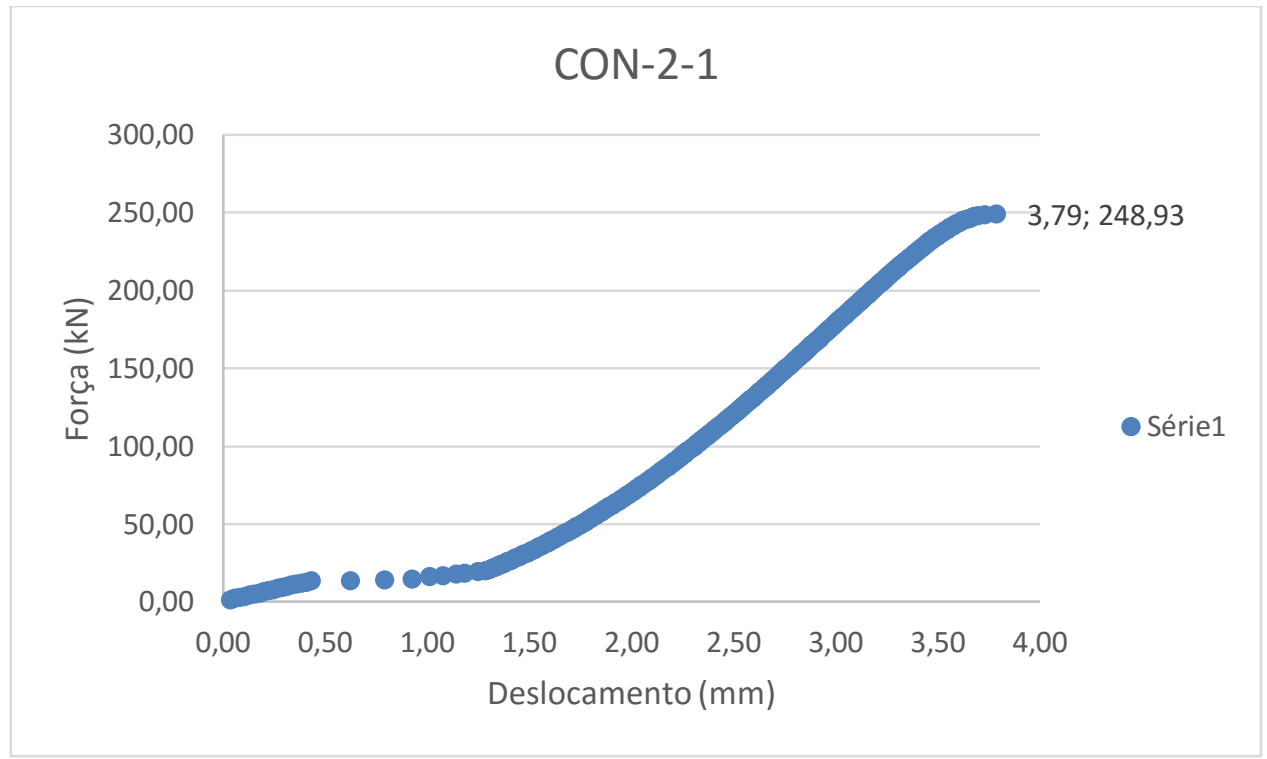

Figura B.3 - Força x deslocamento, CON-2-1.

CON-2-2

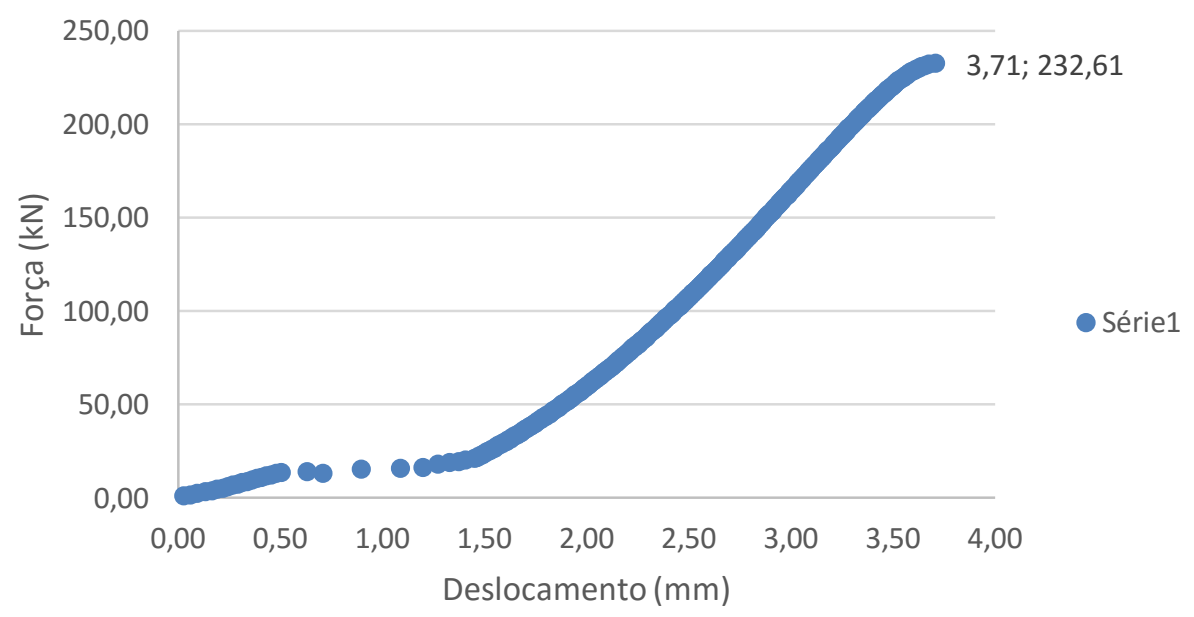

Figura B.4 - Força x deslocamento, CON-2-2. 


\section{$\underline{\text { Série } 3}$}

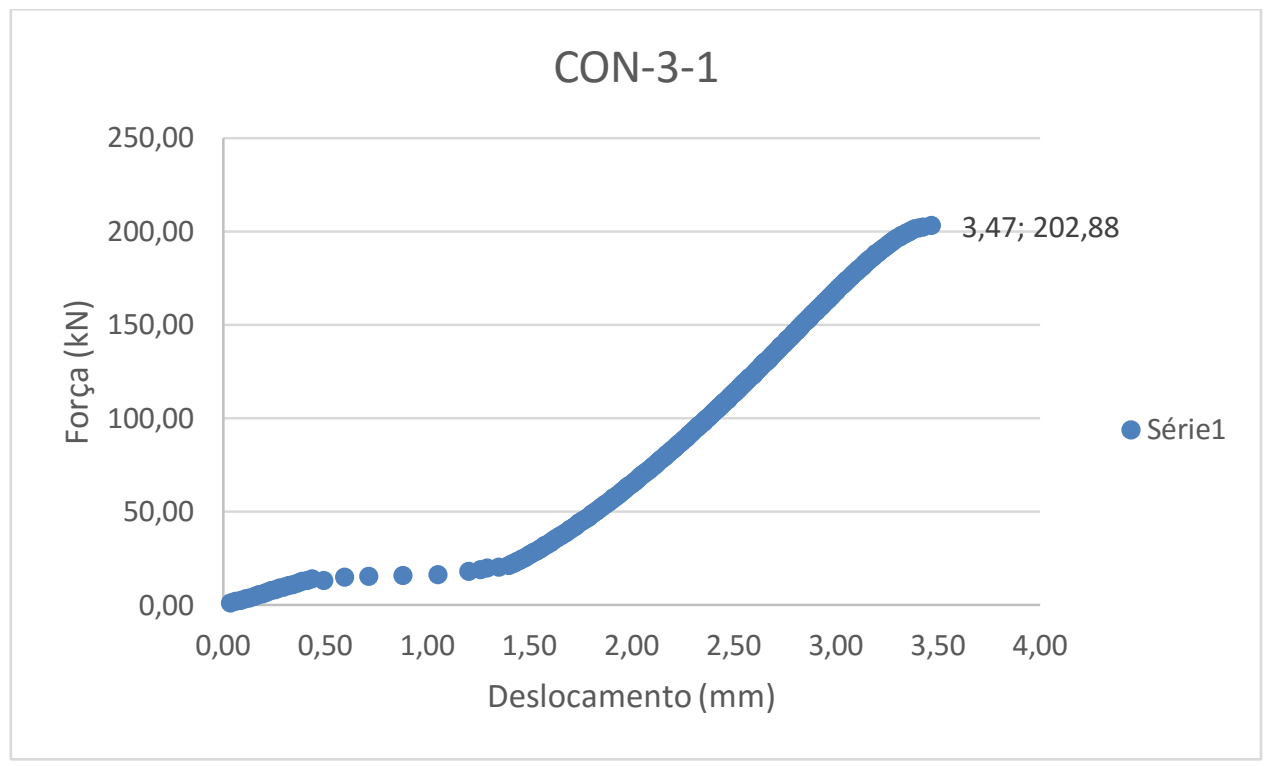

Figura B.5 - Força x deslocamento, CON-3-1.

CON-3-2

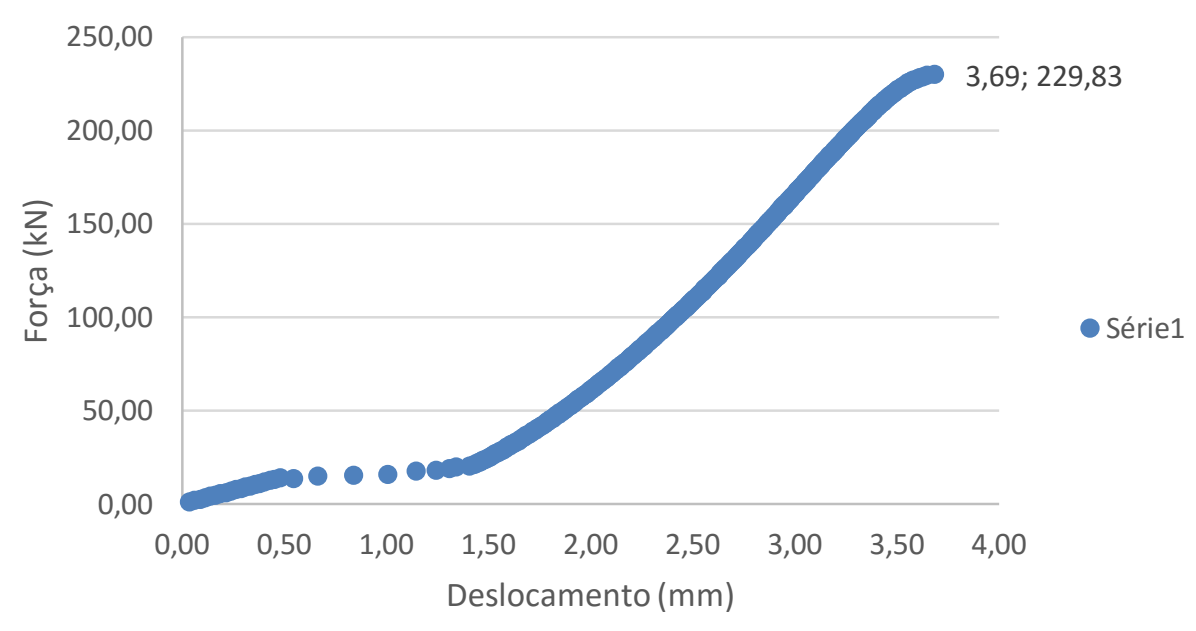

Figura B.6 - Força x deslocamento, CON-3-2. 


\section{$\underline{\text { Série } 4}$}

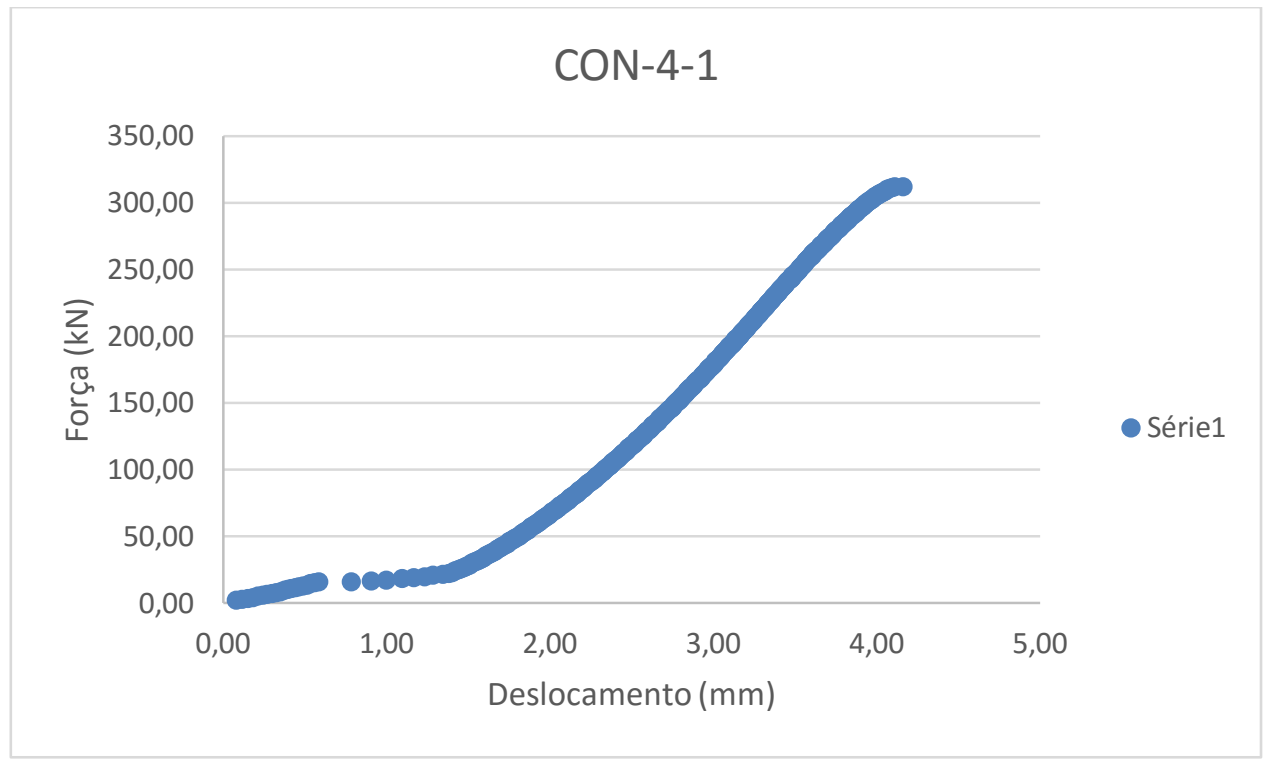

Figura B.7 - Força x deslocamento, CON-4-1.

CON-4-2

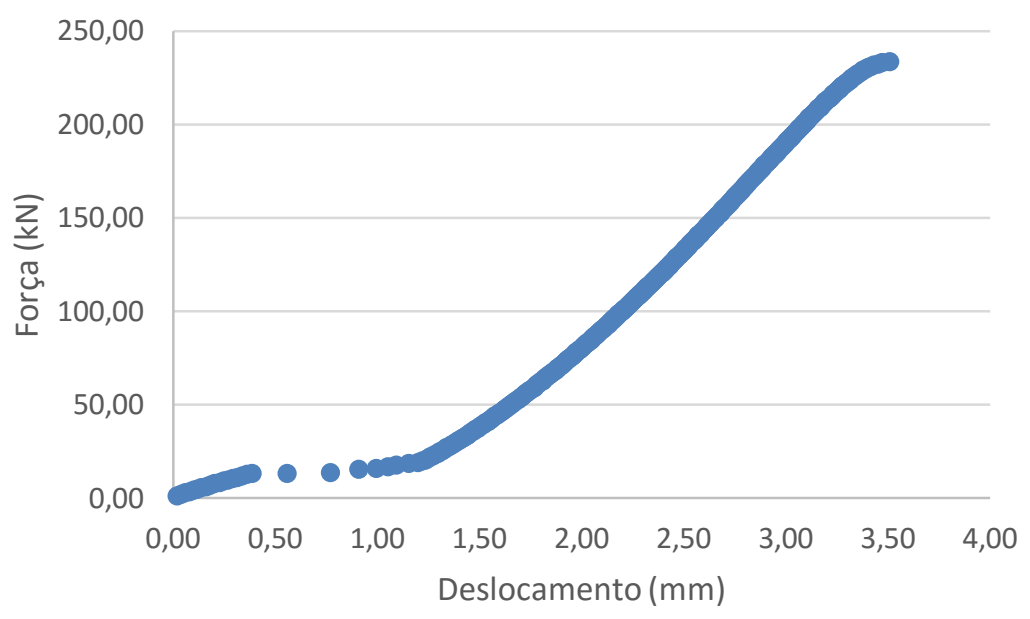

- Série1

Figura B.8 - Força x deslocamento, CON-4-2. 


\section{Série 5}

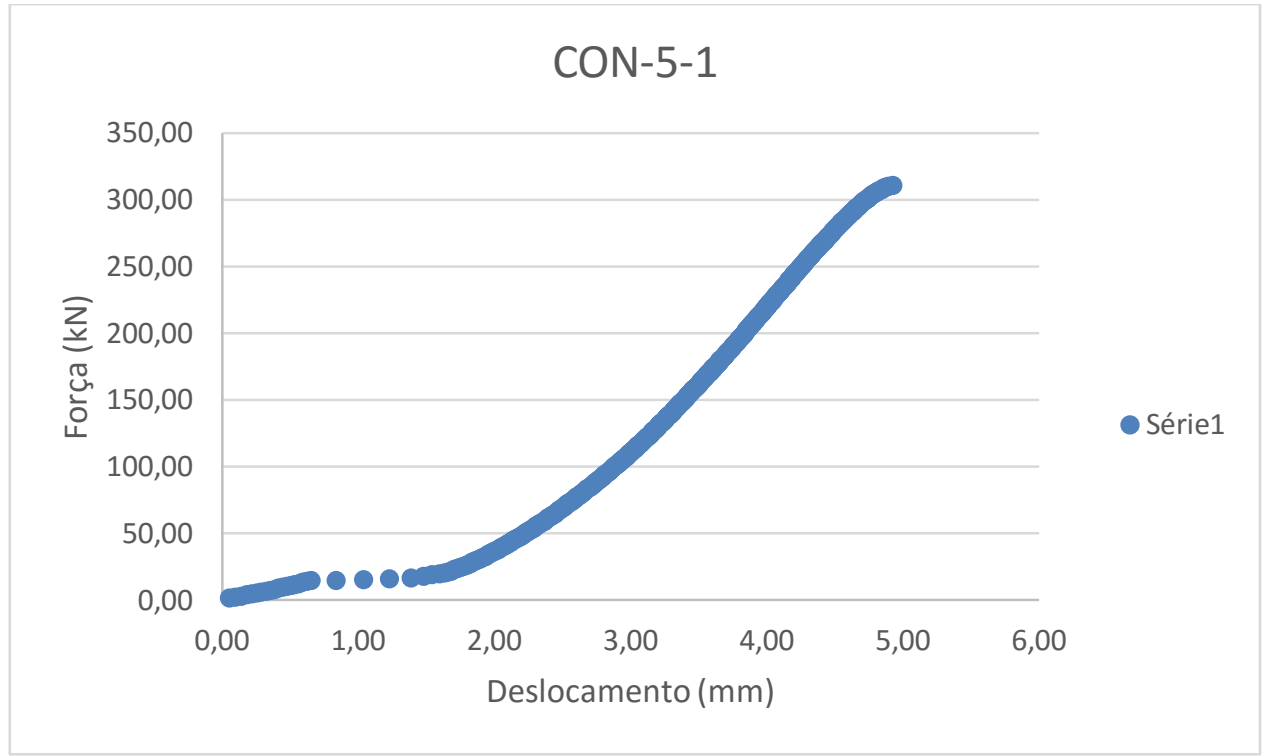

Figura B.9 - Força x deslocamento, CON-5-1.

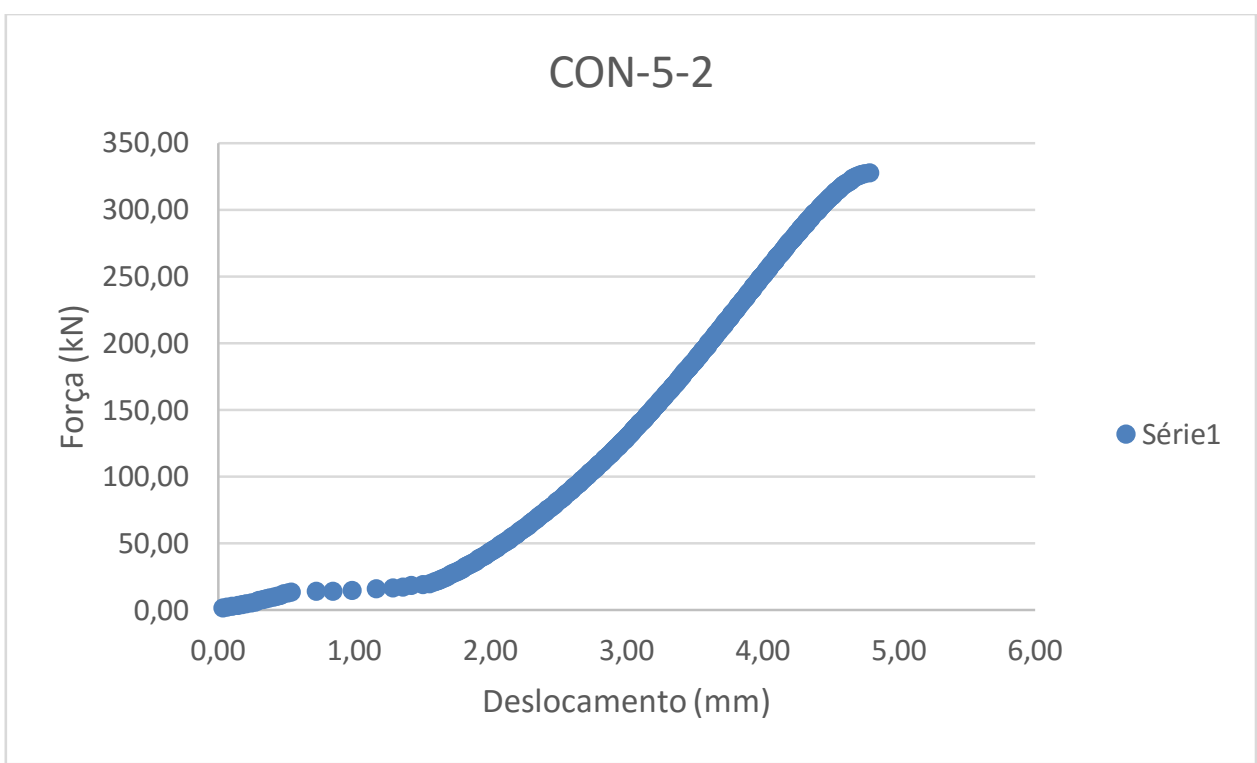

Figura B.10 - Força x deslocamento, CON-5-2. 


\section{Série 6}

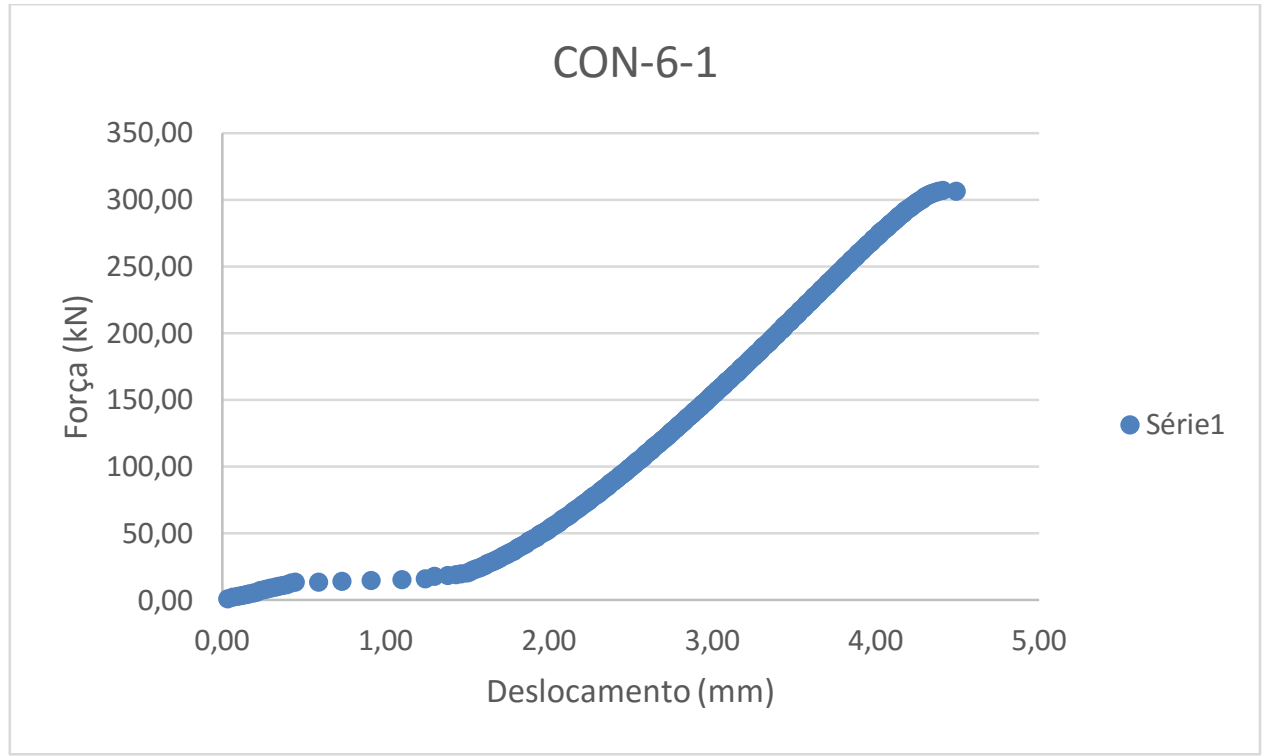

Figura B.11 - Força x deslocamento, CON-6-1.

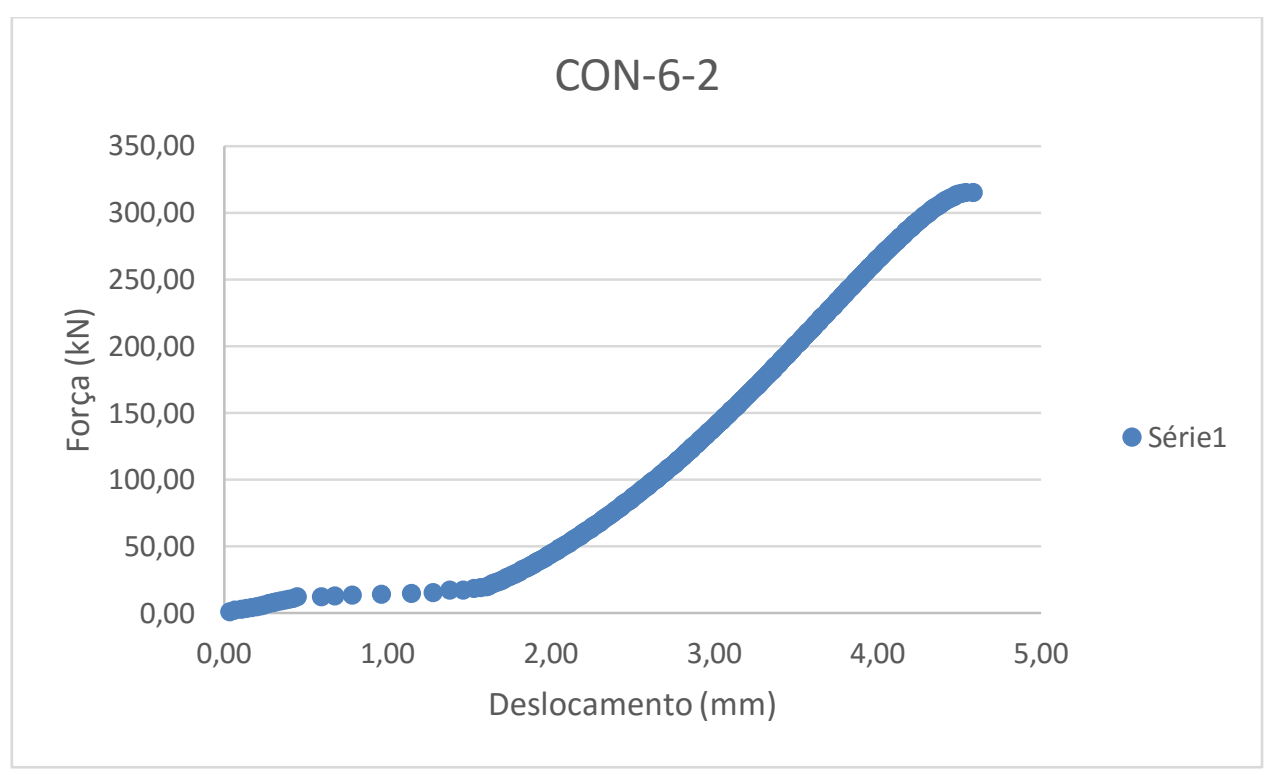

Figura B.12 - Força x deslocamento, CON-6-2. 


\section{Série 7}

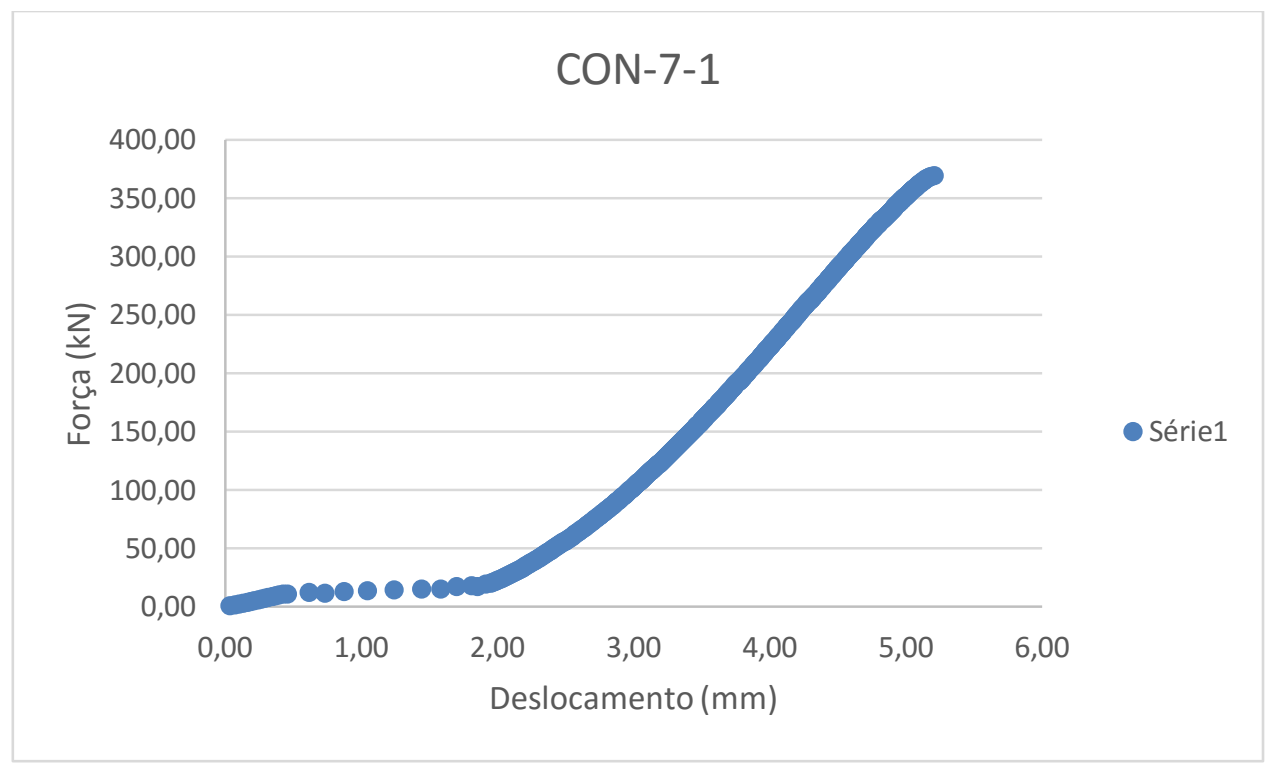

Figura B.13 - Força x deslocamento, CON-7-1.

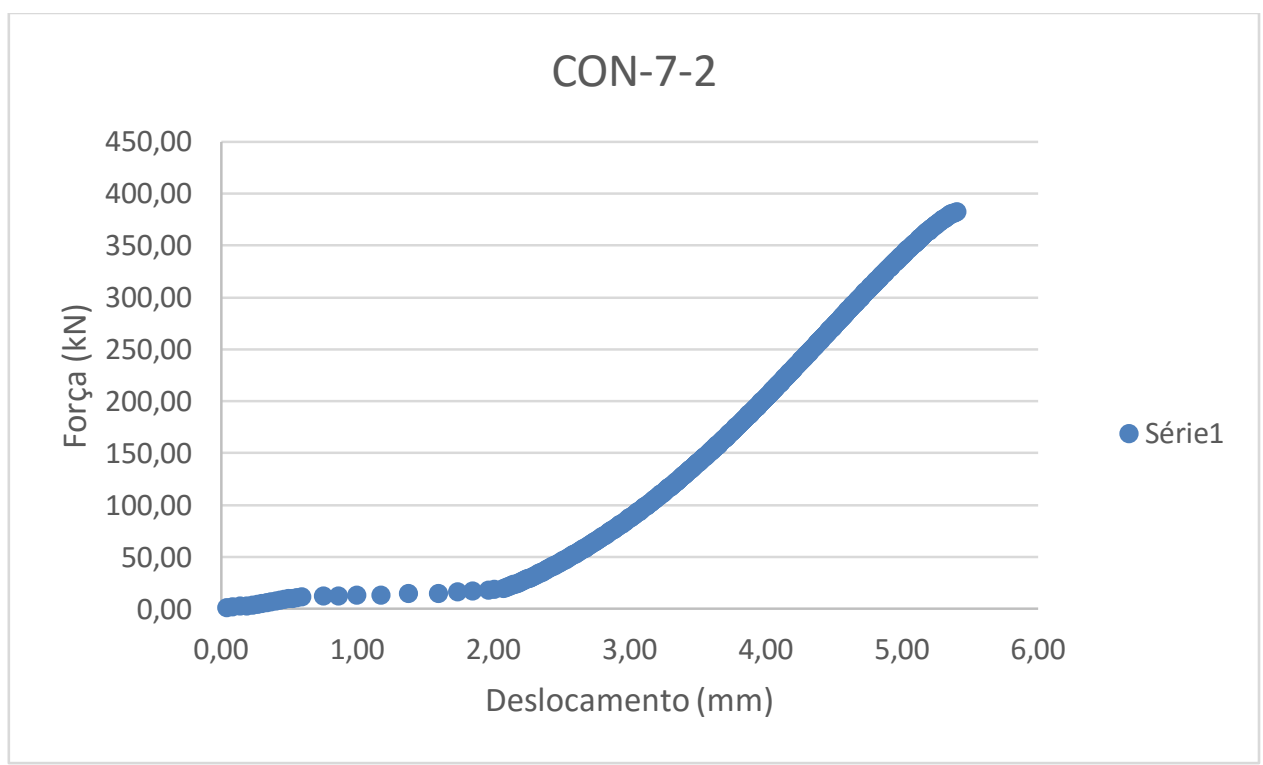

Figura B.14 - Força x deslocamento, CON-7-2. 


\section{Série 8}

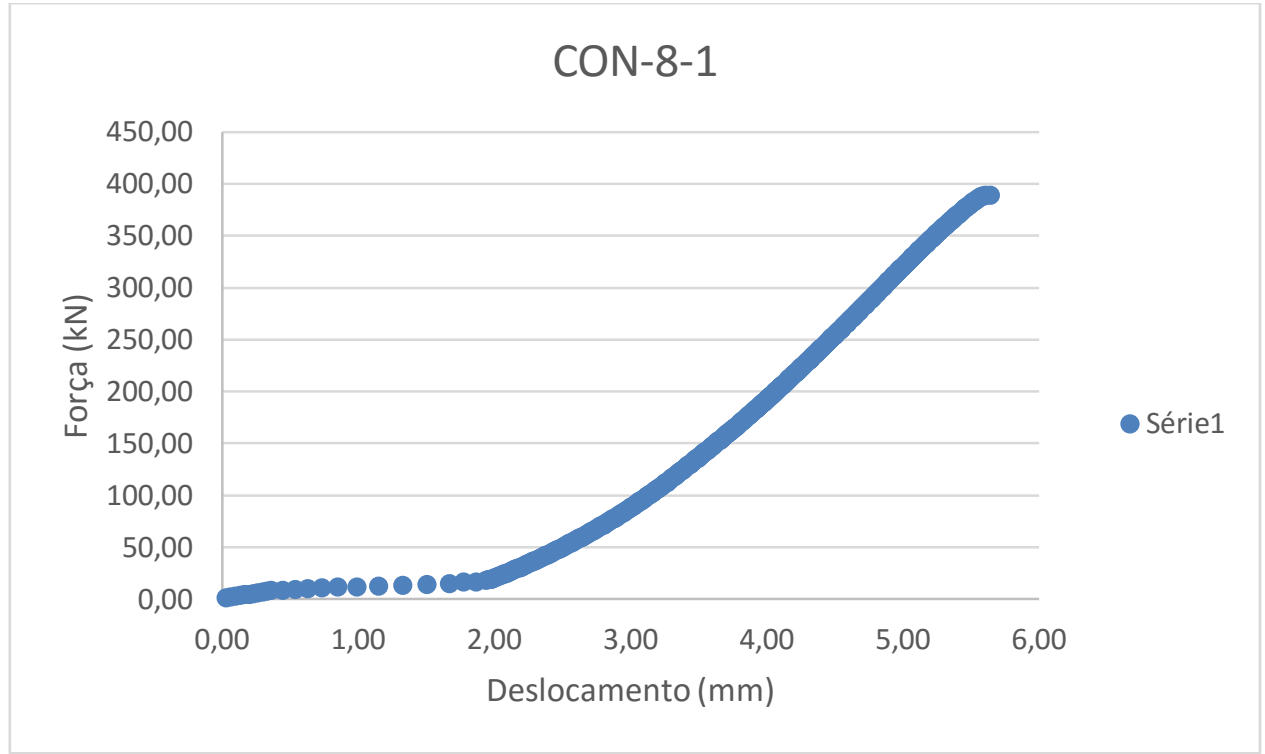

Figura B.15 - Força x deslocamento, CON-8-1.

CON-8-2

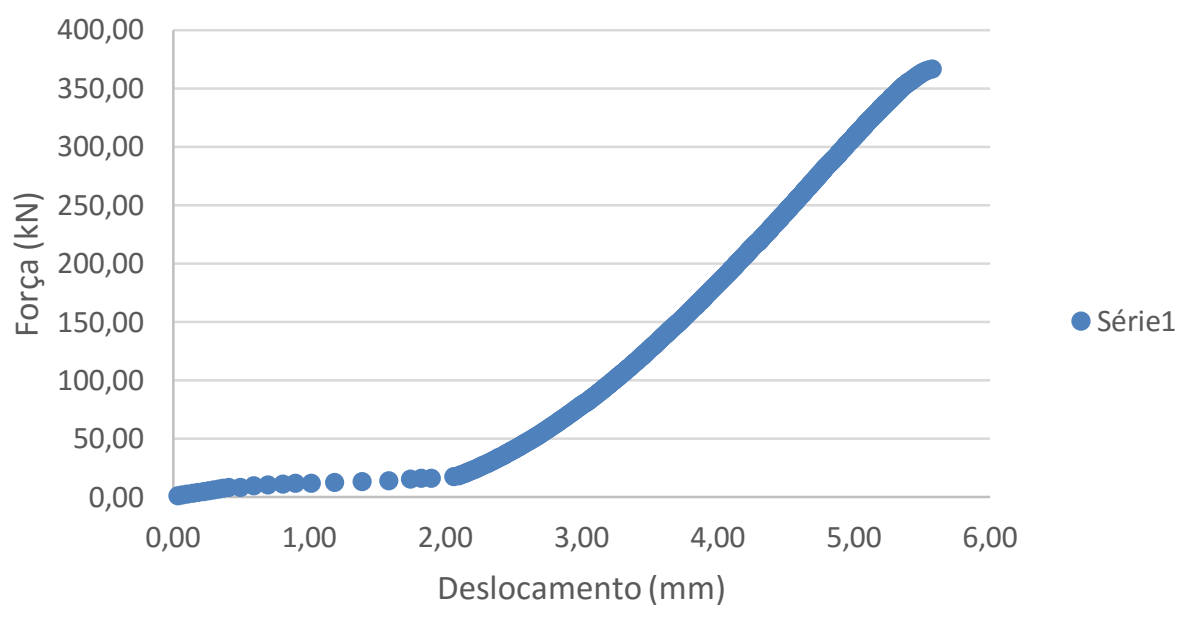

Figura B.16 - Força x deslocamento, CON-8-2. 


\section{Série 9}

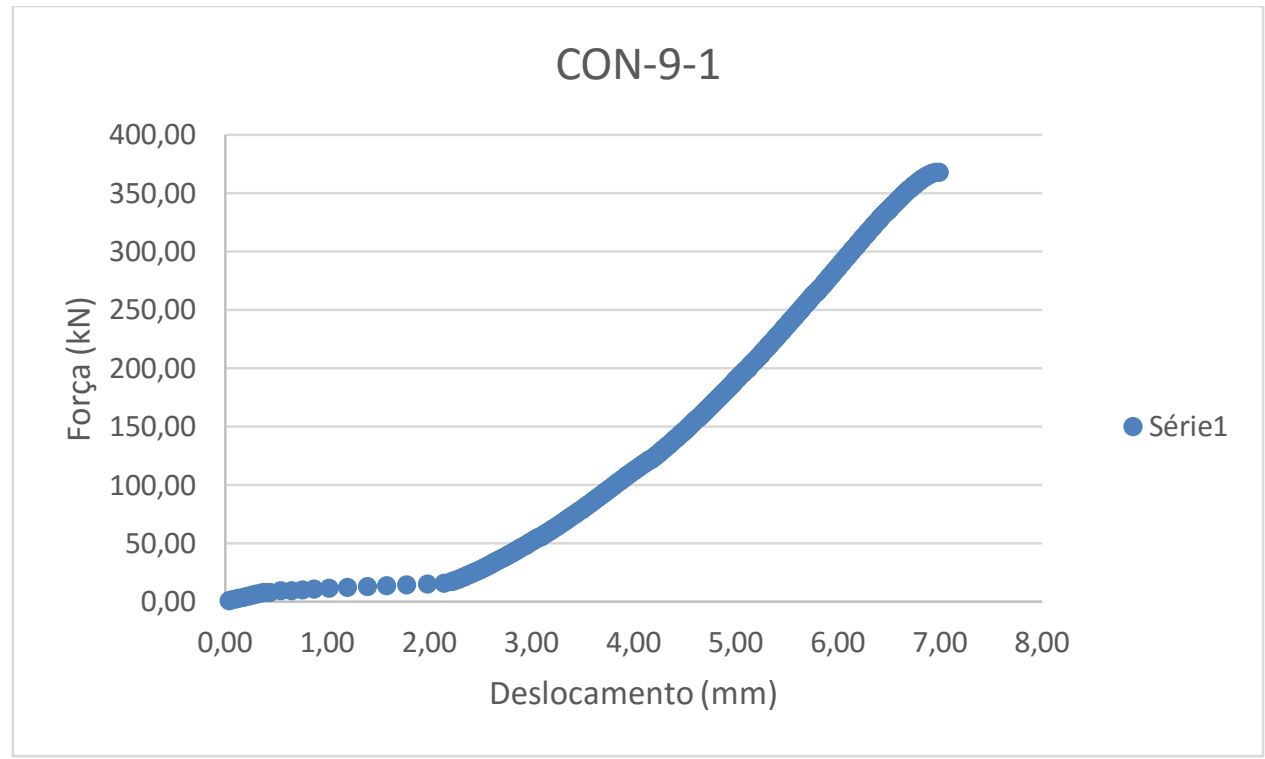

Figura B.17 - Força x deslocamento, CON-9-1.

CON-9-2

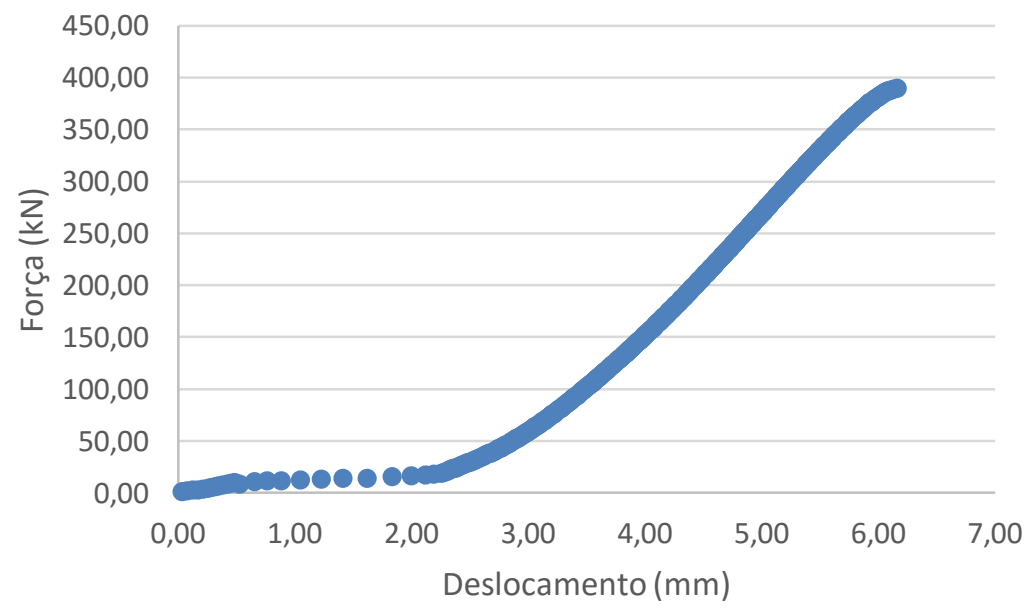

- Série1

Figura B.18- Força x deslocamento, CON-9-2 


\section{Anexo C - Ensaios de tração direta}

Os gráficos desse anexo apresentam os resultados dos ensaios de tração direta.

\section{$\underline{\text { Série } 1}$}

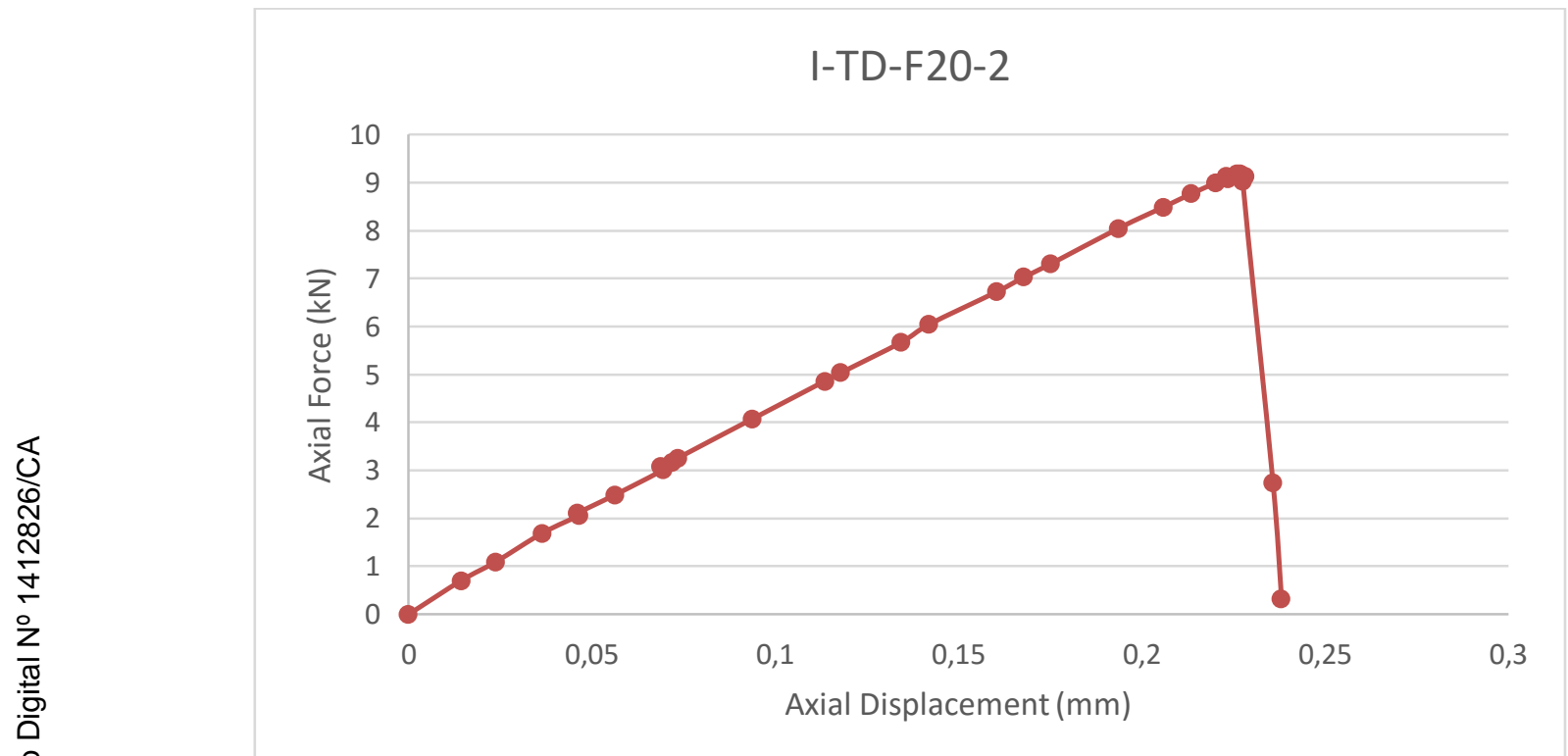

Figura.C.1 - Força x deslocamento, I-TD-F20-2.

\section{$\underline{\text { Série } 2}$}

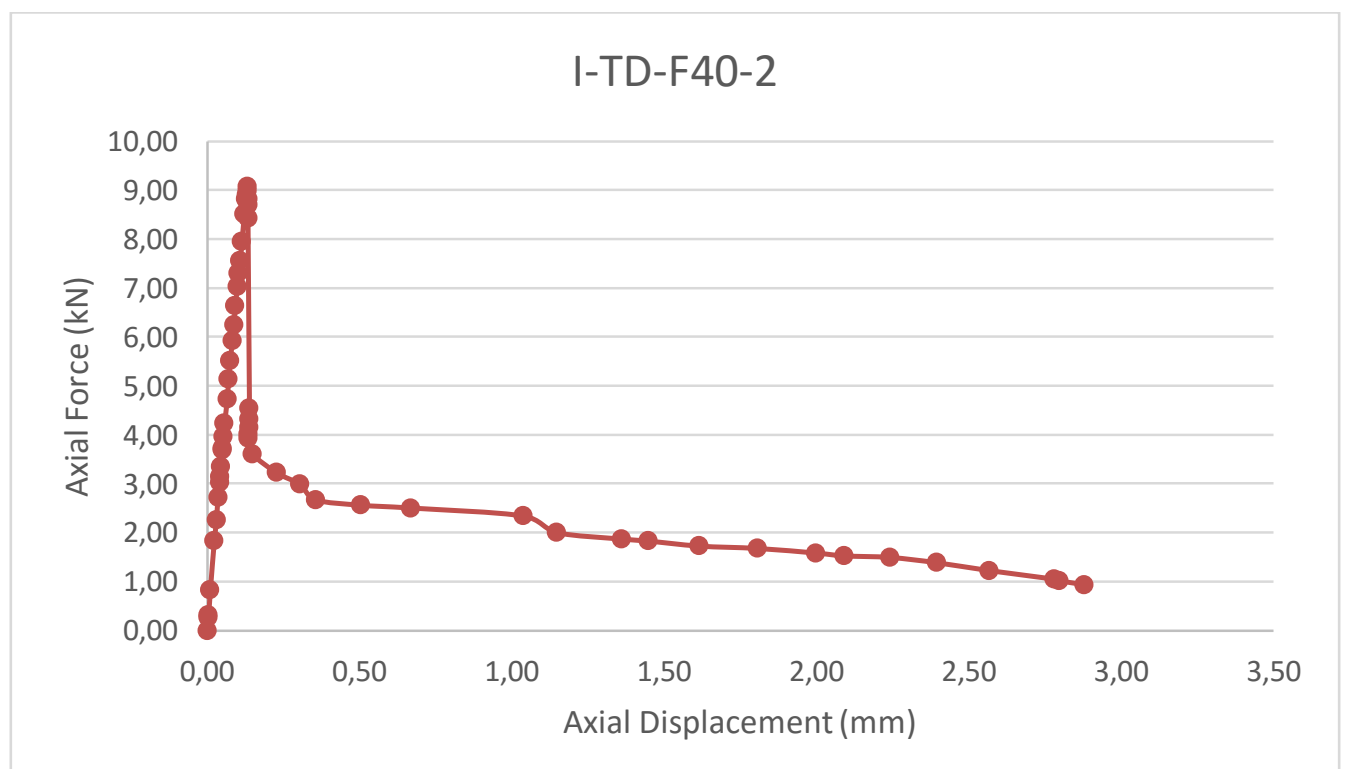

Figura C.2 - Força x deslocamento, I-TD-F40-2. 


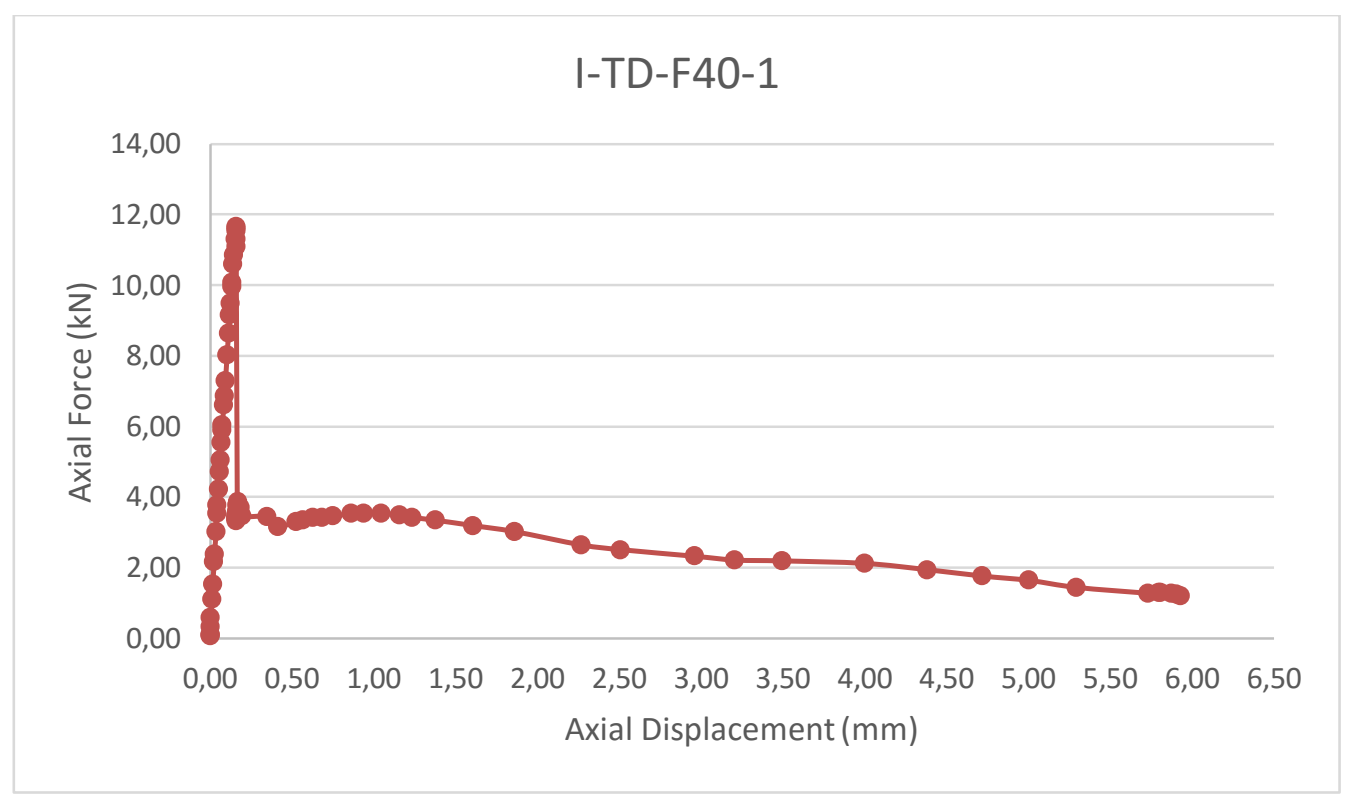

Figura C.3 - Força x deslocamento, I-TD-F40-1.

\section{Série 3}

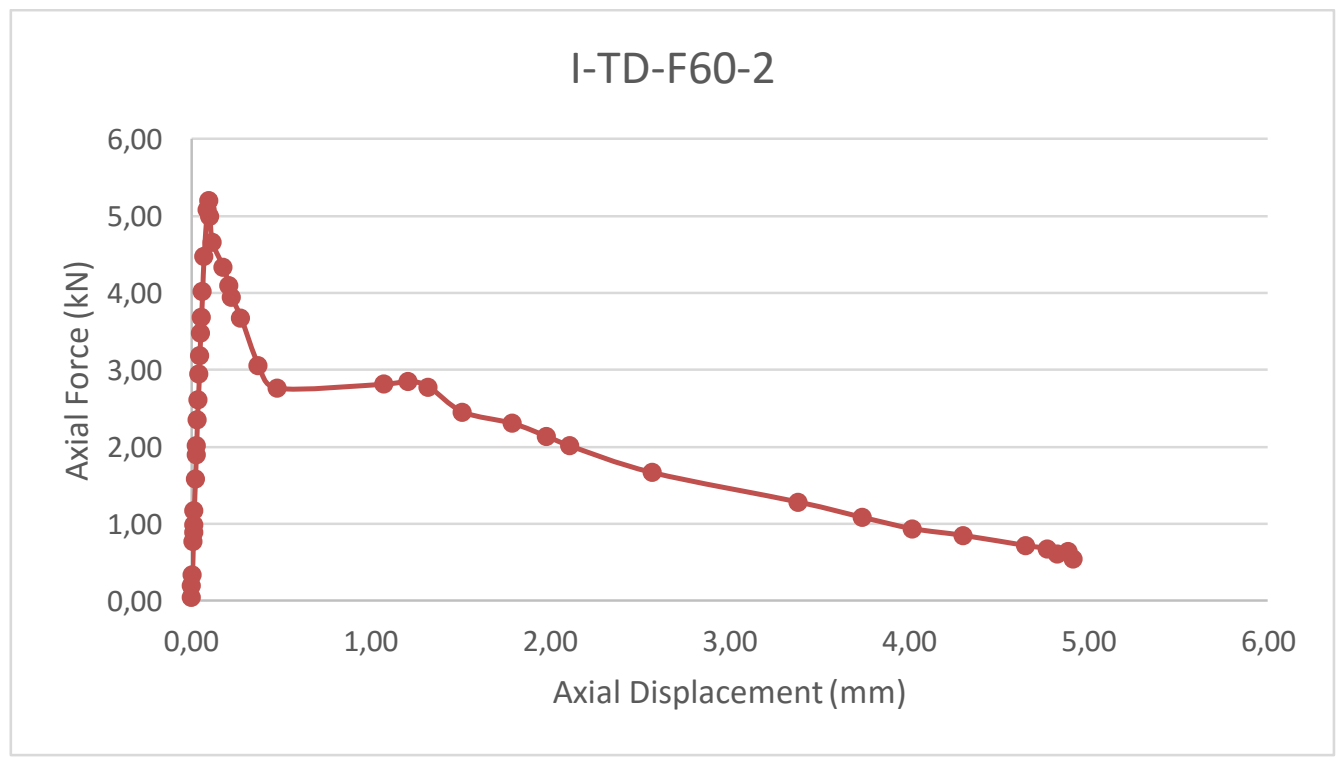

Figura C.4 - Força x deslocamento, I-TD-F60-2. 


\section{$\underline{\text { Série } 4}$}

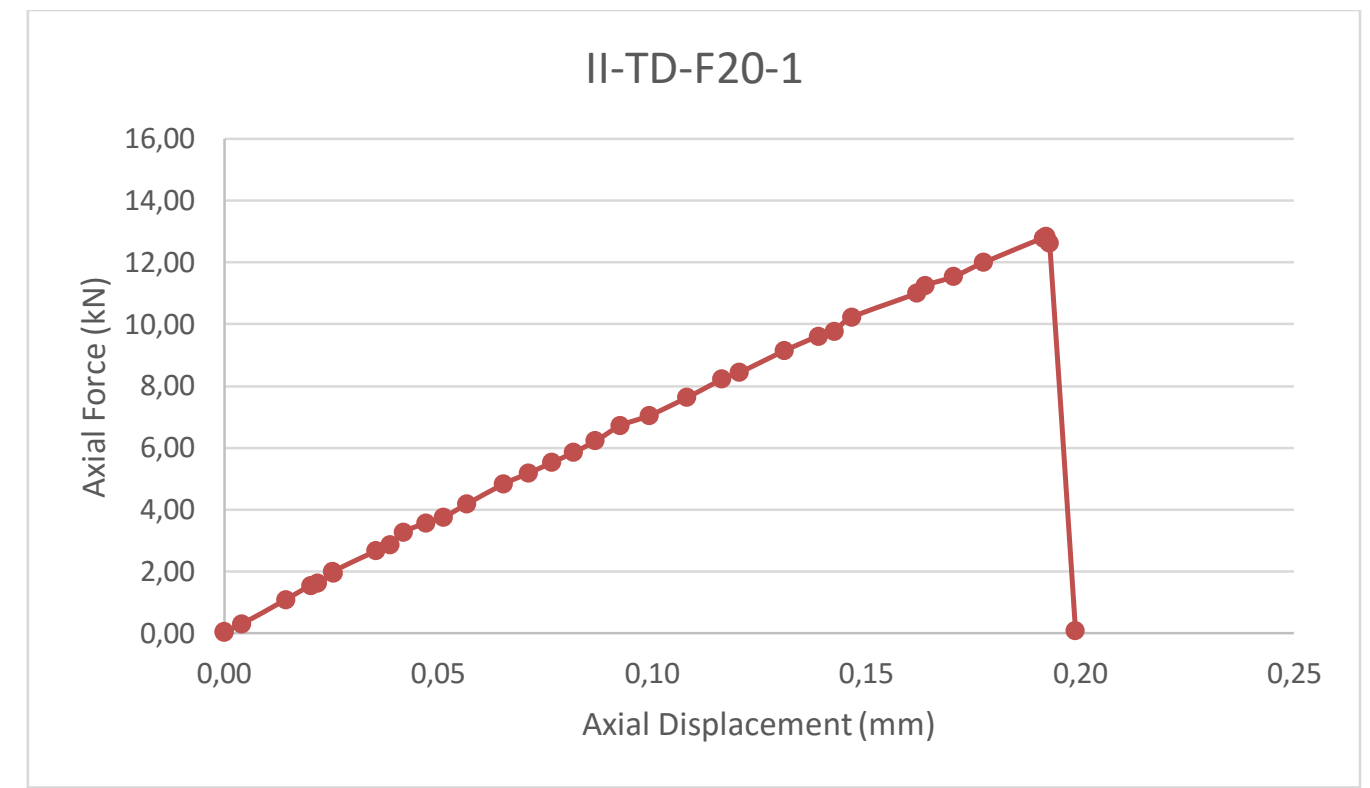

Figura C.5 - Força x deslocamento, II-TD-F20-1.

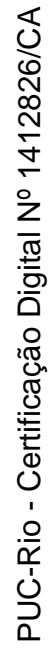

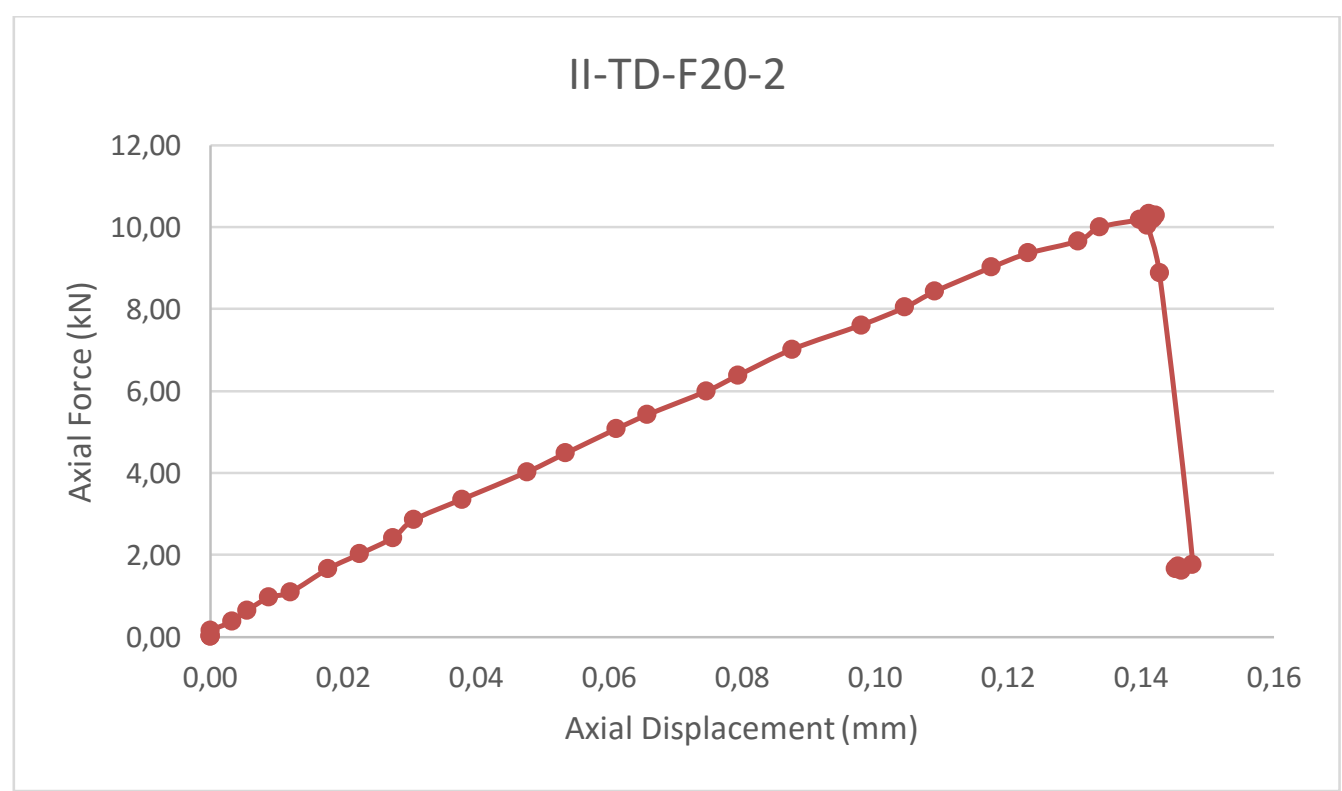

Figura C.6 - Força x deslocamento, II-TD-F20-2. 


\section{Série 5}

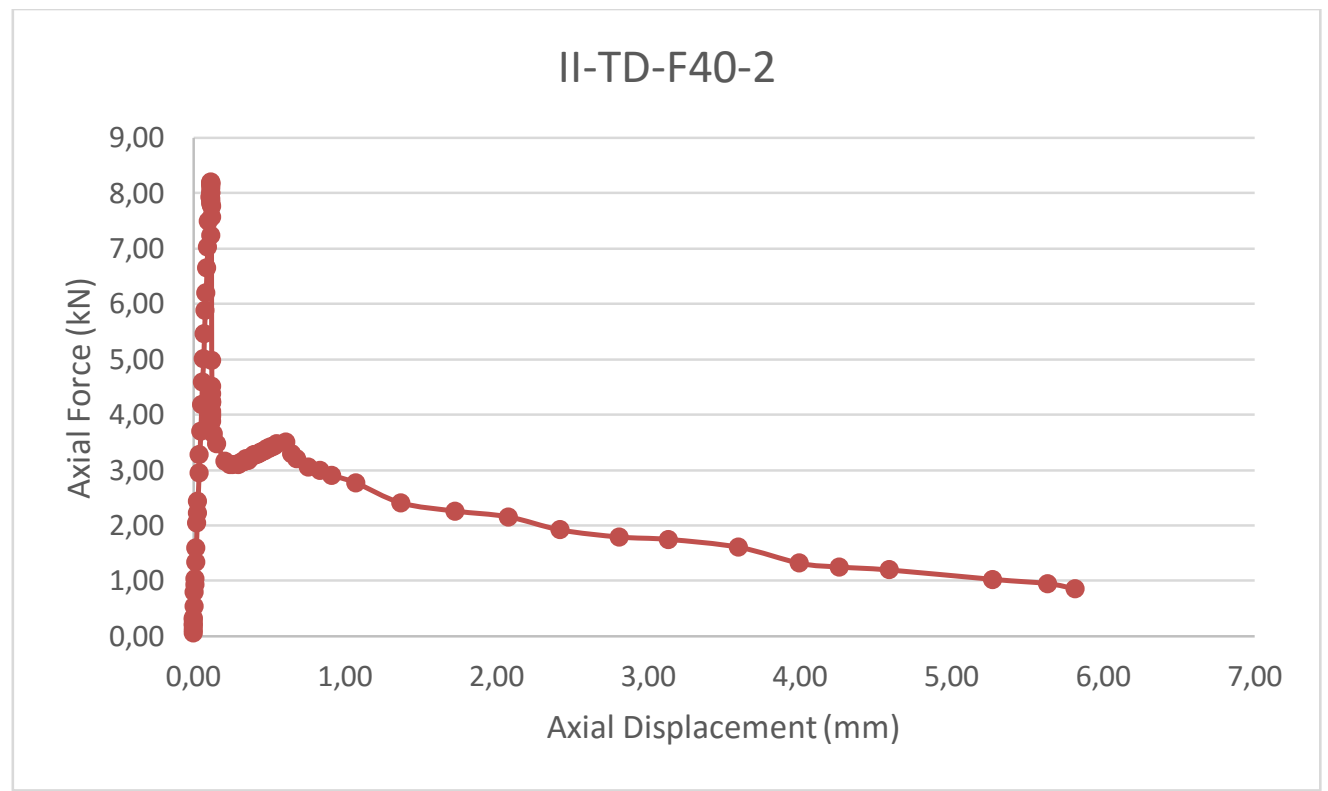

Figura C.7 - Força x deslocamento, II-TD-F40-2.

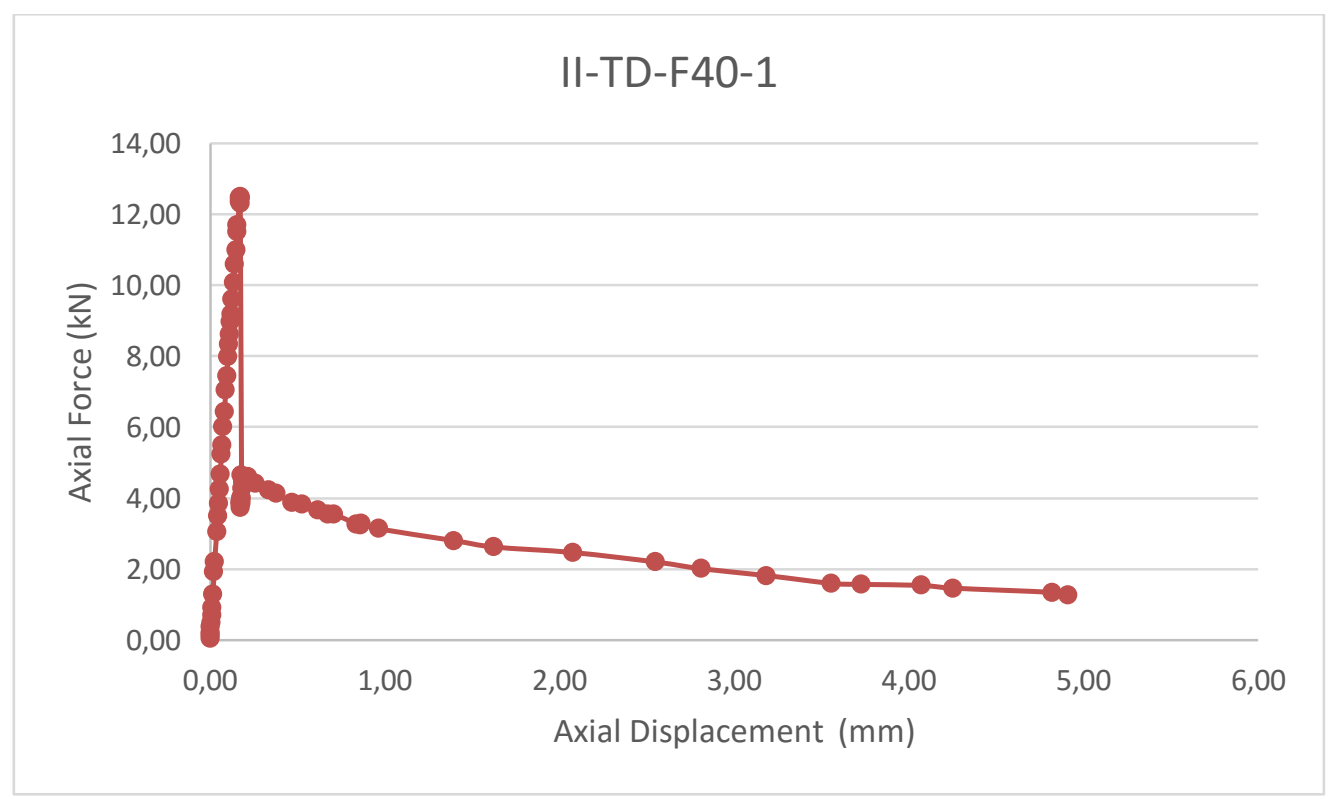

Figura C.8 - Força x deslocamento, II-TD-F40-1. 


\section{Série 6}

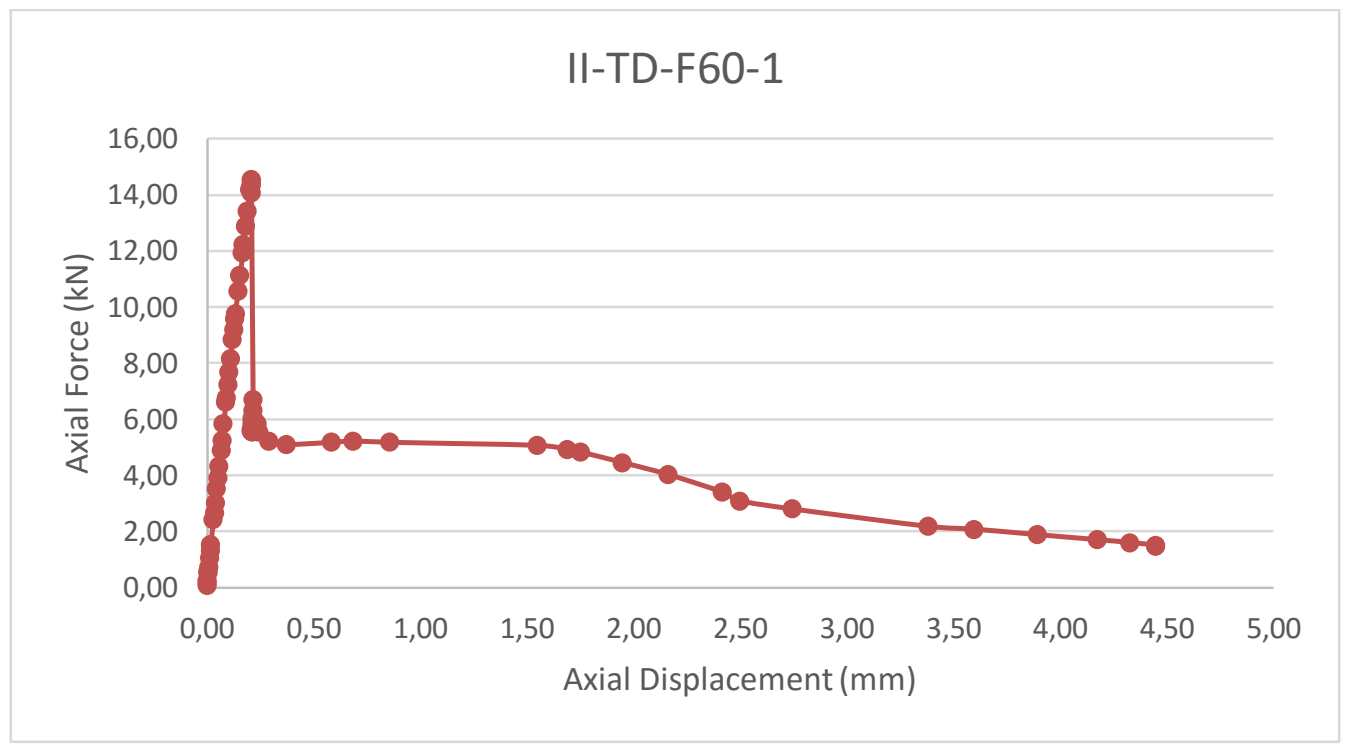

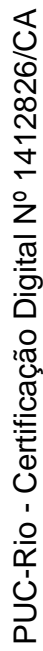

Figura C.9 - Força x deslocamento, II-TD-F60-1.

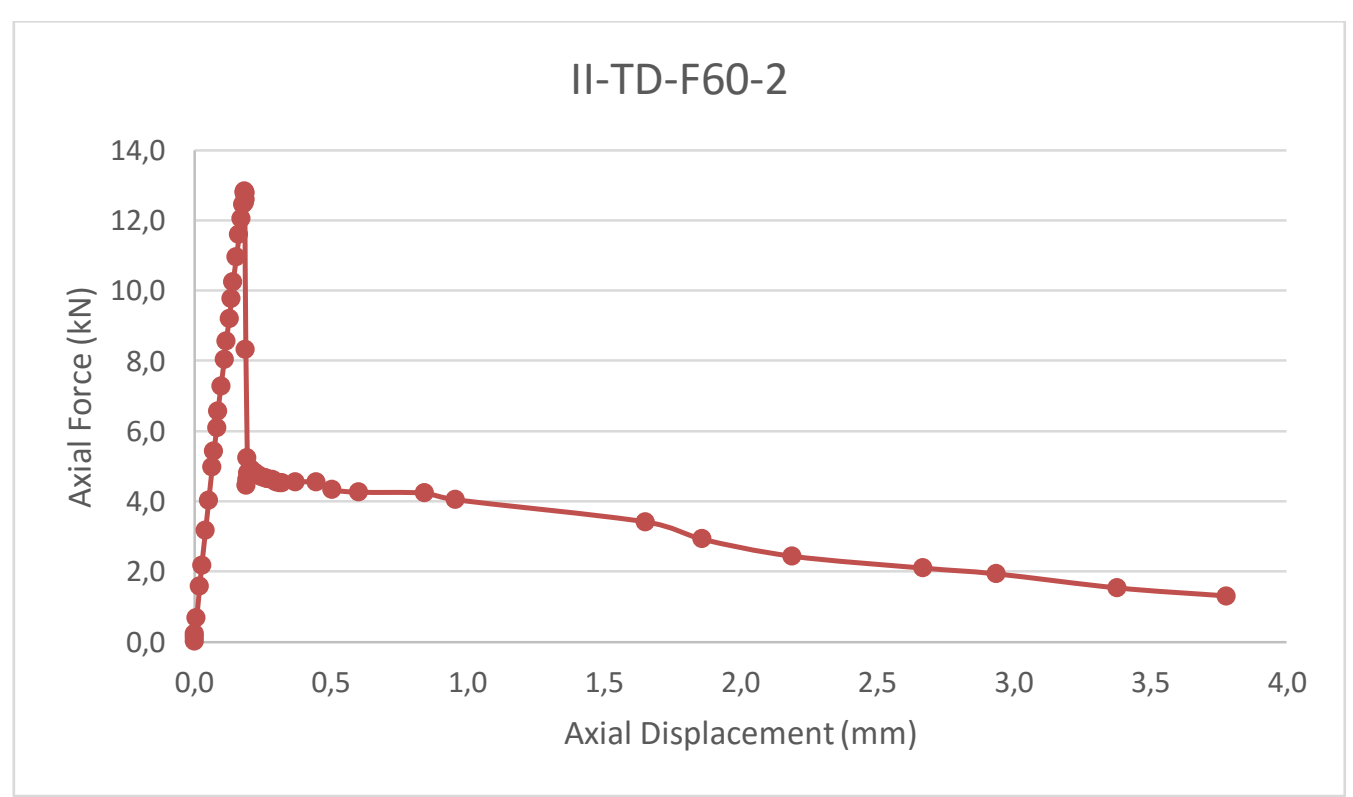

Figura C.10 - Força x deslocamento, II-TD-F60-2. 


\section{Série 7}

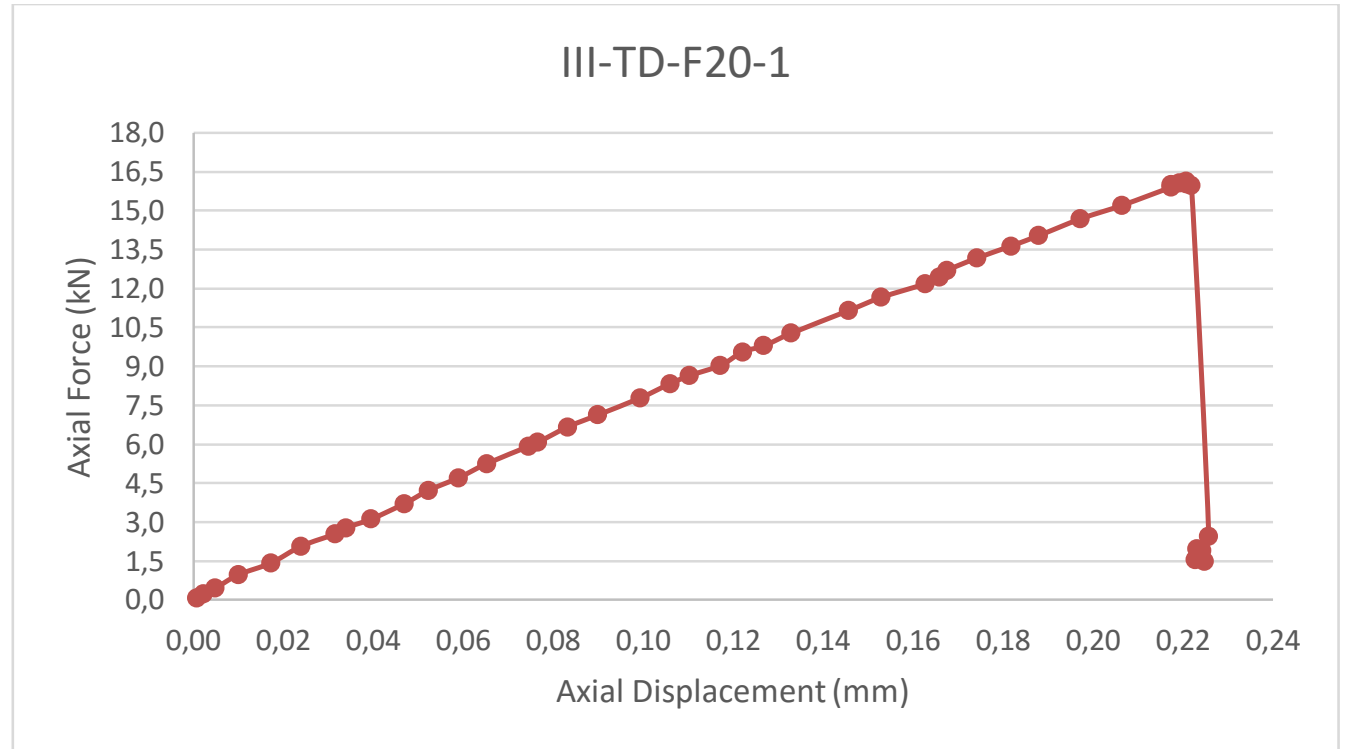

Figura C.11 - Força x deslocamento, III-TD-F20-1.

\section{Série 8}

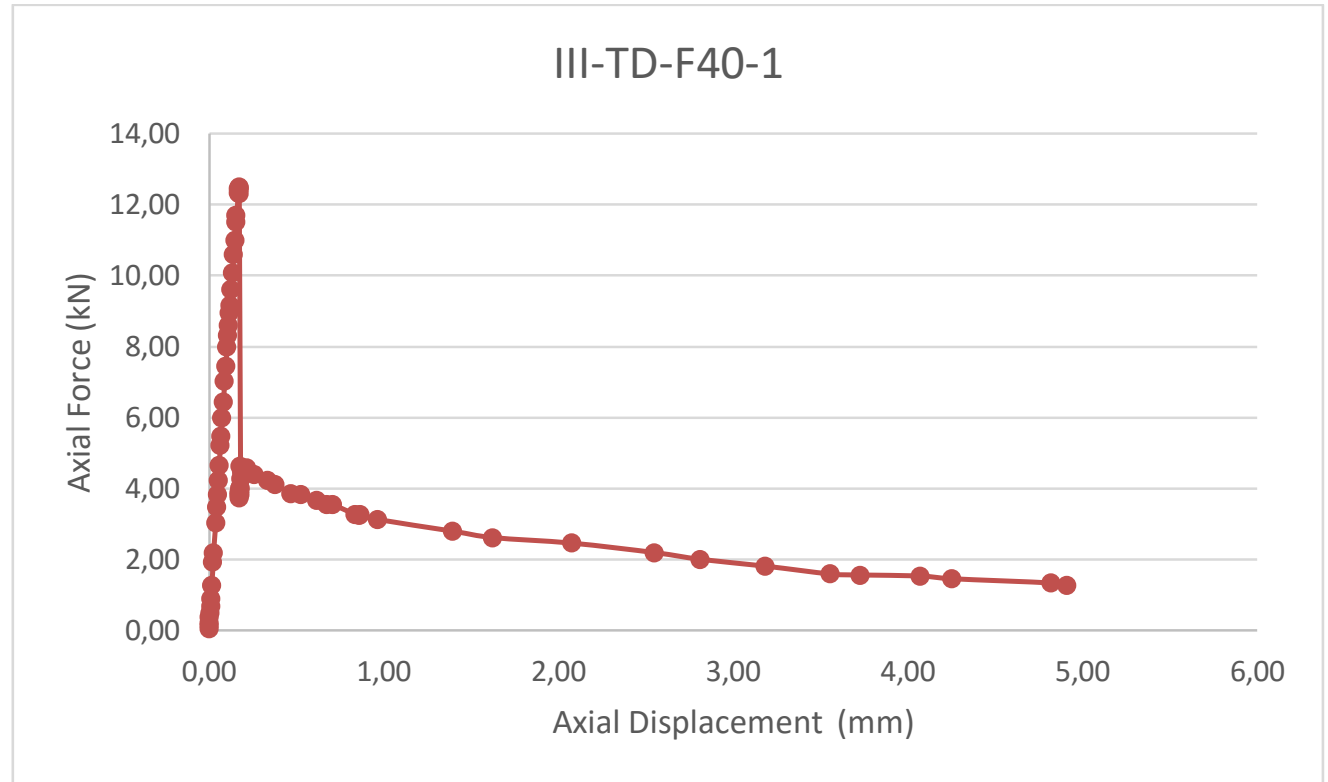

Figura C.12 - Força x deslocamento, III-TD-F40-1. 


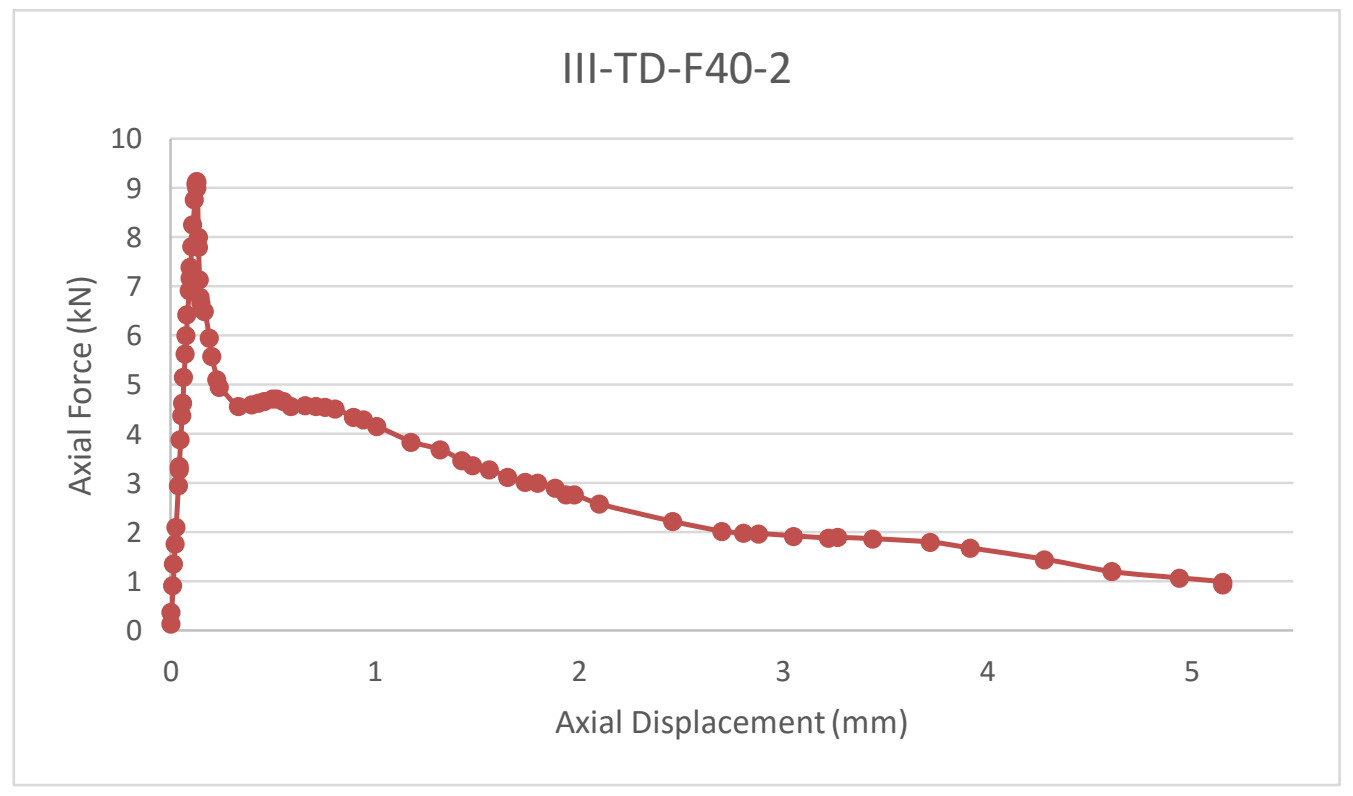

Figura C.13 - Força x deslocamento, III-TD-F40-2.

\section{Série 9}

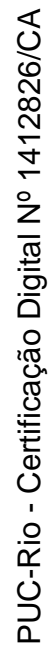

\section{III-TD-F60-1}

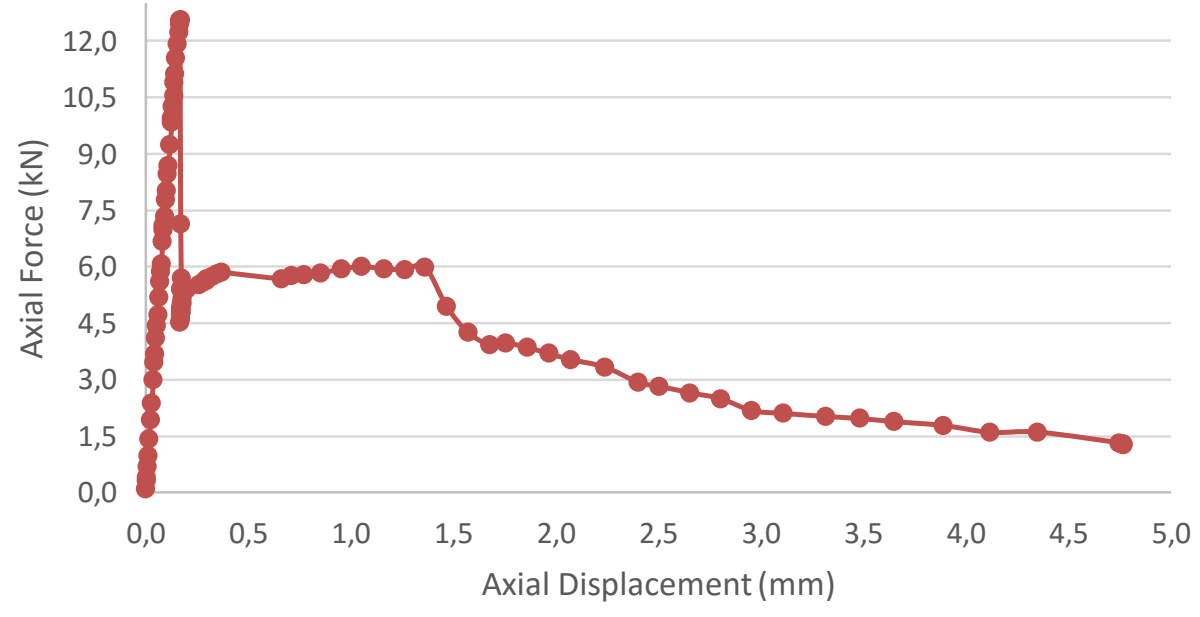

Figura C.14- Força x deslocamento, III-TD-F60-1. 


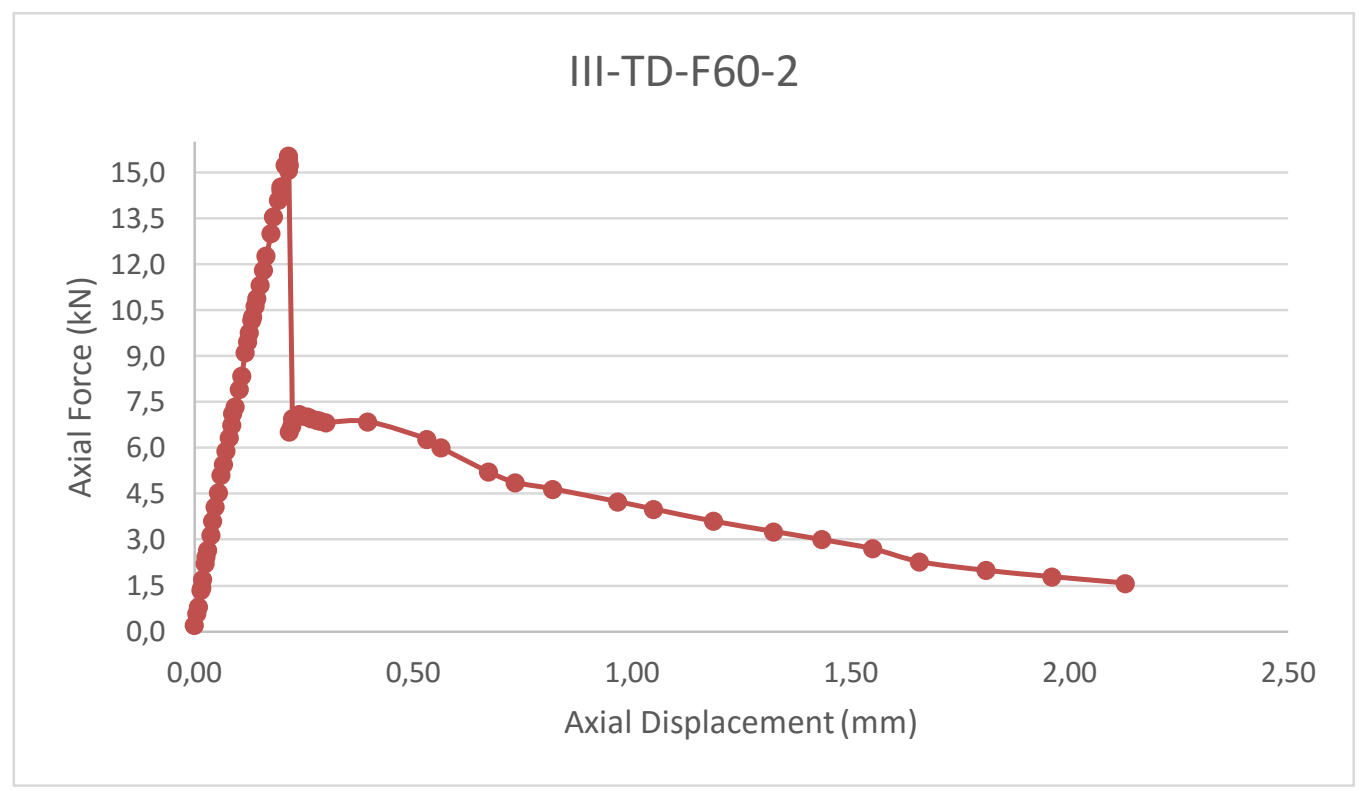

Figura C.15 - Força x deslocamento, III-TD-F60-2

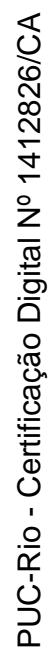




\section{Anexo D - Tensão x deformação específica}

Os gráficos desse anexo apresentam o comportamento da tensão versus deformação específica dos ensaios de tração direta.

\section{$\underline{\text { Série } 1}$}

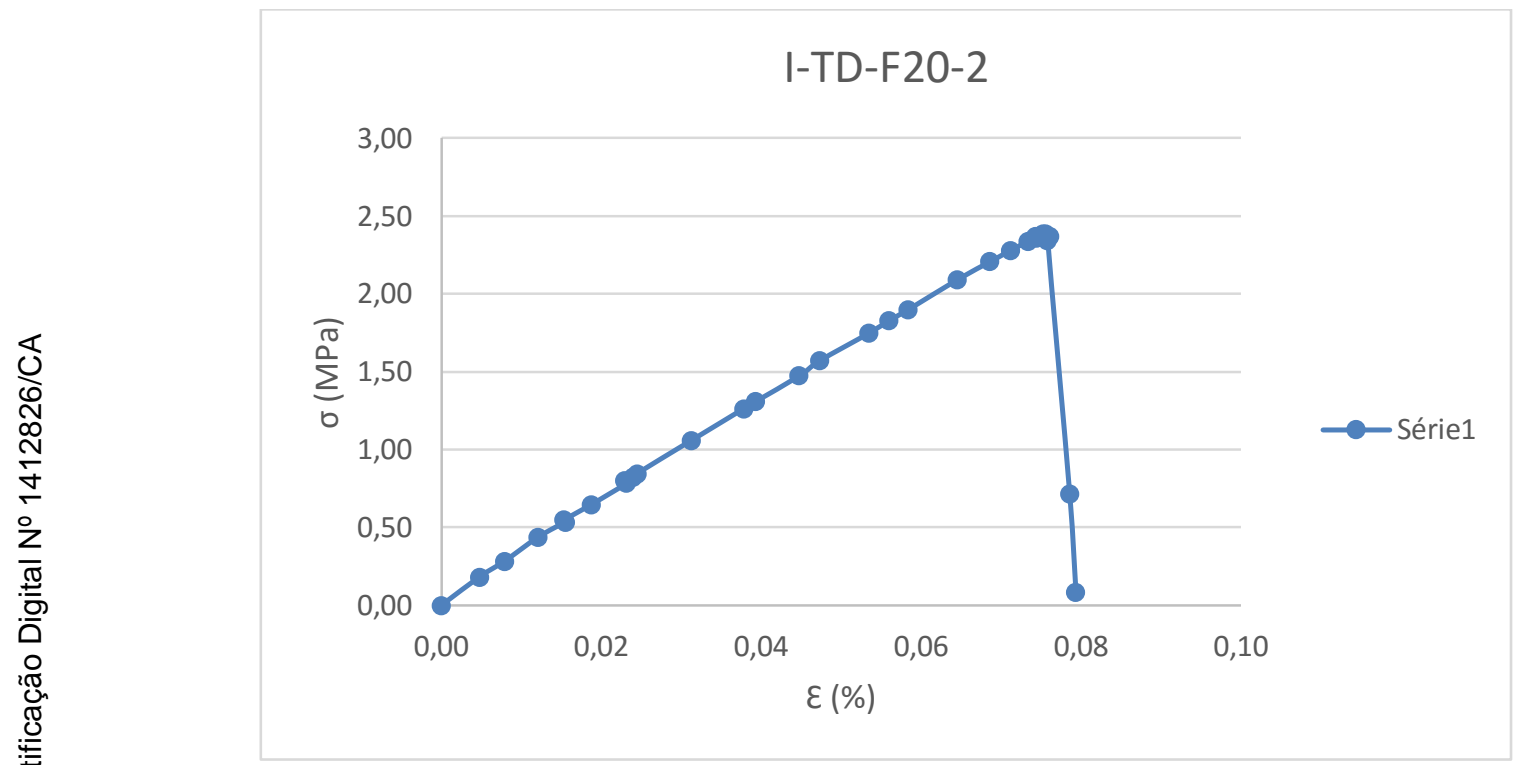

Figura D.1 - Tensão x deformação específica, I-TD-F20-2.

\section{Série 2}

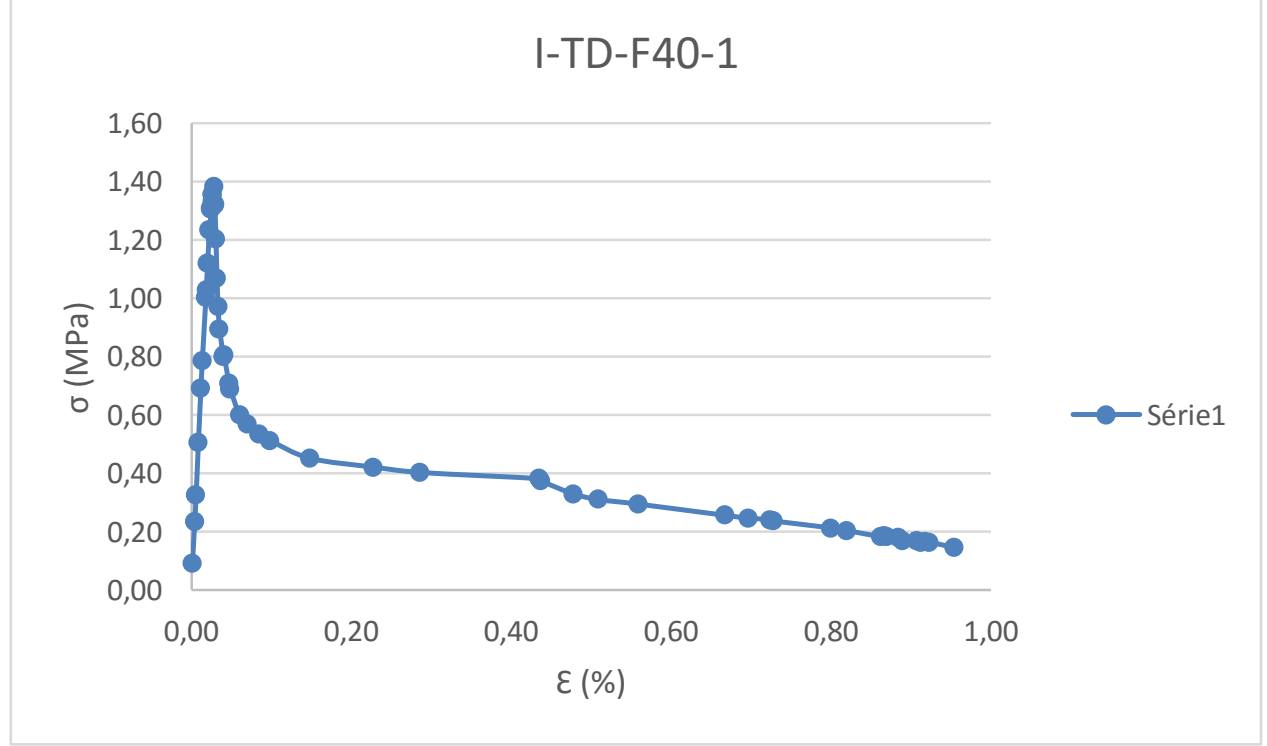

Figura D.2 - Tensão x deformação específica, I-TD-F40-1. 


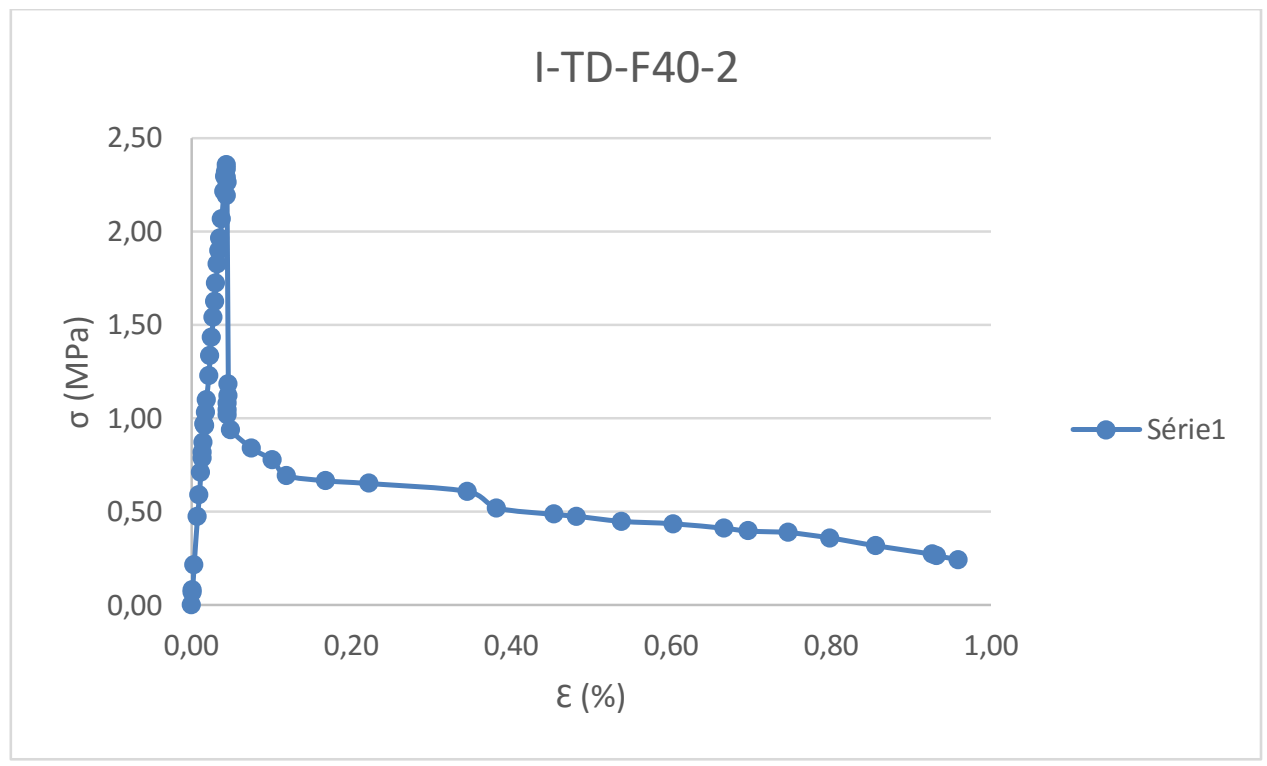

Figura D.3 - Tensão x deformação específica, I-TD-F40-2.

\section{$\underline{\text { Série } 3}$}

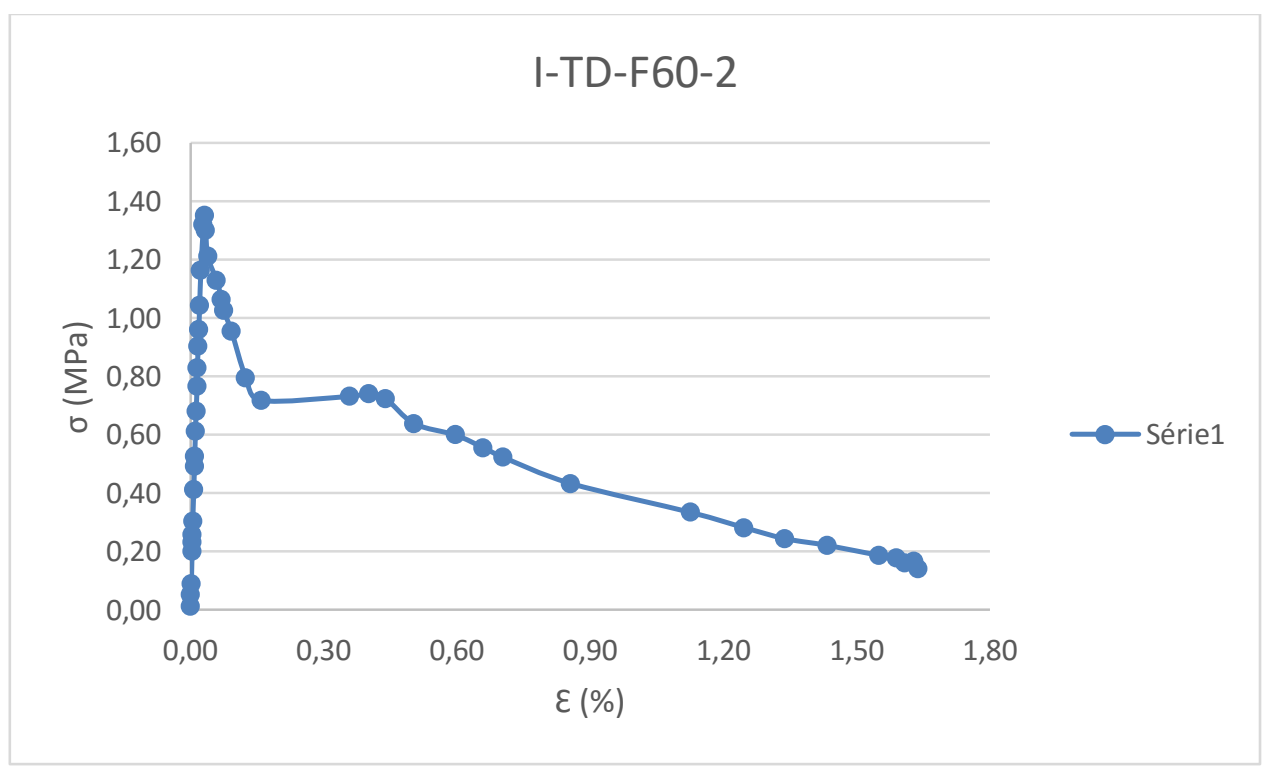

Figura D.4 - Tensão x deformação específica, I-TD-F60-2. 


\section{$\underline{\text { Série } 4}$}

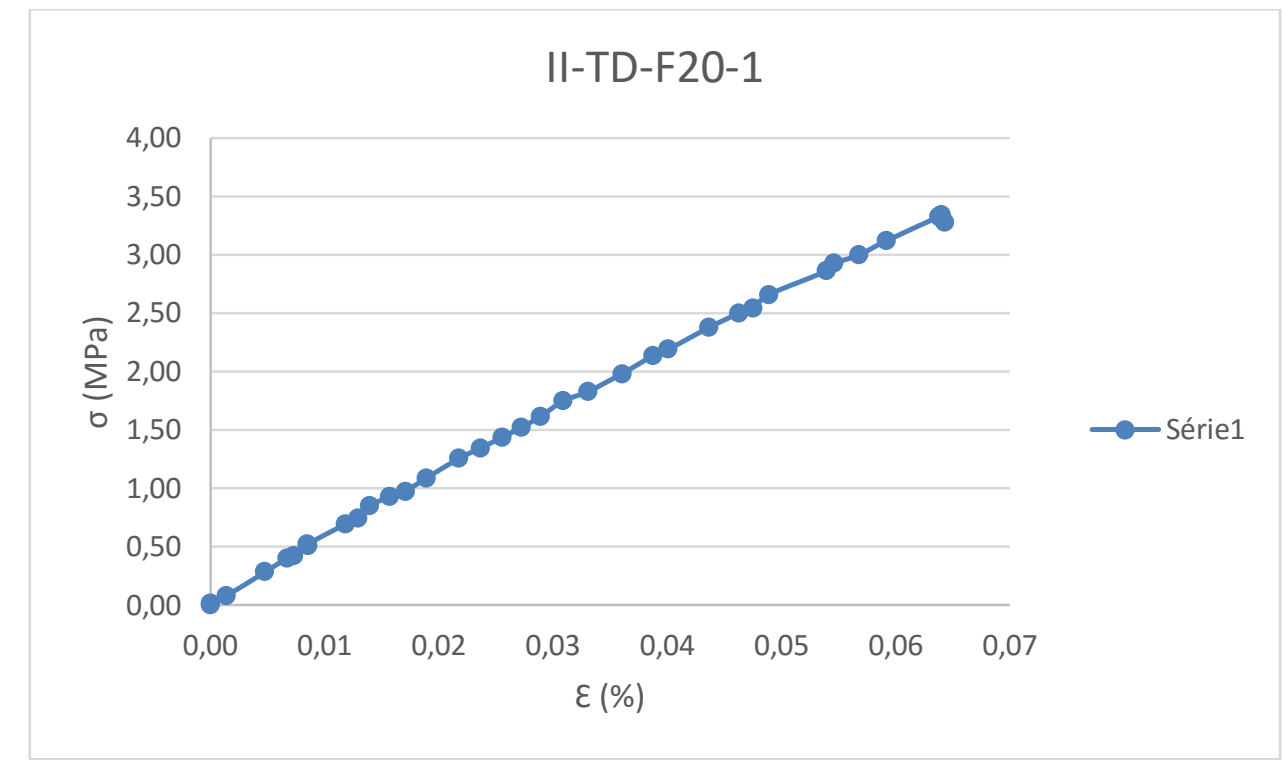

Figura D.5 - Tensão x deformação específica, II-TD-F20-1.

II-TD-F20-2

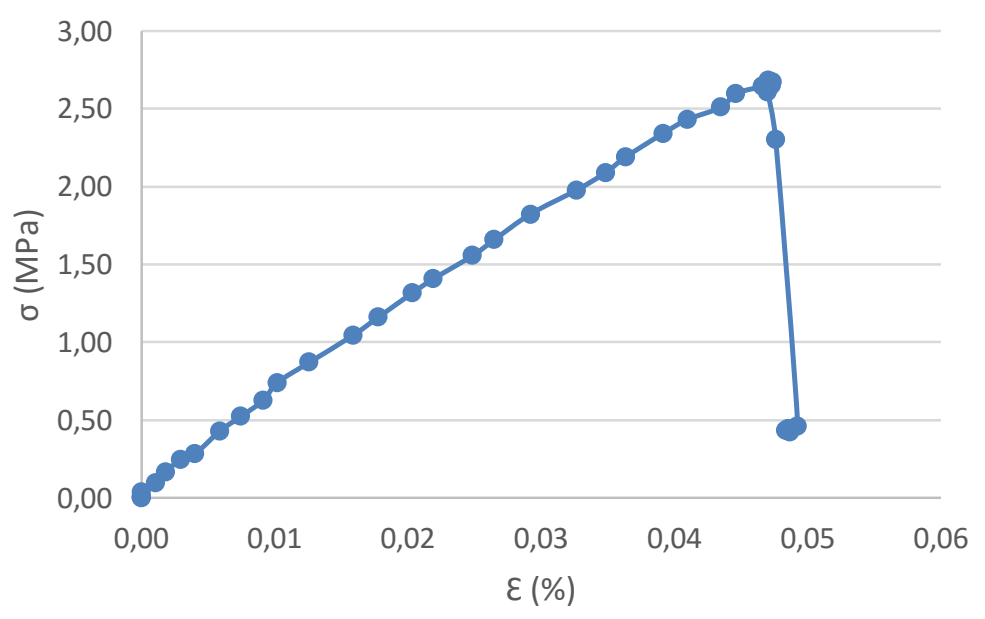

Figura D.6 - Tensão x deformação específica, II-TD-F20-2. 


\section{$\underline{\text { Série } 5}$}

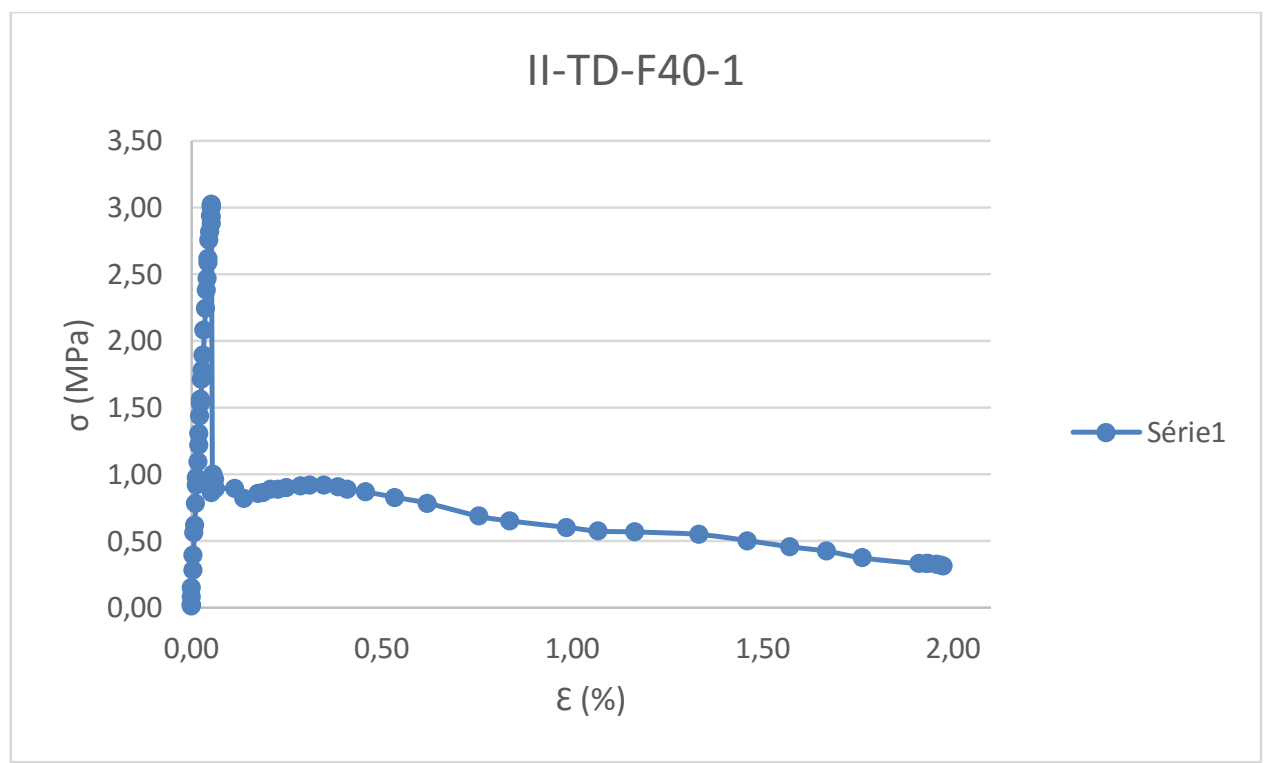

Figura D.7 - Tensão x deformação específica, II-TD-F40-1.

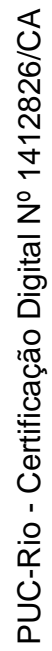

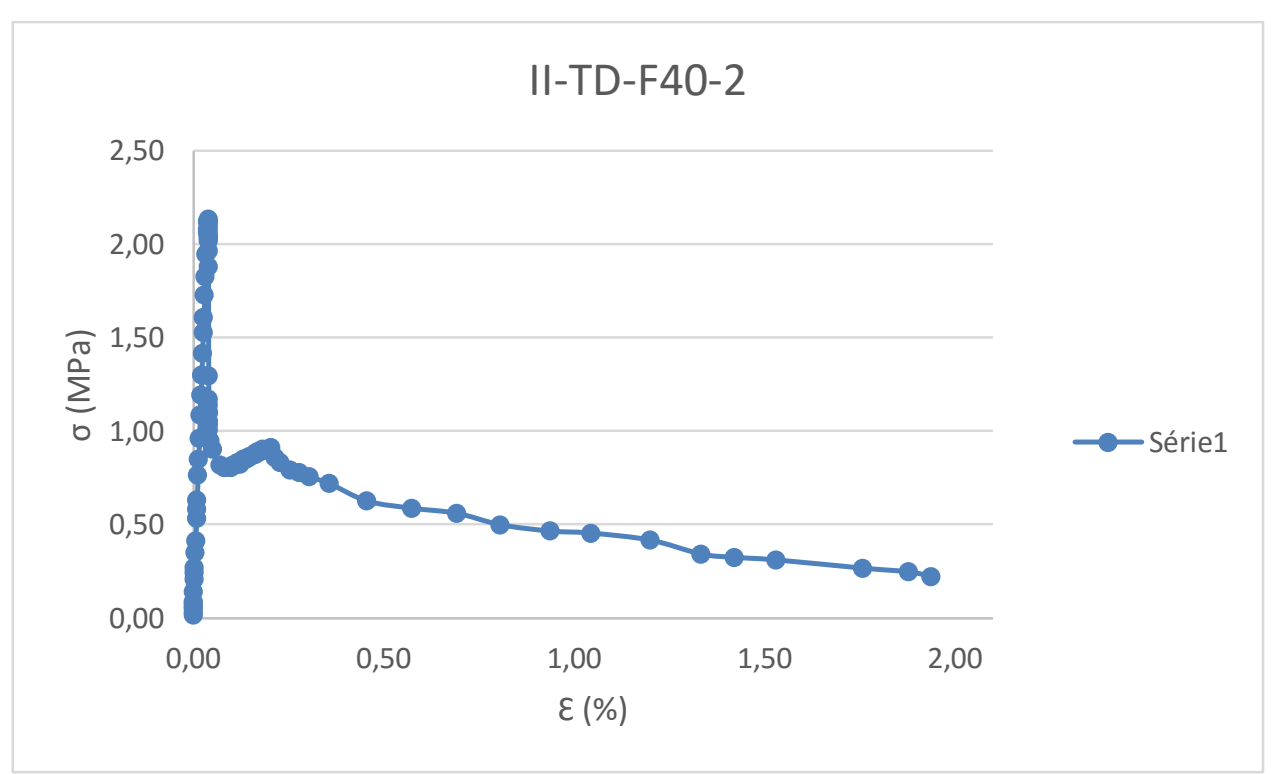

Figura D.8 - Tensão x deformação específica, II-TD-F40-2. 


\section{$\underline{\text { Série } 6}$}

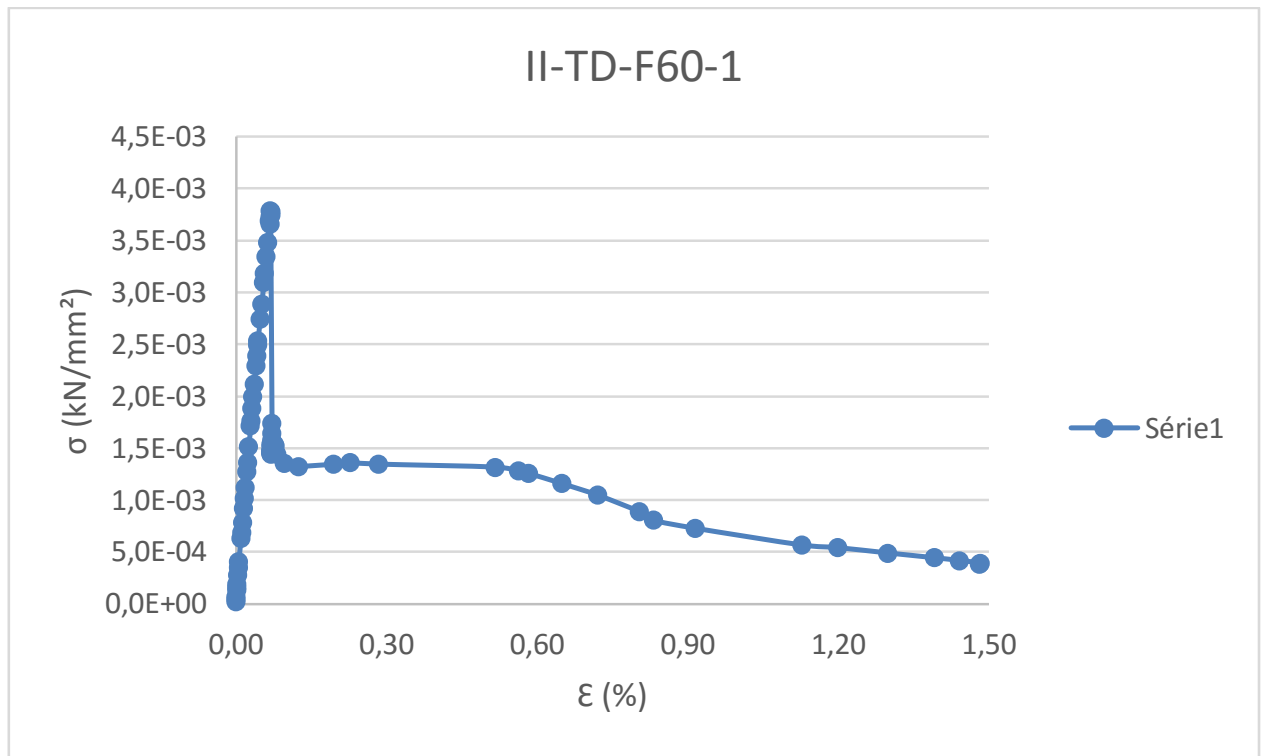

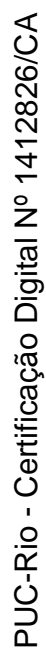

Figura D.9 - Tensão x deformação específica, II-TD-F60-1.

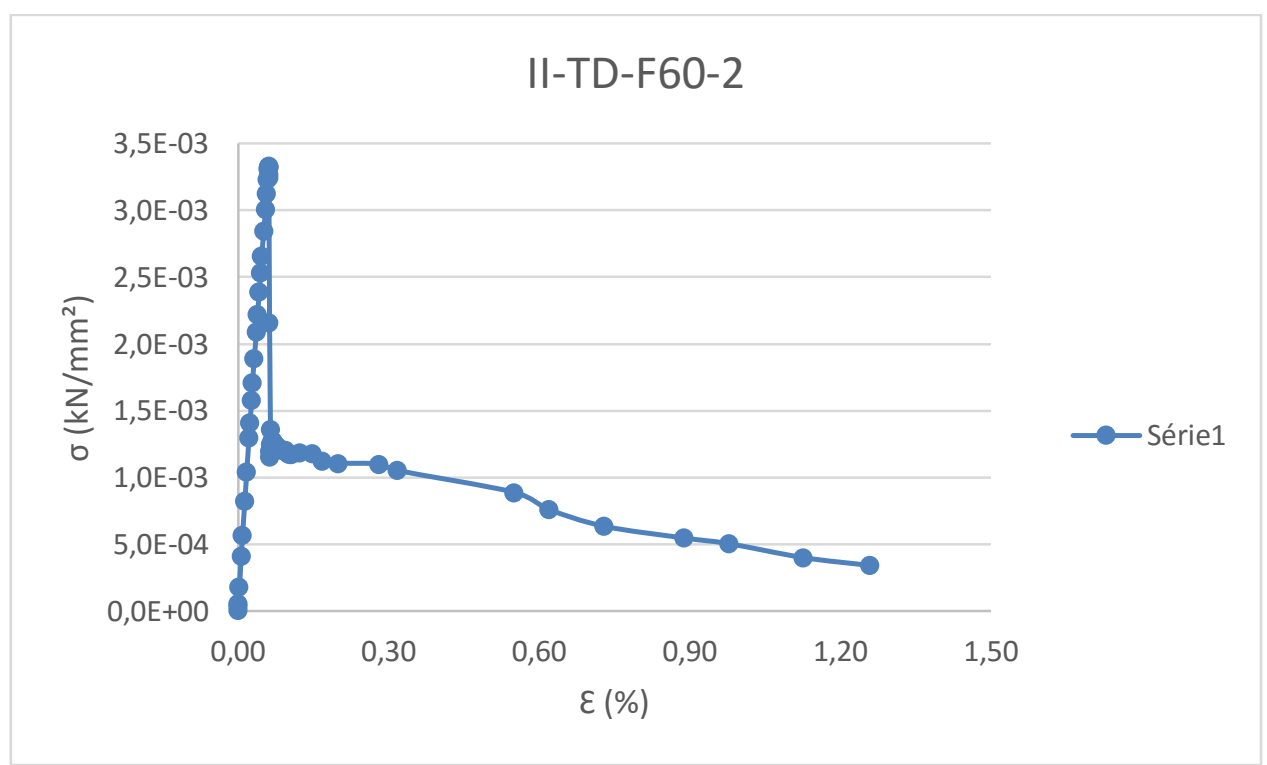

Figura D.10 - Tensão x deformação específica, II-TD-F60-2. 


\section{Série 7}

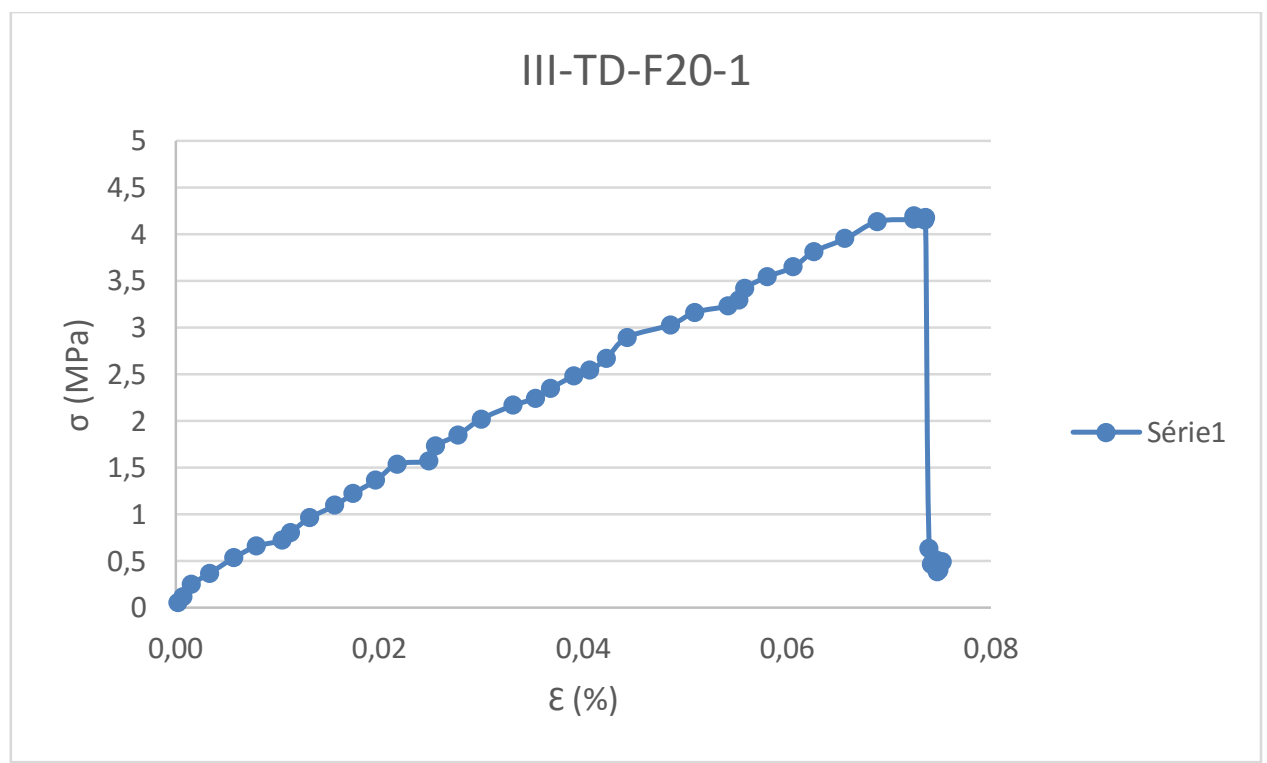

Figura D.11 - Tensão x deformação específica, III-TD-F20-1.

\section{$\underline{\text { Série } 8}$}

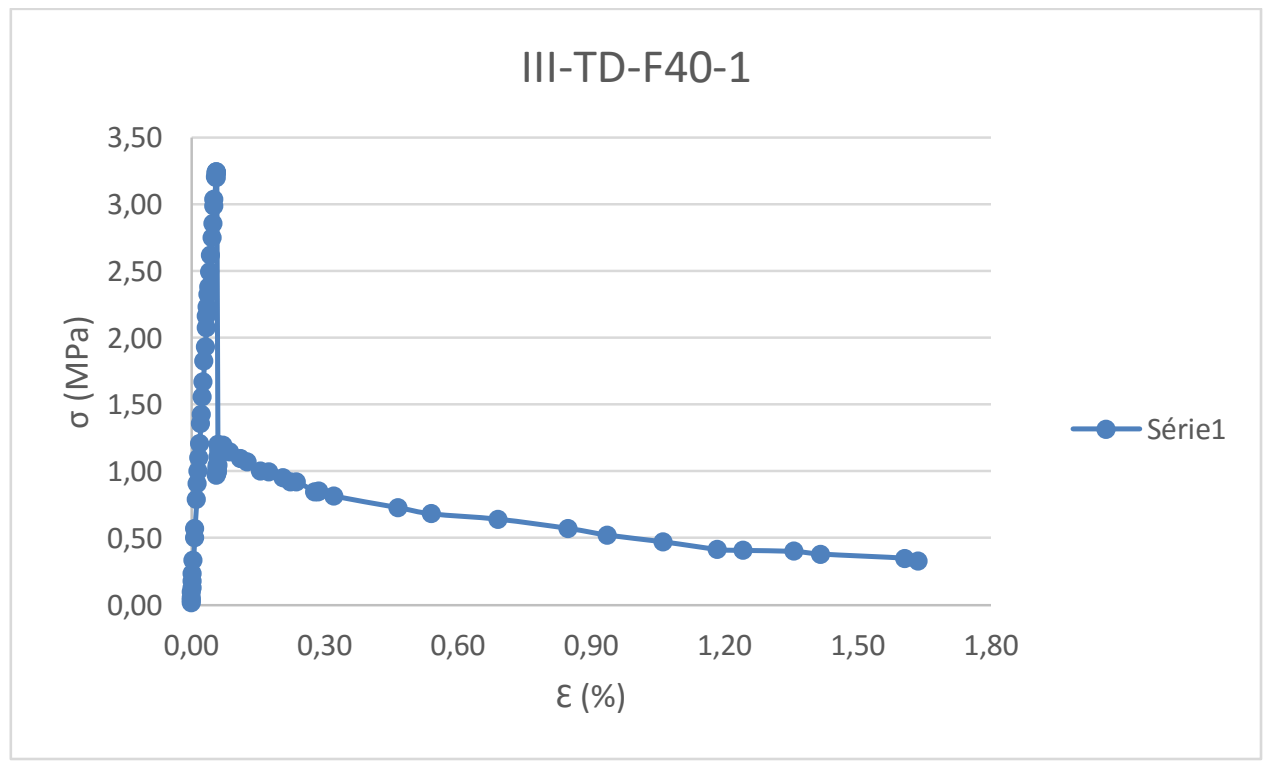

Figura D.12 - Tensão x deformação específica, III-TD-F40-1. 


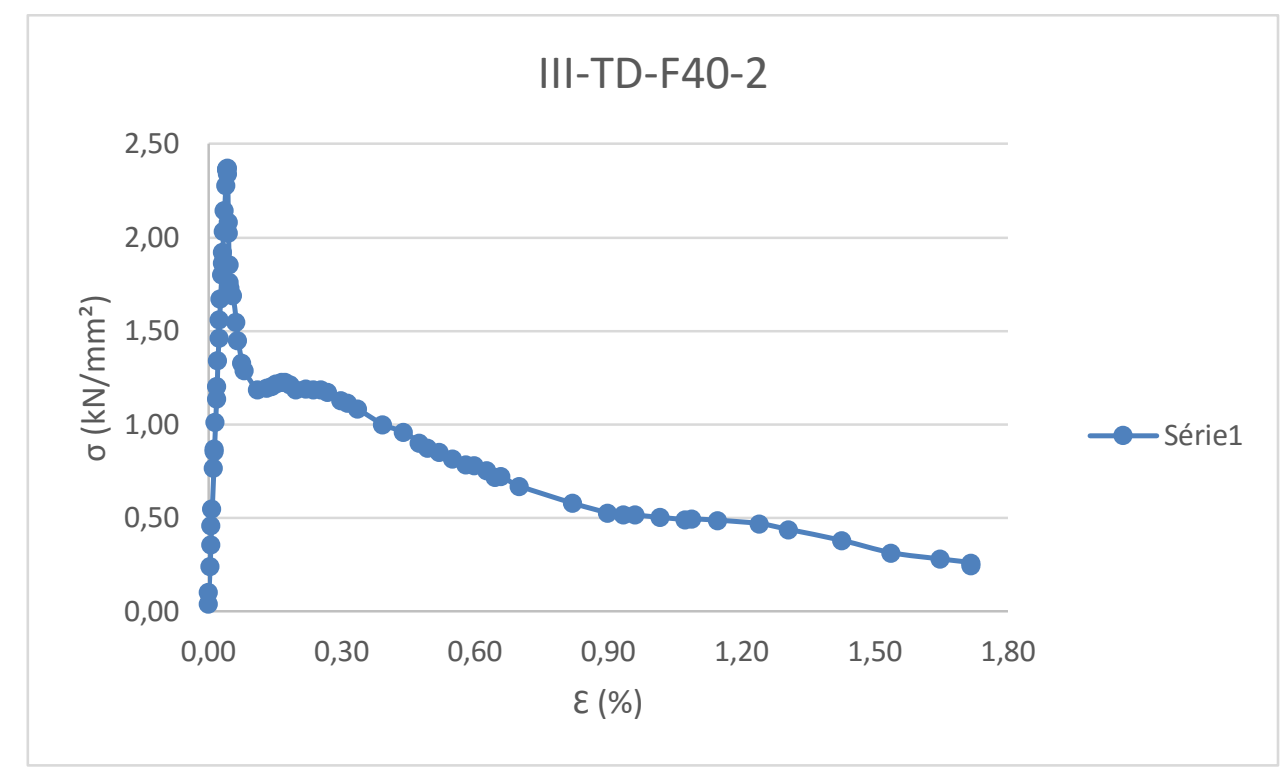

Figura D.13 - Tensão x deformação específica, III-TD-F40-2.

\section{Série 9}

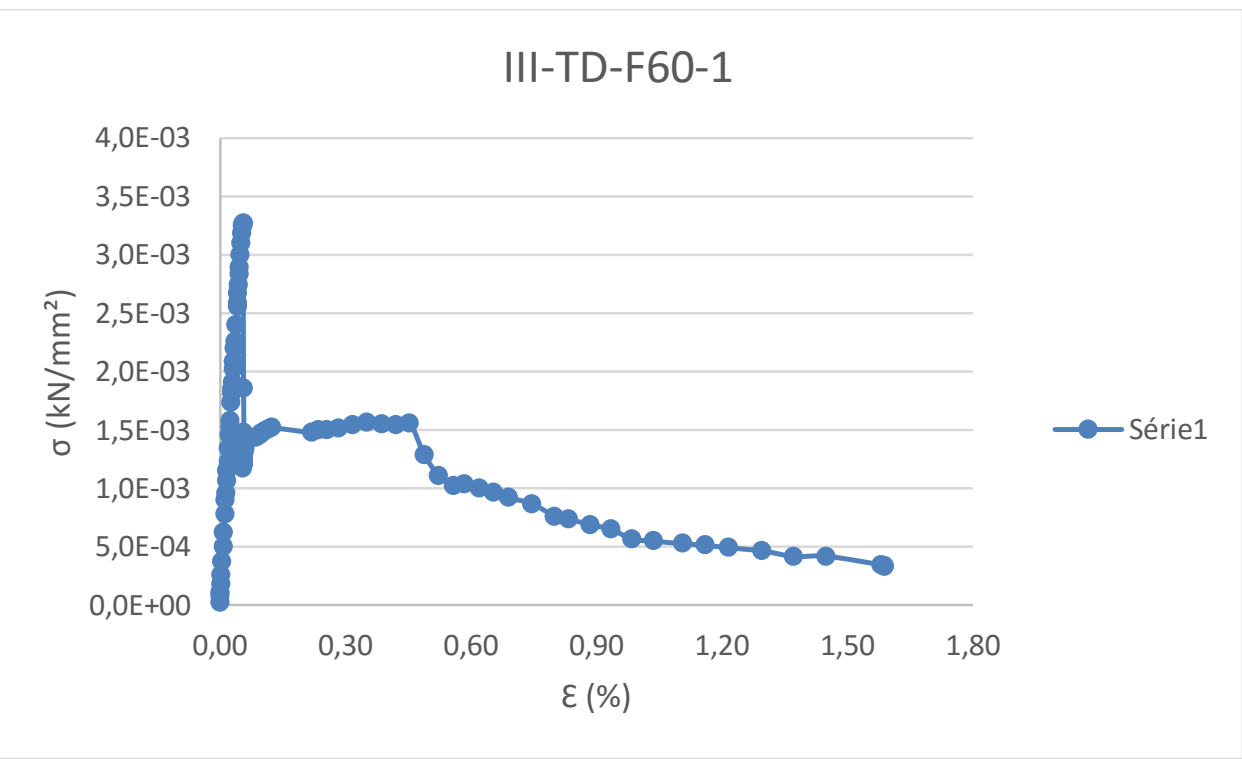

Figura D.14 - Tensão x deformação específica, III-TD-F60-1. 


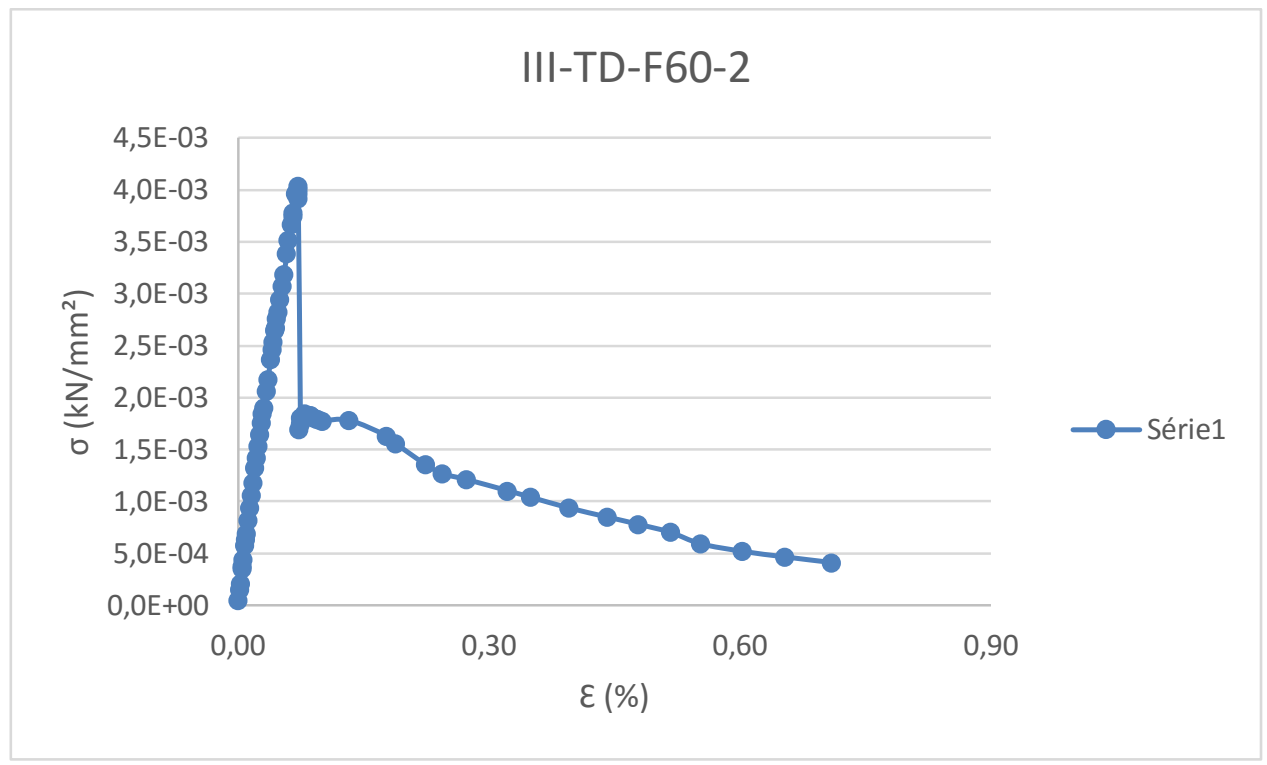

Figura D.15 - Tensão x deformação específica, III-TD-F60-2.

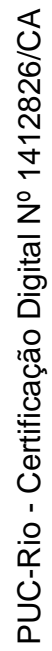

